\title{
DETERMINING PERSPECTIVES OF SELECTED DISCIPLINES CONCERNING \\ THE NATURE OF TECHNOLOGY WITHIN CLASSIC LITERATURE
}

\author{
By \\ Bryan Calvin Maser
}

\author{
A DISSERTATION \\ Submitted to the \\ College of Human Resources and Education \\ at \\ West Virginia University \\ in partial fulfillment of requirements for \\ the degree of \\ Doctor of Education \\ in \\ Technology Education
}

Department of Advanced Educational Studies

Morgantown, West Virginia

1998 


\title{
ABSTRACT \\ DETERMINING PERSPECTIVES OF SELECTED DISCIPLINES CONCERNING THE NATURE OF TECHNOLOGY WITHIN CLASSIC LITERATURE
}

\author{
By Bryan Calvin Maser
}

The purpose of this research was to identify if there was a significant difference between the perspectives of selected disciplines with regard to the nature and history of technology. A content analysis of classic literature from multiple disciplines to determine perspectives concerning the nature of technology served as a basis for the development of a general semantic differential instrument. The instrument was administered to a given population yielding a conceptual scoring of perspectives. Scored concepts were then cross referenced to respective disciplines to determine if the degree of difference between disciplines was statistically significant. 


\section{DEDICATION}

I would like to dedicate this research to Dr. John J. Paterson, who passed away during the course of this research. Dr. Paterson's keen ability to translate my vague notions and interests into a coherent and meaningful methodology was fundamental to this research. My recollections of Dr. Paterson will always be of the enthusiasm he had for his work, and of his commitment to students and quality scholarship. I was fortunate to have had Dr. Paterson serve as my instructor, research advisor, and committee member. 


\section{ACKNOWLEDGMENTS}

Although , I would like to acknowledge all those individuals who may have assisted, supported, and aided me in the course of my research and doctoral degree program of study, I will most surely inadvertently fail to recognize all those deserving of recognition.

I must begin by recognizing my doctoral committee chair Dr. Edward C. Pytlik. The unwavering thoughtfulness and encouragement that Dr. Pytlik extended to me during the course of my research I can never repay. While, Dr. Pytlik's study and intellectual discourse served as the basis and impetus for this research, his willing support for the intellectual and academic freedom I demanded in the course of my doctoral program of study was fundamental to my completing the doctoral degree.

I would like to acknowledge Dr. John G. Wells for the time and consideration he has always willingly and eagerly extended to me. His support, assistance, and encouragement for all of my endeavors during the course of my doctoral study can best be described as unfailing.

I would like to acknowledge Dr. Gary Winn for his enthusiasm and insights. His instruction and lectures broadened my conceptions of the interdisciplinary nature of technology. I will always be grateful to Dr. Winn. For my introduction to Pirsig and the notion of "quality" was inspired by Dr. Winn.

I would like to recognize Dr. Randyl D. Elkin for extending to me his time and careful editing. While, my course of study with Industrial and Labor Relations never included a course with Dr. Elkin, his concern for the success of all the students brought me into frequent and rewarding contact with him.

The final committee member I would like to acknowledge is Dr. Richard T. Walls. While, Dr. Walls became a committee member under an unfortunate circumstance, my coming to work with him can only be called a fortunate experience. For his enthusiasm and insight into issues of methodology in this research may have only been matched by the committee member he came to served on behalf of.

Finally, I would like to recognize all those who contributed and supported me during my course of study. Please note this was an attempt to be inclusive and not exclusive or exhaustive, any slight was not intended. Order is not related to importance of significance.

Dr. David L. McCrory, Dr. Paul W. DeVore, Dr. George Maughan, Carol Spiroff, Barbara D. Maser, Calvin Maser, Mary Jane Maser, Rebecca Maser, Clay Pytlik, Dr. Paul C. Pawlowski, Dr. Paul L. Siciliano, Daphne Gooding, John Jorjeson, Robert D. Mitchell, Ernie Frank III, Lori O' Donnell, Nancie Yost, Dan Van Epps, Amy Van Zant, David L. Roth, Scott Christman, Dr. Debroah Wells, Stephanie Propst, David Ealy, The Reference Librarians of the West Virginia University Evansdale and Wise Libraries, Sarah Sowell, The Taxpayers of the State of West Virginia, Pat Maley, Keri Bailey-Whitacre, Kathryn Madison, Melinda Frye, Dr. Randy Frye, Carol Murray, Dr. Keith C. Van Epps, Barbara L. Van Epps, P. Kevin Capp, Jill Regester 


\section{TABLE OF CONTENTS}

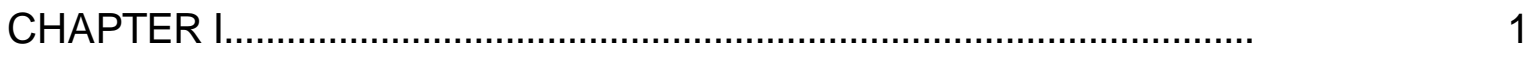

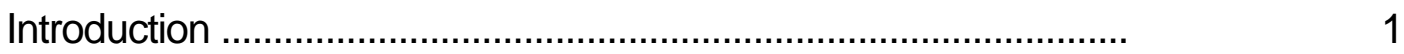

The Meaning of Technology .................................................

Ambiguity.........................................................

Importance............................................................ 2

Divergence Explored............................................ 4

Significance of Understanding Technology.................. 5

Disciplinary Perspective............................................ 5

Statement of the Problem........................................................

Purpose of the Research....................................................

Research Hypothesis....................................................

Assumptions.............................................................

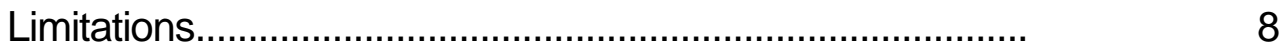

Procedures..................................................................

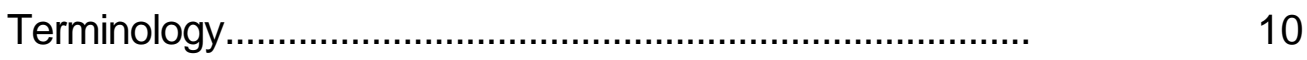

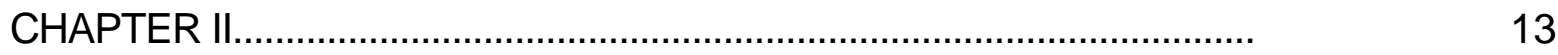

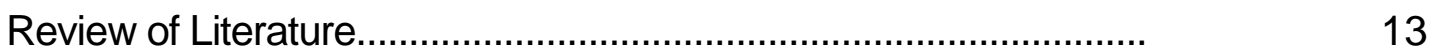

Meaning of Technology ........................................................

Aristotle: The Beginning........................................... 13

Bacon's Revolution.................................................. 27

Philosophic Questioning......................................................

History as Progress................................................. 37

Categorical Approaches........................................... 43

The Meaning of Technology and Disciplinary Conflict............ 59

Disciplinary Perspective and Context.......................... 59

Classics of Technology................................................

Understanding Meaning............................................

Content Analysis....................................................... 81

Identifying Disciplines............................................... 84

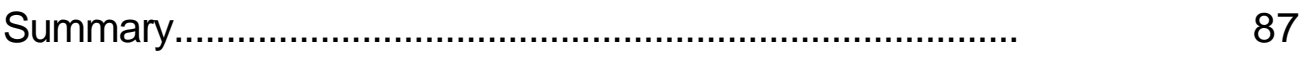


TABLE OF CONTENTS (continued)

CHAPTER III..............................................................................

Methodology ..........................................................................

Statement of the Problem.................................................... 88

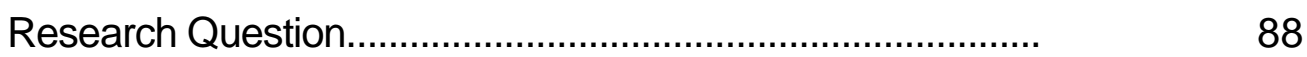

Disciplinary Grouping of Publications................................... 88

Classic Literature..................................................................

Content Analysis........................................................

Semantic Differential.....................................................

Population ..................................................................

Treatment of the Data............................................................

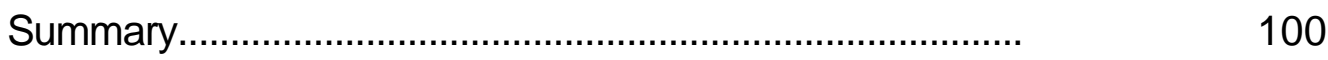

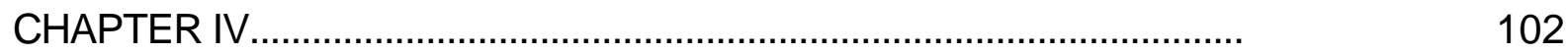

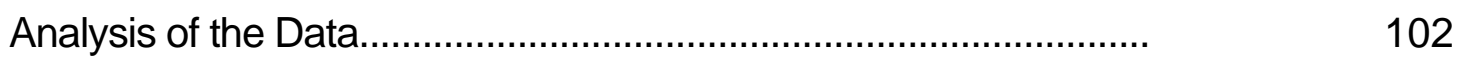

Content Analysis.............................................................

Publication Categorization and Discipline Formation.............. 103

Concept Identification and Reduction................................... 104

Semantic Differential Instrument Construction........................ 106

Semantic Differential Data Collection and Analysis................ 108

Demographics......................................................... 109

Data Scoring and Summation..................................... 115

Data Analysis.............................................................. 116

Graphical Presentations.......................................... 117

D Matrix and Cluster Analysis..................................... 117

Statistical Differences Between Disciplines.................. 120

A Note on Type I Error................................................ 122 
Findings, Conclusions, and Recommendations............................... 125

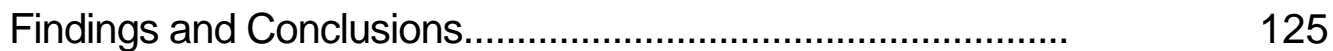

Concepts Used to Characterize Technology................. 125

Technology as A Concept in Semantic Space............... 127

Research Hypothesis................................................. 129

Summary.................................................................

Recommendations for Further Study.......................... 134

Implications................................................................ 136

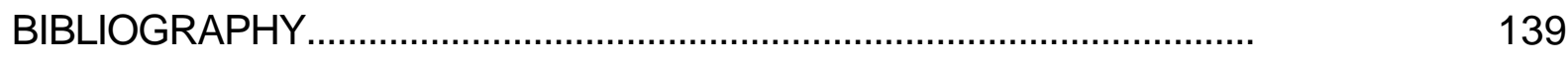

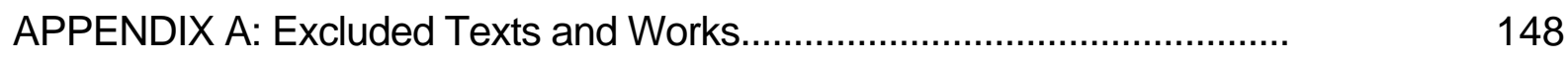

APPENDIX B: Evaluated Works..........................................................

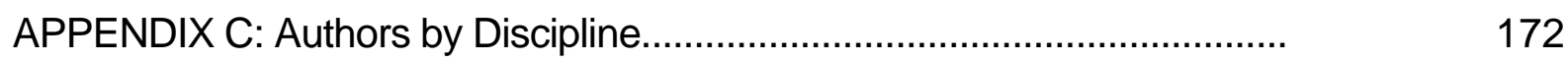

APPENDIX D: Concepts by Discipline..................................................... 178

APPENDIX E: Semantic Differential Instrument......................................... 184

APPENDIX F: Concept Mean Score by Semantic Factor............................. 189

APPENDIX G: Graphical Presentation of Semantic Concepts....................... 197

APPENDIX H: Concept Cluster Assignment.................................................... 202

APPENDIX I: Discipline P-values by Semantic Factor................................. 205

APPENDIX J: Discipline to Discipline Comparisons of Significant Difference 209

APPENDIX K: Discipline Statistics by Factor.............................................. 238

APPENDIX L: Graphical Presentation of Discipline Means on Factors......... 241 


\section{LIST OF FIGURES}

FIGURE 1 Diagrammatic definitions of 'Technology' and 'Technology Practice'........................................................... 58

FIGURE 2 An example semantic differential concept presentation............ 95

FIGURE 3 An example semantic differential concept presentation............. 106

FIGURE 4 Respondent age distribution with an approximate normal curve overlay ......................................................... 110

FIGURE 5 Respondent sex by percentage proportions.............................. 111

FIGURE 6 Respondent educational attainment by proportional percentage 112

FIGURE 7 Semantic differential scale scoring values.............................. 115

FIGURE 8 Cluster distribution of concepts with the concept technology indicated............................................................... 119

FIGURE $9 \quad$ Box plot of factor distributions............................................... 126 


\section{LIST OF TABLES}

TABLE 1 Three Ways of Being-with Technology ..................................

TABLE $2 \quad$ Bi-polar Adjectives by Factor..................................................

TABLE $3 \quad$ Publication Distribution by Discipline Group............................ 105

TABLE $4 \quad$ Respondent Age Descriptive Statistics..................................... 110

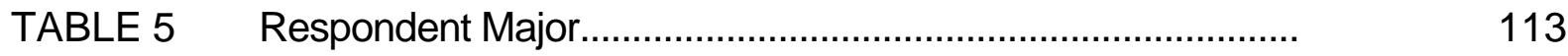

TABLE 6 Mean Ranks of Concepts by Factor and Major.......................... 114

TABLE 7 Test for Significance Difference Between Technology Education and All Other Majors on the Three Semantic Factors............ 115

TABLE $8 \quad$ Cluster Means by Factor......................................................... 120

TABLE 9 Incidents of Null Rejections by Discipline and Factor................ 123 


\title{
CHAPTER 1
}

\author{
Introduction
}

\section{The Meaning of Technology}

\section{Ambiguity}

The meaning of the word technology has become increasingly amorphous. In referring to the increasing manner in which technology has come to be used, Winner (1977) stated that "the word has come to mean everything and anything; it therefore threatens to mean nothing" (p. 10). Marx (1984) stated that, "Among the words that now occupy a central place in the discourse of American studies, there are few whose meaning is less clear or stable than technology" (p. 638). The ambiguity related to the meaning and characterizations of technology continues to be explored (Mitcham, 1994, Custer, 1991, Ihde 1990).

The ambiguity that exists with regard to the meaning of Technology has been attributed to several different factors (Custer, 1991, DeVore, 1980). An emergent and recurring factor is that of disciplinary perspective. In chapter 6 of his text Technology: An Introduction (1980), DeVore in referring to the nature and character of technology stated, "Individual perceptions are largely dependent upon a person's background, the amount of study and reflection about technology, and personal experience with 
technology" (p.216).

The divergence of disciplinary perspectives regarding technology was recognized as early as 1959 by Snow's Rede lecture entitled The Two Cultures. Snow's recognition of disciplinary divergence and its implications has continued to serve as a theme in writings about the nature of technology. Snow's observation was that "Intellectuals, in particular literary intellectuals, are natural Luddites" (p.22). The divergence between the two cultures identified by Snow has as its root the industrial revolution and the growth of technology as a center of human activity.

More recently Mitcham (1994) utilized an engineering and humanities dichotomy to characterize disciplinary perceptions regarding the meaning of technology. Mitcham's contention in his work Thinking through Technology (1994) was that there has existed two distinctly different approaches to the philosophic questioning of the phenomenon technology, that of the engineering philosophy of technology and the humanities philosophy of technology.

Importance

The ambiguity that exists regarding the meaning of technology has been identified as a source of fundamental conflict over issues in a larger socio-political context. Winner (1977) contended that one of the 
consequences of the "chaotic use of the term technology" (p. 10) was that:

It soon becomes clear that in this enlightened age there is almost no middle ground of rational discourse, no available common language with which persons of differing backgrounds can discuss matters of technology in thoughtful, critical terms. Conversations gravitate toward warring polarities and choosing sides. (p.11) Mitcham and Mackey (1972) in referring to the importance of understanding differing conceptions of technology wrote, "The conception one has of technology ultimately determines whether, after the philosophical issues have been exhausted, what remains is an economic, social, or political problem" (p.30). Mitcham (1994) continued to emphasize the social conflict theme: this spectrum of conceptual references is philosophically important....in discussions of the social and ethical consequences of technology debates inevitably arise about whether technology can be limited or even eliminated. But much of this disagreement rests on a failure to clarify differences in assumed definitions. (p. 152)

Technology as the foundation of conflict in and between disciplines of human endeavor, as conceived of by Snow (1959), echoed the importance of coming to an understanding of the meaning of technology to respective disciplines. 


\section{Divergence Explored}

Custer (1991) explored the confusion of scholars regarding the meaning of technology. He used a qualitative analysis to develop a categorical approach to understanding perspectives of technology. Among the conclusions in Custer's research was that of "Similarities and Contrasts Across the Disciplines" (p. 134). Custer (1991) contended that "the most distinct points of contrast between disciplines were in terms of style and approach" (p. 134). However, Custer (1991) added that "A common thread extends across the documents (which were selected for this study).... each document represented a philosophical treatment of technology... Consequently, similar patterns were evident across the four disciplines" ( $p$. 134). Custer emphasized that his research did not include documents from the social sciences, and concluded that "As the research unfolded, the centrality of the social science issue surfaced" (1991, p.134). Custer's suggestions for further research included the replication of the research with expanded disciplines, and the development of a theoretical model "that incorporates the three independent variables which emerged from the study (i.e. methodology, philosophic point of view, and academic affiliation)" (1991, p.141). 


\section{Significance of Understanding Technology}

The conclusions and recommendations for further research presented by Custer (1991) served as a partial foundation for the problem of this research. Given the stated importance of understanding the meaning of the phenomenon of technology across and between disciplines, an attempt to analytically explore possible divergence in perspectives between disciplines becomes significant. Ferre (1995) in asserting the importance of creating a "common playing field" stated that, the "Philosophy of technology can be and is a binder of breaks in the curriculum, a bridger of gaps between specialists, a challenge to ethical examination, and a stimulus for social reform and political action" [on-line].

\section{Disciplinary Perspective}

Two issues that must be resolved prior to any examination of disciplinary perspectives are those of discipline definition and perspective. Custer's (1991) work utilized four disciplines, engineering, philosophy, technology education, and science. This represented an adaptation of the categories developed and utilized by Pytlik (1988) in his Fifty-two Great Books of Technology. Custer's conclusions recognized the limitation of using these disciplines to characterize perspectives of technology: documents from the social sciences (i.e., sociology, political 
science, anthropology, psychology, history, etc.) were excluded from consideration in this study. As the research unfolded, the centrality of the social science dimension surfaced. Discussions of technology were repeatedly couched in its cultural and social contexts (1991, p.134).

Given Custer's assertion with regard to the broad spectrum of disciplines from which technology is perceived an appropriate scheme of disciplinary definition must be adopted.

The issue of defining disciplines so that an accurate understanding of perspectives can be drawn has been addressed through the Library of Congress classification system. The Library of Congress classification system's development was based on disciplinary perspectives (Chan, 1981). "Each of the main classes...is divided into subclasses, representing disciplines or major branches of the main class" (Chan, 1981, p. 277). It is the disciplinary perspective of a work that serves as the manner by which the work is cataloged. A work of literature's Library of Congress catalog designation reflects its statement of perspective within or toward a particular discipline.

Pytlik's (1988) Fifty-two Great Books of Technology was an effort to develop a collection of literary works that "were the most outstanding technology publications because the selections had an important influence 
on society and/or were the classics in their discipline" (p. 54). Additionally, Pytlik's research represents "the first attempt at surveying the scholars in the field of technology to determine classics in its discipline" (1988, p. 66). The findings of Pytlik's research derived an index of classic literature that have technology as a theme.

The index of classics identified by Pytlik (1988) represented the literary works from which this research attempted to examine disciplinary perspectives regarding the nature and meaning of technology. Disciplinary perspectives were to be ascribed to the classics identified by Pytlik based upon their corresponding Library of Congress catalog designations.

\section{Statement of the Problem}

The problem of this research was to determine selected disciplinary perspectives concerning the nature of technology within classic literature.

\section{Purpose of the Research}

The purpose of this research was to lessen the gap of understanding between disciplines regarding the meaning of technology.

\section{$\underline{\text { Research Hypothesis }}$}

$\mathrm{H}_{0}$ : There would be no significant difference at the .05 level between 
the semantic factor scores related to concepts used by individual disciplines to characterize technology.

\section{Assumptions}

The assumptions of this research were:

1. Disciplinary perspectives regarding the meaning of technology can be derived from classic literature.

2. Meaning can be measured quantifiably through the use of the semantic differential technique.

3. The selected sample yielded generalized semantic profile results.

4. The Library of Congress classification system reflected relevant categories of disciplinary perspectives for this research.

5. There existed a cross cultural understanding of meaning for a significant number of concepts.

\section{Limitations}

This research was limited to the extent that:

1. The referenced literature was confined to English and translated sources.

2. The examined literature was derived from the initial collection 
of 240 books identified by Pytlik (1988) during the research for Fifty-two Great Books of Technology.

\section{Procedures}

The following procedures were used to complete the research:

1. Identification of the problem and purpose;

2. A review of literature was conducted to identify commonalties regarding the problem of disciplinary divergence in the meaning and nature of technology, applications of the semantic differential technique, and disciplinary classification.

3. A content analysis of classic literature was conducted to identify words and phrases used to characterize the nature of technology;

4. A semantic differential survey instrument was developed;

5. The semantic differential survey was administered to a selected group of individuals;

6. An atlas of semantic profiles was developed from the semantic differential survey;

7. The semantic profiles were correlated with corresponding authors' disciplines; 
8. D statistic and graphical cluster analysis of semantic profiles by disciplines were conducted;

9. A Mann-Whitney ' $U$ ' test analysis of statistical data for accepting or rejecting the null hypothesis was conducted;

10. Findings and conclusions were discussed;

12. Recommendations for future research were delineated.

\section{Terminology}

For the purposes of this research the following definitions were used:

Discipline: A branch of knowledge or teaching, that has a definable set of precepts (The American Heritage Dictionary, 1983, Shipley, 1970).

Divergence: "to become different in character or form: differ in opinion"

(Webster's Ninth Collegiate Dictionary, 1993, p. 368).

Nature of Technology: Nature has been defined as, "The inherent character or basic constitution of a person or thing" (Webster's Ninth Collegiate Dictionary, 1993, p. 789). The phrase "nature of technology" for the purposes of this research will refer to the inherent character or basic constitution of the phenomenon of technology.

Perspective: "The interrelation in which a subject or its parts are mentally viewed" (Webster's Ninth Collegiate Dictionary, 1993, p.878), "a 
point of view", and "any of various techniques for representing three-dimensional objects and depth relationships on a two-dimensional space" (The American Heritage Dictionary, 1983, pp. 511-12).

Phenomenon of Technology: The use of the phrase "phenomenon" is that of Heidegger's view as presented by Marx (1984):

The word "technology", I assume does not refer to any specific thing or things. Rather it is a name, like "color," "fruit," or "game" for a whole class of entities. Thus, the relation between the class named "technology" and, say a welder's torch (and welding?), or a loom (and weaving?), or a press (and printing?), is roughly parallel to the relation between the class named "color" and say, red; between "fruit" and apples; or between "game" and baseball. "Technology" seems to be the name of a similar class, a probability worth keeping in mind when considering Heidegger's idea that the essence of technology is nothing "technological" (pp. 639-640).

Semantic Differential: "a multivariate differentiation of concept meanings in terms of a limited number of semantic scales of known factor composition" (Osgood \& Suci, 1969, p. 42). 
Semantic Profile: The mean scores of a concept across semantic factors (Jenkins, Russell \& Suci, 1958). 


\section{CHAPTER II}

Review Of Literature

\section{Meaning of Technology}

\section{Aristotle: The Beginning}

The traditional view of technology has been traced back to Aristotle (Hood, 1972). The Aristotelian view identified by Hood is instrumental and extrinsic in its conception. The Aristotelian view holds that "technology is a human arrangement of technics, tools, machines, instruments, materials, science, and personnel, to make possible and serve the attainment of human ends" (Hood, 1972, p. 347). Technology in this conception is merely an extrinsic instrument that serves ends to which it has been directed, "it is not an end in itself but simply a means to some further end" (Hood, 1972, p. 347). Hood emphasized that the Aristotelian view concluded that technology "is not thought to have any meaning in itself" (p. 347), and is said to be "neutral" in its nature (Hood, p. 347).

This is not to say that technology does not have meaningful consequences. Hood (1972) emphasized that a primary precept of the traditional view of technology is that "The meaning of each of these techniques, and the artificial forms which they engender and utilize, is found 
in the human purposes which they serve" (p.348). The traditional conception of technology as conceived by Aristotle viewed technology as the means to pursue the higher order non-utilitarian aspects of human activity. The Aristotelian view recognizes that, although technology should be revered for its expression of artisan knowledge it is through its satisfaction of basic human needs that its most profound character can be expressed (Hood, 1968).

The contemplation of the cosmos is held to be the highest order of human activity within the Aristotelian view. Technology is viewed as serving to free the individual from the pursuit of basic necessities so that the higher ordered contemplation of knowledge may occur. Hood (1972) summarized that:

the traditional or Aristotelian understanding posits a hierarchy of activities in which technology is one of the lower kinds.

Techne...is strictly instrumental to something else from which it receives its complete justification.... Accordingly, technology is subordinate to practical wisdom, to moral and intellectual activities which are their own justification. (p.349)

Explicitly Hood (1968) stated:

Technology is something less than morality, politics, and science, for it is only man's first entry into the cosmos, only partially 
definitive of his being and the being of things. Man rises above the animal level by means of the creation of technology, dominates his impulses and develops his practical capacities; but he has not yet arrived at the apex of his destiny. The benefits of productive and practical cognition are only secondary; their unceasing activity has still an end beyond itself which is theory. (Hood, 1968, p. 69-70) Aristotle (trans. 1915) deals with a conception of technology in his work Ethica Nicomachea, although: the main object of the Nicomachean Ethics...is to furnish the knowledge necessary for acting well: i.e. for a way of acting, a mode of living, in which the agent shall be in the fulfillment of his 'best', of the 'good for man'. (Joachim, 1951, p. 16) Aristotle laid out a conception of human activity that includes a treatment of TÉXVN (craft, art, technique). Aristotle's primary concern with the "supreme felicity of man" lead him to differentiate between ends and subsequently types of human activity (Joachim, 1951, p.16). TÉXVN was viewed by Aristotle as being distinct from the higher order theoretical activities such as science, politics, and philosophy. TÉXVN was conceived of being "identical with a state of capacity to make, involving a true course of reason" (Aristotle, trans. 1915, Ethica Nicomachea, $\left.1140^{\mathrm{a}} 10\right)$.

Although, Aristotle's conception of TÉXVN may have included a "true 
course of reason" it must be emphasized that Aristotle's contentions and analogies placed technology as a lesser form of human knowledge. This is repeatedly evidenced in Aristotle's writings. Aristotle's "true course of reason" with respect to technology is limited. The limitation lies in the contemplation of the individual pursuing a product. Aristotle in drawing a distinction between the virtue of an act and the character of the agent, stated "the products of the arts have their goodness in themselves, so it is enough that they should have a certain character" (Aristotle, trans. 1915, Ethica Nicomachea, $\left.1105^{b} 26-9\right)$. The point being expressed by Aristotle is that higher ordered definition of one's character involves a contemplation of an act that is beyond its mere instrumentality. Joachim (1951) in addressing Aristotle's point wrote:

To know what a good shoe is and how to make it is comparatively a mere superficial knowledge: but to know what the right ideals in life are, and how to secure them -- this is a knowledge which is, so to say, the whole character of the man. (p. 79)

The importance of the point expressed here is that, technology in this view is extrinsic to the character of man. Hood (1968) in expressing the fallacy of the Aristotelian view stated that, "Aristotle's view provides evidence that the popular conception of technology is wrong, that is, the view which holds that man stands in external relation to technology and can be easily 
characterized in such terms" (p. 72). More recently, Postman (1992) wrote of the early Greek philosophers that, "Both Plato and Aristotle scorned the 'base mechanic arts,' probably in the belief that nobility of mind was not enhanced by efforts to increase efficiency or productivity" (p. 25; Muller, 1970, p. 25). Muller (1970) in expressing the Greek attitude toward technology wrote the following:

Behind their failure to consider productive purposes lay the attitude of Archimedes, who founded the science of mechanics and was famous for his inventions. 'Give me a fulcrum and I shall move the world,' he boasted; but according to Plutarch he also declared that engineering and all useful arts were 'ignoble and sordid' -- harking back to the attitude of Pluto and Aristotle toward the 'base mechanic arts'. (pp. 27-28) Mitcham and Mackey (1972) have also provided an outline of understanding with regard to the traditional conception of technology. The outline they provided of the traditionalist view was enclosed within a categorically based anthology entitled Philosophy and Technology: Readings in the Philosophical Problems of Technology (1972). Mitcham and Mackey emphasized that a metaphysical understanding of technology must be arrived at to understand technology in any other context, such as the religious, political, historic, and social. "The term metaphysical indicates that 
technology is to be approached...as a total structure which must be analyzed in terms of its own inherent elements" (pp. 21-22).

Mitcham and Mackey presented a collection of essays that they believed was representative of the metaphysical approach. The Aristotelian viewpoint identified by Hood (1968) was included within the Mitcham and Mackey anthology and was later expanded upon by Mitcham (1979) in Philosophy and the History of Technology.

Mitcham's (1979) essay traces the meaning of the word technology to its root in the works of Plato and Aristotle as a means to "clarify our conceptions of the essence of technology" (p.172). He emphasized that "In philosophical works techne comes to be conceived not only as an activity of some particular sort of character, but as a kind of knowledge" (p.173). Mitcham's (1972) etymological exploration of the meaning of technology through the works of the ancient philosophers Aristotle, Plato and Socrates led to the conclusion that:

Techne in the classical understanding -- and this cannot be emphasized enough when comparing ancient and modern making activities -- is thus fundamentally oriented toward particulars instead of toward the efficient production of many things of the same kind in order to make money. (p. 179) The understanding of the orientation toward particulars was a fundamental 
point expressed by Mitcham in differentiating ancient conceptions of techne and modern technology.

Mitcham (1979) stressed that techne was a form of knowledge that expresses an understanding of particular forms as they are drawn from nature through the sensorimotor experience. The traditional view regarding the requirement of practical imitation in teaching techne is an expression of a non-rational element. Mitcham (1979) stated "there is at the heart of technical activity if not techne itself an irreducible, nonlogical component" ( $p$. 182). In this sense Mitcham contends that techne is differentiated from modern meanings of technology. He stated that:

Here, then is the most fundamental difference between Greek techne and modern technology. Techne involves logos, but only in grasping form, not in directing the actual process of production, activity qua activity. There is no logos of this activity. But is this not precisely what modern technology proposes to furnish, a logos of the activity, a rationalization of the process of production, independent, of it not actually divorced from any particular conception of eidos or form? Is this not precisely why it can so vigorously claim to be neutral, to be dependent in use on what man wants to do with it, on purely extrinsic ends? (p.182) Mitcham's assertion, that there exists a modern conception that stands in 
stark contrast to the Aristotelian or traditional view of technology, has served as a theme in writings concerning the phenomenon of technology.

The contrast and relationship between traditional or Aristotelian views of technology and modern conceptions of technology was emphasized by Mitcham (1994) in his introduction to chapter two of Thinking through Technology :

From the origins of human history, ideas about the meaning of making activities have found expression in sacred myth, in poetry, and in philosophic discourse. The attempt by Francis Bacon (1561-1626) to turn human attention toward technology and to invest human energy in its pursuit, in preference to politics and philosophy (not to mention religion and poetry), was itself undertaken by philosophical and rhetorical means. It was, we might say, the humanities that conceived technology -- especially modern technology -- not technology that conceived the humanities. (p. 39)

Although, according to Mitcham (1972), modern conceptions of technology may have originated from arguments based in a tradition of the humanities, the divergence of thought that has been symbolized by Francis Bacon's argument is fundamentally significant. For as Mitcham (1972) stated in referring to the impact of Bacon upon conceptions of technology, "In the face 
of the success of Bacon's challenge to this traditional understanding and the subsequent appearance of technological societies, humanities philosophy of technology appears as a series of rear-guard attempts to defend the fundamental idea of the primacy of the non-technical" (p. 39).

The change that occurred in the meaning of technology has been traced to transformations in the fundamental notions of the character of matter and the cycle of life as it is related to knowledge and progress (Postman, 1992, Fukuyama, 1992, Mitcham, 1979). However, Mitcham (1979) emphasized that by providing a sense of the transformation in the meaning of technology he "was not, of course, suggesting that this transformation of the term technology took place consciously; I have looked for evidence that this might have been the case but have not found any" (p.187). This point is important in that inferences regarding the revolution of thought must be drawn upon for the development of an understanding regarding the evolution of conceptions of technology.

Mitcham (1979) delineated two traditional conceptions of technology that came to be transformed. The logos, or logic of technological activity was not recognized in the traditional conception of techne. As stated previously, Mitcham (1979) emphasized the notion that, although Aristotle may have recognized a logic of technology in the "grasping of a form", techne remained an activity, whose primary understanding was derived from 
experience not contemplation (p. 182). Aristotle, in drawing a distinction between intellectual virtue and moral virtue utilizes an analogy between the role of experience in techne and moral virtue, when he stated:

all the things that come to us by nature we first acquire the potentiality and later exhibit the activity; but the virtues we get by first exercising them, as happens in the case of the arts as well. For things we have to learn before we can do them, we learn by doing them, e.g. men become builders by building and lyre-players by playing the lyre; so too we become just by doing just acts, temperate by doing temperate acts, brave by doing brave acts. (Aristotle, trans. 1915, Ethica Nicomachea $1103^{\mathrm{a}} 26-38$ )

The only logic seen to exist in techne by Aristotle was the craftsman's grasping of the end form of the product from nature (Mitcham, 1979, pp. 178-179). Mitcham (1979) in addressing Aristotle's emphasis upon techne's drawing from nature being based in experience stated, "The ultimate decision in action rests not with reason but with sensation" (p.78).

A second notion of traditional techne that was to be transformed was that of the end product or form of technology being drawn from nature. Aristotle's traditional conception of techne saw it as an activity, whose limitations were prescribed by nature (Mitcham, 1979, Hood, 1968). Aristotle stated that "art imitates nature" (Aristotle, trans. 1947, Physics, $194^{a}$ 
21). Mitcham (1979) synthesized a conclusion of Aristotle's relationship of techne to nature as follows:

Techne imitates art by uniting form and matter in a particular something. The form is the idea in the mind of the artist, but its union with matter is, as it were, at the mercy of matter and its specific receptivity. Form cannot not be forced into or imposed upon matter, an artisan must let the matter guide the way it will receive form. (p.178)

Mitcham (1979) goes on to assert that traditional conceptions of technology held that, "matter is caught up in a cosmic process, and in that sense living" (p.186). The spirituality of nature held that matter could express a desire for transformation into another form. Therefore, the traditional conceptions of techne held that techne was inherently limited by the receptivity of nature and its character in the cosmos.

The character of nature and its reverence in the past was expressed by Berdyaev (1934). Berdyaev delineated three epochs in history that represented the predominate and existent view of the spirituality of nature in time. The epochs delineated by Berdyaev were the natural-organic, the cultural in the proper sense, and the technical-mechanical. Berdyaev (1934) stated that:

these epochs correspond the different relations of spirit to 
nature -- namely, the diffusion of spirit in nature, the emergence of spirit from nature and formation of a special spiritual sphere; lastly, spirit's active conquest of nature and domination over it. (p. 204) The epoch named the "cultural in the proper sense" most closely reflects the Aristotelian view of spirit and nature. In depicting the evolution of the cultural epoch from the natural-organic epoch, Berdyaev emphasized that although the notions of spirit held in telluric mysticism and animalistic religion faded, individuals still viewed nature as an expression of divinity. Berdyaev stated:

Culture at the height of its development was still encompassed by nature.... Men of that time, however distant they may have been from a natural life, still gazed at the sky, the stars, the fleeting clouds...contemplation of the beauties of nature is predominately a sign of culture. Culture, the state, modes of life, all were understood organically by analogy with the life of organic beings; flourishing of cultures and states appeared to be somewhat in the nature of vegatative-animal process. (p.204)

The understanding of the Aristotelian viewpoint is that nature is of the cosmos and is reflective of a divinity that could only be contemplated through higher order thinking, and only reordered according to its inherent expressive desire to reveal its divine character.

A final conception of the Aristotelian view that was to be transformed 
was previously alluded to by Berdyaev (1934). The organic life cycle evident in nature was an analogy that extended itself into every sphere of human organization and life. As Berdyaev (1934) stated, "the flourishing of cultures and states appeared to be somewhat in the nature of a vegatative-animal process.... Culture was full of symbols: in shapes of earth it reflected heaven, prefigured another world" (p.204).

The Aristotelian cyclical view of the history had significant implications regarding the notions of human progress. Fukuyama (1992) stated that: Aristotle did not assume the continuity of history. That is, he believed that the cycle of regimes was embedded in a larger natural cycle, whereby cataclysms like floods would periodically eliminate not only existing human societies, but all memory of them as well, forcing men start the historical process over again from the beginning. In the Greek view, history thus is not secular but cyclical. (p.56)

Strauss (1954) expressed the classical conception of the cyclical nature of history with regard to progress and direction of technology in relationship to nature:

the opinion that there occur periodic cataclysms in fact took care of any apprehension regarding an excessive development of technology or regarding the danger that man's inventions might 
become his masters and his destroyers. Viewed in this light, the natural cataclysms appear as a manifestation of the beneficence of nature. (p.299)

Muller (1970) in writing of the Greek attitudes and beliefs regarding progress and change wrote:

Greek thinkers were no more confident that the future would be better than the past. Like Plato and Aristotle, they aspired to stability and order, not more freedom and growth; in their visions of a well-ordered state the last thing they wanted was revolution. The obvious impermanence in human affairs led them to conceive history as endless cycle, the rise and fall that is indeed the most familiar story in history, of kingdoms, empires, whole civilizations. (p. 41)

The significance in the points expressed by Berdyaev (1934), Fukuyama (1992), Muller (1970), and Strauss (1954) is that the traditional, classical, or Aristotelian view of history was one in which a greater cosmos based on an organic life cycle predominated the ultimate direction of human destiny. Humankind was bound to the cosmos in such a manner that all that owes its existence to human creation will always be reclaimed by nature. 


\section{Bacon's Revolution}

A revolution in thought with regard to traditional conceptions of technology, nature, and progress came to be evidenced in Western Europe during the 1500s. The Aristotelian viewpoints with regard to the logos of activity, the nature of matter, and the organic analogies of progress were questioned and ultimately transformed to reflect the contemporary understanding of the Western tradition. The embodiment of this transformation in thought was found in the writings of Sir Francis Bacon.

Bacon's writings have come to represent the initial and seminal statement with regard to the contemporary conception of technology, nature, and progress. Postman (1992) proclaimed that, "Francis Bacon...was the first man of the technocratic age.... It was Bacon who first saw, pure and serene, the connection between science and the improvement of the human condition" (p.35).

Winner (1977) in his work, Autonomous Technology traced contemporary notions of technology to Baconian foundations;

The theme of mastery in the literature of technology is even more evident with regard to Western man's relationship to nature.... In no place is this theme more clearly stated than in the writings of the most famous early advocate of a world-transforming scientific revolution, Francis Bacon. (p. 21) 
Winner continued to add the emphatic statement, "the success of Bacon's program as a way of knowing, as a vision of the world, and as a way of operating on material reality is perhaps the most important of all accomplishments in modern history" (p.23).

Historian Lewis Mumford (1964) also emphasized the impact that Bacon has had upon the course of human history:

In a real sense, the success of the mechanical world picture was ensured in advance by Francis Bacon.... Bacon deserves a special place...for outlining an ideal institutional foundation for the systematic achievement and application of ordered knowledge.... He outlined the pragmatic justification for society's commitment to modern science as technology. No sky-gazer like Galileo, no sun-worshipper like Kepler, Bacon brought science down to earth. (p. 106)

In a later essay Mumford (1974) more specifically ascribed the modern faith in technology to Bacon: "From Bacon onward, people thought that the advance of technics would by itself automatically solve the crucial problems of civilization" (p.282). Mitcham (1994) also attributed the foundation of the conception of the "inherent goodness of technology" with the writings of Bacon (p.283).

The transformation in beliefs and attitudes toward technology and 
nature that have been anchored in Bacon were founded in a revolution of thought regarding Aristotelian views. Mesthene (1967) wrote:

Francis Bacon....was the first to foresee the physical power potential in scientific knowledge.... By massive physical changes deliberately induced, we can literally pry new alternatives out of nature. The ancient tyranny of matter has been broken, and we know it. We found, in the seventeenth century, that the physical world was not at all like what Aristotle thought.... We are today coming to the realization that the physical world need not be as it is. (p. 110)

Bacon argued for a systematic and scientific approach to knowledge and its application. When Mesthene (1967) wrote of the ability to "pry new alternatives out of nature" he was expressing the transformation of the Aristotelian concept of nature (p. 110). Bacon reflected a transformation in the Aristotelian belief that nature is of the cosmos and represented a divinity that was knowable only through contemplation. According to the Aristotelians, nature could be transformed through techne only in such a manner that it was an expression of it's inherent willingness to exist in another form. Form as conceived of by technology was limited to the permissiveness of nature's inherent character. Bacon explicitly denied the ability of contemplation to yield true knowledge, and exalted the technological 
path to understanding, "Neither the naked hand nor the understanding left to itself can effect much. It is by instruments and helps that the work is done, which are as much wanted for the understanding as for the hand" (Bacon, Novum Organum, 1954, p. 80).

Mitcham (1972) in a review of Grant's Technology and Empire wrote that Bacon rejected "the ideal of contemplation in favor of the Protestant ethic and experimental science. With the ideal of contemplation destroyed, practice either economic or scientific is all that remains for man" (p.13). Grant (1969) in depicting the rejection of Aristotelian contemplation by Baconians wrote that "the scientists wished to free the minds of men from formulations of medieval Aristotelianism.... They criticized the medieval teleological doctrine as preventing men from observing the world as it is" (p.190). Basalla (1988) stressed that, "Francis Bacon was especially fond of contrasting the sterility of speculative philosophy, which had remained essentially unchanged since Aristotle, with the mechanical arts, which had advanced continuously over the centuries" (p.132). Dick (1955) writing of "Bacon's reaction against the decadent Aristotelianism" stated: he first fell into the dislike of Aristotle, not for the worthlessness of the author, to whom he would ever ascribe all high attributes, but for the unfruitfulness of the way: being a philosophy only strong for disputation and contentions, but barren of production of works for 
the benefit of the life of man. (p. $x)$

Baconians viewed the subject of nature in a revolutionary way. Ortega $y$ Gasset (1939) expressed this new view of nature, in his detailing of the link between the logic of science and technology:

The founding fathers of the new science were well aware that it was made of the same stuff of technology.... In fact, the new technology proceeds in exactly the same way as the new science.

The engineer no longer passes directly from the image of the desired end to search for the means which may obtain it. He stands before the envisaged aim and begins to work on it. He analyzes it. That is to say, he breaks the total results down into the components which have formed it, that is, into its 'causes'.... An Aristotelian...would not have thought of splitting a phenomenon up into its elements. Approaching it in its totality he also tried to find a total cause. This the new mode of thinking: analysis of nature. (p. 313)

The concerted analysis of nature represented a transformation of the Aristotelian notions of experience and particulars. As stated previously, the traditional view held that techne was a limited form of knowledge in that it's understanding was based in sensorimotor experience and bound by nature (Mitcham, 1979). Bacon's aphorisms "knowledge is power" (Volti, 1992, p. 
237) and "Nature to be commanded must be obeyed" (Bacon, Novum

Organum, 1955, p. 462) have come to represent the foundation of the Baconian view of nature.

Bacon's view that nature could be commanded stands in stark contrast to the Aristotelian notion that matter possesses a "desire" (Mitcham, 1979, p. 186). Merchant (1980) wrote of the Aristotelian view as a contrast to Baconian notions:

the view of nature as immanent self-development, the nature naturing herself of the Aristotelians. This was the organic view of nature as a living, growing, self-actualizing being.... The case of art (techne) -- man operating on nature to create something new and artificial. Here, 'nature takes orders from man and works under his authority'.... The Baconian ideal of technological mastery over Nature had helped to create the modern worldview. (pp. $115-116)$

Merchant's point was that nature lost it's spirituality under the Baconian view and "human behavior toward the earth had given way to a new ethic of exploitation" (p. 116). Berdyaev's (1932) "technical-mechanical" (p. 204) epoch had been given birth by Bacon. As Berdyaev stated: "The meaning of the technical age is primarily that it closes the telluric period of human history, when man was determined by the earth not only in the physical but also in the 
metaphysical sense" (p.208).

The notion of "knowledge is power" (Volti, 1992, p. 237), derived from Bacon's aphorism "Human knowledge and human power meet in one; for where the cause is not known the effect cannot be produced" (Bacon, Novum Organum, 1955, p. 462), represents the technological aspect of the Baconian revolution. Bacon exalted the position of technology in the course of human history ( Mitcham, 1994, p.285; Bacon, Novum Organum, 1955, p.537).

Bacon wrote; "the introduction of famous discoveries appears to hold by far the first place among human actions.... The benefits of discoveries may extend to the whole race of man" (p.538). Most specifically Bacon (1955) wrote of the significance of the technological developments of printing, gunpowder, and the magnet, stating that:

For these three have changed the whole face and state of things throughout the world; the first in literature, the second in warfare, the third in navigation; whence followed innumerable changes; in so much that no empire, no sect, no star seems to have exerted greater power and influence in human affairs than these mechanical discoveries" (Novum Organum, p.538-539). The significance in the point drawn here is that Bacon viewed the advancement of technology as the most important and divine human activity 
(Mitcham, 1994, pp. 283-289). The application of human efforts for the systematic understanding of nature and the development of technologies was no longer viewed, as by the Ancients, as being "ignoble and sordid" (Muller, 1970, p. 28), or a "mere superficial knowledge" (Joachim, p.79). Dick (1955) wrote of Bacon's reaction against decadent Aristotelianism: When he looked about him, he came to realize that three discoveries had done more to transform the world in which he lived than had any political theory or any school of philosophy.... Awakened by these realizations Bacon felt impelled to review the whole intellectual history of the western world to see why philosophy had been so productive of words but so barren of fruit for the 'benefit and use of life'. (p. xi)

The final element of Baconian thought that served to transform existing traditional Aristotelian notions of human history was that of progress. The traditional or Aristotelian view of history was cyclical (Fukuyama, 1992, Muller, 1970, Strauss, 1954, Berdyaev, 1934). As previously cited "Aristotle did not assume the continuity of history.... In the Greek view, history thus is not secular but cyclical" (Fukuyama, 1992). This view of history as "a concept of cycles or vast rhythms affecting the totality of things" was based in the notion that:

the physical universe and everything in it is organic and mortal, 
moving from birth through growth to death in huge cycles of time....and that within these cycles of time human institutions are also organic. (Dick, 1955, p. xiii)

Dick in expressing Bacon's rejection of the cyclical view of history wrote: Against these manifold counsels of despair Bacon advanced his arguments of hope.... Because he believed that knowledge is cumulative, he saw no reason to despair. For Bacon asserted that man can control his destiny; he is not the slave of implacable decay unless he chooses to be because knowledge being incremental, need not be subject to the unalterable laws of change and destroy empires. (p. xiv) Bacon espoused a fundamental belief in progress that was based in a faith in technology. Basalla (1988) wrote of Bacon's faith in technology: Technology was a favorite source of examples for the proponents of progress.... The scholastics quibbled over minor philosophical points, practical men developed new ways of powering machines, fighting wars, making books, sailing ships, and constructing buildings. These technical changes were unequivocal proofs of progress.... Inventions were evidence that humanity was on the road to a better society, perhaps even a perfect one. (p. 132) Fukuyama (1992) emphasized the Baconian marriage of the concept 
of mastery over nature and the inevitable progress of humankind through the accumulation of knowledge:

Bacon...assumed the possibility of a knowledge and therefore a mastery of nature, which was in turn subject to a set of coherent and universal laws.... Knowledge of these laws was not only accessible to man as man but was cumulative, such that successive generations could be spared the efforts and mistakes of earlier ones.... Thus the modern notion of progress had its origins in the success of modern natural science, and allowed Francis Bacon to assert the superiority of modernity to antiquity on the basis of inventions. (p.57)

The Baconian notions regarding the systematic accumulation of knowledge and the instrumentality of nature for the betterment of man posited a linear progression to human history. The Aristotelian telluric contemplation of the cosmos and its metaphoric assumptions regarding the cyclical nature of all things had been rejected by Bacon and eventually Western civilization, in favor of a faith in human technological progress. Bacon biographer Dick (1954) wrote:

What Bacon feared and fought was any spirit of resignation or of complacency toward human knowledge.... No man of his time saw more clearly the importance of technological discovery, none set a 
higher value on it.... For him the main value of science was the hope of 'a line and race of inventions that may in some degree subdue and overcome the necessities and miseries of humanity'. (pp. xiv-xv)

Basalla (1988) in writing of the culmination of the Baconian revolution with regard to nature, knowledge, and progress wrote; "The domination of nature joined novelty and progress to form a triad of ideas that emerged in the culture of Renaissance Europe and became instrumental in stimulating technological change" (p.132). Bacon was a representative of the foundation of the technological mindset that has served to shape and create contemporary culture and society.

\section{Philosophic Questioning}

\section{History as Progress}

The technological mindset that came to shape contemporary culture and society remained largely unquestioned until the 20th century. The philosophic questioning of technology began in some degree during the mid 1800's and emerged as a genuine field of thought during the mid 1900s (Mitcham, 1994). The philosophic questioning of technology as a cultural phenomenon has grown in response to the "uneasiness regarding the 
popular belief in the unqualified moral probity and clarity of the modern technological project" (Mitcham, 1994, p. 1). Mitcham (1994) more specifically stated that "the late 1960 's and early 1970 s were a watershed in increasing consciousness of problems associated with technology and in attempts to develop mechanisms for social control" (p. 6).

In 1974, Rapp, writing of the fundamental lack of philosophic consideration of the technological phenomenon stated:

It is an astonishing fact that the commonly accepted and carefully investigated philosophy of science has not found its counterpart in an established philosophy of technology. Hitherto only sporadic and widely scattered attempts have been made to investigate the structure of thinking in technology. (p. vi) Rapp (1974) contended that the lack of philosophic consideration of technology was limited by the adherence to the "traditional view, which regards technology either as a sort of craft or at best as an application of science" (p. ix).

Marx (1984) in delineating Martin Heidegger's conception of technology, stressed the emergence of the thinking of technology as a phenomenon in relation to the cultural and societal acceptance of the ideal of progress based on technological achievement. Marx stressed that a progressive conception of history embodies what is the essence of 
technology as Heidegger envisioned it (p. 645). The "idea of history as progress" was directly related to the emerging industrial state of the late nineteenth and early twentieth centuries (p.645). Marx (1984) wrote:

The concept of history that won favor at the time turns on the idea of 'progress': the belief that history is the record of steady, continuous, cumulative, and (in its most extreme form) a somehow preordained improvement in the material, social, cultural -- indeed, the overall -- conditions of life, and that its driving force is the expansion of human knowledge and power achieved by science and technology. The idea that history is a more or less irreversible continuum of improvement, or progress, was to be the fulcrum of the dominant secular world view in advanced industrial societies in the nineteenth and twentieth centuries. (p. 644) The notion of "history as progress" being widely accepted is then drawn to the represent the "essence of technology" (p. 645). Marx stated that: In nineteenth century America the essential meaning of the new technology had less to do with the apparatus, its specifically technological attributes, than with the cultural context within (or against) which the presence of the apparatus was experienced. Or to be more precise, the essential meaning, value, and purpose of the new technology derived chiefly from the historical role imputed 
to it by adherents of the progressive belief system. (p. 645)

Marx's (1984) conclusion that the essence or contemporary meaning of technology can be traced to historical notions of historical progress, which were latent within the industrialization of the nineteenth and twentieth centuries, is echoed by Mitcham (1979). Mitcham in writing of the inherent connection between the history and the philosophy of technology wrote:

History and technology are both somehow characteristic of modernity. The modern period has been called the 'age of technology'; it has also been called the 'age of historical consciousness'. These views are both grounded in modern man's affirmation of himself. (p. 166)

As the Baconian notion of "knowledge as power" (Volti, 1994, p.237, Mitcham, 1979, p. 166) came to be expressed as a cultural conviction "modern consciousness arose out of the Renaissance humanism and the affirmation of the singular value of man above everything else in nature" was established (Mitcham, 1979, p, 166-167).

Winner (1986) explicitly tied the failure to develop a philosophy of technology to the wide acceptance of the ideals and notions of progress. He wrote:

Why is it that the philosophy of technology has never really gotten underway? Why has a culture so firmly based upon countless 
sophisticated instruments, techniques, and systems remained so steadfast in its reluctance to examine its own foundations? Much of the answer can be found in the astonishing hold the idea of "progress" has exercised on social thought during the industrial age. In the twentieth century it is usually taken for granted that the only reliable sources for improving the human condition stem from new machines, techniques and chemicals. (p. 5)

Winner's assertion in 1986 that a "philosophy of technology has never really gotten underway" (p. 5) implicitly suggests its modernity.

The modernity of the philosophic questioning of technology as phenomenon can also be inferred from the findings of Pytlik (1988). Pytlik's (1988) Identifying the Great Books of Technology represented an effort to identify 50 great books in technology. Pytlik utilized a Delphi study approach to yield a representative listing of written works that participants believed had "an important influence on society and/or were the classics in their discipline" (p. 54). Pytlik's study yielded a listing of 52 great books of technology. Of these 52 books Pytlik (1988) stated that:

It was found that 25 or 48 percent of the Great Books in technology were published since 1970,36 or 69 percent since 1960 and 43 or 82 percent since $1950 \ldots$. Only three selected titles were published prior to the start of the 20th century. (p. 62-63) 
The three works identified in the research, that had publication dates prior to the twentieth century were De Re Metallica (1556), L'Encyclopedie (1763), and The Lives of Engineers (1861). These works fell into two of five sub-categories identified by Pytlik, as "Understanding Technical Systems" and "Innovation, Invention, Inventors" (p. 54). As such they do not represent a concern with the theme of technology as phenomenon that may reside in works selected for the remaining sub-categories, "Philosophy of Technology", "History of Technology", and "Social/Technical Interaction" (p.54).

The conclusion to be drawn from Mitcham (1979 \& 1994), Rapp (1974), Marx (1984), and Pytlik's (1988) Great Books of Technology is that the consideration of technology as a philosophic question is clearly a contemporary phenomenon that has its roots in the evolution of the popular understanding of what technology is and does. However, the ubiquitous nature of technology has allowed it to be characterized in an eclectic manner, and as such the meaning of technology remains unclear. Marx (1984) concluded that there is a: "prevailing confusion displayed by so many intelligent people in our society about what 'technology' is and more important, their lingering uncertainty about whether it is in itself a good or a bad thing" (p. 653). 


\section{Categorical Approaches}

Despite the seeming "confusion" with regard to the understanding of technology referred to by Marx (1984) several methods of categorization have been suggested as a means for framing particular viewpoints of technology. The approaches taken to categorizing viewpoints of technology range in complexity from the critique by Mesthene (1969) of the simplistic pro, con, and ambivalent characterizations of technology, and the Watkins and Meadows (1977) typing of some views as being either that of an advocate or critic of technology, to the "categories of investigation into the nature of technology" proposed by DeVore (1980, p. 220) and the "ways of being with technology" framework developed by Mitcham (1994).

The categorization of viewpoints of technology has been pursued due to the inherent nature of technology to be contextual, and the failure of definitional approaches (Mitcham, 1994, Custer, 1991, DeVore, 1980). The nature of technology and its subsequent characterizations have been dependent upon the context from which the writer is drawing (Mitcham, 1994, Custer, 1991, DeVore, 1980). Custer (1991) in a review of the literature wrote that:

The process of defining technology is precisely the reverse of what could be expected. Throughout the literature, the context for technology was developed prior to developing definitions of 
technology. Throughout the literature the most consistent answer supplied to the question "What is technology?" could be summarized as, "it depends...!". (p. 16)

DeVore (1980) expressed the same conclusion, "one obvious assumption is that the character of technology must be determined from the context in which it exists", and "the character of technology depends also on how it is defined" (p. 233).

It is upon the understanding of the contextual nature of technology that DeVore (1980) contended that four "constants do emerge from the viewpoints and definitions" of technology (p. 220). DeVore then states that, "each of these constants identifies specific categories of investigation about technology which have been pursued" (p. 220). The categories of investigation identified by DeVore are the epistemological, sociological, anthropological, and phenomenological (p. 220-221). DeVore's (1980) categories represent the process by which a viewpoint or definition of technology has been derived. The epistemological category represents those definitions or viewpoints of technology that are "concerned with the creation and development of knowledge" (p. 220). The sociological category represents those definitions or viewpoints that have a sociological analysis approach. The third category identified by DeVore is the anthropological, and represents works that have "the study of the physical creations of 
humankind and the nature and essence of humankind as the creator of technology" (p.221). The final category, phenomenological, encompasses those works whose "focus is on the behavior of systems -- ideological, social, and adaptive -- and on the relationships between the systems" ( $p$. 220).

The emphasis on the process by which a meaning or characterization of technology is derived as a means of categorizing viewpoints was also used by Mitcham (1994). Mitcham's work Thinking through Technology: The Path between Engineering and Philosophy (1994) has been referred to as "a comprehensive resource for the philosophy of technology movement" and "the most comprehensive critical introduction to the emerging philosophy of technology field" (Deitrich, 1995, [on-line]). Mitcham's (1994) work encompassed the conclusions of Custer (1991), and DeVore (1980), with regard to the contextual nature of technology.

Mitcham (1994) recognized the contextual nature of technology, "the thesis is that technology is not a univocal term; it does not mean exactly the same thing in all contexts. It is often, and in significant ways, context dependent -- both in speech and in the world" (p. 152). In his attempt to establish the need for a categorization of philosophical viewpoints Mitcham (1994) in referring to the diverse nature of technology stated explicitly that: In undertaking an analysis of diverse types of technology, 
however, one cannot just dive in. The rich complexity of the subject forces one to adopt at least a provisional classifying or categorizing scheme. Numerous frameworks or preliminary typologies have been proposed and used -- although these have often been more for technical, historical, encyclopedic, or educational and heuristic than philosophical purposes. (p. 154) Mitcham (1994) began by identifying two traditions with regard to the study of the nature and meaning of technology. Mitcham's work began with a focus on the two historical discourses in the philosophy of technology field, the "engineering philosophy of technology" (EPT), and the "humanities philosophy of technology" (Dietrich, 1995).

The engineering philosophy of technology (EPT) identified by Mitcham (1995) has as it primary focus, technology as the "subjective genitive" (p.17). Mitcham states that, "when 'of technology' is taken as a subjective genitive, indicating the subject or agent, philosophy of technology is an attempt by technologist or engineers to elaborate a technological philosophy" (p.17). Mitcham asserted that conceptual issues such as "distinctions between craft and factory production, mechanical and chemical processes, the classification of machines, the possibility of rules for invention, and the socioeconomic implications of automatic machinery" serve as themes in the field of EPT. In part the EPT has been characterized 
by what Mitcham refers to as the "generalization of a engineering rationality" or the promotion of "technocracy" as evidenced by the scientific management movement (p.28). Mitcham sums up the EPT as an "analyses of technology from within, and oriented toward an understanding of the technological way of being-in-the-world as paradigmatic for other kinds of thought and action" (p.39) or more succinctly a "technological philosophy" (p. $62)$.

The humanities philosophy of technology (HPT) has as its focus, technology as the "objective genitive" (p. 17). The HPT is "the attempt of religion, poetry, and philosophy to bring non-transtechnological perspectives to bear on interpreting the meaning of technology" (p. 39). Mitcham contended that the HPT has as its "principle -- the primacy of the humanities over technology" for it was "the humanities that conceived technology -especially modern technology -- not technology that conceived the humanities" (p. 39).

The humanities philosophy of technology embraces most of the contemporary discussions and viewpoints surrounding meaning and character of technology. Within the humanities philosophy of technology field are literary authors, historians, and philosophers. Among these are Lewis Mumford, Martin Heidegger, José Ortega y Gasset, Hans Jonas, Jacques Ellul, and Don Ihde (Mitcham, 1994). Mitcham (1994) contends that the 
"humanities philosophy of technology is inherently more inclusive than engineering philosophy of technology...because of the humanities commitment to a plurality of perspectives" (p. 140). Mitcham's point, that the inclusive nature of the humanities inherently assumes the primary role in defining the meaning of technology, was summarized as follows:

But why should this kind of inclusiveness be a defining characteristic of philosophy? Isn't engineering or technology inclusive of the humanities, in the practical or material sense that without some technology there would not be any human life, much less any humanities -- which also generally use tools of many sorts, from pencils to computers, to perform their distinctive tasks? But the point is that even if engineering includes the humanities on the practical level, once engineers start proposing theories about the nature and meaning of technology they are no longer doing technology but are engaging in a kind of philosophy. (p. 141) It is upon the foundation of the primacy of the humanities philosophy of technology that Mitcham (1994) then constructed his "ways-of-being-with-technology" typology. Mitcham (1994) identified four "modes of the manifestation of technology" (p. 160) and placed them within the context of three basic attitudes toward technology. The modes include the manifestation of technology as knowledge, volition, 
object, and activity (pp. 161-266). The three basic attitudes toward technology identified by Mitcham (1994) are ancient skepticism, enlightenment optimism, and romantic uneasiness.

The mode of technology as knowledge encompasses the epistemological approaches to technology. Mitcham (1994) stressed that while there has existed a traditional acceptance of contrast between the knowledge of nature (biology and physics), and technological knowledge, (engineering and mechanics), a "more analytic epistemological scrutiny of technology" has been argued. Mitcham (1980) cited Carpenter (1974) and Bunge (1967) as having point forth a epistemological structure of technology that included technology as knowledge expressed in sensorimotor skill, maxims or rules of thumb, laws, and theories. A primary concern of those using the technology as knowledge approach, to understanding the character and meaning of technology, is the emphasis on technology as it is expressed in the form of human knowledge.

The mode of technology as object encompasses attempts: to identify technology with particular artifacts, such as tools, machines, electronic devices, consumer products, and the like.... Developed philosophically, it involves a classification of technological objects into various types and ultimately the articulation of an ontology of artifacts. (Mitcham, 1980, p. 306) 
Mitcham (1994) included the object classification scheme of Mumford (1934) as a prime example of an artifact based approach to understanding technology (p. 162). He added that, the use of technology as object has also found an expression in phenomenological interpretations, of Ellul (1964), McLuhan (1964), Winner $(1977,1986)$ and Ihde (1979; 1983). Regardless of the degree to which generalities are struck by those utilizing the technology as object approach, the identification of the artifact as a basis for analysis underlies the technology as object approach to understanding the character and meaning of technology.

The technology as activity approach to understanding the meaning and character of technology has as its focus the "pivotal event in which knowledge and volition unite to bring artifacts into existence or to use them; it is likewise the occasion for artifacts themselves to influence the mind and will" (Mitcham, 1994, p. 209). The technology as activity mode embraces "two broad themes: production and use" (Mitcham, 1994, p. 210). Mitcham (1980) stated that in essence the themes of production or making, and use have traditionally been the domains of the engineer and social scientist respectively (p. 308). Mitcham (1994) identified "behavioral engagements of technology", which served to define the technology as activity mode ( $p$. 210). Among the activities identified are crafting, inventing, designing, manufacturing, working, operating, and maintaining (p. 210). The behavioral 
engagements of technology expressed by Mitcham are reminiscent of the Halfin (1973) study of the intellectual processes of the technologist. Interestingly, Winner (1986) contended that the failure of the philosophy of technology to take hold can be attributed to "the deceptively reasonable notion that...divides the range of possible concerns about technology into two basic categories: making and use" (p. 5). However, the point to be emphasized here is that the technology as activity approach has as its concern the moment of human action within the technological process as a means for understanding the character and meaning of technology.

The technology as volition mode "is the most individualized and subjective of the four modes of manifestation of technology" (p. 250). Technology as volition has as its focus, will. Mitcham (1994) emphasized the difficulty in assessing technology as an expression of will by stating: "it is difficult to get a philosophical purchase on technology as volition. This is because willing...is itself so poorly articulated by philosophy" (p.247). However, viewpoints that fall within the technology as volition category are those that depict the expression of will "as technological desire, as technical motivation or movement, and as consent to technology" (p. 255). Among those that most significantly represent the technology as volition viewpoint is Martin Heidegger (Mitcham, 1994).

The manifestations of technology identified by Mitcham (1994) are 
then expressed with three ways-of-being with technology (p. 275-299). Mitcham's ways-of-being with technology include ancient skepticism, enlightenment optimism, and romantic uneasiness. The ways-of-being with technology is an expression of categories of historical attitudes toward technology.

Ancient skepticism refers to:

the original articulation of a relationship between humanity and technology, an articulation that in its earliest forms is coeval with the appearance of recorded history, can be stated boldly as technology is bad but necessary or, perhaps more carefully as technology is necessary but dangerous. (Mitcham, 1994, p. 277) The ancient skepticism is said to be evidenced by numerous myths such as "Prometheus, Hephaestus, and Daedalus and Icarus" (Mitcham, 1994, p. 277). The use of ancient skeptical myth continues to be utilized by critics of technology today; for example, in Postman's (1994) use of Plato's Thamus to depict the shortsightedness of technological proponents and Muller's (1970) use of Frankenstein as a metaphor in his work titled The Children of Frankenstein: A Primer on Modern Technology and Human Values. Mitcham then summed up the ancient skepticism view:

From the viewpoint of the ancients....being-with technology is an uneasy being-alongside-of and working-to-keep-at-arms-length. 
This premodern attitude looks on technics as dangerous or guilty until proven innocent or necessary -- and in any case, the burden of proof lies with those who favor technology, not those who would restrain it. (p. 283)

Mitcham's (1994) second attitude or way-of-being with technology is that of "enlightenment optimism" (p. 283). Enlightenment optimism "argues the inherent goodness of technology and the consequent accidental character of all misuse" (p. 283). Mitcham (1994) most directly attributes the first articulation of this view to Francis Bacon (p. 283). Mitcham (1994) further contended that not only is technology embraced by those ascribing to enlightenment optimism but is held as a moral and natural imperative. Mitcham (1994) cites Immanuel Kant:

Nature has willed that man should, by himself, produce everything that goes beyond the mechanical ordering of his animal existence, and that he should partake of no other happiness or perfection than that which he himself, independently of instinct, has created by his own reason. (p. 285)

Mitcham contended that enlightenment optimism redefined the human prospect in that; "nature and reason, if not God, command humanity to pursue technology; the human being is redefined not as Homo Sapiens but as Homo Faber" (p. 285). The enlightenment optimism view was then 
furthered by the economically based moral argument of Hume (p. 286). The view that a technologically induced prosperity for the betterment of all humanity had not only material but spiritual benefits as well had taken hold by the 1800s. Mitcham (1994) concluded that enlightenment optimism had: four interrelated arguments: (1) the will to technology is ordained for humanity by God or by nature; (2) technological activity is morally beneficial because, while stimulating human action, it ministers to physical needs and increases sociability; (3) knowledge acquired by a technical closure with the world is more true than abstract theory; and (4) nature is no more real than artifice -- indeed it operates by the same principles. (p. 289) Mitcham (1994) further concluded forcefully that:

It is scarcely necessary to illustrate how aspects of this ideology remain part of intellectual discourse in Marxism, in pragmatism, and in popular attitudes regarding technological progress, technology assessment and public policy, education, and medicine. (p. 289)

Mitcham's (1994) final way-of-being with technology is the most contemporary viewpoint or attitude toward technology. Romantic uneasiness "contains a new way of being-with technology, one that can be neither ancient skepticism nor modern optimism" (p. 290). Mitcham (1994) 
continued by stating that:

romanticism is, of course a multidimensional phenomenon.... it can refer to a permanent tendency in human nature that manifests itself differently at different times.... the romantics propose an organic cosmology; in opposition to scientific rationality.... romanticism can also be interpreted as a questioning -- in fact, the first serious self-conscious questioning -- of modern technology.... romanticism reflects an uneasiness about technology that is nevertheless fundamentally ambivalent. (p. 290)

Romantic uneasiness is an expression or awareness of the paradoxes that technology presents, in that while technology is necessary to the human project it can also be destructive of those characteristics that serve to define what it means to be human. Mitcham identified the following characteristics of the romantic uneasiness viewpoint:

(1) the will to technology is a necessary self-creative act that nevertheless tends to overstep its rightful bounds; (2) technology makes possible a new material freedom but alienates from the decisive strength to exercise it and creates wealth while undermining social affection, (3) scientific knowledge and reason are criticized in the name of imagination; and (4) artifacts are characterized more by process than by structure and invested with 
a new ambivalence associated with the category of the sublime. ( $p$. 297)

Mitcham (1994) summarized his three ways of being-with technology and modes of manifestations of technology in table 1. However, he noted a limitation in presenting the three ways of life in relation to technology by means of the matrix. The limitation lies in the fact that, "the ideas associated with the four aspects of technology as volition, as activity, as knowledge, and as object cannot be separated" (p. 297).

Mitcham's (1994) recognition that the study of the phenomenon of technology cannot be easily categorized was also evident in Pacey's (1983) The Culture of Technology. Pacey (1983) attempted to outline some levels of meaning with regard to the use of the word technology. Pacey contended that, "the problem ... is that technology has become a catchword with a confusion of different meanings" and that, "correct usage of the word in its original sense seems almost beyond recovery" (p. 3). He presented a diagram that represented the various meanings technology may assume in given aspects. The aspects in which the meaning of technology has come to be used were identified by Pacey as being the cultural, organizational, and the technical. Pacey (1983) contended that various disciplines and individuals have propensities toward the use of the meaning of technology within one of its aspects. For instance, Pacey (1983) stated that, "to 
politically-minded people, the organizational aspect [of technology] may

seem most crucial" (p.5). The Pacey diagrammatic definitions of technology

and technology practice is summarized in figure 1 (p. 6).

\section{Table 1}

\section{Three Ways of Being-with Technology}

\begin{tabular}{l|l|l|l}
$\begin{array}{l}\text { Conceptual } \\
\text { Elements }\end{array}$ & $\begin{array}{l}\text { Ancient Skepticism } \\
\text { (Suspicious of } \\
\text { technology) }\end{array}$ & $\begin{array}{l}\text { Enlightenment } \\
\text { Optimism } \\
\text { (promotion of } \\
\text { technology) }\end{array}$ & $\begin{array}{l}\text { Romantic Uneasiness } \\
\text { (ambivalent about } \\
\text { technology) }\end{array}$ \\
\hline $\begin{array}{l}\text { Volition } \\
\text { (transcendence) }\end{array}$ & $\begin{array}{l}\text { Will to technology } \\
\text { involves tendency to } \\
\text { turn away from God or } \\
\text { the gods }\end{array}$ & $\begin{array}{l}\text { Will to technology is } \\
\text { ordained by God or } \\
\text { by nature }\end{array}$ & $\begin{array}{l}\text { Will to technology is } \\
\text { an aspect of } \\
\text { creativity, which tends } \\
\text { to crowd out other } \\
\text { aspects }\end{array}$ \\
$\begin{array}{l}\text { Activity } \\
\text { (ethics) }\end{array}$ & $\begin{array}{l}\text { Personal: Technical } \\
\text { affluence undermines } \\
\text { individual virtue } \\
\text { Societal: Technical } \\
\text { change weakens } \\
\text { political stability }\end{array}$ & $\begin{array}{l}\text { Personal: Technical } \\
\text { activities socialize } \\
\text { individuals } \\
\text { Societal: Technology } \\
\text { creates public wealth }\end{array}$ & $\begin{array}{l}\text { Personal: Technology } \\
\text { engenders freedom } \\
\text { but alienates from } \\
\text { affective strength to } \\
\text { exercise it } \\
\text { Societal: Technology } \\
\text { weakens social bonds } \\
\text { of affection }\end{array}$ \\
$\begin{array}{l}\text { Knowledge } \\
\text { (epistemology) }\end{array}$ & $\begin{array}{l}\text { Technical information } \\
\text { is not true wisdom }\end{array}$ & $\begin{array}{l}\text { Technical } \\
\text { engagement with the } \\
\text { world yields true } \\
\text { knowledge } \\
\text { (pragmatism) }\end{array}$ & $\begin{array}{l}\text { Imagination and vision } \\
\text { are more crucial than } \\
\text { technical knowledge }\end{array}$ \\
$\begin{array}{l}\text { Objects } \\
\text { (metaphysics) }\end{array}$ & $\begin{array}{l}\text { Artifacts are less than } \\
\text { natural objects and } \\
\text { thus require external } \\
\text { guidance }\end{array}$ & $\begin{array}{l}\text { Nature and artifice } \\
\text { operate by the same } \\
\text { mechanical principles }\end{array}$ & $\begin{array}{l}\text { artifacts expand the } \\
\text { process of life and } \\
\text { reveal the sublime }\end{array}$ \\
\hline
\end{tabular}

Note. From Thinking Through Technology: The Path between

Engineering and Philosophy. (p.289) by C. Mitcham, 1994, Chicago: 
University of Chicago Press.

The presentation of Mitcham's (1994), Pacey's (1983) and DeVore's (1980) attempts to categorize the means and methods by which the question of the meaning and character of technology has been explored was done to emphasize the diversity and complexity of the ways

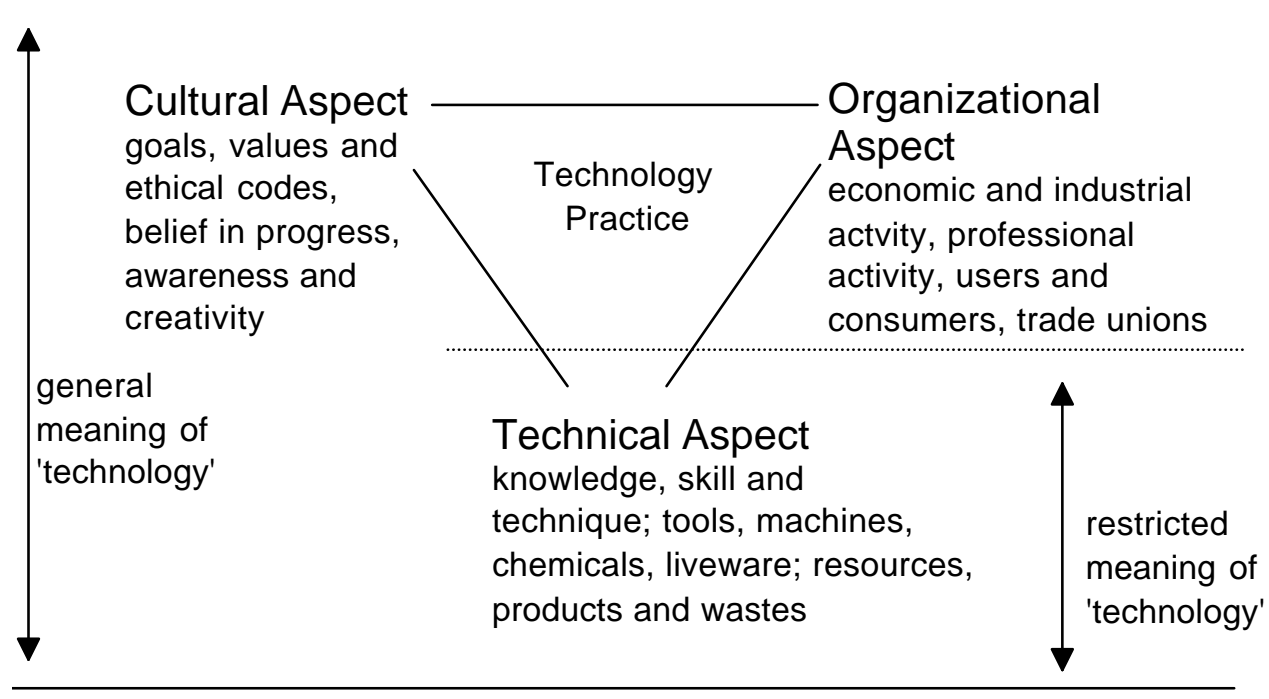

Figure 1. Diagrammatic definitions of 'Technology' and 'Technology

Practice'. Note. From The Culture of Technology (p. 6) by A. Pacey, 1983, Cambridge: The MIT Press.

in which technology is viewed. Custer (1991) recognized the usefulness of the Mitcham (1980) and DeVore (1980) categories as a means for identifying the philosophic and disciplinary context from which "authors 
conceptualized technology" (p. 56). Custer stated that, "after the initial reading... it was obvious that philosophic point of view was an important filter through which authors conceptualized technology" (p. 56).

\section{The Meaning of Technology and Disciplinary Conflict}

\section{Disciplinary Perspective and Context}

Custer's (1991) contention that philosophic viewpoint, disciplinary perspective, and methodology are "primary independent variables...for conceptualizing technology" (p. 122). echoed the conclusions of many other authors, that have sought to address the phenomenon of technology. The seminal recognition of the role disciplinary perspective plays in creating schisms was C. P. Snow's (1959) Two Cultures. In 1959 Sir Charles Snow in his Rede Lecture at Cambridge University outlined a problem which he had encountered in academia and referred to as "two cultures" (1959, p 2).

Snow (1959) believed that intellectual life and "the whole of western society is increasingly being split into two polar groups" (p. 3) The two groups identified by Snow were the "literary intellectuals" and the "scientists" (p. 4). He felt that these groups represented a polarization that was emerging, which was based in a fundamental conflict between a humanist tradition and an industrial and scientific mindset. Snow felt that the growth of 
the conflict between literary intellectuals and scientists was a result of the growing influence of industrialization. As the industrial revolution began to transform society "traditional culture wasn't doing extremely well" (Snow, 1952, p.23). Snow (1952) pointed out that "the academics had nothing to do with the industrial revolution" and "became more abstracted from it as it became more wealthy" (p. 23). He further contended that; "intellectuals have never tried, wanted, or been able to understand the industrial revolution, much less accept it" (Snow, 1952, p. 22). As such, "intellectuals, in particular literary intellectuals, are natural Luddites" (Snow, 1952, p. 22). Snow was also critical of the group he identified as the scientists. He stated in reference to the apparent lack of known appreciation scientists had for traditional literary interests such as "novels, history, poetry, [and] plays" (Snow, 1952, p. 13) that:

It isn't that they lack the interests. Its is much more that the whole literature of the traditional culture doesn't seem to them relevant to those interests. They are, of course, dead wrong. As a result, their imaginative understanding is less than it could be. They are self-impoverished. (Snow, 1952, p.14)

Snow's (1959) Two Cultures has been referred to as a means of outlining the inherent conflict between disciplines with regard to the modern technological project. Watkins and Meador (1977) utilized Snow's (1959) 
Two Cultures in the introductory chapter of their work Technology and Human

Values: Collision and Solution. Watkins and Meador emphasized that Snow's Two Cultures had at its root a reflection of social problems and values:

Snow pointed out that the split in the intellectual community both reflects and magnifies social problems. It dramatizes the critical question of values. The split automatically establishes battle lines between the "doers" (technologists, businessmen, lawyers, doctors) and the "contemplators" (liberal art students, writers, philosophers, psychologist, sociologists, artists, historians, political scientists). (p. 6)

Watkins and Meador (1972) expressed the gap between disciplines by conveying the notion of competing utopias. The point they expressed was that utopias created exclusively by either the engineer or literary intellectual would inherently leave out something of value to all of humanity. Therefore it is contended that the questions of, "What are human values? How do they relate to technology? ... obviously are important to both doers and contemplators" (Watkins \& Meador, 1977, p. 9).

Watkins and Meador (1977) stressed that a discussion of human values and the relationship to technology demonstrated that initial value judgments with regard to technology created divergence in meaning: 
Every word becomes a value judgment when a definition is attached by usage and attitude. A dictionary will supply the generally accepted core meaning of a word, but if the word is at all controversial, such as technology, the real meaning will vary widely among users. (p. 9)

Watkins and Meador (1977) continued in addressing the divergence in the meanings and nature of technology between disciplines to assert that: If they began with the same core meaning, their attitudes would cause a quick divergence. The scope of our value crisis is emphasized by the fact that in the same society, technology will be a scare word to some, a praise word to others. (p. 9)

Despite the divergence that existed with regard to the meaning and nature of technology Watkins and Meador (1977) asserted that, "in modern usage, definitions of technology usually include or imply human benefits. technology 'systematizes and applies practical knowledge' for the benefit of man" ( $p$. 10).

Watkins and Meador's (1977) point that differences in disciplinary values can lead individuals to view technology as either a "scare word" or a "praise word", and C. P. Snow's (1959) Two Cultures can be inferred in part in the work of Martin Heidegger. Heidegger's assertion is that a man in failing to understand the technological age that "enframes" him: 
becomes trapped in one of two attitudes, both equally vain: either he fancies that he can in fact master technology and can by technological means -- by analyzing and calculating and ordering -- control all aspects of his life; or he recoils at the inexorable and dehumanizing control that technology is gaining over him, rejects it as the work of the devil, and strives to discover for himself some other way of life apart from it. (Lovitt, 1977, P. xxxiii)

The expression of the notion that failures in the understanding of the nature and character of technology can lead to or is reflected in conflicts between disciplines in a larger context has also been referred to by Winner (1977). Winner contended that:

Technology has expanded rapidly in both its denotative and connotative meanings. It is now widely used in ordinary and academic speech to talk about an unbelievably diverse collection of phenomena -- tools, instruments, machines, organizations, methods, techniques, systems, and the totality of all these and similar things in our experience. (p. 8)

As such Winner (1977) elaborated that:

Specialist in the various sub-divisions of technology have developed concepts to make their own sphere of activity intelligible to them; but for the most part these concepts remain foreign and 
even mysterious to the nonspecialist or the specialist of another field. In this sense the confusion surrounding the concept "technology" is an indication of a kind of lag in public language, that is a failure of both ordinary speech and social scientific discourse to keep pace with the reality that needs to be discussed. (p. 10)

The propensity of disciplines to utilize concepts and definitions of technology in a manner in which they can distinguish and aggrandize themselves exacerbates disciplinary divergence. According to Winner (1977) this haphazard application of the term technology has a significant consequence: the political implications of advanced technology have a tendency to slide into a polarity of good versus evil. Because there is no middle ground for talking about such things, statements often end up being expressions of total affirmation or total denial. One either hates technology or loves it. (p.10)

Winner (1977) continued by expressing that "scientists, engineers, and managers ... refuse to tolerate any ambiguity on this cherished, threadbare dichotomy" (p. 10). Interestingly, Winner's reference to the "threadbare dichotomy" appeared to be reflected in the Mitcham (1994) conclusions with regard to two distinct histories in the philosophy of technology, that of the engineering and of the humanities. 
Mumford (1964) noted that the split between disciplines was a manifestation of acceptance of the Baconian notion of technology and progress. As noted previously, Bacon emphasized the primacy of technical inventions over the humanities. Mumford (1974) contended that this influenced the exclusion of the humanities from the influential Royal Society of England. Mumford (1974) expressed that this exclusion was not a mere oversight but that, "when the Royal Society was founded in England [1664] ... its members deliberately decided to reject any collaboration with those disciplines which would now be called the social sciences and the humanities" (p. 282). Mumford (1974) contended that "for their purposes, it was possible to leave out of account every human impulse and need, except those which were actively engaged in either the exploration or the exploitation of the physical environment" (p. 282). The profound impact of the early exclusion of humanities by those promoting a "technics" was emphasized by Mumford (1974):

That decision, symbolic of a thousand others that accompanied the stunningly triumphant but one-sided advance of technics, has had the result of limiting the benefits we might legitimately expect from our present mastery of time and space. From Francis Bacon onward, people thought that the advance of technics would by itself automatically solve the crucial problems of civilization. ( $p$. 
282)

Mumford (1972) emphasized that social consideration cannot be ignored if social-technical conflict is to be avoided:

None of our marvelous technical instruments and processes can function efficiently except in a society that has provided adequate social destinations and outlets. When technical advances are not co-ordinated with social advances, the result of an over concentration on technics may be social conflict, frustration, retrogression. (p. 283)

The larger social-technical conflict arising from the intellectual disciplinary dichotomy in meaning with regard to the character and nature of technology suggested by Watkins and Meador (1977), Heidegger (1977) and Snow (1954), and referred to by Winner (1977) and Mumford (1974) was resolved in a slightly different manner by Ellul (1964). Ellul contended in his work, The Technological Society, that the humanities as expressed through art and literature have be subordinated by "technique" (p.128-129). Ellul (1964) asserted that "technique" meaning "the totality of methods rationally arrived at and having absolute efficiency in every field of human activity", (p. xxv) had subordinated the humanities. Ellul (1964) wrote in referring to the impact of "technique" upon the traditional humanities:

We can see this is actually the case in certain phenomena 
considered essential to a civilization, for example, art and

literature. These activities in modern society are tightly

subordinated in different ways to technical necessities by the direct

interference of technique. Modern art and literature manifest in all

points their subordination to the technique which has extended its

power over all activity, and hence over all culture. (p. 228)

The conflict of the disciplines with regard to technology within Ellul's

conception of "technique" is a moot point. "Every field of human activity"

(Ellul, 1964, p. xxv) has been subordinated to the technological mindset that

asserts the primacy of methods rationally derived and having absolute efficiency.

The viewpoints presented here of Winner, Ellul and Mumford have been referred to as determinist by Smith (1994). Smith (1994) asserted that "to the extent that they place technology at the forefront of social and cultural change Mumford, Ellul, and Winner are technological determinist" (p. 34). The point Smith (1994) was making was that a determinist view places technology as the "causal force in history" (p. 34). However, Smith (1994) emphasized that "because, the technocratic perspective springs from so many sources and is so pervasive in society, it is very difficult to pin down" (p.35).

Despite the inherent difficulty in establishing a coherent understanding 
of a technocratic perspective, calls for technological literacy have been made as a means for bridging gaps between disciplines (Segal, 1994; Bugliarello and Doner, 1979). Bugliarello and Doner (1979) emphatically stated that: for the human race to survive and thrive, it is absolutely essential that we understand the nature of the process called technology.... Our future -- not only its shape, but indeed its very existence -depends critically on our ability to relate technology to our humanity. (p. vii)

Bugliarello and Doner (1979) asserted that engineering schools and schools of liberal arts and science exclude cross-disciplinary questions of value. As such they contend that to understand the nature of technology through an exploration of the past requires that disciplines confront shared problems together and that "engineers and historians have traditionally viewed history from nonoverlapping perspectives" (p. viii).

Segal (1994) critiqued efforts to promote technological literacy as a means of converging disciplinary perspectives with regard to technology. Segal (1994) contended that, "more than three decades after C.P. Snow at once identified and lamented the growing gap between the 'two cultures' -the sciences and the humanities -- technological literacy is being widely hailed as the long-sought bridge between them" (p. 195). Segal (1994) cited the technological literacy advocates, Smalley and Brady: "everyone must 
understand technology if we are to function as citizens in such roles as voters, workers, employers, consumers, and ... family members" (p. 195). Segal (1994) continued to emphasize that although widely ignored, it was Snow who first suggested the notion that a "third culture" of technology might best represent the position between disciplines. Snow (1954) suggested that the industrial revolution had created a realm of thought that was not wholly embraced by either the literary or science intellectuals, and that his "insight into industry ... was one of the most valuable pieces of education in [his] life" (p. 33).

Cardwell (1973) echoed Snow's assertion that even science had failed to embrace an understanding of technology when he wrote of the "complete gap between these two branches of scholarship" (p. 3). Segal's (1994) conclusion was that the use of technology as a bridger of gaps between the disciplines was currently so rift with ironies that it failed to create meaningful understanding with regard to the nature and character of technology.

Despite the conclusions of Segal (1994) others have continued to assert that a deeper understanding is needed of the differences between the disciplines that is evident in the emergence of the technological phenomenon. Most recently Ferre (1995) asserted that a "philosophy of technology can be and is a binder of breaks in the curriculum, a bridger of 
gaps between specialists, a challenge to ethical examination, and a stimulus for social reform and political action" [on-line]. Historian Melvin Kranzberg (1973) stated that:

All of us need the understanding which only a broad interdisciplinary approach involving thinkers and doers, theory and fact, idealism and reality can bring to discussions dealing with the technology-society interface, one of the most significant issues of our own and future time. (p. $x x x)$

However, Paul Goodman (1969) suggested that:

Scientific technology occupies a bastard position in the universities, in funding, and in the public mind. To remedy this -so Karl Jaspers in Europe and Robert Hutchins in America have urged -- technology must have its proper place on the faculty as a learned profession important in modern society, along with medicine, law, the humanities, and natural philosophy learning from them and having something to teach them. (p. 245) Goodman's (1969) expression of the importance of having an academic understanding of technology as discipline that can learn from as well as teach other disciplines was reflected in the findings of Custer (1991).

Custer (1991) examined "the historical confusion over (and ignorance of) the concept of technology in education, public policy, and 
economic/industrial growth" (p. 4) and "the existence of contrasting and diverse approaches to understanding technology" (p. 4). Custer's (1991) work entailed the qualitative examination of "key literature from four bellwether disciplines: (a) engineering, (b) the natural sciences, (c) philosophy, and (d) technology education" (p. 5). One of the stated purposes of his work was "to identify significant existing similarities, contrasts, and configurations of thinking and approach across the four selected disciplines" (p. 5). Through his research Custer (1991) was seeking to establish a "conceptual understanding of technology as a content basis for the technology education discipline" (p. 5). As such Custer's focus was upon the methods and processes that have been used by the four identified disciplines to conceptualize technology.

However, Custer's (1991) conclusions identified "the existence of contrasting and diverse approaches to understanding technology that exist within academia" (p. 114). His conclusions with regard to the conceptualization of technology also reflected the assertions of others previously mentioned in that, he called for "a concerted effort ... to extend the scholarship of Technology Education beyond the boundaries of the disciplines" (Custer, 1991, p. 136). To achieve this Custer (1991) stated that "conversation must occur across the broadest possible range of study" ( $p$. 136) and that "based upon the outcomes of [his] study, it is particularly 
important that the boundaries be expanded to include at least ... the social sciences and humanities" (p. 136). Custer (1991) explicitly recommended that his:

study should be replicated using a collection of documents identified and selected by ... scholars of the social sciences (e.g. history, anthropology, psychology, and political science) [and that] the perceptions and beliefs of typical members of other populations should be studied to identify contrast or similarities. (p. 141)

\section{Classics of Technology}

Custer's (1991) work utilized Pytlik's (1988) Great Books of Technology as a starting point in identifying works that represented "a manageable selection of the top documents for analysis; and the best conceptual and scholarly work" (p. 48). Pytlik's (1988) Great Books of Technology was a cross-disciplinary Delphi study of scholars, who were "asked to identify those titles which they believed were the most outstanding technology publications because the selections had an important influence on society and/or were classics in their discipline" (p. 54). The participants were "asked to place their nominations into one of five sub-categories: history of technology; philosophy; social/technical interaction; understanding technical systems; and innovation, invention, inventors" (p. 54). 
Among the scholars who participated in the study were representatives from the liberal arts, sciences, engineering, and technology education (p. 54). Although, Pytlik's three round Delphi study ultimately resulted in a listing of the 52 great books in technology, the initial round of selected documents represented a collection of 240 publications that were broad and diverse. Among the 240 publications identified, 81 works were placed in the social/technical interaction category; 49 in the history of technology; 40 in the innovation, invention, inventors category; 42 in understanding technical systems; and 28 works were placed in the philosophy of technology category. It was noted by Custer (1991) that "documents from the social sciences were excluded from consideration in [his] study" (p.134). However, in the course of his work Custer stated that "the centrality of the social science dimension surfaced" (p. 134). Pytlik's (1988) Great Books of Technology included many documents with a broader social science perspective. Custer stated that "with several of the writers (e.g. Ferkiss, Ellul, Pacey) the treatment of technology was secondary to the examination of the larger socio-cultural dimensions" (p. 134).

\section{Understanding Meaning}

It has been widely recognized that academic affiliation, experience, 
and/or one's disciplinary perspective has an influence upon how one views or interprets the phenomenon of technology (Custer, 1991, Pacey, 1983, DeVore 1980, Watkins and Meador, 1977). Custer (1991) identified "disciplinary association as an independent variable for conceptualizing technology" (p. 130). DeVore (1980) wrote that "individual perceptions are largely dependent on a person's background, the amount of study and reflection about technology, and personal experiences with technology" (p. 216). DeVore (1990) specifically stated that:

Some writers on the topic of technology never define the term; they assume a common understanding. Others define technology from the perspective of their discipline. For instance, economists define technology in reference to production, sociologist from the perspective of social relationships and political structures, and engineers in terms of physical structures or systems. (p. 217) As such DeVore (1980) stressed that: In reviewing the various definitions of technology, the discipline and philosophical background of those who prepared the definitions had an obvious influence on their outlook. If one is an engineer, one defines technology one way, if one is an anthropologist, another way. (p. 218) Given that it has been observed that academic association and/or 
discipline has an influence upon how technology comes to be characterized, how can this difference in meanings be measured? A method for the measurement of meaning was proposed by Osgood (1952). Osgood proposed a method that was "a combination of associational and scaling procedures" that would measure meaning in a multidimensional way" (p. 26). That method was called the semantic differential.

Osgood's (1952) initial proposal of the semantic differential technique was more fully developed and tested in the work of Osgood and Suci (1955) and Osgood, Suci, and Tannenbaum (1957). The semantic differential was defined as a "multivariate differentiation of concept meanings in terms of a limited number of semantic scales of known factor composition" (p. 42 Osgood and Suci, 1955). It has also been more simply defined as a method that "attempts to determine the psychological meaning of a particular concept or construct as perceived by one or more individuals and/or the difference in meaning between two or more constructs" [Semantic Differential Scaling, On-line].

Osgood and Suci (1955) detailed the essential elements to: the logical basis of the semantic differential technique.... 1. The process of description can be conceived as the allocation of a concept to an experiential continuum, definable by a pair of polar opposites. 2. Many different experiential continua, or ways in 
which meanings can vary, are essentially equivalent and hence may be represented by a single dimension. 3 . A limited number of such continua can be used to define a semantic space within which the meaning of any concept can be specified. (p. 43) These points outlined the fundamental elements involved in the construction of a semantic differential scale. The first entails the placement of the examined concept on a scale, which has two polar terms at either end. For instance, the allocation of the concept dog along a continuum that has at one extreme loyal and at the other unloyal. The second point expressed by Osgood and Suci (1955) is that numerous continua can be combined to represent a larger conception on a single dimension. For instance, bipolar adjectives scales of good to bad, valuable to worthless, pleasant to unpleasant, and fair to unfair, have been combined to form a measure of valuation called the evaluative factor (Holup, 1980). The third point expressed by Osgood and Suci (1955) is that a given number of factors, such as the evaluative previously described, can depict the meaning of a concept in terms of a semantic space that has an "unknown dimensionality and is Euclidean in character" (Osgood, Suci, and Tannenbaum, 1957, p. 25).

The semantic differential as depicted by Osgood and Suci (1955) was developed into its most commonly accepted form by Osgood, Suci, and 
Tannenbaum (1957). The work entitled The Measurement of Meaning

(Osgood, Suci, \& Tannenbaum 1957) set out the results of numerous factor analyses that attempted to define a "small number of orthogonal factors, these factors being completely general over both subjects and concepts and always represented by the same set of scales" (p. 325), that could "set up a perfectly general and simple measuring instrument" (p. 325). Osgood et al. (1957) determined that three factors seemed to represent a significant portion of difference in meaning between concepts and that, Osgood's initial assertions that the semantic differential technique was objective, reliable, valid, and sensitive to nuances in meaning were valid (Osgood, 1952).

Osgood et al. (1957) wrote that, "the same three major factors of evaluation, potency, and activity (which were empirically derived rather than theoretically derived) have reappeared in a wide variety of judgmental situations, particularly where the sampling of concepts has been broad" ( $p$. 325). Holup (1980) pointed out that Osgood et al. (1957) had also spelled out criteria for constructing a semantic differential. The criteria were:

(a) select scales to represent each factor (evaluative, potency, activity); (b) select scales that have semantic stability, scales that will not differ between concepts; (c) select scales that are relevant to the concepts; and (d) select scales that are linear between polar opposites and pass through the origin. (Holup, 1980, p. 22) 
Maltz (1963) provided a useful depiction of the semantic differential technique:

In practical application, the semantic space generated by the semantic differential is arrived at by having individuals rate the concepts along graded scales, each having polar (opposite in meaning) adjectives as end points. Three orthogonal cuts through semantic space are generated by using scales which are representative of the three independent factors: evaluative, potency, activity. These axes all meet at one point, the origin designated here as meaninglessness and represented by the midpoints of the scales. (p. 341)

The utility of the semantic differential technique is that "it can be used as a generalized multidimensional attitude test" (Osgood, 1952, p. 35). Osgood (1952) continued that, "concepts...have different connotative significance to different people, and the semantic differential can be used to quantify these differences" (p. 35). In fact, Osgood et al. (1957) stressed that the semantic differential was a "generalizable technique of measurement" (p.76). Most specifically they wrote that:

Although we often refer to the semantic differential as if it were some kind of "test", having some definite set of items and a specific score, this is not the case. To the contrary, it is a very general way 
of getting at a certain type of information, a highly generalizable technique of measurement which must be adapted to the requirement of each research problem to which it is applied. There are no standard concepts and no standard scales; rather, the concepts and scales used in a particular study depend upon the purposes of the research. (Osgood et al, 1957, p. 76)

Carney (1972) stressed the use of the semantic differential in defining differences between groups:

when we pass general judgments on things, we do so not only in terms of whether they are 'good' or 'bad' [evaluative], but also in terms of their strength or weakness [potency], and also their activity or passivity [activity]. We use other dimensions too, of course. But these are the three which people everywhere use, whatever their culture or period in history. (p. 183) Carney also contended that the semantic differential can be used as a means of judging a writer's position based upon where their analyzed words fall in semantic space. Carney further stated that:

Indeed, the semantic differential is most often used as a means of seeing whether members of a language group agree upon the feeling-tone of a word. It can also be used to explore another person's stereotypes or perceptions by content analysis. (p. 185) 
Carney's (1972) assertion that the semantic differential technique can be used to examine writers' positions based upon the words they utilize in their communications has a foundation in the contentions of Carroll (1964). Carroll (1964) contended that while:

it is unlikely...that the whole 'meaning' of a concept can be indexed by the semantic differential technique... it is useful to measure (1) the polarity of concepts, that is, their distance from the center or origin in the semantic space, and (2) the distances between concepts, that is, how different their 'meanings' are. (p.104)

Carroll (1964) was critical of the semantic differential in that he believed that the technique may merely uncover differences in individual experiences. His assertion was that, "concepts are essentially idiosyncratic, dependent on the individual's particular experiences.... One is tempted to call the semantic differential, instead, an 'experiential' differential, since it indexes individuals' experiences or attitudes as classed into concepts" (Carroll, 1964, p. 104-105).

Despite Carroll's noted criticism, the semantic differential has been and continues to be widely used. Holup (1980) stated that, "the semantic differential, developed by Osgood, Suci, and Tannenbaum has been demonstrated to be sufficiently reliable and valid for many research purposes 
related to the observing and measuring the connotative meaning of concepts" (p. 8). Holup (1980) also asserted that, "the scope of semantic differential research literature was ... extensive" (p. 8). Also cited by Holup (1980) as support for the method were Bledsoe (1972), Kerlinger (1973), and Sax (1968). The work of Bobbet (1984) entitled Subjective Meaning of Computer should also be noted for its use of the semantic differential in assessing the meaning of the word computer in response to the common "confusion over the meaning of computer" (p.2).

\section{Content Analysis}

The use of the semantic differential to analyze the content of communications to uncover differences in meanings had been initially promoted by Osgood et al. (1957), and subsequently, by Carroll (1964) and Carney (1972). An initial step in utilizing the semantic differential technique to uncover differences in meaning between writers entails a content analysis of representative documents. Content analysis has been said to be "difficult to define ... because the technique can be used in so many different ways" (Carney, 1972, p. 21). Despite the difficulty in defining content analysis Carney (1972) presented several definitions and identified those elements of content analysis that were consistently asserted as essential to the technique. 
An early definition of content analysis was that of Berelson (1952), "a research technique for the objective, systematic and quantitative description of the manifest content of communication" (p. 18). Carney (1972) presented a subsequent definition of content analysis that explicitly included the making of inferences from communications, "content analysis is any technique for making inferences by objectively and systematically identifying specified characteristics of messages" (p. 5). Carney (1972) also emphasized that the making of inferences can include the identification of characteristics that "set out ... [a] person's perception" (p.5).

More importantly, Carney (1972) stressed that some ideals are inherent in the evolution of the definition content analysis. The ideals to which content analysis strives are objectivity, system, manifest meaning, and description. Carney (1972) contended that in seeking to answer a posed research question through content analysis:

the question must be investigated uniformly, throughout all parts of a defined body of text ('systematic'). In process all data alike, pro and con, are impartially collected ('objective'). Communications are taken at their face meaning, not subjectively interpreted ('manifest'). Findings thus reveal trends or characteristics not otherwise observable because of the mass, complexity, or chaotic nature of the communications ('description'). (p.24) 
Carney emphasized that "all [definitions of content analysis] are agreed on ... objectivity and system" (p.25), and that disagreements exist to the issues of quantifiable versus qualitative means of making inferences. He also pointed out that "the quantitative and manifest restrictions [upon content analysis] have been dropped" (Carney, 1972, p. 25). The significance of this exclusion is that content analysis was then opened to include qualitative and interpretive consideration of communications. Carney's (1972) conclusions led him to state that, "content analysis is a general-purpose analytical infrastructure, elaborated for a wide range of uses" (p. 26). Custer (1991) in referring to Holsti (1969) stated that:

content analysis can generally be defined as any technique for making inferences by objectively and systematically identifying specified characteristics of messages. It has been used extensively in the fields of journalism and policy analysis for the purpose of analyzing the content of both written and spoken forms of communication. (p. 39) Custer (1991) also noted the quantitative versus qualitative split "within content analysis circles" (p. 40) However, any content analysis approach must be analytical in that it is a systematic attempt to achieve objectivity. Some points with regard to the purposes and structure of content analysis that are relevant to research were also expressed by Carney (1972). 
A major purpose of content analysis is facilitating inferences, which "generally involves some form of multistage content analysis" (Carney, 1972, p. 66). The facilitation of inference as depicted by Carney can entail the comparison of groups or cultures through distinctions in their communications. A second significant point expressed by Carney is that, the analytical structure of specific content analysis are operationally defined by the purposes of the research. Thirdly, Carney (1972) stressed prior to introducing the use of the semantic differential technique to analyze meaning that, "a writer's actual words -- adjectives, for instance -- often directly yield telltale clues to his evaluative, ideological or moral viewpoint" (p. 182).

\section{Identifying Disciplines}

The use of content analysis to facilitate inferences with regard to differences between groups or cultures must begin with a definition of groups and the selection of representative communications. The latter concern with selecting a representative work of publications has been addressed previously, in that Pytlik's (1988) work Identifying the Great Books of Technology represents a cross-disciplinary survey of publications that, "were the most outstanding technology publications because the selections had an important influence on society and/or were classics" (p.54). However, the classification of publications into groups based upon which discipline that 
publication most closely represents needs to be addressed.

Custer (1991) identified three means of identifying the disciplinary group into which an author should be classified. These means include "formal academic training (number or level of degrees in a discipline), current professional employment, or a characterization of the 'type of activity' that a scholar's professional activity represents" (Custer, 1991, p.46). Custer (1991) utilized the second means identified, that of current professional employment for use in his research. He believed that an individual's current professional employment highly influenced an individual's conceptual outlook. It should be noted that, Custer identified the problem of limited disciplinary categories in his research of documents associated with technology as a theme. Subsequently, his post research recommendations included the need for research into "the perceptions and beliefs of typical members of other populations" (Custer, 1991, p. 141). Custer's approach to the question of classifying scholars was largely based upon the categories created by Pytlik (1988) in Identifying the Great Books of Technology. It should be noted that Custer's concern with disciplinary classification was scholar based. That is, his classification of publications into a disciplinary class was based upon the discipline of the author of that document.

Another method for classification exists that reflects a classification of documents based upon their content. The Library of Congress Classification 
(LCC) system was constructed at the turn of the 20th century (Chan, 1981). Documents in the LCC system are examined by catalogers to determine their subject content, and their principle concepts. Catalogers then make a determination as to what disciplinary subject heading a document should receive. Chan (1981) contended that a primary merit of the system is that "each schedule was developed by subject specialists rather than by a 'generalist' who cannot be expert in every field" (p. 283).

Although the LCC system is continuously evolving it represents "a practical system which has proved to be satisfactory [and is] based on literary warrant [which] is particularly suited to the needs of academic and research libraries" (Chan, 1981, p. 282). The system was also characterized by Chan (1981):

The Library of Congress Classification is basically classified by discipline. The entire field of knowledge is divided into main classes corresponding to major academic disciplines.... The system forms a hierarchical structure, progressing from the general to the specific. (p. 274)

As such, it can be said that a document's Library of Congress Classification represents a trained cataloguers interpretation of which discipline is most reflected in the content of the work itself. 


\section{Summary}

This chapter outlined the evolution in meaning of technology from the classical understanding to the contemporary manifestations of the term. A discussion of the Aristotelian view of technology was drawn and compared to a Baconian understanding of the character and nature of technology. A review of contemporary attempts to categorize the various viewpoints with regard to the meaning of technology was also presented. The role that disciplinary perspective and context plays in defining differences in meaning with regard to technology was presented as means of establishing a possible context for disciplinary conflict.

An examination of Pytlik's (1988) Identifying Great Books of Technology was provided as to establish its appropriateness as a collection of cross-disciplinary works concerned with technology as a theme in various context. A review of content analysis and the semantic differential techniques as methods for uncovering differences between groups with regard to meaning was also presented. Finally, a summary of the Library of Congress Classification system as a means for identifying the disciplinary content of literature was provided. 
CHAPTER III

Methodology

\section{Statement of the Problem}

The problem of this research was to determine selected disciplinary perspectives concerning the nature of technology within classic literature.

\section{Research Question}

$\mathrm{H}_{0}$ : There would be no significant difference at the .05 level between the semantic factor scores related to concepts used by individual disciplines to characterize technology.

\section{Disciplinary Grouping of Publications}

The assignment of a publication to a disciplinary group was to be based upon the referent publication's Library of Congress classification. Chan's (1990) Immroth's Guide to the Library of Congress Classification was to be utilized as the guide for the categorization of a publication into a discipline. The main class designation was to serve as a discipline category in most cases. However, the researcher determined that the Library of Congress system of classification failed to be an appropriate method of classifying publications into disciplines. This was due to the assignment, by 
the Library of Congress, of a large number of publications to a generalized Technology class. Subsequently, the researcher found that this class failed to provide any meaningful delineation of author disciplines. Author biographical information was then obtained and utilized as the primary means of classification of publications into disciplines.

\section{$\underline{\text { Classic Literature }}$}

The first round results of the Pytlik (1988) Delphi study for Identifying the Great Books of Technology were utilized as the defining collection of publications regarding the nature of technology. The cross disciplinary panel of the first round of the Pytlik Delphi study yielded 240 individual publications. The use of the Pytlik study was justified based upon two factors. The first was that the study represents the "first attempt at surveying scholars in the field of technology to determine the classics in its discipline" (1988).

Secondly, a review of the literature derived no other comprehensive listing of cross disciplinary publications with technology as a theme. This was also reflected in the conclusion of Custer (1991), who utilized Pytlik's (1988) Identifying the Great Books of Technology as an initial document basis for his Technology: A Qualitative Concept Analysis from the Perspectives of Engineering, Philosophy, Natural Science, and Technology Education . 


\section{Content Analysis}

A content analysis of the classic literature identified by Pytlik (1988) was then conducted. The process of content analysis entailed a review of the 240 identified publications by the researcher for references to the character and nature of technology. The procedure for the identifying references by content analysis was objective and systematic in that only direct references to technology, or its metaphor were utilized for this research.

The process entailed a reading of the 240 publications by the researcher to identify those statements and/or sentences that had technology or its metaphor as the object of the sentence. Once a statement or sentence had been identified, a process of unitizing was conducted by the researcher. Single words or word phrases derived from the statement or sentence served as the units for inclusion in the analysis.

Four categories of word/s units were utilized by the researcher. The categories for unitization were technology as metaphor, verb, adjective, and adverb. Carney (1972) emphasized that categories for unitization should be operationally defined and that, "there are no rules for forming categories" ( $p$. 40). The operational justification for the categories identified was based in part upon the evaluative assertion technique identified by Carney (1972), and the researcher's identification of the use of metaphor to depict technology as 
previously indicated in chapter 2 .

The category identified as technology as metaphor encompassed those instances when technology was not clearly identified, but is embodied in a noun that is metaphoric. For instance, Tenner's (1996) discussion of technology explicitly referred to the Frankenstein myth in his discussion of unintended consequences of technology by stating that, "Frankenstein's fateful error was to consider everything but the sum of the parts he had assembled" (p.12). In this case the noun Frankenstein would have been categorized as a metaphor and subsequently included in the researcher's analysis. Another aspect of the technology metaphor can be found in Mumford's (1964) The Myth of the Machine. Mumford referred explicitly on page 38 to the use of machine as a metaphor in diverse disciplinary discourse as an imposition of the technological mindset. As such the noun machine was included in the metaphor category by the researcher for analysis.

The second category was that of verbs. This category represented those instances in which a verb or verbal phrase was used to characterize technology. For example, in the title of Glendinning's (1990) When Technology Wounds: The Human Consequences of Progress the verb wounds served to characterize technology. This category did not include what are known as auxiliary verbs (Tressler and Lipman, 1949) such as is, 
be, does, could, should, and will. For the purposes of this research, verbal phrases were those instances in which verbs served as adjectives (Fowler, 1986). The general rule followed was that any verb or verbal phrase that was used to imply or characterize the object technology within a statement or sentence was included by the researcher for analysis.

The third and fourth categories utilized by the researcher were those of adjectives and adverbs. Adjectives and adverbs that were used to characterize the object of technology within a statement or sentence were included for analysis by the researcher. For example, the use of the adjective autonomous in Winner's (1977) Autonomous Technology: Technics-out-of-Control as a Theme in Political Thought would have been an example of an adjective that was included by the researcher. An adverb that would fall within a category for inclusion in the analysis would have been the use of rigorously by Ellul (1964) when he stated that, "technique alone is rigorously objective" (p. 131).

It should be noted that these four categories were unimportant beyond their capacity to exclude words or phrases. The concern was not with what category a particular word or phrase may have fallen into, but rather, if the word or phrase clearly fit within the context of a given category and it had served to charaterize technology, that the represented concept was then included for analysis. For example, given the Ellul (1962) statement that, 
"technique alone is rigorously objective" (p. 131) the specific categorical placement of rigorously and objective by the researcher was fundamentally unimportant. That Ellul's notion of technology as being "rigorously objective" was subsequently represented within the semantic differential analysis was the critical consideration that was made.

The content analysis of the 240 works identified by Pytlik (1988) yielded a list of keywords and phrases that were used to characterize the nature of technology. A check of the content analysis listing of words and phrases was made to ensure duplication or replication of terms was not present. The final list of terms and phrases then represented concepts that were subjected to semantic differential analysis.

\section{$\underline{\text { Semantic Differential }}$}

The semantic differential technique used for this research utilized the three factors identified by Osgood et al. (1957) as the predominate dimensions by which meaning appears to be derived. The factors most often used in semantic differential analyses are the evaluative, activity and potency factors (Bailey, 1973; Bobbett, 1984; Holup, 1980; "Semantic Differential Scaling", [on-line]; Snider \& Osgood, 1969; Wallace, Russell, \& Suci, 1958).

Bi-polar adjectives were selected to represent each of the three 
factors (evaluative, activity, and potency) for use in the semantic differential instrument based upon the factor analysis work of Osgood and Suci (1955). The selection of the bi-polar adjectives was intitally based upon Osgood's et al. (1957) criteria for constructing scales and was to mirror Holup's (1980) selection of bi-polar adjectives to reflect the broad spectrum of distributive education concepts. The bi-polar adjectives that were to be utilized in this research were presented in Table 2.

Table 2

Bi-polar Adjectives by Factor

\begin{tabular}{lll}
\hline Evaluative & Potency & Activity \\
Good-Bad & Strong-Weak & Fast-Slow \\
Fair-Unfair & Deep-Shallow & Active-Passive \\
Valuable-Worthless & & \\
Pleasant-Unpleasant & & \\
\hline
\end{tabular}

Note. From A Semantic Differential Study of the Connotative Meaning of Thirty Distributive Education Concepts. (p. 22) by J. Holup, 1980, Unpublished doctoral dissertation, Washington State University, Pullman, Washington.

The concepts (the words and phrases derived from the content analysis) were then presented to respondents to be scored on a seven step scale. The seven step scale was selected based upon the Osgood, Suci, and Tannenbaum (1957) recommendations for constructing a semantic differential instrument. Each concept was to be presented to the respondents with eight seven step scales representing the three factors. The 
presentation of the concepts, scales and instructions followed the guidelines provided by Osgood et al. (1957). An example the proposed concept presentation was provided in Figure 2. The use of eight bi-polar

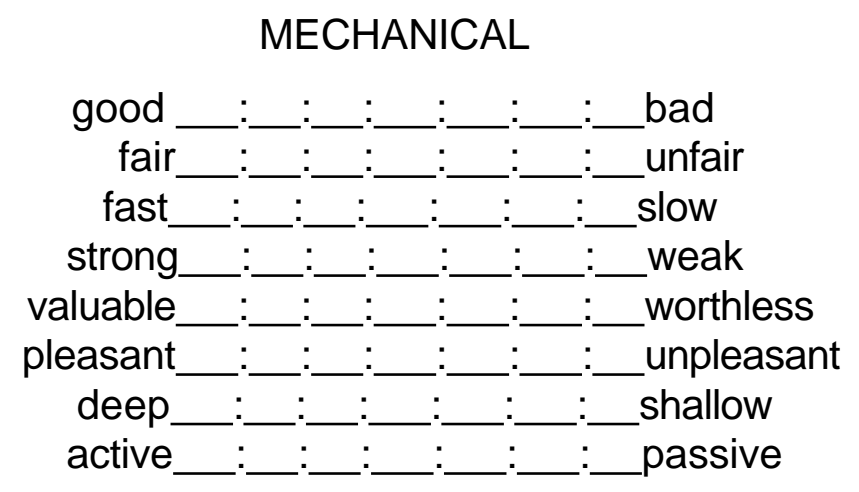

Figure 2. An example semantic differential concept presentation

adjectives was subsequently reduced to three due to two consdierations. First, the length of the survey had become inordinately long to expect that respondents would provide consistent and reliable responses. Secondly, studies by Osgood et. al. (1957) established the primacy of the good to bad, strong to weak, and slow to fast, bi-polar adjective sets in the measurement of the Evaluative, Potency and Activity factors.

Studies by Osgood et al. (1957) established that the order of scales and adjective polarities should be alternated "to prevent the formation of position preferences" (p.82). Osgood et al. also established 
typical instructions to the respondent that were used in this research ( $p$.

82-84). Among the points to be emphasized in the instructions to the respondent were "orientation to the general nature of the task, the significance of scale positions and how to mark them, and the attitude to be taken toward the task (speed, first impressions, but true impressions)" (Osgood et al., 1957, p. 82).

The scoring of scales was from +3 to -3 based upon the polarity of the given adjectives. For example:

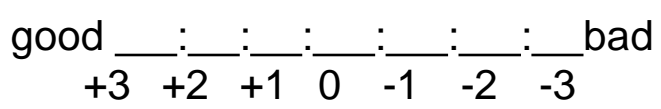

The following adjectives that were scored on the positive spectrum were the evaluative factor adjective of good, the potency adjective of strong; and the activity adjective of fast. The following adjectives were scored on the negative spectrum were the evaluative factor adjective of bad; the potency adjective of weak; and the activity adjective of slow. The assumptions of positive or negative connotations for scoring these bi-polar adjectives reflected the work of Holup (1980), Osgood et al., (1957) and the instructions of Semantic Differential Scaling [on-line]. A mark in the center of a given scale, by the respondent reflected that the given concept has no meaning, is neutral, or equally associated to the bi-polar adjectives (Osgood et al., 
1957).

\section{Population}

The developed semantic differential instrument was given to a sample of 36 adults. The selection of the sample was based upon respondent willingness to participate, convenience, availability, and the acceptance that the generated concepts did not represent issues of latent biases possessed by the sample. Cross cultural issues within the population were not considered based upon findings that suggest that there may be a "pervasive semantic frame of references used by humans" (Kumata \& Schramm, 1956, p. 282). It has been suggested, and the researcher assumed that a cross cultural understanding of meaning existed for a significant number of concepts (Suci, 1960; Tanaka, Oyama, \& Osgood, 1963, Osgood, May, \& Miron, 1975).

\section{Treatment of the Data}

The individual scores for each scale were summed and averaged within each factor (evaluative, potency, and activity) by concept. The resulting mean score for each of the three factors served to comprise the semantic profile for the concept. That is, each concept represented in the 
semantic differential instrument had a mean score related to each of the factors (evaluative, potency, and activity). These three scores represented the relative position of the concept within the semantic space.

A second measure was calculated to represent the relative distance between each concept within the semantic space. Osgood et al. (1957) suggested the use of the "generalized distance formula" (p. 91) as means of representing the geometric distance between concepts within a Euclidean space. The measure was proposed on the grounds that a traditional "product-moment correlation not only distorts the information, but may be completely inapplicable in some cases" (p. 91). The measure is represented in the formula for $D_{a b}$ as:

$$
D_{a b}=\sqrt{\sum_{j} d_{a b^{2}}}
$$

The $D$ represents the relative distance in the semantic space between concept $a$ and concept $b$. The $\mathrm{D}$ is found "by taking the difference between the scores of the two concepts on each factor, squaring the difference, summing the squares, and taking the square root of the sum" (Osgood et al., 1957, p. 91). The $D$ is then typically reported in a matrix with each and every concept drawn in comparison to one another. In this way a cursory view of the relative positions of concepts to one another can be conducted 
(Kerlinger, 1973; Osgood et al., 1957).

Cluster analysis based upon the D scores of the concepts was also carried out to create models of conceptual structures (Osgood et al., 1957; Overall \& Klett, 1972). The creation of clusters and a subsequent visual presentation of the clusters yielded insights into the generalized conceptual structure of the data.

The issue of determining significance of difference between concepts was unclear. Kumata and Schramm (1956) stated that, "there is no adequate method for determining the significance of differences between distances" (p. 281). Osgood et al. (1957) pointed out that while, "it would be much more satisfactory to have some method" (p. 102) for a quantitative index of differences in conceptual structures, "no complete method has been developed" (p. 102). Kerlinger (1973) also emphasized the lack of a method for comparing clusters for significance of difference. Despite this apparent limitation, a technique appropriate to this research did emerge from the literature of Kerlinger (1973), Snider and Osgood (1969), Osgood et al. (1957). Techniques suggested by Osgood et al. (1957) for establishing significant differences between concepts or groups of concepts included the Mann-Whitney 'U' test.

The Mann-Whitney 'U' test (Gravetter \& Wallnau, 1992) was selected as a method of evaluating the difference between the concepts based upon 
disciplinary grouping by semantic profile factors of evaluative, potency, and activity. An assignment of concepts to its referent disciplinary group was made so that a discipline to discipline significance of difference could be made. The mean scale scores of each concept by factor were then rank ordered. The Mann-Whitney 'U' test was then applied to each of the derived disciplinary to disciplinary pairings to establish their relative significance at the à=.05 level. A table of ranking and Mann-Whitney 'U' test for significance was created for each disciplinary to disciplinary pairing evaluated.

\section{Summary}

The fundamental steps followed in this research have been presented and can be summarized as:

1. An analysis of the 240 publications, identified by Pytlik (1988) in his work Identifying the Great Books of Technology, was conducted to determine their respective disciplinary classifications.

2. A content analysis of 240 publications, identified by Pytlik (1988) in his work Identifying the Great Books of Technology, was conducted to identify the words or phrases used to characterize the nature of technology;

3. A semantic differential instrument was constructed based 
upon concepts derived from the content analysis and Osgood et al.'s (1957) identification of the primary factors of the evaluative, potency, and activity;

4. The semantic differential instrument was applied to a selected population;

5. An analysis of the concepts' relative positions within the semantic space between disciplines was conducted.

6. A by discipline presentation of graphical interpretations, D matrixes, and Mann-Whitney 'U' test results were made to characterize the nature of the semantic differential data with regard to the derived concepts. 


\section{CHAPTER IV}

Analysis of Data

The data that served as a basis for this research was obtained through the semantic differential testing of concepts that were derived from a literature content analysis. The research had several fundamental phases, the content analysis, concept identification and reduction, publication categorization, semantic differential testing, and data analysis.

\section{$\underline{\text { Content Analysis }}$}

An original list of 240 publications, identified by Pytlik (1988) in the first round of his Delphi study, were used to initiate this research. The actual total of individually identified publications was 297 . The difference between the 240 publications identified by Pytlik (1988) and the total of 297 identified for this research was a reflection of the individual categorization and utilization by the researcher of articles contained within anthologies identified by Pytlik (1988).

Of the 297 publications identified by the researcher for utilization in this research, 50 were not included in the content analysis. Several factors accounted for the exclusion of an identified publication from the content analysis. First among the factors resulting in the exclusion of a publication from the content analysis was relevance. Publications that did not reflect or 
address technology as a phenomenon in any meaningful way were excluded from the research. A second factor which lead to the exclusion of a publication was repetition. Some publications were duplicated within the context of other publications identified for inclusion in the content analysis. A third and final factor accounting for publication exclusion from the content analysis was inaccessibility. Publications which could not be obtained or correctly identified through the resources provided through the West Virginia University libraries and the United States Library of Congress were excluded from the study (see Appendix A).

The final number of publications utilized for the content analysis phase was 247 (see Appendix B). The content analysis phase entailed the review of the 247 publications for references to technology as a phenomenon. Phrases and concepts used to characterize and depict the nature of technology were noted and indexed in reference to the source publication. The content analysis of the 247 publications yielded a comprehensive list of 370 referenced concepts.

\section{Publication Categorization and Discipline Formation}

The disciplinary categorization of the 247 publications utilized for this research was based upon the individual authors' discipline and profession. The proposed utilization of the Library of Congress system was abandoned 
by the researcher after it proved to be an inappropriate method of discipline categorization. Biographic information was obtained on authors to determine their primary disciplinary field of endeavor. Discipline groups were then delineated based upon the bibliographic information. Table 3 depicts the number and percentage of publications assigned to each of the 16 discipline groups. History led the discipline groups with 68 or $27.53 \%$ of all evaluated publications. Engineering was a distant second with 24 or $9 \%$ of the publications. Education had the least number of publications at 2 or $.81 \%$ of all evaluated publications. An alphabetic listing of authors by disciplines is reported in Appendix C.

A cross reference of concepts to publications then yielded a listing of concepts by those disciplines which utilized them to depict the nature and character of technology. A listing of concepts by discipline is presented in Appendix D.

\section{Concept Identification and Reduction}

The list of 370 concepts was circulated to a three member panel of dissertation committee members. The members were asked to judge the relative appropriateness of each concept for inclusion in the research. Consensus was used to determine if a concept would be included in the 
Table 3

Publication Distribution by Discipline Group

\begin{tabular}{|l|c|c|}
\hline \multicolumn{1}{|c|}{ Discipline Group } & Number & Percent \\
\hline Education & 2 & 0.81 \\
\hline Architecture & 3 & 1.21 \\
\hline Technology \& Society & 4 & 1.62 \\
\hline Theology & 6 & 2.43 \\
\hline Literature & 6 & 2.43 \\
\hline Natural Science & 8 & 3.24 \\
\hline Mathematics & 8 & 3.24 \\
\hline Anthropology & 9 & 3.64 \\
\hline Political Science & 14 & 5.67 \\
\hline Social Science \& Psychology & 14 & 5.67 \\
\hline Writer & 15 & 6.07 \\
\hline Philosophy & 22 & 8.91 \\
\hline Physical Science & 22 & 8.91 \\
\hline Business \& Economics & 22 & 8.91 \\
\hline Engineering & 24 & 9.72 \\
\hline History & 68 & 27.53 \\
\hline Total & 247 & 100 \\
\hline
\end{tabular}

research, excluded from the research, or combined with another concept that was deemed to be similar in meaning. Through this process the initial list of 370 concepts was reduced to 269 concepts. The concept Technology was included by the researcher as a point of reference to bring the total number of concepts to be included in the semantic differential instrument to 270. 


\section{$\underline{\text { Semantic Differential Instrument Construction }}$}

The test instrument utilized in this research was based upon the instructions and formatting styles presented by Osgood et al. (1957). Each concept was presented in the capitalized form at the top center of a set of three bi-polar adjective seven step scales. An example of the format utilized is provided in Figure 3.

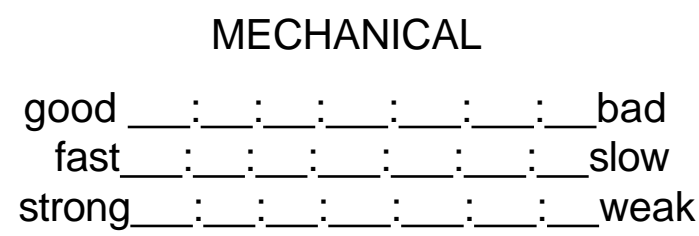

Figure 3. An example semantic differential concept presentation.

This format differs from that proposed in Chapter III, in that only three sets of bi-polar adjectives were utilized instead of the proposed eight. This change in format is a reflection of the length of the instrument and was shortened upon the advice of the research committee. The proposed instrument would have required the individual judgment and completion of 2160 test items by the survey respondents. Therefore, it was determined that a single set of bi-polar adjectives would serve to represent each of the Evaluative, Activity and Potency factors. The bi-polar adjectives of good to bad, fast to slow, and 
strong to weak were selected to represent the Evaluative, Activity, and Potency factors respectively.

It was also determined that the random presentation of the bi-polar adjective scales as proposed in Chapter III would be frustrating to respondents due to the instrument's length. Therefore, the proposal to randomize scale order and sequence was abandoned for a consistent presentation. Additionally, concept sequence was not randomized for two primary reasons. First, it was determined that the difficulties inherent in randomized concept presentation and subsequent data entry reliability would be too cumbersome for both the survey respondents and the researcher. Additionally, it was determined that the presentation of the concepts in alphabetic order did not present any foreseeable difficulties with regard to central tendencies or patterned bias across the Evaluative, Activity, or Potency factor. However, the researcher evenly distributed surveys that presented the concepts in both ascending and descending alphabetic order. This was done to counter any fatigue effect that may have occurred during the course of the completion of the survey. A partial semantic differential instrument presented to survey respondents has been included in Appendix E. 


\section{$\underline{\text { Semantic Differential Data Collection and Analysis }}$}

The semantic differential instrument was distributed to a total of 36 potential respondents. Respondents were selected on two primary criteria: Willingness to complete the instrument; and respondent confidence in their relative familiarity with the concepts presented in the document. Respondents were given an opportunity to review the instrument and then asked if they were both willing and comfortable with their ability to complete the instrument. Of the 36 instruments distributed to respondents 35 completed instruments were returned. Of the 35 instruments returned, 34 were included in the data analysis.

The decision to exclude one of the completed and returned instruments was based upon two observations made by the researcher: Respondent time to complete the survey; and the apparent central tendency between the three factor scales for the given survey. The excluded survey was completed within 15 minutes. This varied greatly from the observed time of over an hour and half for the vast majority of the other respondents. Additionally, the respondent exhibited a consistent tendency to score concepts on the Activity and Potency scales in the identical position with the corresponding Evaluative scale. It was therefore assumed that the respondent had failed to make individual judgments on both the Activity and Potency scales. 


\section{Demographics}

A limited amount of demographic information was obtained from the respondents. Age, sex, educational attainment, and college major comprised the sum of demographics obtained for this research. Figure 4 depicts the age distribution of respondents, while Table 4 provides a statistical overview of the respondent age distribution. The mean age was 43 years, with the youngest respondent being 22 and the oldest 73 years of age. An analysis of the age distribution of the respondents to the survey indicated that it was wide and varied, which indicated that there existed no latent bias in the selection of respondents with respect to age.

A second demographic obtained from respondents was that of sex. The proportion of males and females participating as respondents to the semantic differential survey is presented in Figure 5 . Of the 34 respondents to the survey $52.94 \%$ (18 of 34 ) indicated that they were male, $47.06 \%$ ( 16 of 34) indicated they were female. This relatively equal distribution of male and female respondents to the survey eliminated potential bias in the survey results due to the sex of the respondents.

A third demographic obtained from survey respondents was that of educational attainment. Respondents were asked to indicate their highest level of educational attainment. The proportion of those respondents who held either a Doctorate, Master's, Bachelor's, or High School diploma 


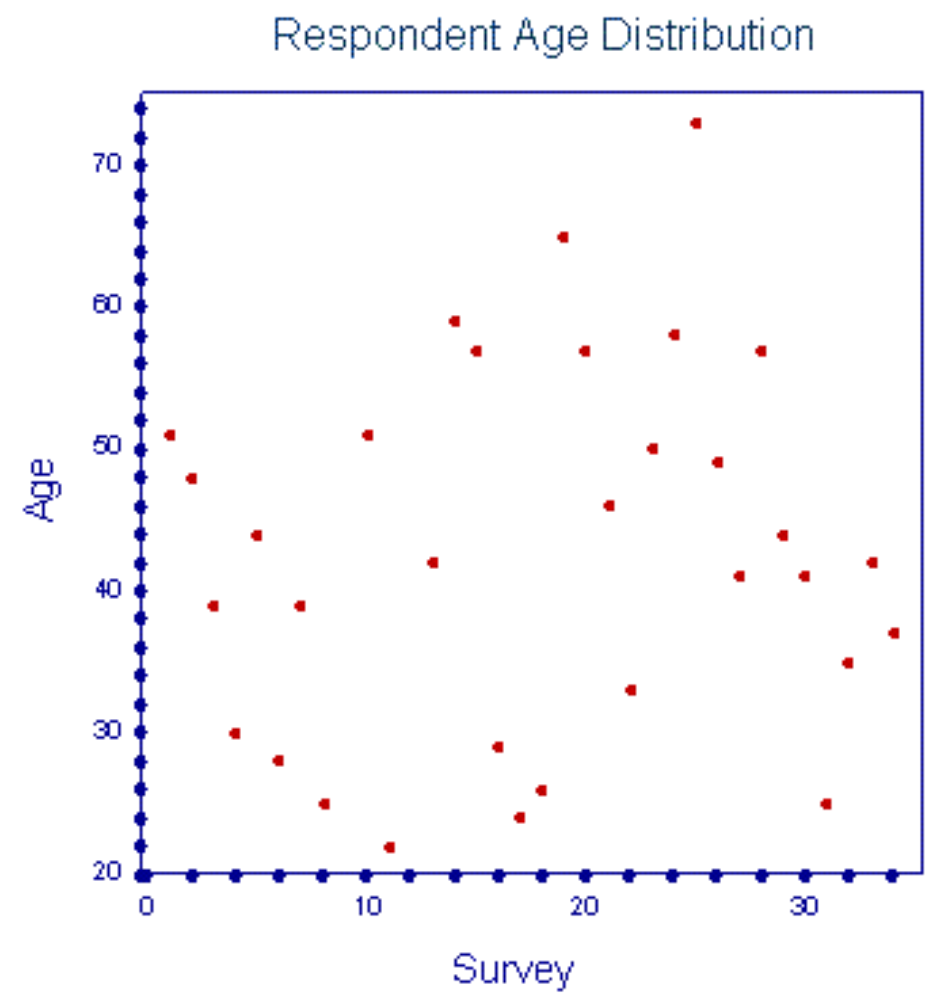

Figure 4. Respondent age distribution.

Table 4

Respondent Age Descriptive Statistics

\begin{tabular}{|l|r|}
\hline \multicolumn{1}{|c|}{ Statistic } & \\
\hline Mean Age (years) & 43.24 \\
\hline Standard Deviation & 13.18 \\
\hline Minimum Age & 22 \\
\hline Maximum Age & 73 \\
\hline
\end{tabular}

Note. Population $=33$ one respondent failed to indicate age 


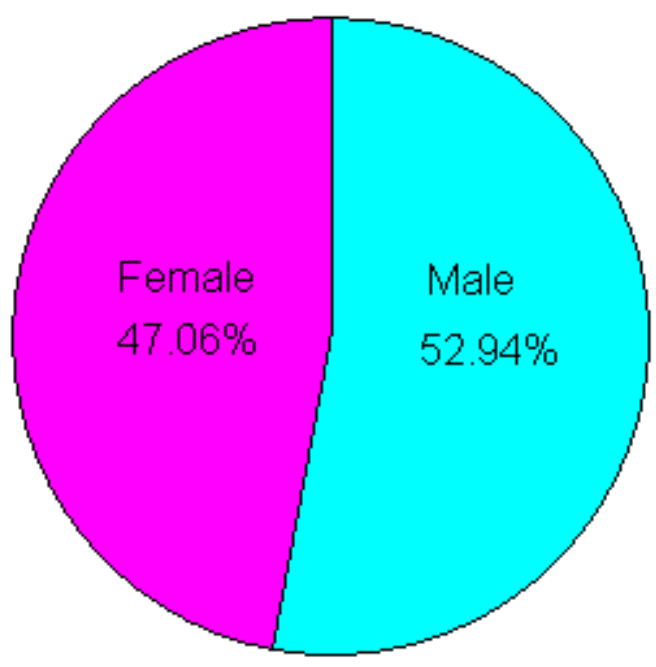

Figure 5. Respondent sex by percentage proportions

is reported in Figure 6. The largest percentage of respondents held a Master's degree, $41.18 \%$, or 14 of 34 respondents. The smallest category was that of high school diploma at $14.71 \%$, or 5 of 34 respondents. The finding that over $75 \%$ of the respondents held at least a college degree, and that over $64 \%$ held at least a graduate degree ensured the likelihood of respondent familiarity with the concepts presented in the survey.

A final category of demographic information obtained from respondents was that of education major. Respondents were asked to indicate their educational major in an open ended format. A summary of respondent responses is presented in Table 5. A large portion of 


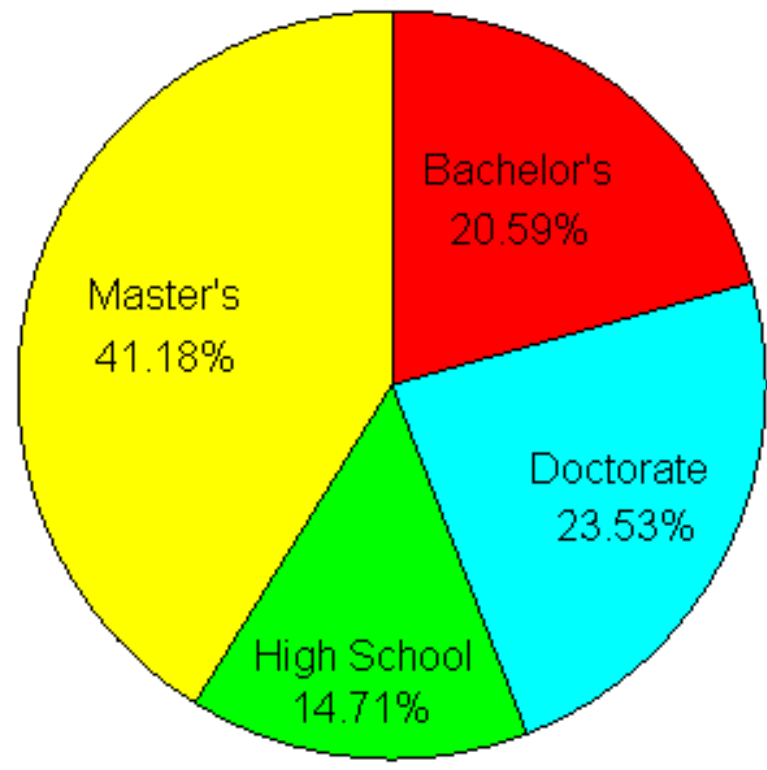

Figure 6. Respondent educational attainment by proportional percentage

the respondents identified Technology Education as their major, 13 of 34, or $38.24 \%$. Five respondents failed to report a major. Of the remaining 15 majors identified, all were reported just once, except medicine, which had 2 respondents.

To determine if any potential bias existed with regard to the large number of Technology Education majors, a Mann-Whitney 'U' Test was conducted to determine if a significant difference existed between Technology Education majors' mean score rankings of concepts on the three semantic differential factors and all other respondents. The Mann-Whitney $U$ test was utilized for two primary reasons. The first being the non-parametric 
Table 5

$\underline{\text { Respondent Major }}$

\begin{tabular}{|l|c|c|}
\hline \multicolumn{1}{|c|}{ Major } & Frequency & Percentage \\
\hline Technology Education & 13 & 38.24 \\
\hline Not Reported & 5 & 14.71 \\
\hline Medicine & 2 & 5.88 \\
\hline Accounting & 1 & 2.94 \\
\hline Business Administration & 1 & 2.94 \\
\hline Education/ Business & 1 & 2.94 \\
\hline Educational Psychology & 1 & 2.94 \\
\hline Foreign Languages & 1 & 2.94 \\
\hline History & 1 & 2.94 \\
\hline Nursing & 1 & 2.94 \\
\hline Philosophy & 1 & 2.94 \\
\hline Political Science & 1 & 2.94 \\
\hline Rehabilitation Counseling & 1 & 2.94 \\
\hline Secondary Education & 1 & 2.94 \\
\hline Sociology & 1 & 2.94 \\
\hline Special Administration & 1 & 2.94 \\
\hline Special Education & 1 & 2.94 \\
\hline Total & 34 & 100 \\
\hline
\end{tabular}

nature of semantic differential scoring of meaning, and the second being the relatively small number of respondents.

It was found that the mean rank of Technology Education majors did not differ significantly from the other majors on any of the three factors of 
Evaluative, Activity or Potency. A summary of the mean ranks and sum of ranks resulting from this test is presented in Table 6 .

Table 6

Mean Ranks of Concepts By Factor and Major

\begin{tabular}{|c|l|c|c|c|}
\hline Factor & \multicolumn{1}{|c|}{ Major } & N & Mean Rank & Sum of Ranks \\
\hline Evaluative & Technology Education & 270 & 271.3 & 73,252 \\
\hline & All Others & 270 & 269.7 & 72,818 \\
\hline Activity & Technology Education & 270 & 263.16 & 71,053 \\
\hline & All Others & 270 & 277.84 & 75,016 \\
\hline Potency & Technology Education & 270 & 273.21 & 73,765 \\
\hline & All Others & 270 & 267.79 & 72,304 \\
\hline
\end{tabular}

The test reported an approximated Z-Score and a p-value, which reflected the probability that the differences between Technology Education and all other majors was not significant. For purposes of this research, a $p$-value of less than .05 was utilized to demonstrate a significant difference between Technology Education and all other majors. As indicated in Table 7, the p-value was greater than .05 across the factors of Evaluative, Potency and Activity, indicating that no significant difference between Technology Education respondents and all other respondents on any of the three factors. 


\section{Table 7}

$\underline{\text { Test for Significance Difference Between Technology Education and All }}$ Other Majors on the Three Semantic Factors

\begin{tabular}{|l|r|r|r|}
\hline & Evaluative & Potency & Activity \\
\hline Z Score & -.120 & -.403 & -1.093 \\
p-value & .905 & .687 & .274 \\
\hline
\end{tabular}

\section{Data Scoring and Summation}

The data collected were scored for each respondent's survey by concept, across the three factors of Evaluative, Potency and Activity. The values of $3,2,1,0,-1,-2,-3$ were assigned to positions on the seven step scale. The scoring of the three scales presented was 3 for the position closest to good, strong, and fast, and -3 for the position closest to bad, weak, and slow (see Figure 7).

$$
\begin{aligned}
& \text { good _ _ _ : _ : _ : _ :__ : bad } \\
& +3+2+1 \quad 0 \quad-1 \quad-2 \quad-3 \\
& \text { fast _ : _ : : : : _ : : slow } \\
& \begin{array}{lllllll}
+3 & +2 & +1 & 0 & -1 & -2 & -3
\end{array} \\
& \text { strong }+3+2: \frac{1}{+3}: \frac{:}{0}: \frac{:}{-1}: \frac{-}{-3}^{\text {weak }}
\end{aligned}
$$

Figure 7. Semantic differential scale scoring values

Upon completing the scoring of individual survey responses for the three 
factor scales on the 270 concepts, a mean score for all survey responses for each concept by each factor was then generated. The mean score of concepts across the three factors was reported in Appendix F. The 3 highest ranked concepts for the Evaluative factor were, knowledge, creative and humane with scores of $2.74,2.59$, and 2.56 respectively. The 3 lowest ranked concepts for this factor were brutality, loss of freedom and destruction/devastation with scores of $-2.91,-2.76$, and -2.76 respectively. The three highest ranked concepts for the Activity factor were accelerating, catastrophe and disaster with scores of $1.94,1.82$, and 1.62 respectively. The three concepts with the lowest ranking on this factor were monotonous, evolutionary and (cultural, social and economic lag) with scores of -1.68 , -1.38 , and -1.38 respectively. The three highest ranked concepts on the Potency factor were liberation/freedom, knowledge and skill with scores of $2.24,2.15$, and 2.03 respectively. The lowest ranked concepts on this factor were vulnerability, unalive and fragmentation with scores of $-1.68,-1.09$, and -1.03 respectively.

\section{Data Analysis}

The characterization of the data obtained in this research was reported in several ways. In Chapter III it was determined that the combination of graphical presentations of concepts, a concept by concept 
squared Euclidean or D distance matrix, and a cluster analysis of concepts would provide meaningful insight into the manner in which technology was characterized, and that a Mann-Whitney ' $U$ ' statistical testing of mean differences would establish the validity of the null hypothesis that: $\mathrm{H}_{0}$ : There would be no significant difference at the .05 level between the semantic factor scores related to concepts used by individual disciplines to characterize technology.

\section{Graphical Presentations}

The data yielded a three dimensional presentation of the meaning of concepts within semantic space. Concepts were judged upon the three scales of Evaluative, Activity, and Potency which were then translated into the $x, y$, and $z$ axis of a graph, to create a visual comparison of concepts. Mean scores of the concepts across the three factors served as points to which the 270 concepts were graphed (see appendix G).

\section{$\underline{D}$ Matrix and Cluster Analysis}

The relationship of concepts to one another were examined through the use of a squared Euclidean distance analysis and a cluster analysis. The squared Euclidean distance analysis yielded a D matrix of values that represented the distance between each and every concept to every other 
concept. The D matrix generated for this research yielded a table which was 270 concepts by 270 for a total of 36,315 individual distance values.

A cluster analysis was then conducted to determine a conceptual structure of the concepts. The number of clusters utilized was based upon that distribution of concepts that had the largest number of concepts within each cluster while maintaining intuitive distinctions between clusters. It was found that the use of 10 clusters yielded conceptual structures with the best distribution of concepts across the clusters. This yielded the grouping of concepts reported in Appendix $\mathrm{H}$. The use of a smaller or large number of clusters resulted in the lack of distinctions between individual clusters that were intuitively meaningful to the researcher, or clusters groupings that did not possess a significant number of concepts, respectively. The concept of technology fell into cluster 2 , and its specific location in semantic space and cluster distribution is depicted in Figure 8. Two of the ten clusters had only one concept each. Clusters 9 and 10 had the concepts reckless and vulnerability respectively. Attempts to integrate these concepts into larger clusters failed due to the disintegration of any meaningful division between other clusters. Table 8 presents the number of concepts in each cluster $(\mathrm{N})$ and the mean scores for each cluster of concepts across each of the factors of Evaluative, Activity, and Potency. Cluster 2, to which the concept technology belongs, was located in the semantic space which 


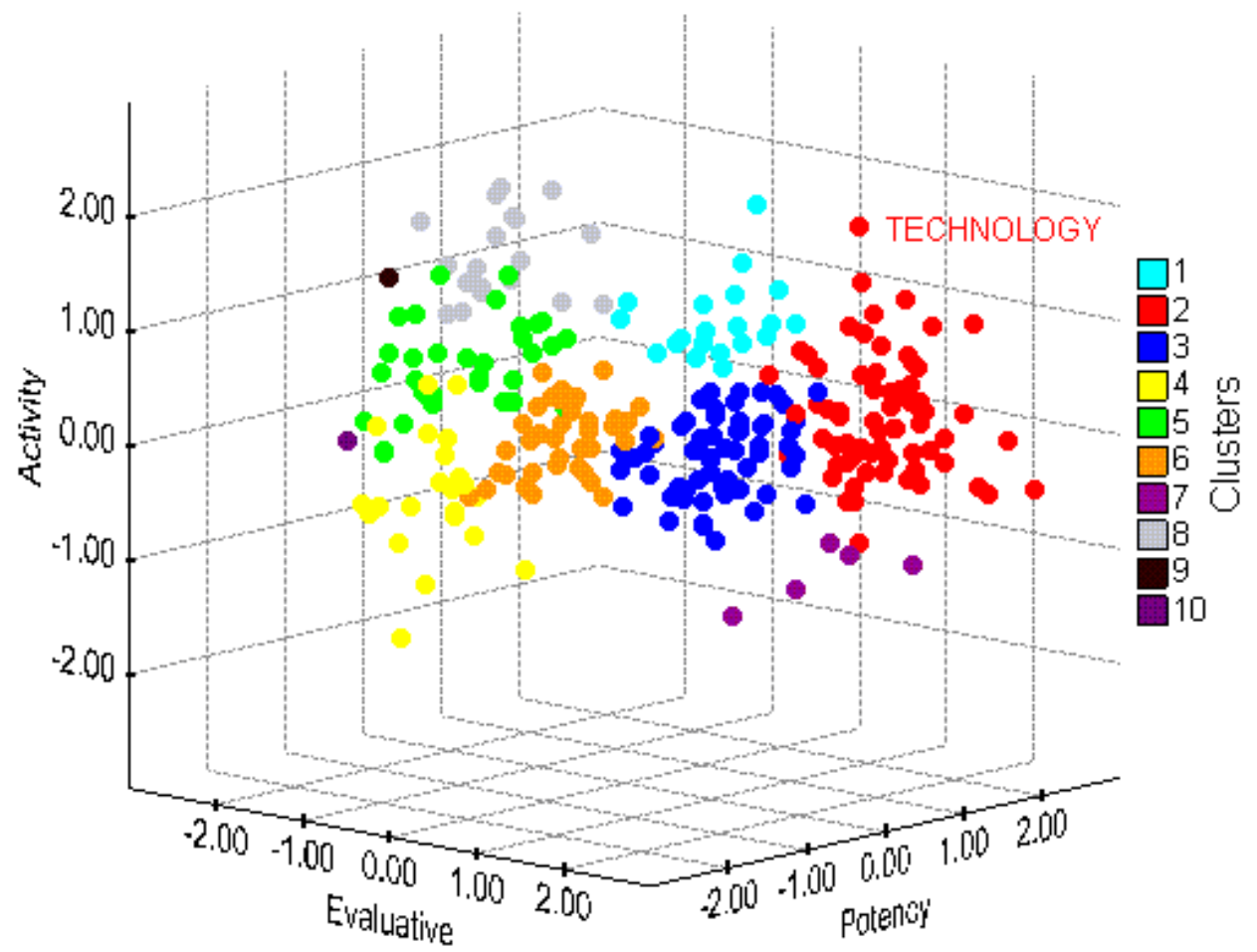

Figure 8. Cluster distribution of concepts with the concept technology indicated.

was positive on all three of the scales -- Evaluative, Activity, and Potency. Cluster 2 also exhibited the largest positive means on both the Evaluative and Potency factors. 


\section{Table 8}

\section{Cluster Means By Factor}

\begin{tabular}{|c|c|c|c|c|}
\hline Cluste & & Evaluative & Activity & Potency \\
\hline \multirow{2}{*}{1} & $\mathrm{~N}$ & 20 & 20 & 20 \\
\hline & Mean & 158 & .915 & 1.041 \\
\hline \multirow{2}{*}{2} & $\mathrm{~N}$ & 70 & 70 & 70 \\
\hline & Mean & 1.795 & .261 & 1.368 \\
\hline \multirow{2}{*}{3} & $\mathrm{~N}$ & 60 & 60 & 60 \\
\hline & Mean & .533 & -.126 & .651 \\
\hline \multirow{2}{*}{4} & $\mathrm{~N}$ & 22 & 22 & 22 \\
\hline & Mean & -1.749 & -.595 & -.532 \\
\hline \multirow{2}{*}{5} & $\mathrm{~N}$ & 33 & 33 & 33 \\
\hline & Mean & -2.020 & .297 & .233 \\
\hline \multirow{2}{*}{6} & $\mathrm{~N}$ & 38 & 38 & 38 \\
\hline & Mean & -.854 & -.150 & .250 \\
\hline \multirow{2}{*}{7} & $\mathrm{~N}$ & 5 & 5 & 5 \\
\hline & Mean & 1.535 & -1.029 & .918 \\
\hline \multirow{2}{*}{8} & $\mathrm{~N}$ & 20 & 20 & 20 \\
\hline & Mean & -2.416 & 1.107 & 1.075 \\
\hline \multirow{2}{*}{9} & $\mathrm{~N}$ & 1 & 1 & 1 \\
\hline & Mean & -2.088 & 1.353 & -.441 \\
\hline \multirow{2}{*}{10} & $\mathrm{~N}$ & 1 & 1 & 1 \\
\hline & Mean & -1.529 & .029 & -1.676 \\
\hline \multirow[t]{2}{*}{ Total } & $\mathrm{N}$ & 270 & 270 & 270 \\
\hline & Mean & -.078 & .142 & .686 \\
\hline
\end{tabular}

\section{Statistical Differences Between Disciplines}

The final analysis of data established the validity of the null hypothesis that; $\mathrm{H}_{0}$ : There would be no significant difference at the .05 level between the semantic factor scores related to concepts used by individual disciplines to characterize technology. A Mann-Whitney 'U' test was conducted on a 
discipline to discipline basis to determine if significant differences existed between disciplines on any of the three semantic factors of evaluative, activity, and potency. The Mann-Whitney 'U' test was selected because semantic meaning is non-parametric in nature, and because score distributions of concepts would not approximate normal distributions. Additional factors included the necessity of using a statistical procedure that could account for small population samples and that no other adequate measure existed for determining the significant differences between points in Euclidean space. The Mann-Whitney 'U' test compared the concepts in each and every discipline group to every other discipline group on each of the semantic factors. The total number of unique group to group comparisons for each factor was derived by dividing, the square of the total number of groups minus the total number of groups, by 2. For 16 discipline groups over the three factors this yielded a total of 360 individual tests for significant difference. Due to the relatively large number of tests conducted only a summary of the $p$-values has been reported. A discipline by discipline matrix of $p$-values for each factor of Evaluative, Activity, and Potency is provided in Appendix G. The null hypothesis that: $\mathrm{H}_{0}$ : There was no significant difference at the .05 level between the semantic factor scores related to concepts used by individual disciplines to characterize technology for this research, was rejected in those incidences in which the reported 
p-value was less than .05. Those discipline-to-discipline comparisons that were found to exhibit a significant difference and thus reject the null hypothesis is indicated in bold type in Appendix I. In those specific incidences in which the null hypothesis was rejected, a mean rank, the sum of mean ranks, the Mann-Whitney $U$ statistics, and the approximated Z-scores are reported in Appendix J. The null hypothesis was rejected in 36 of the 360 tests for significance in this research. Those cases in which a significant difference was found to exist between two disciplines on a factor is listed in Table 9. The discipline which exhibited the greater positive mean value on the factor was listed first. On the Evaluative factor 26 of 120 tests for significant differences rejected the null hypothesis. The disciplines of Physical Science and Natural Science were found to account for 17 of 26 rejections on the Evaluative factor. The discipline Physical Science accounted for 8 of 10 rejections of the null hypothesis on the Potency factor. No rejections of the null hypothesis occurred on the Activity factor.

\section{A Note on Type I Error}

It was found that 36 tests for significance resulted in the rejection of the null hypothesis. At the .05 significance level utilized in this analysis the probability of Type I error, the false rejection of the null hypothesis, was 18 in 360 tests. As such, the utilization of the .05 significance level for 
Table 9

Incidents of Null Rejection by Disciplines and Factor

\begin{tabular}{|l|c|}
\hline \multicolumn{1}{|c|}{ Discipline $>$ Discipline } & Factor \\
\hline Anthropology $>$ Literature & Evaluative \\
\hline Anthropology $>$ Natural Science & Evaluative \\
\hline Anthropology $>$ Philosophy & Evaluative \\
\hline Anthropology $>$ Political Science & Evaluative \\
\hline Anthropology $>$ Writer & Evaluative \\
\hline Business \& Economics $>$ Natural Science & Evaluative \\
\hline Business \& Economics $>$ Political Science & Evaluative \\
\hline Education $>$ Literature & Evaluative \\
\hline Education $>$ Natural Science & Evaluative \\
\hline Education $>$ Philosophy & Evaluative \\
\hline Education $>$ Political Science & Evaluative \\
\hline Education $>$ Writer & Evaluative \\
\hline Engineering $>$ Natural Science & Evaluative \\
\hline History $>$ Natural Science & Evaluative \\
\hline Physical Science $>$ History & Evaluative \\
\hline Political Science $>$ History & Evaluative \\
\hline Physical Science $>$ Literature & Evaluative \\
\hline Physical Science $>$ Mathematics & Evaluative \\
\hline Physical Science $>$ Natural Science & Evaluative \\
\hline Social Science \& Psychology $>$ Natural Science & Evaluative \\
\hline Physical Science $>$ Philosophy & Evaluative \\
\hline Physical Science $>$ Political Science & Evaluative \\
\hline Physical Science $>$ Social Science \& Psychology & Evaluative \\
\hline Physical Science $>$ Technology \& Society & Evaluative \\
\hline Physical Science $>$ Theology & Evaluative \\
\hline Physical Science $>$ Writer & Evaluative \\
\hline Anthropology $>$ Literature & Potency \\
\hline Anthropology $>$ Natural Science & Potency \\
\hline
\end{tabular}




\begin{tabular}{|l|c|}
\hline \multicolumn{1}{|c|}{ Discipline $>$ Discipline } & Factor \\
\hline Physical Science $>$ History & Potency \\
\hline Physical Science $>$ Literature & Potency \\
\hline Physical Science $>$ Natural Science & Potency \\
\hline Physical Science $>$ Philosophy & Potency \\
\hline Physical Science $>$ Political Science & Potency \\
\hline Physical Science $>$ Writer & Potency \\
\hline Physical Science $>$ Engineering & Potency \\
\hline Physical Science $>$ Architecture & Potency \\
\hline
\end{tabular}

the 360 tests conducted in this analysis resulted in the probability that Type lerror could have accounted for $50 \%$ (18 of 36 ) of the rejections of the null hypothesis. 


\section{CHAPTER V}

Findings, Conclusions, and Recommendations

The problem of this research was to determine selected disciplinary perspectives concerning the nature of technology within classic literature.

\section{Findings and Conclusions}

The notion that the meaning of the word technology had become increasingly amorphous and that there existed a gap of understanding between disciplines regarding the meaning of technology fueled the purpose and direction of this research. It was believed that an examination of the various perspectives that disciplines had concerning the nature of technology might serve as a basis to lessen the gap of understanding between disciplines regarding the meaning of technology. The examination of disciplinary perspectives concerning the nature of technology yielded several fundamental findings and conclusions regarding the different manners in which technology has been characterized.

\section{Concepts Used to Characterize Technology}

It was found that those concepts used to characterize the phenomenon of technology were widely dispersed over semantic space. This wide 
dispersion of concepts through semantic space was caused primarily by the distribution of concepts on the Evaluative semantic factor. Figure 9

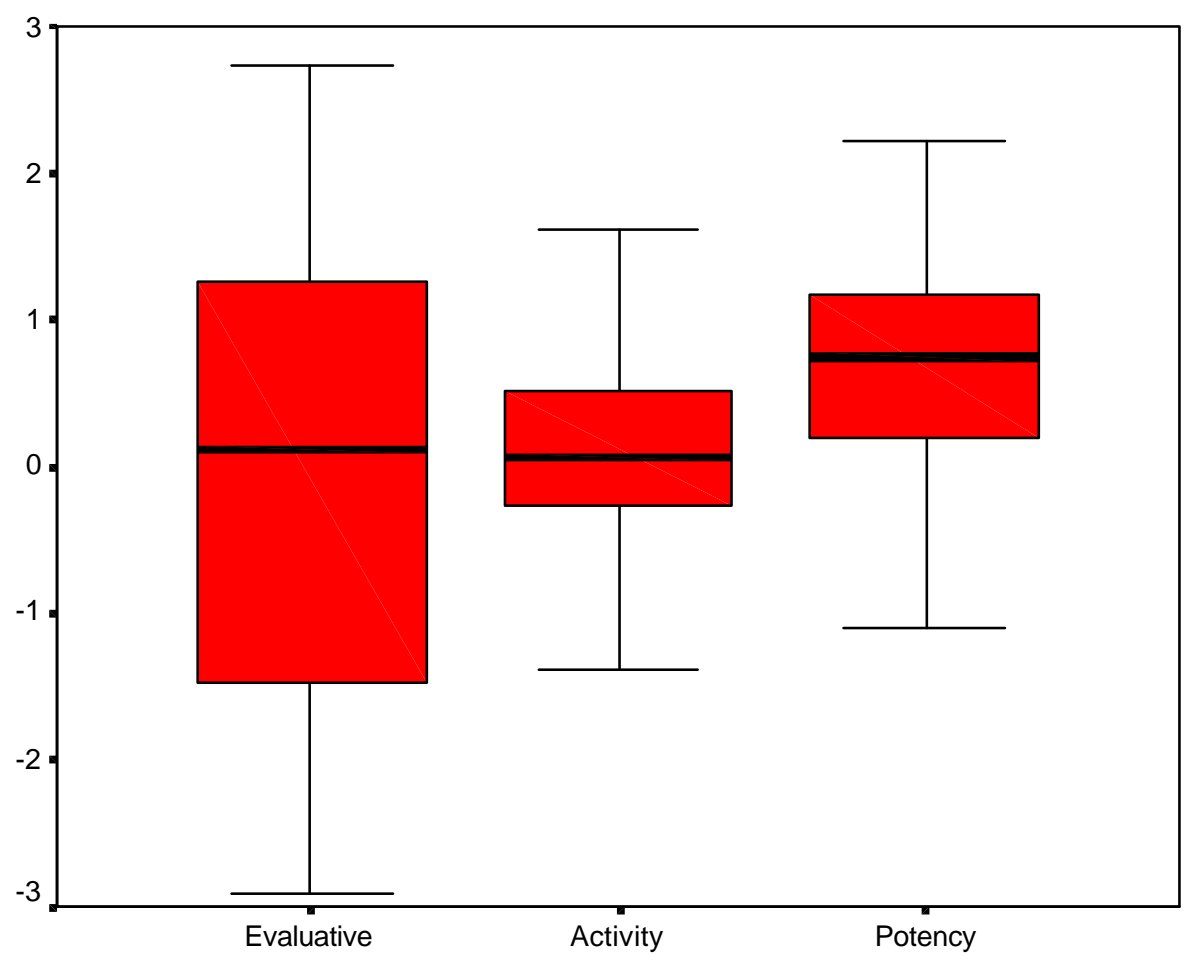

Figure 9. Box plot of factor distributions. Two standard deviations represented by $\mathrm{T}$ and __ represents factor median.

represents a box plot of the 270 concepts on each of the three semantic factors. The distribution of Evaluative scores was widely dispersed over the scale, whereas both the Activity and Potency scales tended to be more compact in their distribution. The Potency factor exhibited a tendency 
toward the rating of strong, indicating that the concepts used to characterize technology tended to be potent in nature, regardless of the concepts' rating on the other semantic factors. A further examination of the graphic relationships of factors to one another and concepts in semantic space indicate support for the following conclusions (See Appendix G).

1. Concepts utilized to characterize technology are widely dispersed in semantic meaning.

2. Concepts used to characterize technology tend to be potent.

3. Concepts used to characterize technology are widely dispersed in evaluative meaning.

4. Concepts used to characterize technology tend to be active and potent.

5. Concepts used to characterize technology tend to be positive and potent.

\section{Technology as a Concept in Semantic Space}

It was found that the concept Technology was rated as being positive, active, and potent. The concept Technology had the mean semantic scores of $1.38,1.62$, and 1.71 on the Evaluative, Activity, and Potency factors respectively. This indicated that respondents believed that technology was 
positive, active, and potent in meaning. Additionally, cluster and D-matrix analysis found that the concept Technology held a place in semantic space which was most similar to other concepts commonly thought of as being positive, active, and potent. The five concepts most closely related to technology in semantic meaning were, Western World, Dynamic, American, Momentum, and Mobility. Cluster 2 which contained the concept Technology, was replete with concepts that were rated positive, active and potent (See Appendix H). This contrasted significantly with the generally diverse distribution of all the concepts, utilized to depict the nature of technology, through semantic space (See Appendix G). Additionally, it should be noted that the concept Technology did hold a position which was disparate from the general distribution of all concepts. This indicated that respondents had a strong tendency to view the concept Technology as being unique in meaning from most of the other concepts they were presented. Therefore, the following conclusions were drawn about Technology as a concept in semantic space.

1. Technology was viewed as a positive, active and potent concept by the respondents.

2. The concept Technology was closely associated with concepts that were highly positive, active, and potent in meaning . 
3. Technology held a space in semantic space which was unique from most of the concepts used to characterize it.

\section{$\underline{\text { Research Hypothesis }}$}

The research hypothesis for this research that: $\mathrm{H}_{0}$ : There would be no significant difference at the .05 level between the semantic factor scores related to concepts used by individual disciplines to characterize technology, was rejected in 36 of the 360 tests for significance in the research. Significant differences in the meaning of concepts utilized by various disciplines existed in 26 and 10 cases on the semantic factors Evaluative and Potency respectively. There existed no significant differences between the concepts utilized by the various disciplines on the Activity semantic factor.

Those incidents in which a test for significant difference between two disciplines resulted in the hypothesis being rejected have been summarized in Appendix J. Graphical presentation of the relationship between the concepts utilized by the two disciplines under comparison was also included in Appendix J.

The disciplines which exhibited the greatest number of rejections of the null hypotheses on the Evaluative factor were the Physical Sciences and the Natural Sciences. The Physical Sciences were significantly different 
from 10 of 15 disciplines on the Evaluative factor. The Natural Sciences differed significantly with 7 of 15 disciplines on the Evaluative factor. It was found that the mean value of the concepts utilized by the Physical Sciences was the most positive of all other disciplines on the Evaluative factor (See Appendix K). Other disciplines which had positive mean values on the Evaluative factor and that differed significantly with several other disciplines were, Anthropology and Education. The Natural Sciences had the most negative concept mean value on the Evaluative factor. Another discipline that had negative mean values on the Evaluative factor and that differed significantly with several other disciplines was Political Science.

Therefore, it was found that most of the significant differences between disciplines existed between those that used positive evaluative concepts, such as Physical Sciences, Anthropology, and Education, and those that used negative evaluative concepts, such as Natural Sciences and Political Sciences. On the Evaluative factor, these discipline groups were found to be involved in every rejection of the null hypothesis that: $\mathrm{H}_{0}$ : There would be no significant difference at the .05 level between the semantic factor scores related to concepts used by individual disciplines to characterize technology. It was found that the distribution of disciplines was clustered around a positive Evaluative factor mean of .14 (see Appendix L) with the outlying three disciplines that were highly positive, and the two highly 
negative disciplines accounting for all of the significant differences found between specific disciplines.

Significant differences were also found to exist on the Potency semantic factor in 10 of 120 discipline to discipline comparisons (See Appendices I and $\mathrm{J}$ ). Of the 10 tests for significance difference that rejected the null hypothesis that: $\mathrm{H}_{0}$ : There would be no significant difference at the .05 level between the semantic factor scores related to concepts used by individual disciplines to characterize technology, 8 involved the discipline of Physical Science. This was attributed to the high Potency factor values associated with the concepts utilized by Physical Science to characterize technology (see Appendix K). The remaining 2 tests for significance on the Potency factor that resulted in the rejection of the null hypothesis involved the discipline Anthropology. Anthropology was found to differ significantly with Literature and Natural Science on the Potency factor. Anthropology exhibited high Potency factor values which contrasted significantly with the lower Potency factor values of concepts utilized by Literature and Natural Sciences (see Appendices $\mathrm{K}$ and L).

It was found that the null hypothesis was not rejected on the Activity semantic factor for any of the 120 discipline to discipline comparisons. This was attributed to the narrow distribution of Activity values (see figure 9). However, it should be noted that the discipline Anthropology did exhibit a 
negative mean Activity factor value, and that the disciplines Literature and Theology had negative median Activity factor values (see Appendices $\mathrm{K}$ and L). This indicated that the disciplines of Anthropology, Literature, and Theology utilized some concepts which differed from other disciplines with regard to the Activity factor.

Upon the completion of the data analysis and hypothesis testing it was concluded that:

1. The Physical Sciences, Anthropology and Education utilized concepts that were significantly positive on the Evaluative semantic factor scale.

2. The Natural Sciences and Political Sciences utilized concepts that were significantly negative on the Evaluative semantic factor scale.

3. The disciplines of Physical Science, Anthropology, and Education utilized concepts to characterize technology which were significantly different from other disciplines on the Evaluative semantic factor.

4. The disciplines of Natural Science and Political Science utilized concepts to characterize technology which were significantly different from other disciplines on the Evaluative semantic 
factor.

5. The discipline of Physical Science utilized concepts which were significantly more potent than concepts utilized by other disciplines.

6. The discipline of Anthropology utilized concepts which were significantly more potent than concepts utilized by the disciplines of Natural Science and Literature.

\section{Summary}

The amorphous manner in which technology has come to be characterized served as the impetus for this research. The assertion of C.P. Snow (1959) that there existed two divergent cultures within academia, and that fundamental differences between disciplines often serve to shape the debate surrounding technology, was explored in part by this research. By expanding the understanding of the manner in which technology has come to be characterized by various disciplines, it was believed that a lessening of the gap of understanding between disciplines can occur.

Upon the completion of this research it was found that technology has indeed been characterized amorphously. Often concepts which differed significantly from individual conceptions of technology have been used to characterize technology. However, the assertion that there exists two 
cultures with regard to technology remains unproven. The greatest divergence between disciplines in this research was found to exist between disciplines within a single culture as identified by Snow (1959). It was found that the Natural and Physical sciences differed on the Evaluative and Potency factors. This indicated that those in the sciences, who have had as their focus the natural processes of the biological environment, view technology in a different manner than those whose focus has been the physical sciences of astronomy, physics, and chemistry. The tendency to hold a cyclical, naturalistic or organic view of reality versus a mechanistic view may be at the heart of the difference between the sciences with regard to technology. Additionally, the Physical and Natural sciences have had a different relationship with technology, one whose advancement and achievements have been largely dependent upon the development of new technologies, and the latter whose focus has been dealing with the effects of technology upon the environment.

\section{$\underline{\text { Recommendations For Further Study }}$}

The phenomenon of Technology has been characterized in an amorphous manner. This can result in substantial ambiguities regarding the true nature and character of technology. A continued context of ambiguity regarding technology can only serve to foster misunderstandings between 
various individuals and disciplines. The debates surrounding various social prescriptions for dealing with the phenomenon of technology threaten to remain mired if consensus is not reached about the precepts of technology under question. A primary responsibility of the technology education professional is to communicate a context of precepts about technology which can become widely and commonly accepted. To achieve this end, a deeper understanding of how technology is currently conceptualized by various individuals and disciplines needs to be drawn. This research marked an initial attempt at drawing a conceptual map of the phenomenon of technology from the perspective of various disciplines. Recommendations for further study would include:

1. An examination of contemporary publications to identify those concepts utilized to characterize technology and to compare those results with this study to identify any changing attitudes.

2. The semantic testing of the concept technology across differing bi-polar adjectival scales.

3. A statistical analysis of the publications based upon other characteristics, such as the date of publication, to identify other possible correlations. 
$\underline{\text { Implications }}$

A primary and fundamental implication that can be drawn from this research is that a framework of understanding regarding the meaning of technology does not exist within the popular lexicon. As Winner (1977) suggested technology has indeed "come to mean everything and anything" (p. 10), and has come to mean nothing. What does this bode for those who live in a society in which Marx (1984) suggested 'technology' has come to "occupy a central place in the discourse" (p.638)? And what then are those who suppose that they are 'technology educators" to make of their discipline and of their responsibilities?

This researcher would suggest that in beginning to answer these questions that those who claim to be technology educators clearly define that about which they are educating. This is not a call for a collection of rigid prescriptions and definitions that serve to confine a discipline and its thinking, but rather at a minimum a "definable set of precepts" (Shipley, 1970). As Marx (1984) suggested it was the view of Heidegger that the phenomenon of technology should be considered a "class" of precepts that contains many entities.

One need only to turn to the document entitled Technology for All Americans published by the International Technology Education Association 
(1996) to understand Winner's (1977) assertion that technology "comes to mean everything and anything" for the supposed leaders of 'technology education". While, some clear delineations about technology education seemed to have been made within this publication, it is hard to visualize actually what it is that the International Technology Education Association (ITEA) left out. The overriding platitude was that "Technology is human innovation in action" (ITEA, p. i), while seemingly positive, what is conveyed about the discipline in this statement? The researcher cannot recall another discipline that has a similar ill defined platitude as its clarion call. What should the discipline that calls itself technology education draw upon from the document Technology for All Americans ? A rationale and structure was provided, however the ITEA (1996) document contains an endless stream of statements about technology and technology education similar to this:

"Technological literacy is much more than knowledge about computers and their application. It involves a vision where each citizen has a degree of knowledge about nature, behavior, power, and consequences of technology from a broad perspective. Inherently, it involves educational programs where learners become engaged in critical thinking as they design and develop products, systems, and environments to solve practical problems". (p. 1). 
Clearly, a discipline that has to continuously state unequivocally that which it is not and then subsequently embraces ill defined and value laden terms such as "practical", "vision", "degree of knowledge", and "critical thinking", and concerns itself with creating "literacy", can only be adding to the confusion that surrounds it.

While, the researcher may be critical of aspects of the document entitled Technology for All Americans it should be noted that the document has elements that moved to establish the "precepts" upon which it has been suggested that a discipline must be founded. Although, the voice of the ITEA may be loudest, it is by no means is the only voice in technology education. Many authors cited in the course of this work have held out prescriptions for defining the precepts of the study of technology (DeVore, 1980, Mitcham, 1994, Pacey, 1983). The discourse of a discipline must be around its precepts not its promotion through calls for an ill defined universal literacy.

It is this primary implication that the researcher hopes to convey through this research: the primary responsibility of those who call themselves technology educators should be to the endless pursuit of an understanding of those precepts which serve to define the nature of the phenomenon of technology. The ability to educate others with regard to one's discipline begins with the requirement that one can clearly articulate and promote a coherent context of understanding of the phenomenon under consideration. 


\section{BIBLIOGRAPHY}

Appleyard, B. (1993) . Understanding the Present: Science and the Soul of Modern Man. New York: Doubleday.

Aristotle. (1915) . Ethica Nicomachea. In W. Ross (Ed and Trans.) The Complete Works of Aristotle (Volume IX) . London: Oxford University Press.

Aristotle. (1947) . Physics. In R. McKeon (Ed and Trans) . Introduction to Aristotle. Chicago: The University of Chicago Press.

Bacon, F. (1954) . Novum Organum. In S. Commins \& R. Linscott (Eds.) Man and The Universe: The Philosophers of Science (pp. 75-158). Washington Square Press: New York.

Bacon, F. (1955) . Novum Organum. In H. Dick . (1955) . Selected Writings of Francis Bacon. New York: The Modern Library.

Basalla, G. (1988). The Evolution of Technology. New York: Cambridge University Press.

Berdyaev, N. (1934). Man and Machine. In C. Mitcham \& R. Mackey (Eds.) . (1972). Philosophy and Technology: Readings in the Philosophical Problems of Technology (pp. 203-213). New York: The Free Press.

Berelson, B. (1952) . Content Analysis in Communication Research. New York: Free Press.

Biography and Genealogy Master Index . (1980-) . Detroit: Gale Research Inc.

Biography Index . (1946, January, 1949-, July) . New York: H.W. Wilson Co.

Bledsoe, J. (1972) . Essentials of Educational Research (2nd ed). Athens: Optima House

Bobbett, J. (1984) . Subjective Meaning of Computer. Unpublished doctoral dissertation, Arizona State University, Tempe, Arizona. 
Bugliarello, G. (1973) . The Engineer and the Historian. In G. Bugliarello and D. Doner. (Eds.) . (1979). The History and Philosophy of Technology (pp. 50-56). Urbana: University of Illinois Press.

Bugliarello, G. \& Doner, D. (Eds.) . (1979) . The History and Philosophy of Technology, Urbana: University of Illinois Press.

Bunge, M. (1967) . Toward a Philosophy of Technology . In C. Mitcham \& R. Mackey (Eds.) . (1972) . Philosophy and Technology: Readings in the Philosophical Problems of Technology (pp. 62-76). New York: The Free Press.

Cardwell, D. (1994) . The Norton History of Technology. New York: W.W. Norton \& Company.

Cardwell, D. (1973) . Problems of a Data Base. In G. Bugliarello and D. Doner. (Eds.) . (1979). The History and Philosophy of Technology. Urbana: University of Illinois Press.

Carney, T. (1972). Content Analysis: A Technique for Systematic Inference From Communications. Winnipeg: University of Manitoba Press.

Carpenter, S. (1974) . Modes of Knowing and Technological Action. Philosophy Today, Summer, 162-168.

Carroll, J. (1964) . Language and Thought. Englewood Cliffs: Prentice Hall, Inc.

Chan, L. (1981) . Cataloging and Classification: An Introduction. New York: McGraw-Hill Book Company.

Chan, L. (1990) . Immroth's Guide to the Library of Congress Classification. (4th ed.) . Englewood: Libraries Unlimited, Inc.

Contemporary Authors . (1981-) . Detroit: Gale Research Inc.

Contemporary authors cumulative index . (1976-1982) . Detroit: Gale Research Inc. 
Custer, R. (1991). Technology: A Qualitative Concept Analysis from The Perspectives of Engineering, Philosophy, Natural Science, and Technology Education. Unpublished doctoral dissertation, University of Missouri-Columbia, Columbia, Missouri.

Deitrich, R. (1995) . Thinking through Technology, Journal of Technology Education, 6, 2 .

DeVore, P. (1980). Technology: An Introduction. Worcester: Davis Publications, Inc.

Dick, H. (1955) . Selected Writings of Francis Bacon. New York: The Modern Library.

Durbin, P. (Ed.) . (1988) . Technology and Contemporary Life. Boston: D. Reidel Publishing Company.

Ellul, J. (1964) . The Technological Society. New York: Alfred A. Knopf, Inc.

Ferre, F. (1988) . Philosophy of Technology. Englewood Cliffs: Prentice-Hall, Inc.

Ferre, F. (1995, Fall) . Philosophy and Technology after Twenty Years [On-line] Symposium: Philosophy And Technology After Twenty Years, 1, (1-2) . Society for Philosophy \& Technology. Available: http://scholar.lib.vt.edu/ejournals/SPT/v1_n1n2/contents.html

Fowler, H. (1986) . The Little, Brown Book (3rd ed.) .Boston: Little, Brown \& Company.

Fukuyama, F. (1992) . The End of History and The Last Man. New York: The Free Press.

Glendinning, C. (1990) . When Technology Wounds: The Human Consequences of Progress. New York: William Morrow and Company, Inc.

Goodman, P. (1969) . Can Technology Be Humane? In A. Teich (Ed.) (1993) . Technology and The Future, (pp. 239-264). New York: St. Martin's Press. 
Grant, G. (1969) . Technology and Empire. In C. Mitcham, \& R. Mackey (Eds.) (1972). Philosophy and Technology: Readings in the Philosophical Problems of Technology (pp. 187-200). New York: The Free Press.

Gravetter, F. \& Wallnau, L. (1992) . Statistics for the Behavioral Sciences (3rd ed). New York: West Publishing Company.

Green, A. W. (1966) . Sir Francis Bacon. New York: Twanye Publishers, Inc.

Halfin, H. (1973) . Technology -- A Process Approach. Unpublished doctoral dissertation, West Virginia University, Morgantown, WV.

Harkins, W.E. (1962) . Karel Capek. New York: Columbia University Press.

Heidegger, M. (1977) . The Question Concerning Technology and Other Essays (W. Lovitt, Trans.). New York: Harper and Row Publishers.

Holsti, O. (1969) . Content Analysis for the Social Sciences and Humanities. Reading: Addison-Wesley.

Holup, J. (1980) . A Semantic Differential Study of the Connotative Meaning of Thirty Distributive Education Concepts. Unpublished doctoral dissertation, Washington State University, Pullman, Washington.

Hood, W. (1968) . A Heideggerian Approach to the Problem of Technology. Unpublished doctoral dissertation, Penn State University: State College, Pennsylvania.

Hood, W. (1972) . The Aristotelian Versus the Heideggerian Approach to the Problem of Technology. In C. Mitcham, \& R. Mackey (Eds.) . Philosophy and Technology: Readings in the Philosophical Problems of Technology (pp. 347-363). New York: The Free Press.

Ihde, D. (1990). Technology and the Lifeworld: From Garden to Earth. Bloomington: The Indiana University Press.

Ihde, D. (1983). Existential Technics. Albany: State University of New York Press. 
Ihde, D. (1979). Technics and Praxis: A Philosophy of Technology. Boston: D. Reidel.

Immroth, J. (1972) . Library of Congress Classification. In A. Maltby. (Ed.). Classification in the 1970's (pp.123-143). Hamden: Linnet Books \& Clive Bingley.

International Technology Education Association, (1996) . Technology for All Americans. Reston, Virginia

Jenkins, J., Russell, W., \& Suci, G. (1958) . An Atlas of Semantic Profiles for 360 Words, American Journal of Psychology, 71, 688-699.

Joachim, H. (1951) . Aristotle: The Nicomachean Ethics. London: Oxford University Press.

Kerlinger, T. (1973) . Foundations of Behavioral Research (2nd ed) . New York: Holt, Rinehart \& Winston.

Kranzberg, M. (1973) . Introduction: Trends in the History and Philosophy of Technology. In G. Bugliarello and D. Doner. (Eds.) . (1979). The History and Philosophy of Technology (pp. xiii-xxxi) . Urbana: University of Illinois Press.

Kumata, H. \& Schramm, W. (1956) . A Pilot of Cross-Cultural Meaning. In J. Snider \& C. Osgood (Eds.). (1969). Semantic Differential Technique: A Sourcebook (pp. 273-282). Chicago: Aldine Atherton.

Leavis, F. (1962). Two Cultures? The Significance of C.P. Snow with an Essay on Sir Charles Snow's Rede Lecture. New York: Random House, Inc.

Lovitt, W. (1977). Introduction. In M. Heidegger. (1977) . The Question Concerning Technology and Other Essays (W. Lovitt, Trans.) . (pp. xiii-xxxix). New York: Harper and Row Publishers.

Maltby, A. (1972) . (Ed.) . Classification in the 1970's. Hamden: Linnet Books \& Clive Bingley.

Maltz, H. (1963) . Ontogenetic Change in the Meaning of Concepts. In J. Snider \& C. Osgood (Eds.). (1969). Semantic Differential Technique: A Sourcebook (pp. 340-347). Chicago: Aldine Atherton. 
Marx, L. (1984). On Heidegger's Conception of "Technology" and Its Historical Validity. The Massachusetts Review, Winter, 638-652.

McKeon, R. (1947) . Introduction to Aristotle. Chicago: The University of Chicago Press.

McLuhan, M. (1964) . Understanding Media: The Extensions of Man. New York: McGraw-Hill.

Merchant, C. (1980) . Mining the Earth's Womb. In J. Rothschild. (Ed.) . (1983) . Machine Ex Dea: Feminist Perspectives on Technology. (pp. 99-117). New York: Pergamon Press.

Mesthene, E. (1969) . The Role of Technology in Society. In A. Teich (Ed.) . (1993) . Technology and The Future. (pp. 73-88). New York: St. Martin's Press.

Mesthene, E. (1967) . Technology and Wisdom . In C. Mitcham \& R. Mackey (Eds.) . (1972) . Philosophy and Technology: Readings in the Philosophical Problems of Technology (pp. 116-129). New York: The Free Press.

Meyer, M. (1983). Meaning and Reading: A Philosophical Essay on Language and Literature. Amsterdam: John Benjamins Publishing Company.

Miller, L. (1978) . The Design of A Method for Identifying Behavioral Characteristics of the Phenomenon of Technology and for Deriving Their Implications for Education. Unpublished doctoral dissertation, West Virginia University, Morgantown, West Virginia.

Mitcham, C. (1994). Thinking through Technology: The path between Engineering and Philosophy. Chicago: The University of Chicago Press.

Mitcham, C. (1980). Philosophy of Technology. In P. Durbin. (Ed.) . (1980) . A Guide to The Culture of Science, Technology, and Medicine (pp. 282-363) . New York: The Free Press. 
Mitcham, C. (1979) . Philosophy and the History of Technology. In Bugliarello, G. \& Doner, D. B. (Eds.) . The History and Philosophy of Technology (pp. 163-201). Urbana: University of Illinois Press.

Mitcham, C. \& Mackey, R. (Eds.) . (1972) . Philosophy and Technology: Readings in the Philosophical Problems of Technology. New York: The Free Press.

Muller, H. (1970) . The Children of Frankenstein: A Primer on Modern Technology and Human Values. Bloomington: Indiana University Press.

Mumford, L. (1934) . Technics and Civilization. New York: Harcourt \& Brace Company.

Mumford, L. (1964) . The Myth of the Machine: The Pentagon of Power. New York: Harcourt Brace Jovanovich, Inc.

Mumford, L. (1974) . Interpretations and Forecasts: 1922-1972, Studies in Literature, History, Biography, Technics, and Contemporary Society. New York: Harcourt Brace Jovanivich, Inc.

Ortega y Gasset, J. (1939). Thoughts on Technology . In C. Mitcham \& R. Mackey (Eds.) . (1972) . Philosophy and Technology: Readings in the Philosophical Problems of Technology (pp. 290-313). New York: The Free Press.

Osgood, C. (1952) . The Nature and Measurement of Meaning. In J. Snider \& C. Osgood (Eds.). (1969). Semantic Differential Technique: A Sourcebook (pp. 3-41). Chicago: Aldine Atherton.

Osgood, C. \& Suci, G. (1955) . Factor Analysis of Meaning. In J. Snider \& C. Osgood (Eds.). (1969) . Semantic Differential Technique: A Sourcebook (pp. 42-84). Chicago: Aldine Atherton.

Osgood, C. May, W. \& Miron, M. (1975). Cross-Cultural Universals of Affective Meaning. Urbana: University of Illinois Press.

Osgood, C., Suci, G., and Tannenbaum, P. (1957). The Measurement of Meaning. Urbana: University of Illinois Press.

Pacey, A. (1983) . The Culture of Technology. Cambridge: The MIT Press. 
Paterson, A. (1973) . Francis Bacon and Socialized Science. Springfield: Charles C. Thomas Publisher.

Postman, N. (1992) . Technopoly: The Surrender of Culture to Technology. New York: Random House.

Pytlik, E. (1988) . Identifying the Great Books of Technology, Journal of Technology and Society, 2, 1, 53-66.

Rapp, F. (Ed.) . (1974) . Contributions to a Philosophy of Technology. Boston: D. Reidel Publishing Company.

Rothschild. J. (Ed.) . (1983) . Machine Ex Dea: Feminist Perspectives on Technology. New York: Pergamon Press.

Sax, G. (1968) . Empirical Foundations of Educational Research. Englewood Cliffs: Prentice-Hall.

Segal, H. (1994) . Future Imperfect: The Mixed Blessing of Technology in America. Amherst: The University of Massachusetts.

Semantic Differential Scaling. [On-line] . www2.ed.psu/espse/staff/droberts/5501.htm

Shipley, J. T. (1970) . Dictionary of Word Origins, Totown, New Jersey: Littlefield, Adams \& Co.

Skaine, J. (1988) . On Drawing Circles or The Art of Defining a Discipline, Journal of Industrial Teacher Education, 25, 3, 77-78.

Smith, M. and Marx, L. (Eds.) (1994). Does Technology Drive History?: The Dilemma of Technological Determinism. Cambridge: The MIT Press.

Smith, M. R. (1994) . Technological Determinism in American Culture. In M.R. Smith and L. Marx. (Eds.) . Does Technology Drive History?: The Dilemma of Technological Determinism (pp. 1-35) . Cambridge: The MIT Press.

Snider, J. \& Osgood, C. (Eds.) . (1969) . Semantic Differential Technique: A Sourcebook. Chicago: Aldine Atherton. 
Snow, C. (1969). The Two Cultures and A Second Look. Cambridge: Cambridge University Press.

Strauss, L. (1958). Thoughts on Machiavelli. Glencoe, Illinois: The Free Press.

Suci, G. (1960) . A Comparison of Semantic Structures in American Southwest Culture Groups. In J. Snider \& C. Osgood (Eds.). (1969) . Semantic Differential Technique: A Sourcebook (pp. 283-288). Chicago: Aldine Atherton.

Tanaka, Y. Oyama, T. \& Osgood, C. (1963). A Cross-Cultural and Cross-Concept Study of the Generality of Semantic Space. In J. Snider \& C. Osgood (Eds.). (1969). Semantic Differential Technique: A Sourcebook (pp. 289-302). Chicago: Aldine Atherton.

Teich, A. (Ed.) . (1993) . Technology and the Future. New York: St. Martin's Press.

Tenner, E. (1996) . Why Things Bite Back: Technology and the Revenge of Unintended Consequences. New York: Random House.

Tondl, L. (1974) . On The Concepts of 'Technology' and 'Technological Sciences'. In F. Rapp. (Ed.) . Contributions to a Philosophy of Technology. Boston: D. Reidel Publishing Company.

Tressler, J. \& Lipman, M. (1949) . Business English in Action. Boston: D.C. Heath and Company.

Volti, R. (1992) . Society and Technological Change. St. Martin's Press: New York.

Watkins, B. \& Meador, R. (1977) . Technology and Human Values: Collision and Solution. Ann Arbor: Ann Arbor Science Publishers Inc.

Webster's Ninth Collegiate Dictionary . (1990) . Springfield, MA: Merriam-Webster.

Winner, L. (1977). Autonomous Technology: Technics-out-of-Control as a Theme in Political Thought. Cambridge: The MIT Press. 
APPENDIX A

APPENDIX A

Excluded Works and Texts 


\section{APPENDIX A}

\section{Excluded Texts and Works}

al-Jazari, I.A. (1974) . The Book of Ingenious Mechanical Devices (D.R. Hill, Trans.) . Boston: D. Reidel Publishing Company. (Original work published 1204/1206)

Allee, W.C. \& Park, T. (1939, February 24) . Concerning Ecological Principles. Science, 89, 166-169.

Beaune, J. (1973) . Technology from an Encyclopedic Point of View, In. G. Bugliarello \& D.B. Doner (Eds.), The History and Philosophy of Technology (pp.202-226) . Urbana: The University of Illinois Press.

Berbaum, J. (1982) . Etude systemique des actions de formation. Paris: Presses universitaires de France.

Biringuccio, V. (1942) . Pirotechnia (S.C. Smith \& M.T. Gnudi, Trans.) . New York: The American Institute of Mining and Metallurgical Engineers. (n.d)

Brooks, F.P. Jr., (1975) . The Mythical Man-Month. Philippines: Addison-Wesley Publishing Company Inc.

Brown, L. (1977) . Redefining National Security. Washington, DC: Worldwatch Institute.

Chandler, A.D. (1981) . The American System and Modern Management, In O. Mayr \& R.C. Post (Eds.), Yankee Enterprise: The Rise of the American System of Manufactures (pp. 153-170) . Washington, DC: Smithsonian Institution.

Chestnut, H. (1965) . Systems Engineering Tools. New York: John Wiley \& Sons, Inc.

Comstock, J.H. (1924) . An Introduction to Entomology. Ithaca: Cornell University Press.

Corliss, W.R. (1967) . Scientific Satellites. Washington, DC: National Aeronautics and Space Administration.

Council on Environmental Quality \& The Department of State. (1980). The Global 2000 Report to the President. Washington, DC: U.S. Government Printing Office.

Daumas, M. (Ed.) .(1962) . A History of Technology (E.B. Hennessy, Trans.) . New York: Crown Publishers, Inc.

Da Vinci, L. (1960) . Leonardo da Vinci, 1452-1519. New York: International Business Machines Corporation, Department of Arts and Sciences. 


\section{APPENDIX A (continued)}

Davis, D. (1974) Energy Politics. New York: St. Martin's Press.

Dale. "An Economist's Look at Society"

Diderot, D. (1778) . Encyclopedie ou dictionnaire raisonne des sciences des arts et des metiers. Geneve, Neufchatel: Pellet, Societe Typographique.

Durbin, P.T \& Rapp, F. (1983) . Philosophy and Technology. Dordrecht, Holland: Reidel.

Douds, C.F. \& Rubenstein, A.H. (1978) . Review and Assestment of the Methodology Used to Study Behavioral Aspects of Innovation Process. In P. Kelly \& M. Kranzberg (Eds.) , Technological Innovation: A Critical Review of Current Knowledge (pp. 231-334). San Francisco: The San Francisco Press.

Einstein, A. \& Infeld, L. (1938) . The Evolution of Physics. New York: Simon and Schuster.

Ferguson, E.S. (1981) . History and Historiography, In O. Mayr \& R.C. Post (Eds.) , . Yankee Enterprise: The Rise of the American System of Manufactures (pp. 1-23). Washington, DC: Smithsonian Institution.

Finterbusch, K. \& Wolf, C.P. (Eds.) . Methodology of Social Impact Assessment. Stroudsburg, PA: Hutchinson Ross Publishing.

Forrester, J.W. (1961) . Industrial Dynamics. Cambridge: The M.I.T. Press.

Foucault, M. (1973) . The Birth of the Clinic (A.M. Sheridan Smith, Trans.) . New York: Pantheon Books.

Gibbons, M. \& Gummett, P. (Eds.) . (1984) . Science, Technology, and Society Today. Manchester: Manchester University Press.

Guilmartin, J.F. Jr. (1974) . Gunpowder and Galleys. Cambridge: Cambridge University Press.

Hall, A.R. (1963) . The Changing Technical Act. In C.F. Stover (Eds.), The Technological Order (pp. 117-131) . Detroit: Wayne State University Press.

Hall, R.C. (1977) . Lunar Impact: A History of Project Ranger. Washington, DC: National Aeronautics and Space Administration.

Harris, N. (1981) . The Drama of Consumer Desire, In O. Mayr \& R.C. Post (Eds.), Yankee Enterprise: The Rise of the American System of Manufactures (pp. 186-216) . Washington, DC: Smithsonian Institution. 


\section{APPENDIX A (continued)}

Healy, T. (1976) . Energy and Society. San Francisco: Boyd \& Frase Publishing Company.

Hodges, A. (1983) . Alan Turing: The Enigma. New York: Simon and Schuster.

Houndshell, D.A. (1981) . The System: Theory and Practice, In O. Mayr \& R.C. Post (Eds.) , Yankee Enterprise: The Rise of the American System of Manufactures (pp. 127-152) . Washington, DC: Smithsonian Institution.

How Things Work, Volume 3.

Illinois Institute of Technology. (1968) . Technology in Retrospect and Critical Events in Science (National Science Foundation Report No. C535).

Koenne, W. (1973) . On the Relationship Between Philosophy and Technology in German Speaking Countries, In. G. Bugliarello \& D.B. Doner (Eds.), The History and Philosophy of Technology (pp.38-49). Urbana: The University of Illinios Press.

Koestler, A. (1941) . Darkness at Noon. New York: The Macmillan Company.

Koestler, A. (1968) . The Ghost in The Machine. New York: The Macmillan Company.

Laszlo, E. (Ed.) . (1972) . The Relevance of General Systems Theory. New York: George Braziller.

Leslie, S.T. (1983) . Boss Kettering. New York: Columbia University Press.

Maclaurin, W.R. (1949) . Invention and Innovation in the Radio Industry. New York: Arno Press

Mansfield, E. (1978) . The Economics of Industrial Innovation: Major Questions, State of the Art, and Needed Research, In P. Kelly \& M. Kranzberg (Eds.), Technological Innovation: A Critical Review of Current Knowledge (pp. 194-214). San Francisco: The San Francisco Press.

Mayr, O. (1970) . The Origins of Feedback Control. London: The M.I.T. Press.

Morrison, F.B. (1956) . Feeds and Feeding (22nd ed.) . Clinton, IA: The Morrison Publishing Company.

Mumford, L. (1961) . The City in History. New York: Harcourt, Brace \& World, Inc. 


\section{APPENDIX A (continued)}

Musson, A.E. (1981) . British Origins, In O. Mayr \& R.C. Post (Eds.), Yankee Enterprise: The Rise of the American System of Manufactures (pp. 25-48) . Washington, DC: Smithsonian Institution.

National Resources Committee. (June, 1937) . Technological Trends and National Policy. Washington, DC: Department of the Interior.

Nelson, D. (1981) . The American System and Modern Management, In O. Mayr \& R.C. Post (Eds.) , Yankee Enterprise: The Rise of the American System of Manufactures (pp. 171-187). Washington, DC: Smithsonian Institution.

Randell, B. (Ed.) . (1973) . The Origins of Digital Computers. New York: Springer-Verlag.

Richta, R. (1969) . Civilization at the Crossroads (M. Slingova, Trans.) . Czechoslovakia: International Arts and Sciences, Inc.

Rosenbloom, R.S. (1978) . Technological Innovation in Firms and Industries: An Assestment of the State of the Art. In P. Kelly \& M. Kranzberg (Eds.), Technological Innovation: A Critical Review of Current Knowledge (pp. 215-230). San Francisco: The San Francisco Press.

Rosenstreich, N. (1967) . Technology and Politics, In C. Mtcham \& R. Mackey (Eds.) . (1972) , Philosophy and Technology (pp. 151-160) . New York: The Free Press.

Sellers, G.E. (n.d.) . Early Engineering Reminiscences, 1815-40. Washington: Smithsonian Institution.

Silvern, L.C. (1965) . Systems Engineering of Education. Los Angeles: Education \& Training Consultants Company.

Silvern, L.C. (1972) . Systems Engineering Applied to Training. Houston: Gulf Publishing Company.

Smith, M.R. (1981) . Military Entrepreneurship, In O. Mayr \& R.C. Post (Eds.), Yankee Enterprise: The Rise of the American System of Manufactures (pp. 63-102) . Washington, DC: Smithsonian Institution.

Trachtenberg, A. (1965) . Brooklyn Bridge: Fact and Symbol. New York: Oxford University Press.

Uselding, P. (1981) . Measuring Techniques and Manufacturing Practice, In O. Mayr \& R.C. Post (Eds.), Yankee Enterprise: The Rise of the American System of Manufactures (pp. 103-126) . Washington, DC: Smithsonian Institution. 


\section{APPENDIX A (continued)}

Vitruvius, (1926) . Ten Books on Architecture (M.H. Morgan, Trans.) . Cambridge: Harvard University Press. (n.d.)

Ying-sing, S. (1980) . Exploitation of the Work of Nature (C. Li, Trans.) . Taipei, Taiwan: China Academy. (Original work published in 1637)

Worldwatch Institute. (1984-1997) . The State of the World. Washington, DC: Author. 
APPENDIX B

APPENDIX B

Evaluated Works 


\section{APPENDIX B}

\section{Evaluated Works}

Adkins, B.M. (Ed.) . (1983) . Man and Technology. Suffolk: The St. Edmundsbury Press.

Agricola, G. (1950) . De Re Metallica (H.C. Hoover \& L.H. Hoover, Trans.) . New York: Dover Publications, Inc. (Original work published 1556)

Aitken, H.G.J. (1976) . Syntony and Spark: The Origins of Radio. New York: John Wiley \& Sons.

Aitken, H.G.J. (1985) . The Continuous Wave: Technology and American Radio. Princeton: Princeton University Press.

Alcorn, P.A. (1986) . Social Issues in Technology. Englewood Cliffs: Prentice-Hall, Inc.

Allen, F., Hart, H., Miller, D.C., Ogburn, \& W.F., Nimkoff, M.F. (1957) . Technology and Social Change. New York: Appleton-Century-Crofts Inc.

Ashton, T.S. (1968) . The Industrial Revolution. In J. Burke \& M. Eakin (Eds.) . (1979), Technology and Change (pp. 47-54) . San Francisco: Boyd \& Fraser Publishing.

Barnett, H.G. (1953) . Innovation: The Basis of Cultural Change. New York: McGraw-Hill Book Company.

Beard, C.A. \& Beard, M.R. (1927) . The Rise of American Civilization. New York: The MacMillan Company.

Bell, D. (1973) . The Coming Post-Industrial Society. New York: Basic Book Inc. Publishers.

Berdyaev, N. (1934) . Man aand Machine, In C. Mtcham \& R. Mackey (Eds.) . (1972), Philosophy and Technology (pp. 203-213) . New York: The Free Press.

Bernard, H.R., \& Pelto, P.J., (Eds.) (1972) . Technology and Social Change. New York: The MacMillan Company.

Bertalanffy, L. V. (1968) . General Systems Theory. New York: George Braziller.

Betz, M.J., McGowan, P., \& Wigand, R.T. (Eds.) . (1984) . Appropriate Technology Choice and Development. Durham: Duke Press Policy Studies.

Boorstin, D.J. (1978) . The Republic of Technology. New York: Harper \& Row. 


\section{APPENDIX B (continued)}

Brady, R. (1961) . Organization, Automation \& Society. Berkeley: University of California Press.

Braverman, H. (1974) . Labor and Monopoly Capital. New York: Monthly Review Press.

Bright, J.R. \& Schoeman, M.E.F. (1973) . A Guide to Practical Technological Forecasting. Englewood Cliffs: Prentice-Hall, Inc.

Brown, H., Bonner, J. \& Weir, J. (1957) . The Next Hundred Years. New York: The Viking Press.

Bronowski, J. (1973) . Ascent of Man. Boston: Little, Brown and Company.

Buchanan, R.A. (1968) . The Churches in a Changing World, In C. Mtcham \& R. Mackey (Eds.) . (1972) , Philosophy and Technology (pp. 237-246) . New York: The Free Press.

Buchanan, S. (1963) . Technology as A Sysytem of Exploitation, In C.F. Stover (Eds.), The Technological Order (pp. 151-159) . Detroit: Wayne State University Press.

Bugliarello, G. (1973) . The Engineer and the Historian. In. G. Bugliarello \& D.B. Doner (Eds.) . The History and Philosophy of Technology (pp.50-56). Urbana: The University of Illinios Press.

Bugliarello, G. \& Doner, D.B. (Eds.) . (1973) . The History and Philosophy of Technology. Urbana: The University of Illinois Press.

Bulliet, R.W. (1975) . The Camel and The Wheel. New York: Columbia University Press.

Bunge, M. (1973) . Philosophic Inputs and Outputs of Technology, In. G. Bugliarello \& D.B. Doner (Eds.), The History and Philosophy of Technology (pp.262-281) . Urbana: The University of Illinois Press.

Bunge, M. (1974) . Towards a Philosophy of Technology, In A.C. Michalos (Ed.), Philosophical Problems of Science \& Technology (pp. 28-48). Boston: Allyn \& Bacon Inc.

Burke, J. (1978) . Connections. Boston: Little, Brown and Company.

Burke, J. \& Eakin, M. (Eds.) . (1979) . Technology and Change. San Francisco: Boyd \& Fraser Publishing. 


\section{APPENDIX B (continued)}

Burstyn, H.L. (1973) . What can the History of Technology Contribute? , In. G.

Bugliarello \& D.B. Doner (Eds.), The History and Philosophy of Technology (pp.57-80) . Urbana: The University of Illinios Press.

Butler, S. (1872) . Erewhon. New York: Magnum Books.

Calder, R. (1962) . After the Seventh Day. New York: The New American Library.

Cantril, H. (1950) . The 'Why' of Man's Experience. New York: The MacMillan Company.

Capek, K. (1923) . R.U.R. New York: Samuel French.

Cardwell, D.S.L. (1972) . Turning Points in Western Technology. Canton, MA: Watson Publishing International.

Carson, R. (1962) . Silent Spring. New York: Houghton Mifflin Company.

Caws, P. (1973) . Praxis and Technics, In. G. Bugliarello \& D.B. Doner (Eds.), The History and Philosophy of Technology (pp.227-238). Urbana: The University of Illinios Press.

Childe, V. G. (1936) . Man Makes Himself. New York: The New American Library.

Cipolla, C.M. (1967) . Clocks and Culture. In J. Burke \& M. Eakin (Eds.) . (1979), Technology and Change (pp. 60-67) . San Francisco: Boyd \& Fraser Publishing.

Clarke, W.N. (1963) . Technology and Man: A Christian Vision. In C.F. Stover (Eds.), The Technological Order (pp. 38-58) . Detroit: Wayne State University Press.

Coates, V.T. \& Finn, B. (1979) A Retrospective Technology Assessment: Submarine Telegraphy. San Francisco: San Francisco Press Inc.

Commoner, B. (1972) . The Closing Circle. New York: Alfred A. Knopf.

Compton, D.W. (Ed.). (1967) . The Interaction of Science and Technology. Urbana: University of Illinois Press.

Constant, E.W. (1980) . The Origins of the Turbojet Revolution. Baltimore: The John Hopkins University Press.

Corn, J.J. \& Horrigan, B. (1984) . Yesterday's Tomorrows. New York: Summit Books.

Cowan, R.S. (1983) . More Work for Mother. New York: Basic Books, Inc. 


\section{APPENDIX B (continued)}

Cox, H. (1965) . The Secular City. New York: The MacMillan Company.

Daniels, George H. (1970) . Technological Change and Social Change. In J. Burke \& M. Eakin (Eds.) . (1979), Technology and Change (pp. 161-167) . San

Francisco: Boyd \& Fraser Publishing.

Davis, K. (1974) . The Migrations of Human Populations. In J. Burke \& M. Eakin (Eds.) . (1979) , Technology and Change (pp. 175-185) . San Francisco: Boyd \& Fraser Publishing.

De Camp, L.S. (1963) . The Ancient Engineers. Cambridge: The M.I.T. Press.

de Grazia, S. (1962) . Of Time, Work, and Leisure. New York: The Twentieth Century Fund.

DeGreene, K.B. (Ed.) . Systems Psychology. New York: McGraw-Hill Book Company.

De Gregori, T.R. (1985) . A Theory of Technology. Ames: The lowa State University Press.

Derry, T.K. \& Williams, T.I. (1960) . A Short History of Technology. Cambridge: Oxford University Press.

Dessauer, F. (1927) . Technology in Its Proper Sphere, In C. Mtcham \& R. Mackey (Eds.) . (1972) , Philosophy and Technology (pp. 317-334) . New York: The Free Press.

De Solla Price, D. (1974) . Gears from Greeks. Philadelphia: American Philosophical Society.

DeVore, P. (1980) . Technology: An Introduction. Worcester: Davis Publications.

Donovan, A.L. (1973) . Toward a Social History of Technological Ides: Joesph Black, James Watt and the Separate Condensor. In G. Bugliarello \& D.B. Doner (Eds.) . The History and Philosophy of Technology (pp. 19-30) . Urbana: The University of Illinois Press.

Drucker, P. (1966) . The Technological Revolution and Its Lessons. In J. Burke \& M. Eakin (Eds.) . (1979) , Technology and Change (pp. 39-46) . San Francisco: Boyd \& Fraser Publishing.

Drucker, P. (1967) . Applied Science and Technology. In J. Burke \& M. Eakin (Eds.) . (1979) , Technology and Change (pp. 245-250) . San Francisco: Boyd \& Fraser Publishing. 


\section{APPENDIX B (continued)}

Dubos, R. (1976) . The New Environmental Attitude. In J. Burke \& M. Eakin (Eds.) . (1979) , Technology and Change (pp. 141-144) . San Francisco: Boyd \& Fraser Publishing.

Durbin, P. (Ed.) . A Guide to the Culture of Science Technology and Medicine. New York: The Free Press.

Edge, D. (1973) . Technological Metaphor and Social Control, In. G. Bugliarello \& D.B. Doner (Eds.), The History and Philosophy of Technology (pp.309-323) . Urbana: The University of Illinios Press.

Eisenstein, E. L. (1979) . The Printing Press as an Agent of Change. Cambridge: Cambridge University Press.

Ellul, J. (1964) . The Technological Society (J. Wilkinson, Trans.) . Toronto: Alfred A. Knopf Inc.

Ellul, J. (1977) . The Technological System. New York: The Continuum Publishing Corporation.

Elton, C. (1933) . The Ecology of Animals. New York: John Wiley \& Sons, Inc.

Fagen, M.D. (Ed.) . (1975) . A History of Engineering and Science in the Bell System (Vols. I-VII) . Short Hills, NJ: Bell Telephone Laboratories, Inc.

Fairbairn, W. (1877) . The Engineering Profession. In J. Burke \& M. Eakin (Eds.) . (1979) , Technology and Change (pp. 267-272) . San Francisco: Boyd \& Fraser Publishing.

Feibleman, J.K. (1961) . Pure Science, Applied Science, and Technology: An Attempt at Definitions, In C. Mtcham \& R. Mackey (Eds.) . (1972), Philosophy and Technology (pp. 33-41) . New York: The Free Press.

Feibleman, J.K. (1982) . Technology and Reality. The Hague: Martinus Nijhoff Publishers.

Ferkiss, V.C. (1969) . Technological Man: The Myth and the Reality. New York: George Braziller.

Flexner, J.T. (1944) . Steamboats Come True. New York: The Viking Press.

Florman, S. (1976) . The Existential Pleasures of Engineering. New York: St. Martin's Press.

Forbes, R.J. (1950) . Man The Maker. New York: Henry Schuman. 
APPENDIX B (continued)

Forbes, R.J. (1955) . Studies in Ancient Technology (Vols. I-X) . Leiden, Netherlands: E.J. Brill.

Forrester, J.W. (1968) . Principles of Systems. Cambridge: Wright-Allen Press, Inc.

Forrester, J.W. (1969) . Urban Dynamics. Cambridge: The M.I.T. Press.

Forrester, J.W. (1973) . World Dynamics. Cambridge: Wright-Allen Press, Inc.

Fromm, E. (1968) . The Revolution of Hope: Toward a Humanized Technology. New York: Harper \& Row.

Gabor, D. (1970) . Innovations: Scientific, Technological and Social. London: Oxford University Press.

Galbraith, J.K. (1967) . The New Industrial State. Boston: Houghton Mifflin Company.

Gendron, B. (1977) . Technology and The Human Condition. New York: St. Martin's Press.

Giedion, S. (1948) . Mechanization Takes Command. New York: Oxford University Press.

Gilfillan, S.C. (1935) . The Sociology of Invention. Chicago: Follet Publishing Company.

Gill, E. (1940) . Christianity in the Machine Age, In C. Mtcham \& R. Mackey (Eds.) . (1972) , Philosophy and Technology (pp. 214-236) . New York: The Free Press.

Gimpel, J. (1976) . Environmental Pollution in the Middle Ages. In J. Burke \& M. Eakin (Eds.) . (1979), Technology and Change (pp. 135-140) . San Francisco: Boyd \& Fraser Publishing.

Goodman, P. \& Goodman, P. (1947) . Communitas. Chicago: The University of Chicago Press.

Habakkuk, H.J. (1962) . American and British Technology in the Nineteenth Century. Cambridge: Cambrige University Press.

Hallion, R.P. (Ed.) . The Wright Brothers: Heirs of Prometheus. Washinton, DC: National Air \& Space Museum.

Hardin, G. (1968, December 13) . A Tragedy of the Commons. Science, 162. 1243-1248. 


\section{APPENDIX B (continued)}

Harman, W.W. (1976) . An Incomplete Guide to the Future. San Francisco: San Francisco Press.

Hartner, W. (1963) . The Place of Humanism in a Technological World. In C.F. Stover (Eds.) The Technological Order (pp. 160-169) . Detroit: Wayne State University Press.

Heidegger, M. (1977) . The Question Concerning Technology and Other Essays (W. Lovitt, Trans.) . New York: Harper \& Row.

Heilbonner, R.L. (1967) . Do Machines Make History? . In J. Burke \& M. Eakin (Eds.) . (1979) , Technology and Change (pp. 145-153) . San Francisco: Boyd \& Fraser Publishing.

Helmer, O. (1966) . Social Technology. New York: Basic Books Inc.

Hibbard, W.R. Jr. (1968) . Mineral Resources: Challenge or Threat? . In J. Burke \& M. Eakin (Eds.) . (1979) , Technology and Change (pp. 130-134) . San Francisco: Boyd \& Fraser Publishing.

Highet, G. (1954) . The Migration of Ideas. New York: Oxford University Press.

Hindle, B. (1981) . Emulation and Invention. New York: New York University Press.

Hobsbawm, E.J. (1968) . Industry and Empire. New York: Pantheon Books.

Hostetler, J.A. (1963) . Amish Society. In J. Burke \& M. Eakin (Eds.) . (1979), Technology and Change (pp. 47-54) . San Francisco: Boyd \& Fraser Publishing.

Holley, I.B. Jr. (1953) . Ideas and Weapons. New Haven, CT: Yale University Press.

Hounshell, D.A. (1984) . From the American System to Mass Production 1800-1932. Baltimore: The John Hopkins University.

Hoyle, F. (1956) . Man and Materialism. New York: Harper \& Brothers Publishers.

Hughes, P. (1978) . Inventors: The Problems They Choose, The Ideas They Have, and The Inventions The Make, In P. Kelly \& M. Kranzberg (Eds.), Technological Innovation: A Critical Review of Current Knowledge (pp. 165-182). San Francisco: The San Francisco Press.

Hughes, T.P. (1971) . Elmer Sperry: Inventor and Engineer. Baltimore: The John Hopkins University Press. 
APPENDIX B (continued)

Hughes, T. (1983) . Networks of Power: Electrification in Western Society 1800-1930. Baltimore: The John Hopkins University Press.

Hunter, L.C. (1949) . Steamboats on Western Rivers. Cambridge: Harvard University Press.

Huxley, A. (1932) . Brave New World. New York: Harper \& Brothers Publishers.

Jacobson, H.B. \& Roucek, J.S. (Eds.) . (1959) . Automation and Society. New York: Philosophical Library.

Jarvie, I.C. (1967) . Technology and the Structure of Knowledge, In C. Mtcham \& R. Mackey (Eds.) . (1972), Philosophy and Technology (pp. 54-61) . New York: The Free Press.

Jenkins, R.V. (1975) . Images and Enterprise. Baltimore: The John Hopkins University Press.

Jensen, N.F. (1978) . The Food People Problem, In J. Burke \& M. Eakin (Eds.) . (1979) , Technology and Change (pp. 186-192) . San Francisco: Boyd \& Fraser Publishing.

Jeremy, D.J. (1981) . Transalantic Industrial Revolution: The Diffusion of Textile Technologies Betwen Britian and America, 1790-1830s. Cambridge: The M.I.T. Press.

Jewkes, J. (1958) . The Sources of Invention. New York: MacMillan \& Company, Ltd.

Jonas, H. (1984) . The Imperative of Responsibility. Chicago: University of Chicago Press.

Joravsky, D. (1973) . What Do We Ask of the History of Technology? , In. G. Bugliarello \& D.B. Doner (Eds.), The History and Philosophy of Technology (pp.128-134) . Urbana: The University of Illinios Press.

Josephson, M. (1959) . Edison. New York: McGraw-Hill Book Company.

Jünger, E. (1932) Technology as the Mobilization of the World Through the Gestalt of the Worker, In C. Mtcham \& R. Mackey (Eds.) . (1972), Philosophy and Technology (pp. 269-289). New York: The Free Press.

Jungk, R. (1956) . Brighter than a Thousand Suns (J. Cleugh, Trans.) . New York: Grove Press Inc.

Kahn, H. \& Wiener, A.J. (1967) . The Year 2000. New York: The MacMillan Company. 


\section{APPENDIX B (continued)}

Kash, D.E., White, I.L,.Bergey, K.H., Chartock, M.A., Devine, M.D., Leonard, R.L., Salomon, S.N., \& Young, H.W. (1973) . Energy Under the Oceans. Norman: University of Oklahoma Press.

Kasson, J.F. (1976) .Civilizing the Machine: Technology and Republican Values in America 1776-1900. New York: Grossman Publishers.

Kelly, P. \& Kranzberg, M. (Eds.) . (1978) . Technological Innovation: A critical Review of current Knowledge. San Francisco: San Francisco Press.

Kidder, T. (1982) . The Soul of a New Machine. Boston: Little Brown and Company.

King, H.C. (1955) . The History of the Telescope. Cambridge: Sky Publishing Company.

Klemm, F. (1959) . A History of Western Technology. New York: Charles Scribner's Sons.

Klir, J. \& Valach, M. (1965) Cybernetic Modeling (W.A. Ainsworth, Trans.) . Princeton: London lliffe Books, Ltd.

Kranzberg, M. \& Pursell, C.W. (Eds.) . (1967) . Technology in Western Civilization (Vols. 1-2) . New York: Oxford University Press.

Kuznets, S. (1978) . Technological Innovation and Economic Growth,In P. Kelly \& M. Kranzberg (Eds.) , Technological Innovation: A Critical Review of Current Knowledge (pp. 335-356). San Francisco: The San Francisco Press.

Lambright, W.H. (1976) . Governing Science and Technology. London: Oxford University Press.

Landes, D.S. (1983) . Revolution in Time. Cambridge: The Belknap Press.

Landes, D.S. (1969) . The Unbound Prometheus. Cambridge: Cambridge University Press.

Langrish, J., Gibbons, M., Evans, W.G., \& Jevons, E.R., (1972) . Wealth From Knowledge. New York: John Wiley \& Sons, Inc.

Layton, E.T., Jr. (1971) . The Revolt of the Engineers. Cleveland: The Press of Case Western Reserve University.

Leakey, R.E. (1981) . The Making of Mankind. New York: E.P. Dutton.

Lenin, V.I. (1970) . Imperialism: The Highest Stage of Capitalism. In V.I. Lenin, Collected Works (Vol. 1, pp. 667-763) . Moscow: Progress Publishers. 
Lenski, G. \& Lenski, J. (1974) . Human Societies: An Introduction to Macrosociology (2nd ed.) . New York: McGraw-Hill Book Company.

Leontief, W. (1966) . Input-Output Economics. New York: Oxford University Press.

Lechtman, H. \& Steinberg, A. (1973) . The History of Technology: An Anthropological Point of View, In. G. Bugliarello \& D.B. Doner (Eds.) , The History and Philosophy of Technology (pp.135-162). Urbana: The University of Illinios Press.

Lewis, C.S. (1947) . The Abolition of Man, In C. Mtcham \& R. Mackey (Eds.) . (1972), Philosophy and Technology (pp. 143-150) . New York: The Free Press.

Linder, S. B. (1971) . The Role of Science Policy in Solving Social Problems, In A.C. Michalos (Ed.) , (1974) . Philosophical Problems of Science \& Technology (pp. 516-524) . Boston: Allyn \& Bacon Inc.

Lowrance, W.W. (1976) . Of Acceptable Risk. Los Altos: William Kaufmann, Inc.

Mackenzie, D. \& Wajcman, J. (Eds.) . (1985) . The Social Shaping of Technology. Philadelphia: Open University Press.

Macpherson, C.B. (1967) . Democratic Theory: Ontology and Technology, In C. Mtcham \& R. Mackey (Eds.) . (1972), Philosophy and Technology (pp. 161-170). New York: The Free Press.

Malinowski, B. (1925) . Magic, Science and Religion. Garden City: Doubleday Anchor Books.

Marcuse, H. (1964) . One-Dimensional Man. Boston: Beacon.

Martin, J. (1981) . Telematic Society: A Challenge for Tomorrow. Englewood Cliffs: Prentice-Hall, Inc.

Martino, J.P. (1972) . Technological Forecasting for Decision Making. New York: American Elsevier Publishing Company, Inc.

Marx, K. (1949) . Communist Manifesto. Chicago: Henry Regnery Company. (Original work published 1888)

Marx, K. (1906) . Capital: A Critique of Political Economy (Vol. 1-3, F. Engel, Ed., S. Moore \& E. Aveling, Trans.) . Chicago: Charles H. Kerr \& Company.

Marx, L. (1964) . The Machine in the Garden. New York: Oxford University Press. 


\section{APPENDIX B (continued)}

Mason, O.T. (1915) . The Origins of Invention: A Study of Industry Among Primitive People. London: The Walter Scott Publishing Company.

Mayr, O. \& Post, R.C. (Eds.) . (1981) . Yankee Enterprise: The Rise of the American System of Manufactures. Washington, DC: Smithsonian Institution.

Mazur, A. (1981) . The Dynamics of Technical Controversy. Washington, DC: Communications Press Inc.

McCullough, D. (1972) . The Great Bridge. New York: Simon and Schuster.

McLuhan, M. (1962) . The Gutenberg Galaxy. Toronto: University of Toronto Press.

Mead, M. (1953) . Cultural Patterns and Technical Change. Deventer, Holland: The ljsel Press, Ltd.

Meadows, D.L. (1972) . Limits to Growth. New York: Universe Books, Inc.

Meier, H.A. (1957) . Technology and Democracy 1800-1860. In J. Burke \& M. Eakin (Eds.) . (1979), Technology and Change (pp. 211-213) . San Francisco: Boyd \& Fraser Publishing.

Mesarovic, M., \& Pestel, E. (1974) . Mankind at the Turning Point. New York: E.P. Dutton \& Company, Inc.

Mesthene, E. G. (1967) . Technology and Wisdom, In C. Mtcham \& R. Mackey (Eds.) . (1972) , Philosophy and Technology (pp. 109-115) . New York: The Free Press.

Mesthene, E.G. (1968) . How Technology Will Shape the Future, In C. Mtcham \& R. Mackey (Eds.) . (1972), Philosophy and Technology (pp. 116-129) . New York: The Free Press.

Michalos, A.C. (Ed.) . (1974) . Philosophical Problems of Science \& Technology. Boston: Allyn \& Bacon Inc.

Miernyk, W.H. (1955, August 4) . Men, Machines, and Electronic Brains. The Commercial and Financial Chronicle 182, 9-27.

Mirsky, J. \& Nevins, A. (1952) . The World of Eli Whitney. New York: The MacMillan Company.

Mitcham, C. (1973) . Philosophy and the History of Technology, In. G. Bugliarello \& D.B. Doner (Eds.), The History and Philosophy of Technology (pp.163-201) . Urbana: The University of Illinios Press. 
Mitcham, C \& Mackey, R. (Eds.) . (1972) . Philosophy and Technology. New York: The Free Press.

Morison, E.E. (1966) . Men, Machines, and Modern Times. Cambridge: The M.I.T. Press.

Morison, E. (1975) . From Know-How to Nowhere. New York: Basics Books, Inc.

Morley, S.G. (1956) . The Ancient Maya (Rev. ed.) . Standford: Standford University Press. (Original work published in 1946)

Morton, J.A. (1971) . Organizing for Innovation. New York: The McGraw-Hill Book Company.

Mumford, L. (1934) . Technics and Civilization. Orlando, Harcourt, Brace \& Company.

Mumford, L. (1951) . Art and Technics. New York: Columbia University Press.

Mumford, L. (1964) . The Myth of the Machine: The Pentagon of Power. New York: Harcourt, Brace Jovanovich, Inc.

Mumford, L. (1970) . The All-Seeing Eye. In J. Burke \& M. Eakin (Eds.) . (1979), Technology and Change (pp. 65-67) . San Francisco: Boyd \& Fraser Publishing.

Noble, D. (1977) . America by Design. New York: Alfred A. Knopf.

Noble, D.F. (1984) . Forces of Production. New York: Alfred A. Knopf.

Ogburn, W.F. (1946) . The Social Effects of Aviation. New York: Houghton Mifflin Company.

Ogburn, W.F. (1964) . Technology as Environment. In J. Burke \& M. Eakin (Eds.) . (1979), Technology and Change (pp. 154-160). San Francisco: Boyd \& Fraser Publishing.

Oliver, J. W. (1956) . History of American Technology. New York: The Ronald Press Company.

Ortega y Gasset, J. (1939) . Thoughts on Technology, In C. Mtcham \& R. Mackey (Eds.) . (1972) , Philosophy and Technology (pp. 290-313) . New York: The Free Press.

Orwell, G. (1984) . 1984. New York: Harcourt.

Pacey, A. (1974) . The Maze of Ingenuity. Cambridge: The M.I.T. Press. 


\section{APPENDIX B (continued)}

Pacey, A. (1983) . The Culture of Technology. Cambridge: The M.I.T. Press.

Papanek, V. (1972) . Design for the Real World. New York: Random House.

Petroski, H. (1985) . To Engineer is Human. New York: St. Martin's Press.

Pirsig, R.M. (1974) . Zen and the Art of Motorcycle Maintenance. New York: William Morrow \& Company.

Popkin, R. (1971) . Technology of Necessity: Scientific and Engineering Development in Israel. New York: Praeger Publishers.

Porter, A.L., Rossini, F.A., Carpenter, S.R., Roper, A.T., Larson, R.W., \& Tiller, J.S. (1980) . A Guidebook for Technology Assessment and Impact Analysis. New York: North Holland.

Prentis, S. (1984) . Biotechnology: A New Industrial Revolution. New York: George Braziller, Inc.

Price, D. (1965) . The Scientific Estate. London: Oxford University Press.

Pynchon, T. (1973) . Gravity's Rainbow. New York: The viking Press, Inc.

Pytlik, E.C., Lauda, D.P. \& Johnson, D.L. (1985) . Technology, Change and Society. Albany: Delmar Publishers, Inc.

Ramo, S. (1969) . The Systems Approach. In J. Burke \& M. Eakin (Eds.) . (1979) . Technology and Change (pp. 47-54) . San Francisco: Boyd \& Fraser Publishing.

Ramo, S. (1983) . What's Wrong with Our Technological Society and How to Fix It. New York: McGraw-Hill Book Company.

Rapp, F. (1981) . Analytical Philosophy of Technology (S.R. Carpenter \& T. Langenbruch, Trans.) . Boston: D. Reidel Publishing Company.

Ravetz, J.R. (1971) . Social Problems of Industrialized Science. In J. Burke \& M. Eakin (Eds.) . (1979), Technology and Change (pp. 262-266) . San Francisco: Boyd \& Fraser Publishing.

Ribeiro, D. (1968) . The Civilizational Process (B.J. Meggers, Trans.) . Washington, DC: Smithsonian Institution Press.

Rifkin, J. (1983) . Algeny. New York: The Viking Press. 


\section{APPENDIX B (continued)}

Rosenberg, N. (1972) . Technology and Resource Endowment. In J. Burke \& M. Eakin (Eds.) . (1979), Technology and Change (pp. 126-129) . San Francisco: Boyd \& Fraser Publishing.

Rosenberg, N. (1973) . Technology, Economy and Values. In. G. Bugliarello \& D.B. Doner (Eds.), The History and Philosophy of Technology (pp.81-111) . Urbana: The University of Illinios Press.

Rosenberg, N. (1978) . Technological Innovation and Natural Resources: The Niggardliness of Nature Reconsidered. In P. Kelly \& M. Kranzberg (Eds.), Technological Innovation: A Critical Review of Current Knowledge (pp. 183-198). San Francisco: The San Francisco Press.

Rosenberg, N. (1981). Why in America? , In O. Mayr \& R.C. Post (Eds.), Yankee Enterprise: The Rise of the American System of Manufactures (pp. 49-61) . Washington, DC: Smithsonian Institution.

Roszak, T. (1972) . Where The Wasteland Ends. New York: Doubleday \& Company.

Ruthven, K. (1983) . Society and the New Technology. Cambridge: Cambridge University Press.

Sagan, C. (1977) . The Dragons of Eden. New York: Random House.

Sahal, D. (1981) . Patterns of Technological Innovation. Reading, MA: Addison-Wesley Publishing Company, Inc.

Sale, K. (1980) . Human Scale. New York: Coward, McCann \& Geoghegan.

Sarton, G. (1959) . A History of Science. Cambridge: Harvard University Press.

Schmookler, J. (1966) . Invention and Economic Growth. Cambridge: Harvard University Press.

Schofield, R.E. (1963) . The Lunar Society of Birminghan. Oxford: The Clarendon Press.

Schon, D.A. (1967) . Technology and Change. New York: Delacorte Press.

Schumacher, E.F. (1973) . Small is Beautiful. New york: Harper \& Row Publishers.

Segal, H. (1985) . Technological Utopianism in American Culture. Chicago: The University of Chicago Press. 
APPENDIX B (continued)

Shelley, M. (1994) . Frankenstein (3rd ed.) . New York: Dover Publications, Inc.

(Original work published in 1831)

Simon, H. (1977) . What Computers Mean For Man and Society. In J. Burke \& M. Eakin (Eds.) . (1979), Technology and Change (pp. 68-76). San Francisco: Boyd \& Fraser Publishing.

Simon, Y.R. (1951) . Pursuit of Happiness and Lust for Power in Technological Society, In C. Mtcham \& R. Mackey (Eds.) . (1972), Philosophy and Technology (pp. 171-186). New York: The Free Press.

Sinclair, B. (1980) . A centennial History of the American Society of mechanical Engineers: 1880-1980. Toronto: University of Toronto Press.

Singer, C., Holmyard, E.J., Hall, A.R., Williams, T.I. (Eds.) . (1954) . A History of Technology (Vol. I-V) . Oxford: Clarendon Press.

Singer, H. (1977) . Technologies for Basic Needs. Geneva: International Labour Office.

Skolimowski, H. (1966). Structure of Thinking in Technology, In C. Mtcham \& R. Mackey (Eds.) . (1972), Philosophy and Technology (pp. 42-49) . New York: The Free Press.

Skolimowski, H. (1973). Philosophy of Technology as a Technology of Man, In. G. Bugliarello \& D.B. Doner (Eds.), The History and Philosophy of Technology (pp.325-336) . Urbana: The University of Illinios Press.

Slaby, S. (1973) . What Should We Ask of the History of Technology? , In. G. Bugliarello \& D.B. Doner (Eds.), The History and Philosophy of Technology (pp.112-127) . Urbana: The University of Illinios Press.

Smiles, S. (1905) . Lives of the Engineers (Vol. I-V) . New York: Charles Scribner's Sons.

Smith, C.S. (1973) . Remarks on the Discovery of Techniques and on Sources for The Study of Their History. In. G. Bugliarello \& D.B. Doner (Eds.), The History and Philosophy of Technology (pp. 31-37). Urbana: The University of Illinios Press.

Smith, M.R. (1977) . Harper's Ferry Armory and the New Technology. Ithaca: Cornell University Press.

Snow, C.P. (1959) . Two Cultures and The Scientific Revolution. New York: Cambridge University Press. 


\section{APPENDIX B (continued)}

Stover, C.F. (Ed.) . (1963) . The Technological Order. Detroit: Wayne State University Press.

Sun, E.Z. (1973) . Chinese History of Technology: Some Points for Comparison with the West. In. G. Bugliarello \& D.B. Doner (Eds.), The History and Philosophy of Technology (pp.38-49) . Urbana: The University of Illinios Press.

Susskind, C. (1973) . Understanding Technology. Baltimore: The John Hopkins University Press.

Susskind, C. \& Zybkow, M. (1978) . Ecology of Innovation, Douds, C.F. \& Rubenstein, A.H. (1978) . Review and Assestment of the Methodology Used to Study Behavioral Aspects of Innovation Process. In P. Kelly \& M. Kranzberg (Eds.), Technological Innovation: A Critical Review of Current Knowledge (pp. 1-164) . San Francisco: The San Francisco Press.

Svensson, F. (1973) . The Technological Challenge to Political Theory, In. G. Bugliarello \& D.B. Doner (Eds.), The History and Philosophy of Technology (pp.294-307) . Urbana: The University of Illinios Press.

Teich, A. (Ed.) . (1972) . Technology and Man's Future. New York: St. Martin's Press.

Toffler, A. (1970) . Future Shock. New York: Random House.

Tsipis, K. (1983) . Arsenal: Understanding Weapons in the Nuclear Age. New York: Simon and Schuster.

Ure, A. (1861) . Philosophy of Manufactures. New York: Burt Kranklin.

Usher, A.P. (1988) . A History of Mechanical Inventions (Rev. ed.) . New York: Dover Publications, Inc.

Van Melsen, A. (1961) . Science and Technology. Pittsburgh: Duquesne University Press.

Vonnegut, K. (1952) . Player Piano. New York: Holt, Rinehart \& Winston, Inc.

Wagar, J.A. (1970) . Growth Versus the Quality of Life. In J. Burke \& M. Eakin (Eds.) . (1979) , Technology and Change (pp. 214-221) . San Francisco: Boyd \& Fraser Publishing.

Wallace, A. F. (1978) . Rockdale. New York: Alfred A. Knopf.

Watson-Watt, R. (1963) . Technology in the Modern World. In C.F. Stover (Eds.) (pp. 1-9) . Detroit: Wayne State University Press. 
Weaver, R.M. (1970) . Humanism in the Age of Science and Technology, In C. Mtcham \& R. Mackey (Eds.) . (1972), Philosophy and Technology (pp. 136-142) . New York: The Free Press.

White, L., Jr. (1962) . Medieval Technology and Social Change. London: Oxford University Press.

White, L., Jr. (1968) . Machina Ex Deo. Cambridge: The M.I.T. Press.

Wiener, N. (1950) . The Human Use of Human Beings. Garden City: Doubleday \& Company, Inc.

Winner, L. (1986) . The Whale and the Reactor. Chicago: The University of Chicago Press.

Winner, L. (1977) . Autonomous Technology. Cambridge: The M.I.T. Press.

Wojick, D. (1973) . The Structure of Technological Revolutions, In. G. Bugliarello \& D.B. Doner (Eds.), The History and Philosophy of Technology (pp.238-261) . Urbana: The University of Illinios Press.

Zaheer, S.H. (1967) . India's Need for Advanced Science and Technology. In J. Burke \& M. Eakin (Eds.) . (1979), Technology and Change (pp. 193-197) . San Francisco: Boyd \& Fraser Publishing.

Ziman, J. (1968) . What is Science?, In A.C. Michalos (Ed.) . (1974), Philosophical Problems of Science \& Technology (pp. 5-27). Boston: Allyn \& Bacon Inc.

Zvorikine, A. (1963) . Technology and the Laws of Its Development. In C.F. Stover (Eds.), The Technological Order (pp. 59-81) . Detroit: Wayne State University Press. 


\section{APPENDIX C}

\section{APPENDIX C}

Authors by Discipline 


\section{APPENDIX C}

Authors by Discipline

Anthropology

Barnett, H.G.

Hostetler, J.A.

Lechtman, H. \& Steinberg, A.

Mead, M.

Wallace, A.F..

Bernard, H. R. \& Pelto, P.S.

Leakey, R.E.

Malinowski, B.

Ribeiro, D.

Architecture

Giedon, S.

Papanek, V.

Goodman, P. \& Goodman, P.

\section{Business \& Economics}

Brady, R. A.

De Gregori, T.R.

Galbraith, J.K.

Jacobson, H. B. \& Roucek, J. S.

Kuznets, S.

Linder, S.B.

Max, K.

Rosenberg, N.

Schumacher, E.F.
Braverman, $\mathrm{H}$.

Drucker, $\mathrm{P}$.

Heilbonner, R. L.

Jewkes, J.

Leontief, W.

Marx, K. \& Engels F.

Miernyk, W.H.

Schmookler, J.

Singer, Hans

\section{Education}

DeVore, $\mathrm{P}$.

Pytlik, E.C. Lauda, D.P. \& Johnson, D.L.

\section{Engineering}

Adkins, Bruce M.

Betz, M.J., McGowan, P. and Wigand, R.T. Fairbairn, W. S.

Forrester, Jay W.

Harman, Willis W.

Martin, James

Mason, Otis T.
Bright, J.R. \& Schoeman, M.E.F.

Fagen, M.D., et.al.

Florman, S.

Gabor, D.

Klir, J. \& Valach, M.

Martino, Joesph P.

Meadows, Dennis L. 


\section{APPENDIX C (continued)}

\section{Engineering (continued)}

Morton, J.A.

Ramo, $S$

Susskind, C. \& Zybkow, M.

Watson-Watt, S. R.
Petroski, H.

Sahal, D.

Susskind, C.

History

Aitken, Hugh G.J.

Beard, C. A. \& Beard, M., R.

Bugliarello, G.

Burke, J. \& Eakin, M. C.

Childe, V. G.

Constant, E. W. III

Cowan, R. S.

De Solla P., D.

Donovan, A. L.

Gimpel, J.

Hallion, R.P.

Hindle, Brooke

Holley, I.B. Jr.

Hughes, T. P.

Jenkins, R. V.

Joravsky, D.

Kelly, P. \& Kranzberg, M.

Klemm, F.

Landes, D. S.

Mayr, O. \& Post, R. C.

Meier, H. A.

Morison, E.

Noble, D. F.

Roszak, T.

Schofield, R. E.

Sinclair, B.

Smith, C. S.

Sun, E-tu Zen

White, L. Jr.
Ashton, T.S.

Boorstin, D. J.

Bulliet, R. W.

Burstyn, H. L.

Cipolla, C. M.

Corn, J. J. \& Horrigan, B.

Daniels, G. H.

Derry, T.K. \& Williams, T.I.

Eisenstein, E. L.

Habakkuk, H.J.

Hartner, W.

Hobsbawm, E.J.

Hounshell, D. A.

Hunter, L. C.

Jeremy, D. J.

Kasson, J. F.

King, H. C.

Kranzberg, M. \& Pursell, C.W.

Layton, E. T. Jr.

Mazur, A.

Mirsky, J. \& Nevins, A.

Mumford, L.

Oliver, J. W.

Sarton, G.

Segal, $\mathrm{H}$.

Singer, C, Holmyard, E.J., Hall, A.R.

Smith, M. R.

Usher, A. P.

Zvorikine, A. 
APPENDIX C (continued)

\section{Literature}

Burke, J.

Marx, L.

Morley, S. G.

Bronowski, J.

Kahn, H. \& Wiener, A. J.

Ravetz, J. R.

Wiener, N.

Agricola, G.

Carson, R.

Elton, C.

Rifkin, J.

Bunge, $M$.

Durbin, $P$.

Gendron, B.

Jonas, $\mathrm{H}$.

Mesthene, E.G.

Ortega y Gasset, J.

Rapp, F.

Simon, Yves R.

Van Melsen, A.
Highet, G.

McLuhan, $M$.

Weaver, R. M.

Mathematics

Helmer-Hirshberg, $\mathrm{O}$.

Mesarovic, M. \& Pestel, E.

Ruthven, K.

Natural Science

Philosophy

Bertalanffy, L. V.

Commoner, B.

Hardin, G.

Wagar, J. A.

Caws, $P$.

Feibleman, J. K.

Heidegger, M.

Marcuse, $\mathrm{H}$.

Mitcham, C.

Pirsig, R.

Schon, D. A.

Skolimowski, $\mathrm{H}$.

Physical Science

Brown, H., Bonner, J. \& Weir, J.

Calder, R.

Cardwell, D.S.L.

Compton, D. W.

Dessauer, F.

Forbes, R.J.

Dubos, R.

Hoyle, F.

Jensen, N. F.

Jungk, $R$

Lowrance, W. W.

Pacey, A.

Prentis, S.

Sagan, C. 
APPENDIX C (continued)

Physical Science (continued)

Snow, C.P.

Ure, A.

Ziman, J.

Buchanan, S. de Grazia, S.

Junger, $\mathrm{E}$.

Lambright, W. H.

Macpherson, C.B.

Stover, C. F.

Winner, L.

Allen, F. et.al.

Cantril, $\mathrm{H}$.

De Greene, Kenyon B.

Fromm, Erich

Lenski, G. \& Lenski, J.

Ogburn, W.F.
Tsipis, $\mathrm{K}$.

Zaheer, S. H.

Langrish, J. et. al..

\section{Political Science}

Coates, Vary T. \& Finn, B.

Ferkiss, V. C.

Kash, D.E. White, I.L. Bergey, K.H.

Lenin, V.I.

Price, D. K.

Svensson, F.

Social Science \& Psychology

Bell, D.

Davis, K.

Ellul, J.

Gilfillan, S.C.

Mackenzie, D. \& Wacjman, J.

Simon, H. A.

Technology \& Society

Alcorn, P. A.

Slaby, $S$.

Porter, A. L., et. al.

Teich, A.

Theology

Berdyaev, N.

Clarke, W. N.

Gill, E.

Buchanan, R.A.

Cox, $\mathrm{H}$.

Lewis, C.S.

Writer

Butler, S.

Capek, K.

De Camp, L. S. 


\section{APPENDIX C (continued)}

Writer (continued)

Huxley, A.

Kidder, T.

Popkin, R.

Sale, K.

Smiles, S.

Vonnegut, K.
Josephson, M.

Orwell, G.

Pynchon, T.

Shelley, M.

Toffler, A. 


\section{APPENDIX D}

\section{APPENDIX D}

Concepts by Discipline 
Concept by Discipline

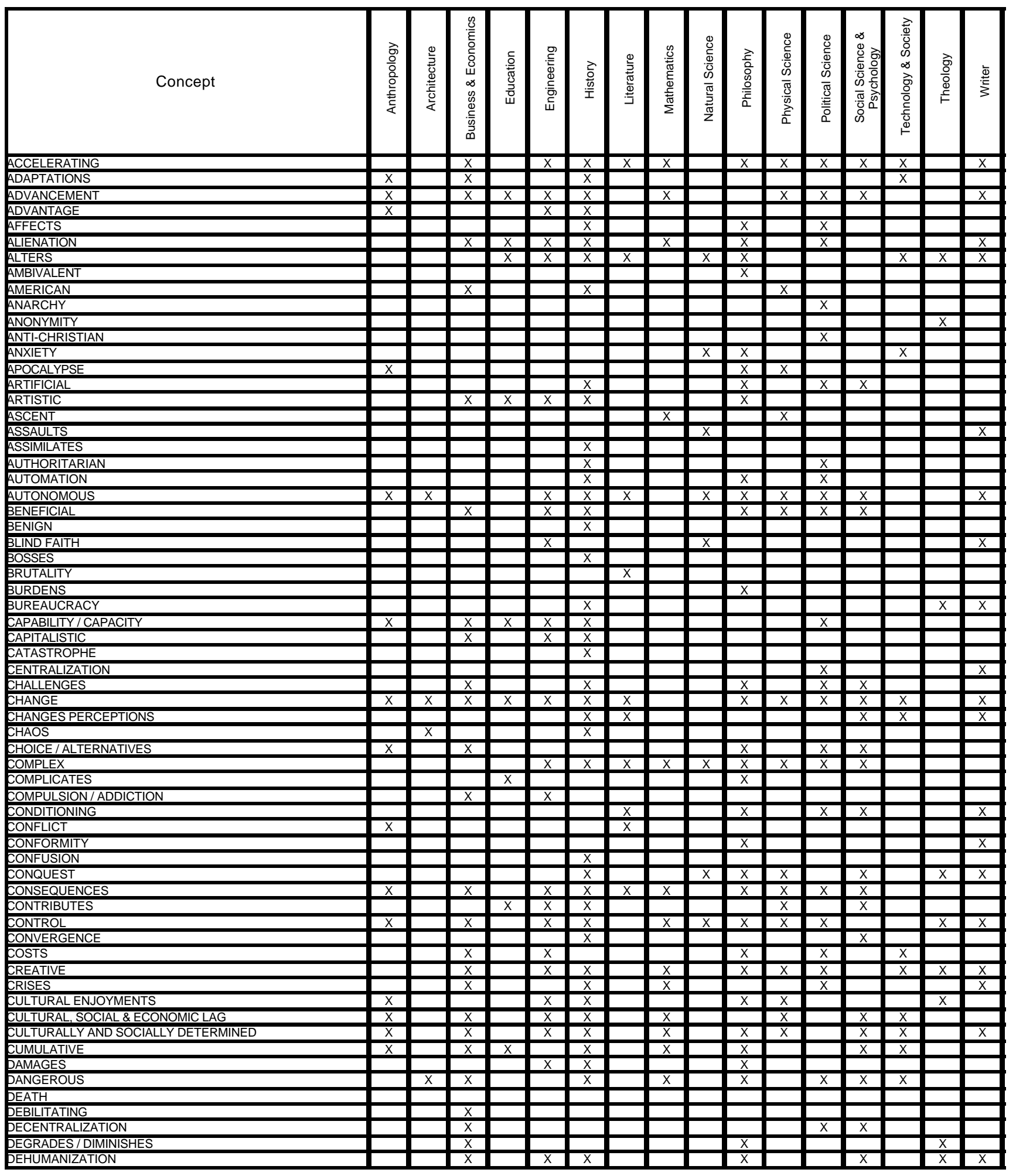




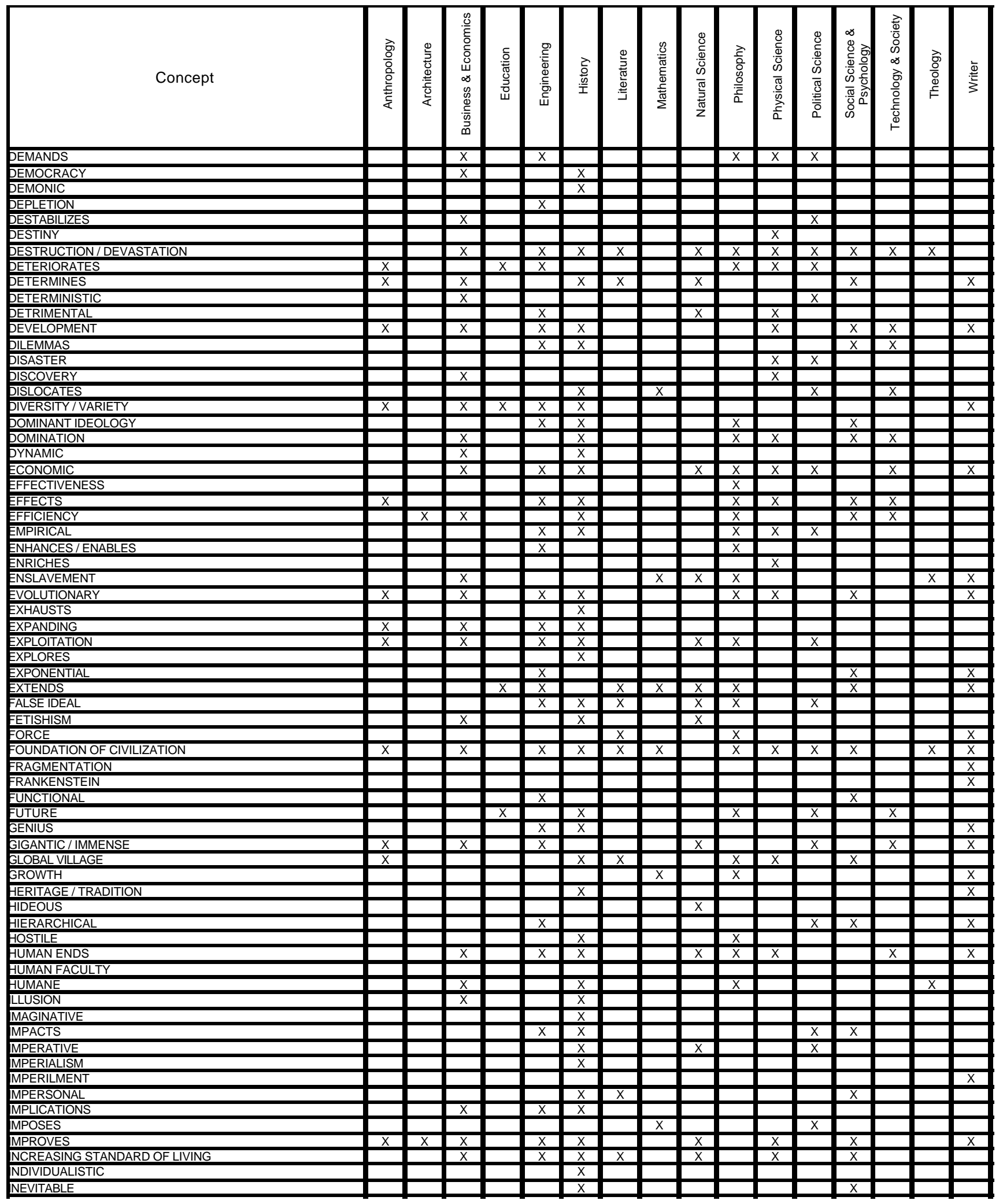




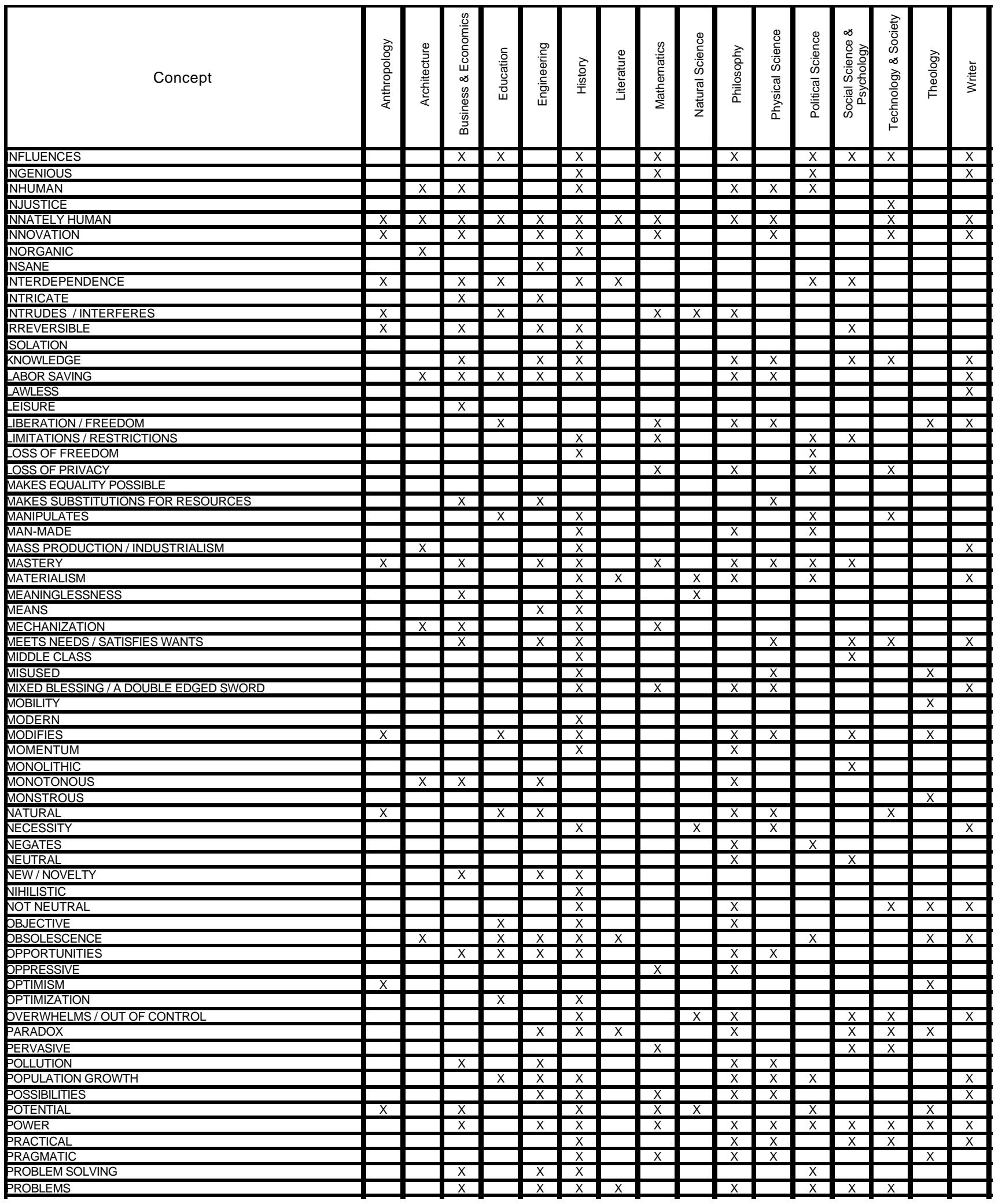




$$
\text { APPENDIX D (continued) }
$$

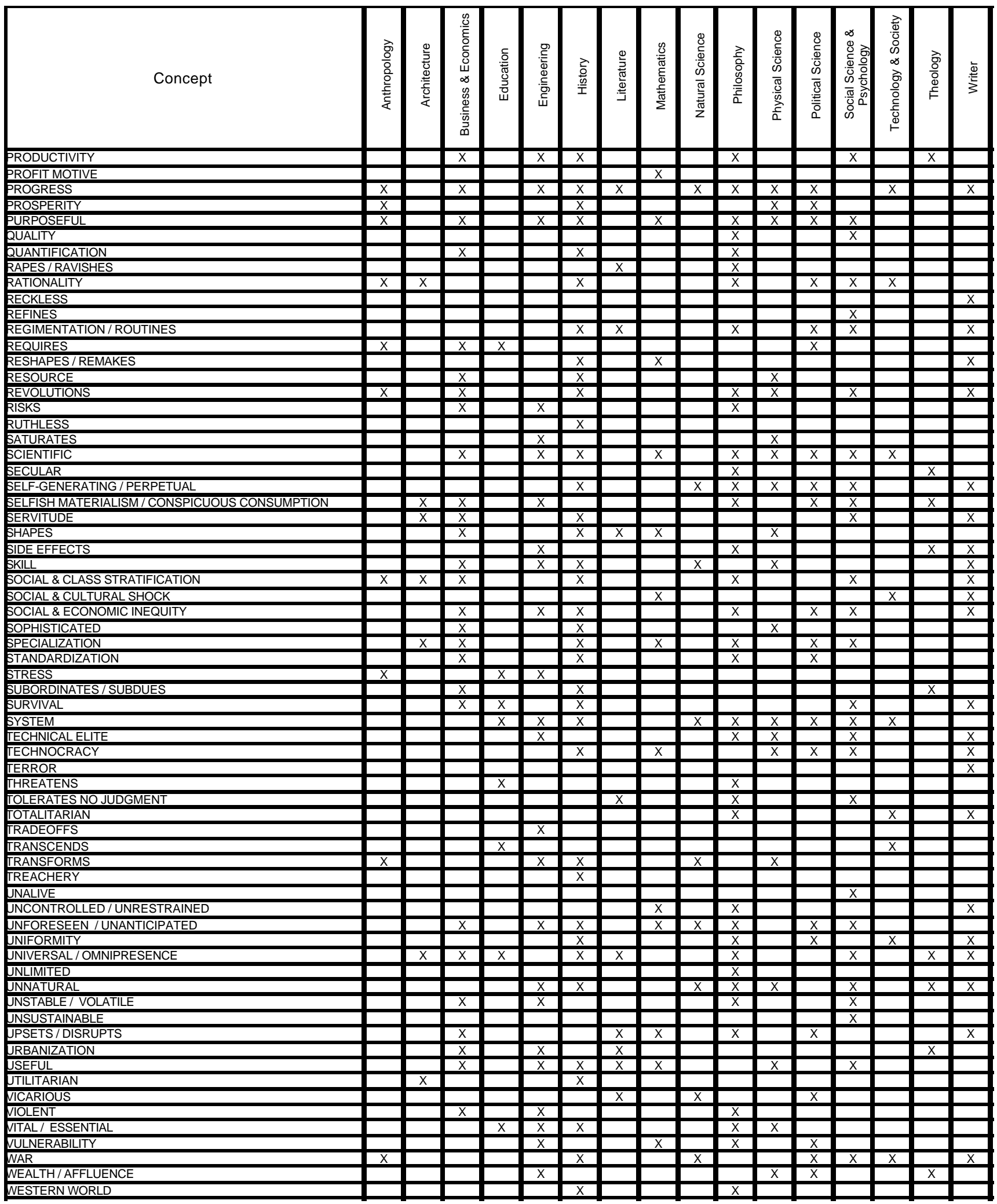




\section{APPENDIX D (continued)}

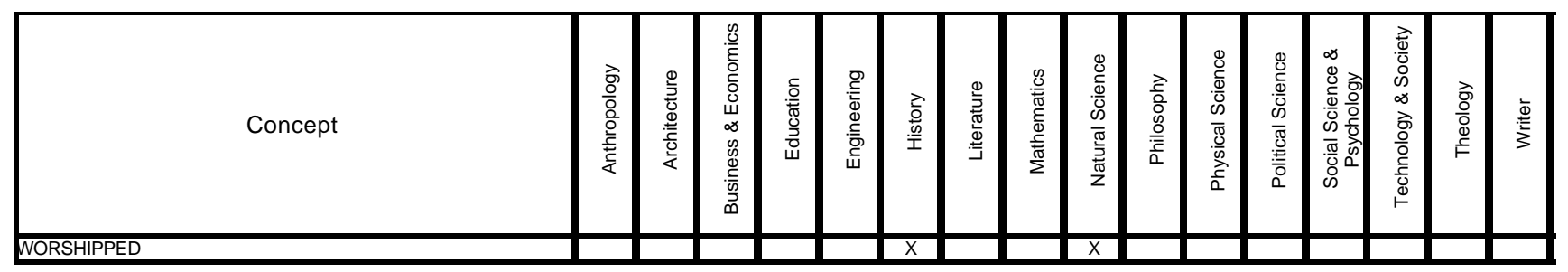




\section{APPENDIXE}

\section{APPENDIX E}

Semantic Differential Instrument 


\title{
APPENDIX E
}

\section{A SEMANTIC DIFFERENTIAL SURVEY OF CONCEPTS}

\author{
In Support of the Doctoral Dissertation of \\ Bryan C. Maser \\ West Virginia University \\ Department of Advanced Educational Studies \\ Technology Education Program \\ 1998
}




\section{APPENDIX E (continued)}

\section{Instructions and Purpose of the Study}

The purpose of this study is to measure the meanings of certain concepts to various individuals by having them judge concepts against a series of descriptive scales. In taking this test please make your judgments on the basis of what these concepts mean to you. On each page of this booklet you will find a different concept to be judged and beneath it a set of scales. You are to rate the concept on each of these scales in order.

Here is how you are to use these scales:

If you feel that the concept at the top of the page is very closely related to one end of the scale you should place your check-mark as follows:
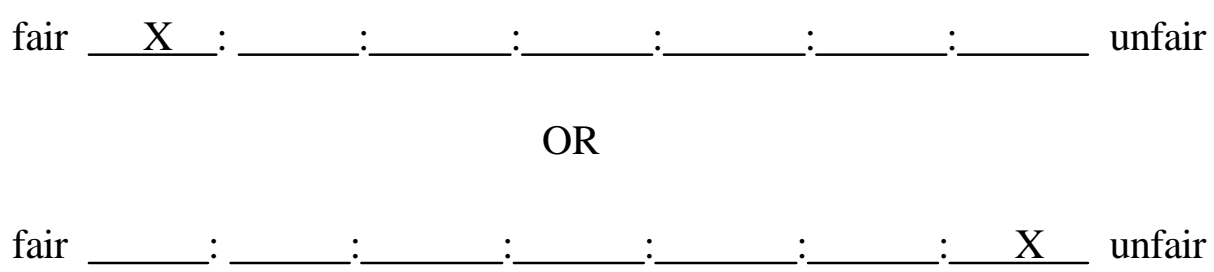

If you feel that the concept is quite closely related to one or the other end of the scale (but not extremely), you should place your check-mark as follows:
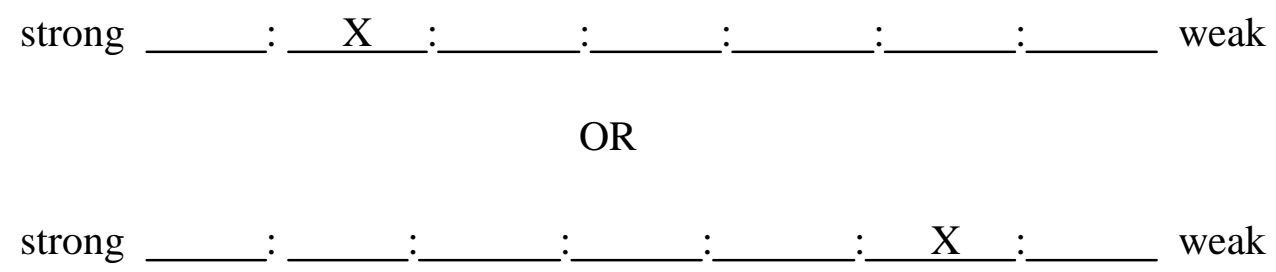

If the concept seems only slightly related to one side as opposed to the other side (but is not really neutral), then you should check as follows:

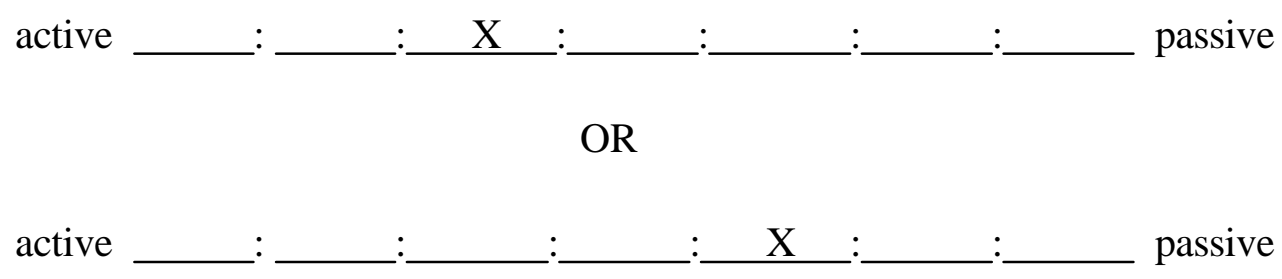

The direction toward which you check, of course, depends upon which of the two ends of the scale seem most characteristic of the concept you are judging. If you consider the concept to be neutral on the scale, both sides of the scale equally associated with the concept, then you should place your check-mark in the middle space: 


\section{APPENDIX E (continued)}

safe $: \quad: \quad: \quad X \quad:$ dangerous

IMPORTANT: (1) Place your check-marks in the middle of spaces, not on the boundaries:

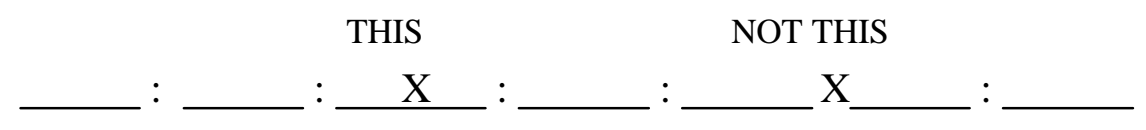

(2) Be sure you check every scale for every concept -- do not omit any.

(3) Never put more than one check-mark on a single scale.

Sometimes you may feel as though you have had the same item before on the test. This will not be the case, so do not look back and forth through the items. Do not try to remember how you checked similar items earlier in the test. make each item a separate and independent judgment. Work at fairly high speed through this test. Do not worry or puzzle over individual items. It is your first impressions, the immediate "feelings" about the items, that we want. On the other hand, please do not be careless, because we want your true impressions.

DEMOGRAPHIC INFORMATION

1. What is your age? (YEARS)

2. Your sex? (Fill in corresponding $O$ )

O FEMALE

O MALE

3. Highest level of educational attainment? (Fill in corresponding $O$ )

O DOCTORATE DEGREE OR HIGHER

O MASTER'S DEGREE

O BACHELOR'S DEGREE 


\section{ABSTRACTIONS}

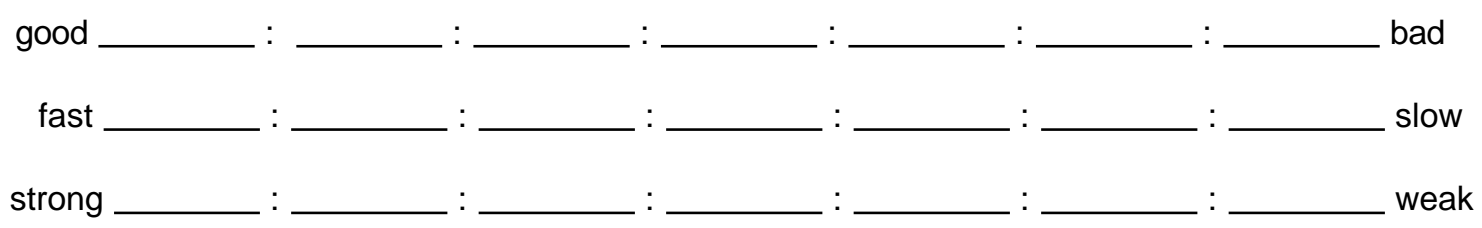

ACCELERATING
good
:
: bad
fast

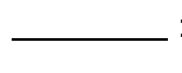
: slow
strong
:
: weak

\section{ACCOMPLISHMENT}

good

?

: bad

fast :

: slow

strong : : weak

\section{ACHIEVEMENT}
good
:
:
: bad
fast
:
: slow
strong
:
:
: weak

\section{ADAPTATIONS}
good
:
:
bad
fast
:
:
: slow strong : : weak 
APPENDIX F

\section{APPENDIX F}

Concept Mean Scores by Semantic Factor 
Concept Mean Scores By Semantic Factor

\begin{tabular}{|c|c|c|c|}
\hline Concept & 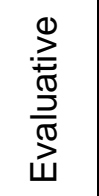 & 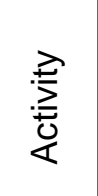 & $\begin{array}{l}\text { তे } \\
\frac{c}{0} \\
\stackrel{0}{0} \\
0\end{array}$ \\
\hline ACCELERATING & 0.59 & 1.94 & 1.50 \\
\hline ADAPTATIONS & 1.74 & -0.35 & 1.21 \\
\hline ADVANCEMENT & 2.00 & 0.53 & 1.65 \\
\hline ADVANTAGE & 1.76 & 0.71 & 1.68 \\
\hline AFFECTS & 0.29 & -0.09 & 0.32 \\
\hline ALIENATION & -1.97 & -0.41 & 0.09 \\
\hline ALTERS & 0.26 & -0.12 & 0.18 \\
\hline AMBIVALENT & -1.15 & -0.71 & -0.68 \\
\hline AMERICAN & 1.53 & 1.03 & 1.82 \\
\hline ANARCHY & -2.38 & 0.29 & 0.06 \\
\hline ANONYMITY & 0.00 & -0.32 & -0.26 \\
\hline ANTI-CHRISTIAN & -1.94 & 0.12 & 0.21 \\
\hline ANXIETY & -1.41 & 0.18 & 0.21 \\
\hline APOCALYPSE & $\begin{array}{l}-1.41 \\
\end{array}$ & 0.65 & 0.79 \\
\hline ARTIFICIAL & -0.82 & 0.03 & -0.38 \\
\hline ARTISTIC & 2.18 & -0.65 & 0.68 \\
\hline ASCENT & 1.35 & 0.18 & 1.18 \\
\hline ASSAULTS & -2.53 & 1.18 & 0.79 \\
\hline ASSIMILATES & 1.24 & -0.47 & 0.71 \\
\hline AUTHORITARIAN & -1.15 & 0.41 & 1.09 \\
\hline AUTOMATION & 0.56 & 1.59 & 1.00 \\
\hline AUTONOMOUS & 0.82 & 0.18 & 1.00 \\
\hline BENEFICIAL & 2.38 & 0.29 & 1.47 \\
\hline BENIGN & 0.97 & -0.32 & -0.06 \\
\hline BLIND FAITH & -1.26 & 0.38 & -0.12 \\
\hline BOSSES & -0.62 & 0.00 & 0.76 \\
\hline BRUTALITY & -2.91 & 0.85 & 1.00 \\
\hline BURDENS & -1.44 & -0.53 & 0.41 \\
\hline BUREAUCRACY & -1.18 & -1.26 & 0.09 \\
\hline CAPABILITY / CAPACITY & 1.29 & 0.38 & 1.12 \\
\hline CAPITALISTIC & 0.50 & 0.79 & 1.12 \\
\hline CATASTROPHE & -2.65 & 1.82 & 1.32 \\
\hline CENTRALIZATION & -0.47 & -0.41 & 0.38 \\
\hline CHALLENGES & 2.03 & 0.53 & 1.44 \\
\hline CHANGE & 1.15 & 0.06 & 0.76 \\
\hline CHANGES PERCEPTIONS & 0.82 & -0.97 & 0.29 \\
\hline CHAOS & -2.18 & 0.94 & 0.65 \\
\hline CHOICE / ALTERNATIVES & 2.21 & 0.06 & 1.26 \\
\hline COMPLEX & 0.41 & -0.47 & 0.59 \\
\hline
\end{tabular}


APPENDIX F (continued)

Concept Mean Scores By Semantic Factor

\begin{tabular}{|c|c|c|c|}
\hline Concept & 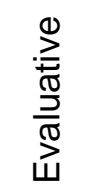 & 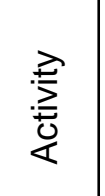 & $\begin{array}{l}\text { তे } \\
\frac{c}{0} \\
\stackrel{0}{0} \\
0\end{array}$ \\
\hline COMPLICATES & -1.03 & -0.41 & 0.03 \\
\hline COMPULSION / ADDICTION & -2.35 & -0.32 & -0.06 \\
\hline CONDITIONING & 0.21 & -0.71 & 1.03 \\
\hline CONFLICT & -0.76 & 0.03 & 0.59 \\
\hline CONFORMITY & -0.88 & -0.47 & -0.32 \\
\hline CONFUSION & -1.74 & -0.44 & -0.50 \\
\hline CONQUEST & -0.50 & 0.65 & 1.44 \\
\hline CONSEQUENCES & -0.21 & -0.12 & 0.59 \\
\hline CONTRIBUTES & 1.88 & \begin{tabular}{|c|}
-0.18 \\
\end{tabular} & 1.29 \\
\hline CONTROL & -0.06 & 0.03 & 1.21 \\
\hline CONVERGENCE & 0.85 & -0.41 & 0.41 \\
\hline COSTS & -0.26 & 0.06 & 0.68 \\
\hline CREATIVE & 2.59 & -0.03 & 1.47 \\
\hline CRISES & -1.59 & 1.26 & 1.09 \\
\hline CULTURAL ENJOYMENTS & 1.88 & -0.03 & 0.97 \\
\hline CULTURALLY AND SOCIALLY DETERMINED & -0.06 & -0.62 & 0.74 \\
\hline CULTURAL, SOCIAL \& ECONOMIC LAG & -1.44 & -1.38 & -0.71 \\
\hline CUMULATIVE & 0.41 & -0.38 & 0.62 \\
\hline \begin{tabular}{|l|} 
DAMAGES \\
\end{tabular} & -2.38 & 0.76 & 0.62 \\
\hline DANGEROUS & -2.24 & 0.85 & 1.29 \\
\hline DEATH & -1.17 & 0.17 & 0.51 \\
\hline DEBILITATING & -2.24 & -0.68 & -0.62 \\
\hline DECENTRALIZATION & 0.65 & -0.74 & 0.03 \\
\hline DEGRADES / DIMINISHES & -2.47 & -0.50 & -0.12 \\
\hline DEHUMANIZATION & -2.56 & -0.32 & -0.18 \\
\hline DEMANDS & -0.32 & 0.50 & 1.09 \\
\hline DEMOCRACY & 2.18 & -0.41 & 1.68 \\
\hline DEMONIC & -2.59 & 0.74 & 1.06 \\
\hline DEPLETION & -1.88 & -0.65 & -0.38 \\
\hline DESACRALIZATION / NEGLECT OF SPIRIT & -2.38 & -0.94 & -0.71 \\
\hline DESTABILIZES & -1.68 & 0.12 & 0.00 \\
\hline DESTINY & 0.06 & -0.56 & 0.65 \\
\hline DESTRUCTION / DEVASTATION & -2.76 & 1.47 & 1.82 \\
\hline DETERIORATES & -2.09 & -1.12 & -0.50 \\
\hline DETERMINES & 0.62 & -0.32 & 0.65 \\
\hline DETERMINISTIC & 0.03 & -0.09 & 0.59 \\
\hline DETRIMENTAL & -2.09 & -0.09 & 0.21 \\
\hline DEVELOPMENT & 1.41 & -0.12 & 1.18 \\
\hline DILEMMAS & -0.97 & \begin{tabular}{l|l|}
-0.12 \\
\end{tabular} & 0.50 \\
\hline
\end{tabular}


APPENDIX F (continued)

Concept Mean Scores By Semantic Factor

\begin{tabular}{|c|c|c|c|}
\hline Concept & 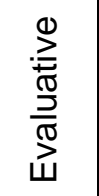 & 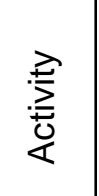 & $\begin{array}{l}\text { তे } \\
\frac{c}{0} \\
\stackrel{0}{0} \\
0\end{array}$ \\
\hline DISASTER & -2.65 & 1.62 & 1.44 \\
\hline DISCOVERY & 2.06 & 0.18 & 1.06 \\
\hline DISLOCATES & -1.24 & 0.62 & 0.12 \\
\hline DIVERSITY / VARIETY & 1.82 & -0.24 & 0.94 \\
\hline DOMINANT IDEOLOGY & -1.03 & -0.32 & 0.94 \\
\hline DOMINATION & -1.85 & 0.68 & 1.32 \\
\hline \begin{tabular}{|l|} 
DYNAMIC \\
\end{tabular} & 1.44 & 1.18 & 1.41 \\
\hline ECONOMIC & 0.76 & -0.12 & 0.71 \\
\hline EFFECTIVENESS & 1.97 & 0.41 & 1.56 \\
\hline EFFECTS & 0.47 & 0.24 & 0.65 \\
\hline EFFICIENCY & 2.09 & 0.94 & 1.41 \\
\hline EMPIRICAL & 0.68 & 0.06 & 0.79 \\
\hline ENHANCES / ENABLES & 1.88 & 0.18 & 1.26 \\
\hline ENRICHES & 2.03 & 0.35 & 1.32 \\
\hline ENSLAVEMENT & -2.59 & -0.12 & 0.35 \\
\hline EVOLUTIONARY & 0.79 & -1.38 & 0.85 \\
\hline EXHAUSTS & -1.35 & -0.41 & -0.03 \\
\hline EXPANDING & 0.65 & 0.21 & 0.82 \\
\hline EXPLOITATION & -2.38 & 0.56 & 0.09 \\
\hline EXPLORES & 1.82 & -0.41 & 0.85 \\
\hline EXPONENTIAL & 0.09 & 1.06 & 0.91 \\
\hline EXTENDS & 0.74 & 0.09 & 0.74 \\
\hline FALSE IDEAL & -2.12 & -0.03 & -0.29 \\
\hline FETISHISM & -1.74 & -0.32 & -0.71 \\
\hline FORCE & -0.06 & 0.85 & 1.38 \\
\hline FOUNDATION OF CIVILIZATION & 1.21 & -0.97 & 1.06 \\
\hline FRAGMENTATION & -1.09 & -0.38 & -1.03 \\
\hline FRANKENSTEIN & -1.09 & -0.91 & 0.97 \\
\hline FUNCTIONAL & 1.82 & 0.44 & 1.24 \\
\hline FUTURE & 1.29 & 0.74 & 0.82 \\
\hline GENIUS & 1.76 & 0.56 & 1.35 \\
\hline GIGANTIC / IMMENSE & -0.26 & -0.41 & 1.00 \\
\hline GLOBAL VILLAGE & 0.62 & 0.09 & 0.56 \\
\hline GROWTH & 1.50 & -0.06 & 1.15 \\
\hline HERITAGE / TRADITION & 1.76 & -1.15 & 1.59 \\
\hline HIDEOUS & -2.29 & -0.03 & 0.26 \\
\hline HIERARCHICAL & -0.47 & -0.71 & 0.76 \\
\hline HOSTILE & -2.29 & 0.88 & 0.85 \\
\hline HUMAN ENDS & 0.62 & -0.26 & 0.41 \\
\hline
\end{tabular}


APPENDIX F (continued)

Concept Mean Scores By Semantic Factor

\begin{tabular}{|c|c|c|c|}
\hline Concept & 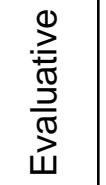 & 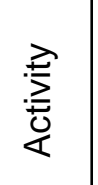 & $\begin{array}{l}\text { তे } \\
\text { ग } \\
\stackrel{0}{0} \\
0\end{array}$ \\
\hline HUMAN FACULTY & 1.15 & 0.06 & 0.65 \\
\hline HUMANE & 2.56 & -0.24 & 1.50 \\
\hline ILLUSION & -0.79 & 0.32 & 0.00 \\
\hline IMAGINATIVE & 2.21 & 0.24 & 1.26 \\
\hline IMPACTS & -0.06 & 0.82 & 1.03 \\
\hline IMPERATIVE & 0.09 & 0.59 & 1.00 \\
\hline IMPERIALISM & -1.76 & 0.00 & 0.88 \\
\hline IMPERILMENT & -1.74 & 0.35 & 0.50 \\
\hline IMPERSONAL & -1.65 & -0.21 & -0.38 \\
\hline IMPLICATIONS & -0.12 & 0.06 & 0.24 \\
\hline IMPOSES & -1.32 & 0.53 & 0.56 \\
\hline IMPROVES & 2.18 & 0.03 & 1.32 \\
\hline INCREASING STANDARD OF LIVING & 1.76 & -0.41 & 1.03 \\
\hline INDIVIDUALISTIC & 1.29 & -0.18 & 1.24 \\
\hline INEVITABLE & -0.76 & -0.38 & 0.44 \\
\hline INFLUENCES & 0.32 & 0.24 & 1.09 \\
\hline INGENIOUS & 1.59 & 0.38 & 1.12 \\
\hline INHUMAN & -2.50 & 0.03 & -0.06 \\
\hline INJUSTICE & -2.59 & 0.26 & -0.09 \\
\hline INNATELY HUMAN & 0.85 & -0.06 & 0.71 \\
\hline INNOVATION & 1.74 & 0.35 & 1.38 \\
\hline INORGANIC & -0.35 & 0.18 & 0.21 \\
\hline INSANE & -2.06 & 0.06 & -0.26 \\
\hline INTELLECTUAL & 2.03 & 0.65 & 1.47 \\
\hline INTERDEPENDENCE & 0.91 & -0.35 & 0.68 \\
\hline INTRICATE & 0.59 & -0.44 & 0.18 \\
\hline INTRUDES / INTERFERES & -1.97 & 0.24 & 0.41 \\
\hline IRREVERSIBLE & -1.32 & -0.15 & 0.82 \\
\hline ISOLATION & \begin{tabular}{|c|}
-1.76 \\
\end{tabular} & -0.71 & -0.12 \\
\hline KNOWLEDGE & 2.74 & 0.18 & 2.15 \\
\hline LABOR SAVING & 1.38 & 0.47 & 0.59 \\
\hline LAWLESS & -2.56 & 0.71 & 0.18 \\
\hline LEISURE & 1.74 & -1.00 & 0.41 \\
\hline LIBERATION / FREEDOM & 2.35 & -0.29 & 2.24 \\
\hline LIMITATIONS / RESTRICTIONS & -1.00 & -0.24 & 0.35 \\
\hline LOSS OF FREEDOM & -2.76 & 0.18 & 0.06 \\
\hline LOSS OF PRIVACY & -2.47 & -0.03 & -0.15 \\
\hline MAKES EQUALITY POSSIBLE & 1.65 & -0.21 & 1.29 \\
\hline MAKES SUBSTITUTIONS FOR RESOURCES & 1.06 & -0.12 & 0.62 \\
\hline
\end{tabular}


APPENDIX F (continued)

Concept Mean Scores By Semantic Factor

\begin{tabular}{|c|c|c|c|}
\hline Concept & 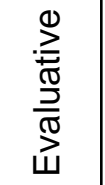 & 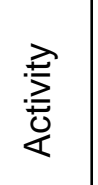 & $\begin{array}{l}\text { Jे } \\
\text { D } \\
\stackrel{0}{0} \\
0\end{array}$ \\
\hline MAN-MADE & 0.79 & 0.03 & 0.71 \\
\hline MANIPULATES & -0.91 & 0.26 & 0.35 \\
\hline MASS PRODUCTION / INDUSTRIALISM & 0.50 & 1.26 & 1.35 \\
\hline MASTERY & 1.74 & 0.03 & 1.68 \\
\hline MATERIALISM & -1.26 & 0.82 & 0.38 \\
\hline MEANINGLESSNESS & -1.91 & -0.56 & -0.94 \\
\hline MEANS & 0.85 & 0.03 & 0.82 \\
\hline MECHANIZATION & 0.71 & 1.06 & 1.15 \\
\hline MEETS NEEDS / SATISFIES WANTS & 1.32 & 0.32 & 1.06 \\
\hline MIDDLE CLASS & 0.71 & -0.06 & 0.32 \\
\hline MISUSED & -1.62 & 0.18 & -0.38 \\
\hline MIXED BLESSING / A DOUBLE EDGED SWORD & -0.09 & 0.03 & 0.09 \\
\hline MOBILITY & 1.74 & 1.15 & 1.21 \\
\hline MODERN & 0.85 & 1.03 & 0.97 \\
\hline MODIFIES & 0.68 & -0.12 & 0.41 \\
\hline MOMENTUM & 1.18 & 1.15 & 1.24 \\
\hline MONOLITHIC & -0.59 & -0.59 & 0.85 \\
\hline MONOTONOUS & -1.79 & -1.68 & -0.74 \\
\hline MONSTROUS & -1.71 & -0.47 & 1.18 \\
\hline NATURAL & 1.79 & -0.74 & 1.15 \\
\hline NECESSITY & 0.38 & 0.03 & 0.79 \\
\hline NEGATES & -0.76 & 0.00 & 0.21 \\
\hline NEUTRAL & -0.12 & -0.29 & -0.26 \\
\hline NEW / NOVELTY & 0.82 & 0.38 & 0.41 \\
\hline NIHILISTIC & -1.76 & -0.35 & -0.56 \\
\hline NOT NEUTRAL & 0.12 & 0.18 & 0.65 \\
\hline OBJECTIVE & 1.82 & -0.12 & 1.38 \\
\hline OBSOLESCENCE & -1.18 & -0.59 & -0.26 \\
\hline OPPORTUNITIES & 2.18 & 0.38 & 1.32 \\
\hline OPPRESSIVE & -2.38 & -0.12 & 0.35 \\
\hline OPTIMISM & 2.06 & 0.65 & 1.38 \\
\hline OPTIMIZATION & 1.71 & 0.47 & 1.56 \\
\hline OVERWHELMS / OUT OF CONTROL & -2.41 & 1.35 & 1.06 \\
\hline PARADOX & -0.35 & -0.21 & 0.15 \\
\hline PERVASIVE & -0.47 & 0.18 & 0.21 \\
\hline POLLUTION & -2.71 & 0.53 & 0.74 \\
\hline POPULATION GROWTH & -0.66 & 1.11 & 0.80 \\
\hline POSSIBILITIES & 1.71 & 0.18 & 0.97 \\
\hline POTENTIAL & 1.79 & 0.15 & 1.26 \\
\hline
\end{tabular}


APPENDIX F (continued)

Concept Mean Scores By Semantic Factor

\begin{tabular}{|c|c|c|c|}
\hline Concept & 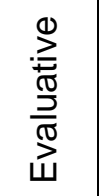 & 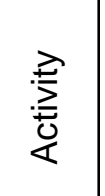 & $\begin{array}{l}\text { তे } \\
\frac{c}{0} \\
\stackrel{0}{0} \\
0\end{array}$ \\
\hline POWER & 0.68 & 0.38 & 1.62 \\
\hline PRACTICAL & 1.65 & 0.18 & 1.12 \\
\hline PRAGMATIC & 1.12 & 0.24 & 0.76 \\
\hline PROBLEM SOLVING & 2.12 & -0.21 & 1.44 \\
\hline PROBLEMS & -0.68 & -0.12 & 0.26 \\
\hline PRODUCTIVITY & 1.97 & 0.62 & 1.38 \\
\hline PROFIT MOTIVE & 0.24 & 0.71 & 1.00 \\
\hline PROGRESS & 1.79 & 0.24 & 1.38 \\
\hline PROSPERITY & 1.91 & 0.24 & 1.53 \\
\hline PURPOSEFUL & 1.94 & 0.12 & 1.56 \\
\hline QUALITY & 2.18 & -0.26 & 1.71 \\
\hline QUANTIFICATION & 0.41 & -0.03 & 0.38 \\
\hline RAPES / RAVISHES & -2.56 & 1.38 & 0.56 \\
\hline RATIONALITY & 1.53 & -0.15 & 1.15 \\
\hline RECKLESS & -2.09 & 1.35 & -0.44 \\
\hline REFINES & 1.26 & -0.32 & 0.76 \\
\hline REGIMENTATION / ROUTINES & 0.12 & -0.41 & 0.35 \\
\hline RELIABILITY & 2.21 & 0.03 & 1.44 \\
\hline REQUIRES & 0.26 & 0.03 & 0.44 \\
\hline RESHAPES / REMAKES & 0.94 & -0.26 & 0.74 \\
\hline RESOURCE & 1.62 & -0.41 & 1.15 \\
\hline REVOLUTIONS & 0.24 & 0.65 & 1.12 \\
\hline RISKS & 0.38 & 0.62 & 0.74 \\
\hline RUTHLESS & -2.35 & 1.00 & 0.76 \\
\hline SATURATES & -0.56 & -0.15 & 0.35 \\
\hline SCIENTIFIC & 1.47 & 0.12 & 1.41 \\
\hline SECULAR & 0.21 & -0.03 & 0.59 \\
\hline SELF-GENERATING / PERPETUAL & 0.94 & -0.18 & 0.97 \\
\hline SELFISH MATERIALISM / CONSPICUOUS CONSUMPTION & -2.44 & 0.97 & 0.00 \\
\hline SERVITUDE & -1.50 & -0.76 & -0.59 \\
\hline SHAPES & 0.50 & -0.15 & 0.59 \\
\hline SIDE EFFECTS & -1.00 & -0.06 & 0.12 \\
\hline SKILL & 2.29 & 0.82 & 2.03 \\
\hline SOCIAL \& CLASS STRATIFICATION & -1.32 & -0.50 & -0.09 \\
\hline SOCIAL \& CULTURAL SHOCK & -0.85 & 0.85 & 0.71 \\
\hline SOCIAL \& ECONOMIC INEQUITY & -1.47 & -0.38 & 0.24 \\
\hline SOPHISTICATED & 1.00 & 0.41 & 0.97 \\
\hline SPECIALIZATION & 1.21 & 0.62 & 1.15 \\
\hline STANDARDIZATION & 0.09 & 0.32 & 0.71 \\
\hline
\end{tabular}


APPENDIX F (continued)

Concept Mean Scores By Semantic Factor

\begin{tabular}{|c|c|c|c|}
\hline Concept & 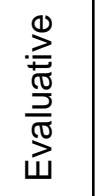 & 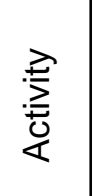 & 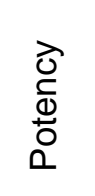 \\
\hline STRESS & -1.26 & 0.59 & 0.65 \\
\hline SUBORDINATES / SUBDUES & -1.21 & -0.32 & 0.06 \\
\hline SURVIVAL & 1.88 & -0.12 & 1.79 \\
\hline SYSTEM & 0.71 & 0.32 & 0.79 \\
\hline TECHNICAL ELITE & 0.47 & 0.91 & 1.15 \\
\hline TECHNOCRACY & -0.79 & 0.59 & 0.21 \\
\hline TECHNOLOGY & 1.38 & 1.62 & 1.71 \\
\hline TERROR & -2.53 & 1.35 & 1.32 \\
\hline THREATENS & -2.21 & 0.94 & 0.76 \\
\hline TOLERATES NO JUDGMENT & -1.59 & 0.26 & 0.12 \\
\hline TOTALITARIAN & -2.15 & 0.38 & 0.97 \\
\hline TRADEOFFS & 0.62 & 0.12 & 0.26 \\
\hline TRANSCENDS & 1.18 & 0.00 & 1.12 \\
\hline TRANSFORMS & 0.88 & 0.03 & 0.91 \\
\hline TREACHERY & $\begin{array}{ll}-2.53 \\
\end{array}$ & 0.53 & -0.03 \\
\hline UNALIVE & -1.59 & -0.68 & -1.09 \\
\hline UNCONTROLLED / UNRESTRAINED & -1.74 & 1.09 & 0.50 \\
\hline UNFORESEEN / UNANTICIPATED & -0.68 & 0.26 & -0.03 \\
\hline UNIFORMITY & -0.76 & -0.32 & -0.47 \\
\hline UNIVERSAL / OMNIPRESENCE & 0.56 & -0.03 & 1.35 \\
\hline UNLIMITED & 0.47 & 0.47 & 0.85 \\
\hline UNNATURAL & -1.24 & -0.15 & -0.06 \\
\hline UNSTABLE / VOLATILE & -1.91 & 0.85 & 0.18 \\
\hline UNSUSTAINABLE & -1.82 & -0.06 & -0.71 \\
\hline UPSETS / DISRUPTS & -1.65 & 0.62 & 0.44 \\
\hline URBANIZATION & -0.06 & 0.82 & 0.53 \\
\hline USEFUL & 2.24 & 0.56 & 1.62 \\
\hline UTILITARIAN & 1.09 & 0.29 & 0.88 \\
\hline VICARIOUS & 0.26 & 0.21 & 0.15 \\
\hline VIOLENT & -2.68 & 1.53 & 1.35 \\
\hline VITAL / ESSENTIAL & 1.85 & 0.71 & 1.53 \\
\hline VULNERABILITY & -1.53 & 0.03 & -1.68 \\
\hline WAR & -2.26 & 1.00 & 1.68 \\
\hline WEALTH / AFFLUENCE & 1.26 & 0.41 & 1.74 \\
\hline WESTERN WORLD & 1.03 & 1.32 & 1.65 \\
\hline WORSHIPPED & 0.35 & \begin{tabular}{c|c|}
-0.44 \\
\end{tabular} & 1.15 \\
\hline
\end{tabular}




\section{APPENDIX G}

\section{APPENDIX G}

\section{Graphical Presentation of Semantic Concepts}




\section{APPENDIX G}

Graphical Presentation of Semantic Concepts

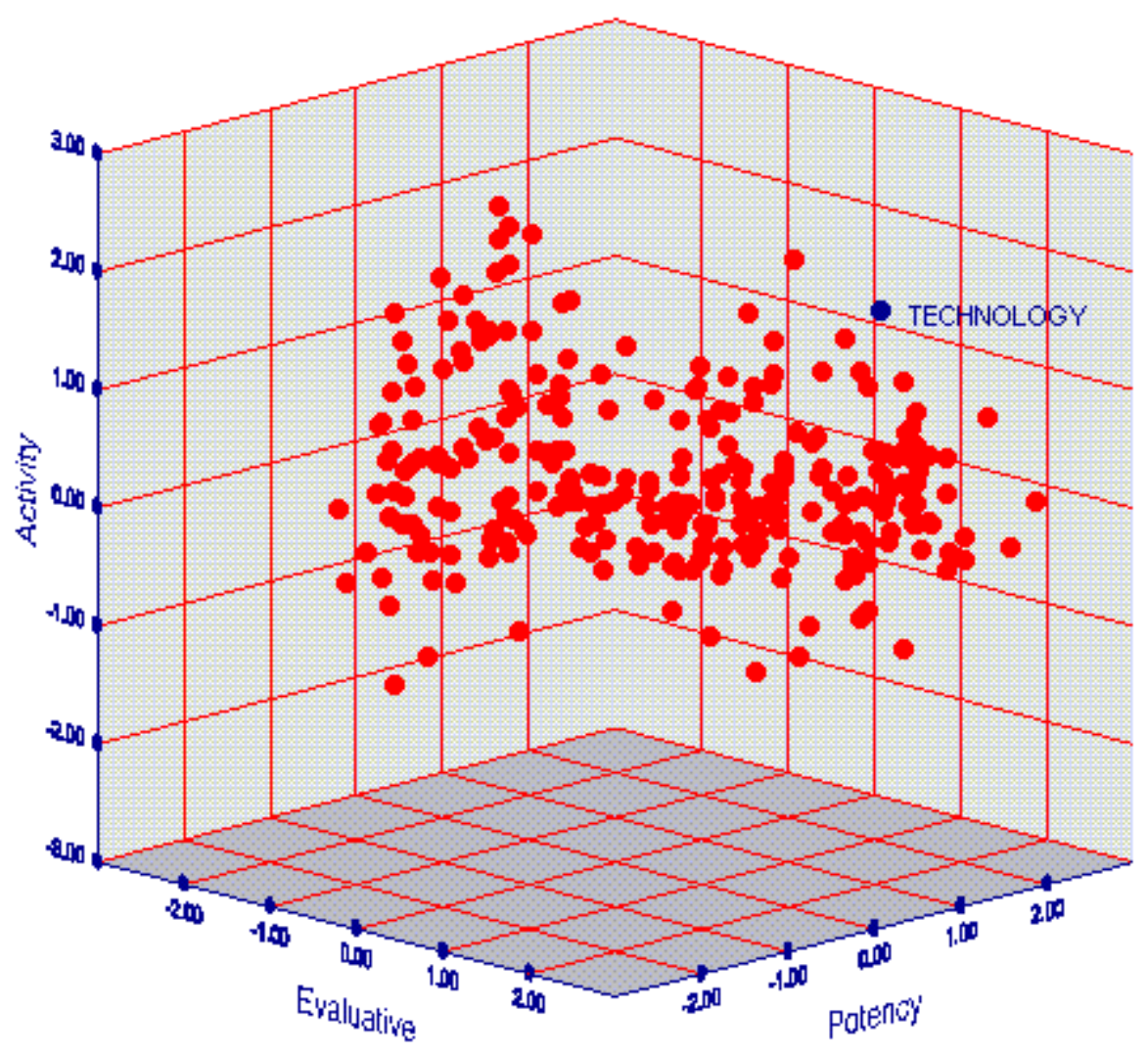

Concepts in three dimensional semantic space, Technology indicated 
APPENDIX G (continued)

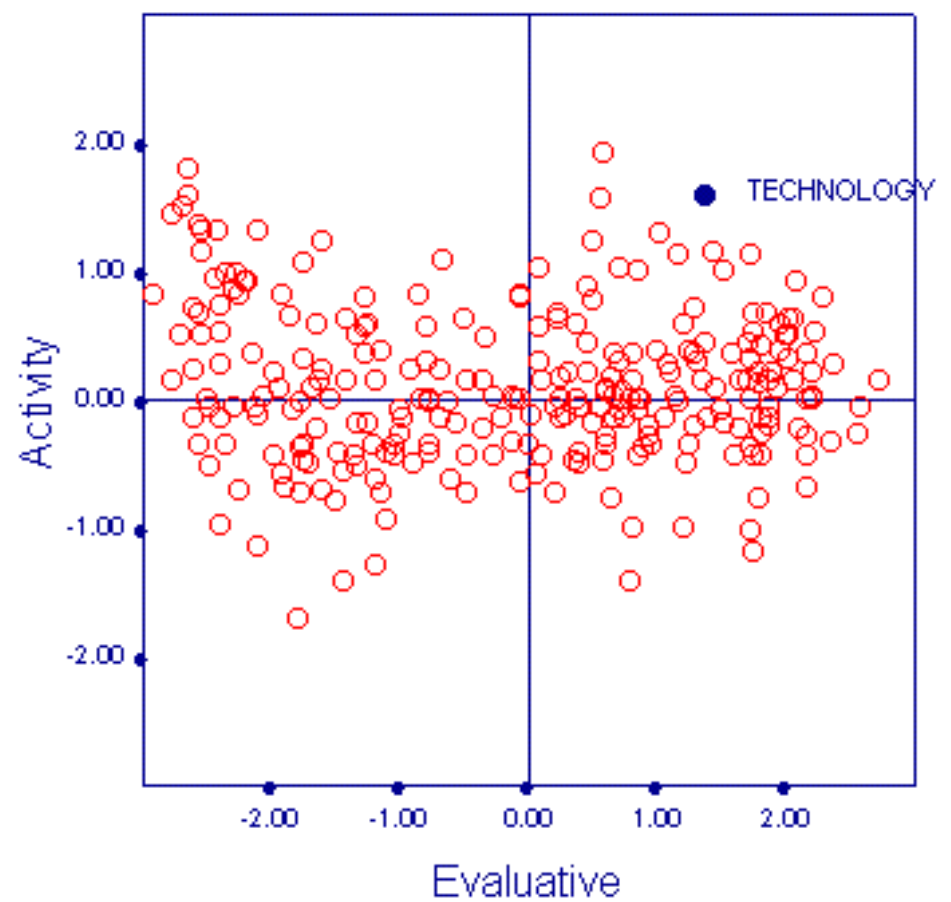

270 Concepts by the semantic factors of Evaluative and Activity

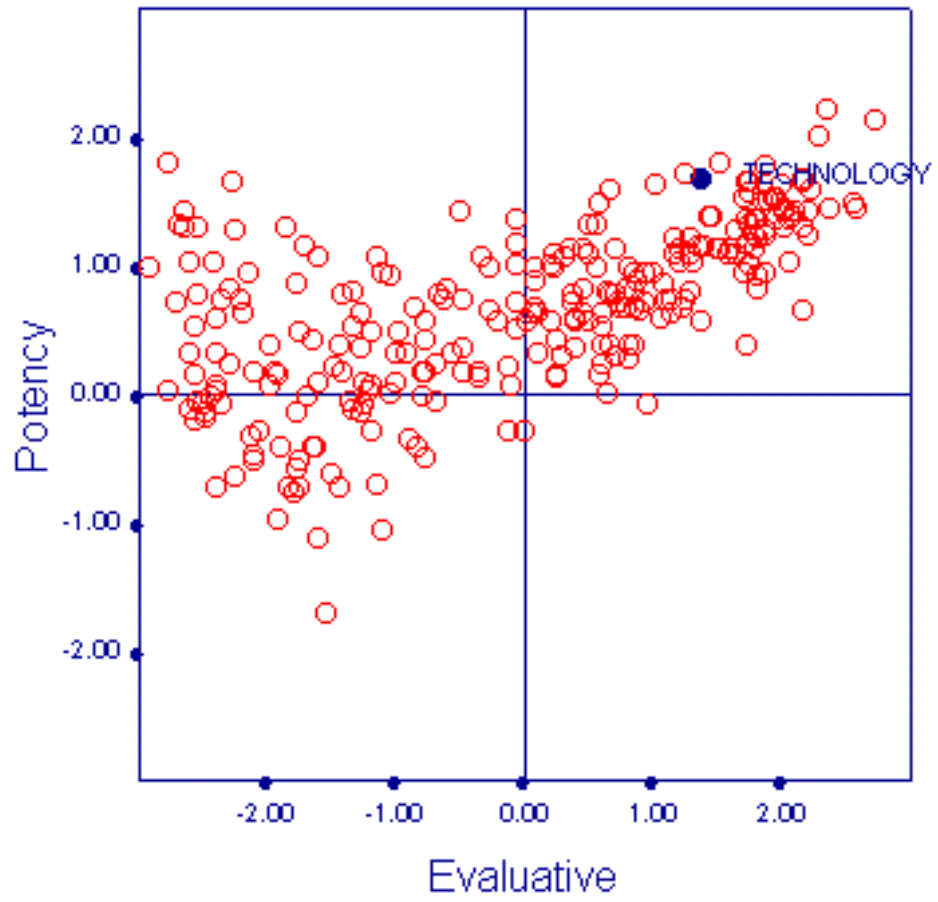

$\underline{270 \text { Concepts by the semantic factors of Evaluative and Potency }}$ 
APPENDIX G (continued)

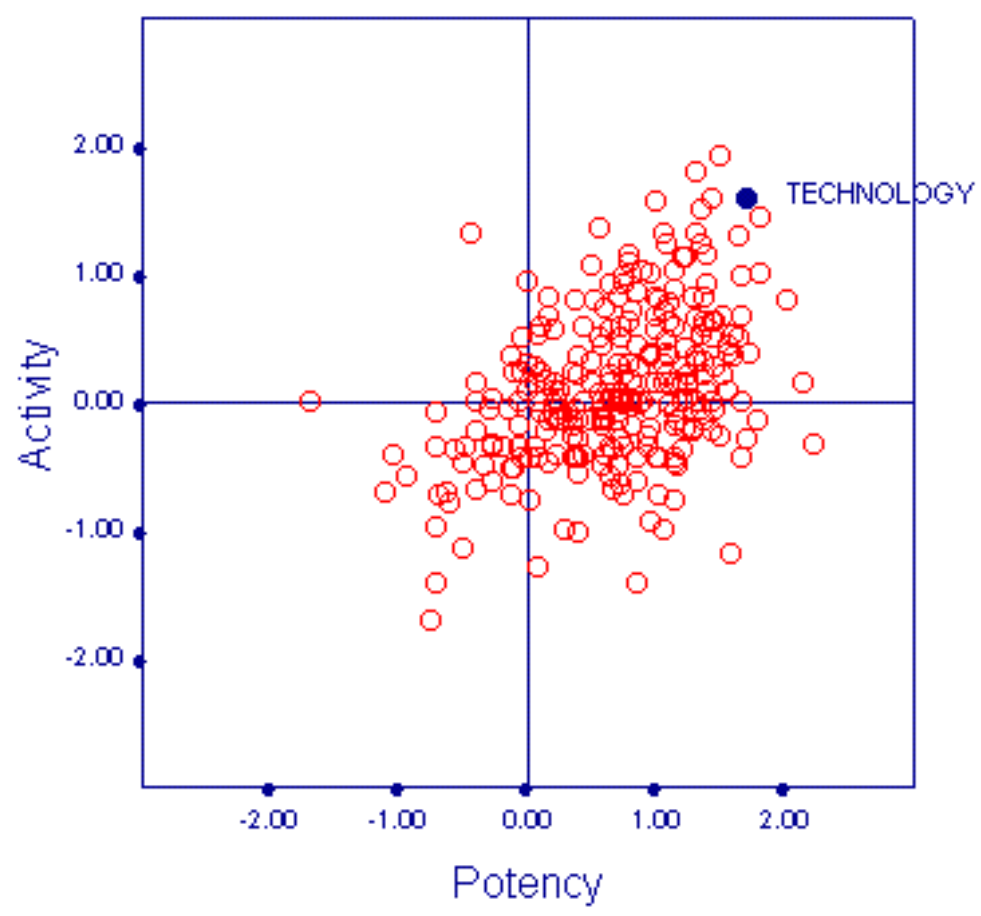

$\underline{270 \text { Concepts by the semantic factors of Potency and Activity. }}$

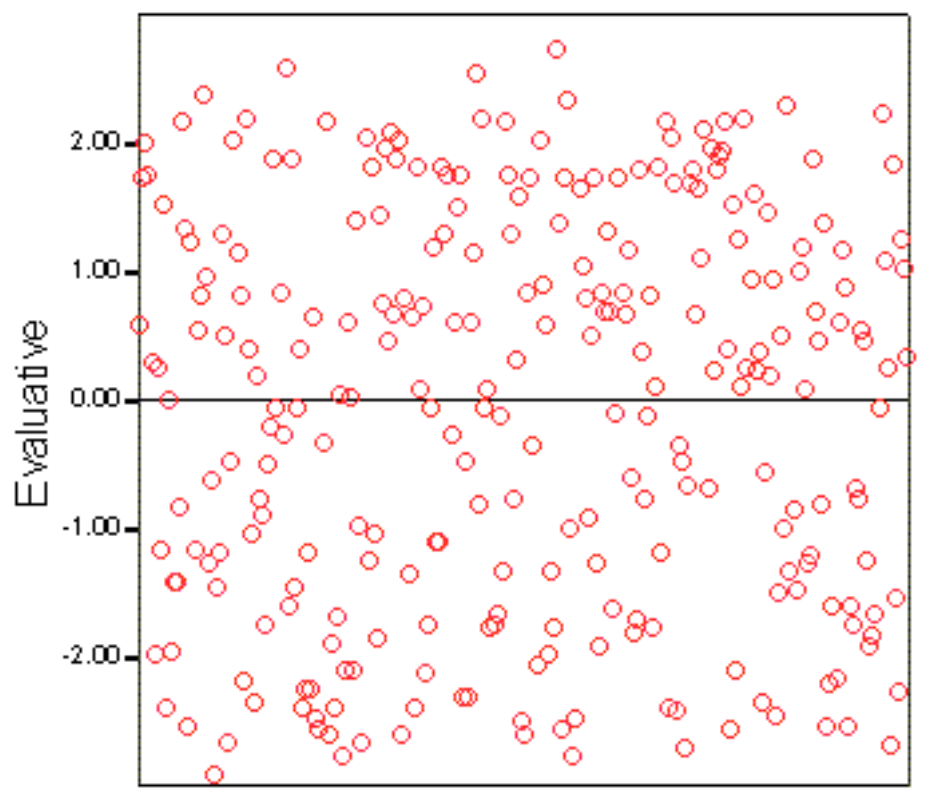

Distribution of 270 concepts on the Evaluative scale 
APPENDIX G (continued)

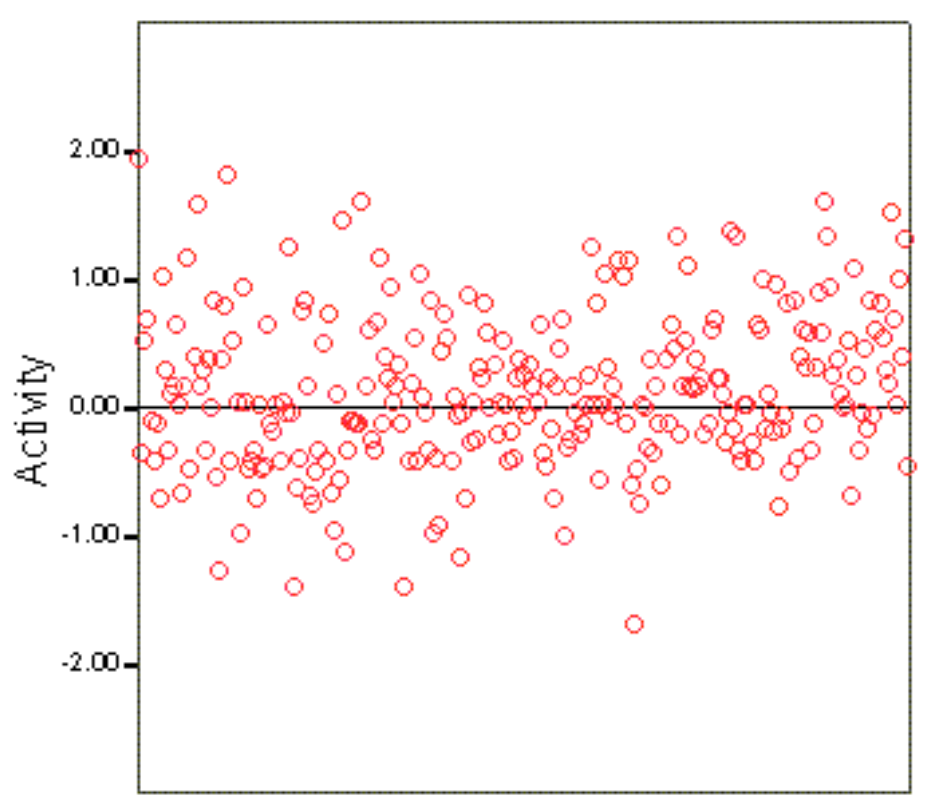

Distribution of 270 concepts on the Activity scale

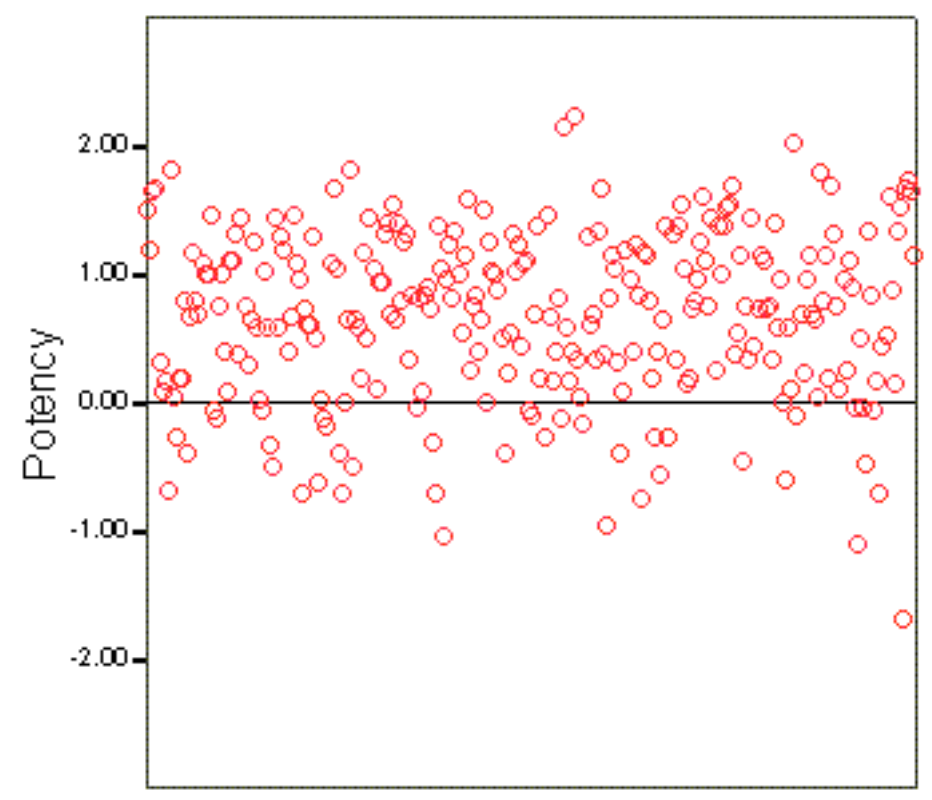

Distribution of 270 concepts on the Potency scale 


\section{APPENDIX $\mathrm{H}$}

\section{APPENDIX H}

Concept Cluster Assignment 


\section{APPENDIX H}

\section{Concept Cluster Assignment}

\begin{tabular}{|c|c|c|}
\hline \multicolumn{3}{|c|}{ CLUSTER 1} \\
\hline $\begin{array}{c}\text { Accelerating } \\
\text { Conquest } \\
\text { Force } \\
\text { Urbanization } \\
\text { Population Growth } \\
\text { Social \& Cultural Shock } \\
\text { Mass Production/ Industrialism }\end{array}$ & $\begin{array}{l}\text { Automation } \\
\text { Demands } \\
\text { Impacts } \\
\text { Mechanization } \\
\text { Revolutions } \\
\text { Technical Elite }\end{array}$ & $\begin{array}{l}\text { Capitalistic } \\
\text { Expotential } \\
\text { Imperative } \\
\text { Modern } \\
\text { Risks } \\
\text { Unlimited }\end{array}$ \\
\hline \multicolumn{3}{|c|}{ CLUSTER 2} \\
\hline $\begin{array}{c}\text { Adaptations } \\
\text { Ascent } \\
\text { Challenges } \\
\text { Creative } \\
\text { Development } \\
\text { Effectiveness } \\
\text { Enriches } \\
\text { Genius } \\
\text { Imaginative } \\
\text { Individualistic } \\
\text { Intellectual } \\
\text { Meets Needs / Satisfies Wants } \\
\text { Opportunities } \\
\text { Possibilities } \\
\text { Problem Solving } \\
\text { Prosperity } \\
\text { Rationality } \\
\text { Scientific } \\
\text { Useful } \\
\text { Dynamic } \\
\text { Mobility } \\
\text { Specialization } \\
\text { Western World } \\
\text { Increasing Standard of Living }\end{array}$ & $\begin{array}{c}\text { Advancement } \\
\text { Beneficial } \\
\text { Choice / Alternatives } \\
\text { Cultural Enjoyments } \\
\text { Discovery } \\
\text { Efficiency } \\
\text { Explores } \\
\text { Growth } \\
\text { Improves } \\
\text { Ingenious } \\
\text { Makes Equality Possible } \\
\text { Natural } \\
\text { Optimism } \\
\text { Potential } \\
\text { Productivity } \\
\text { Purposeful } \\
\text { Reliability } \\
\text { Survival } \\
\text { Vital / Essential } \\
\text { Future } \\
\text { Momentum } \\
\text { Technology } \\
\text { Knowledge }\end{array}$ & $\begin{array}{c}\text { Advantage } \\
\text { Capability / Capacity } \\
\text { Contributes } \\
\text { Democracy } \\
\text { Diversity / Variety } \\
\text { Enhances / Enables } \\
\text { Functional } \\
\text { Humane } \\
\text { Skill } \\
\text { Innovation } \\
\text { Mastery } \\
\text { Objective } \\
\text { Optimization } \\
\text { Practical } \\
\text { Progress } \\
\text { Quality } \\
\text { Resource } \\
\text { Transcends } \\
\text { American } \\
\text { Labor Saving } \\
\text { Power } \\
\text { Wealth / Affluence } \\
\text { Liberation / Freedom }\end{array}$ \\
\hline \multicolumn{3}{|c|}{ CLUSTER 3} \\
\hline $\begin{array}{c}\text { Affects } \\
\text { Autonomous } \\
\text { Changes Perceptions } \\
\text { Consequences } \\
\text { Costs } \\
\text { Decentralization } \\
\text { Deterministic } \\
\text { Empirical } \\
\text { Gigantic / Immense } \\
\text { Human Ends } \\
\text { Innately Human } \\
\text { Makes Substituions for Resources } \\
\text { Middle Class } \\
\text { Necessity } \\
\text { Pragmatic } \\
\text { Regimentation / Routines } \\
\text { Secular } \\
\text { Sophisticated } \\
\text { Tradeoffs } \\
\text { Utilitarian }\end{array}$ & $\begin{array}{c}\text { Alters } \\
\text { Benign } \\
\text { Complex } \\
\text { Control } \\
\text { Culturally \& Socially Determined } \\
\text { Destiny } \\
\text { Economic } \\
\text { Expanding } \\
\text { Global Village } \\
\text { Human Faculty } \\
\text { Interdependence } \\
\text { Man-made } \\
\text { Modifies } \\
\text { New / Novelty } \\
\text { Quantification } \\
\text { Requires } \\
\text { Self Generating / Perpetual } \\
\text { Standardization } \\
\text { Transforms } \\
\text { Vicarious }\end{array}$ & $\begin{array}{c}\text { Assimulates } \\
\text { Change } \\
\text { Conditioning } \\
\text { Convergence } \\
\text { Cummulative } \\
\text { Determines } \\
\text { Effects } \\
\text { Extends } \\
\text { Hierarichical } \\
\text { Influences } \\
\text { Intricate } \\
\text { Means } \\
\text { Monolithic } \\
\text { Not Neutral } \\
\text { Refines } \\
\text { Reshapes / Remakes } \\
\text { Shapes } \\
\text { Systems } \\
\text { Universal / Omnipresence } \\
\text { Worshipped }\end{array}$ \\
\hline
\end{tabular}


APPENDIX H (continued)

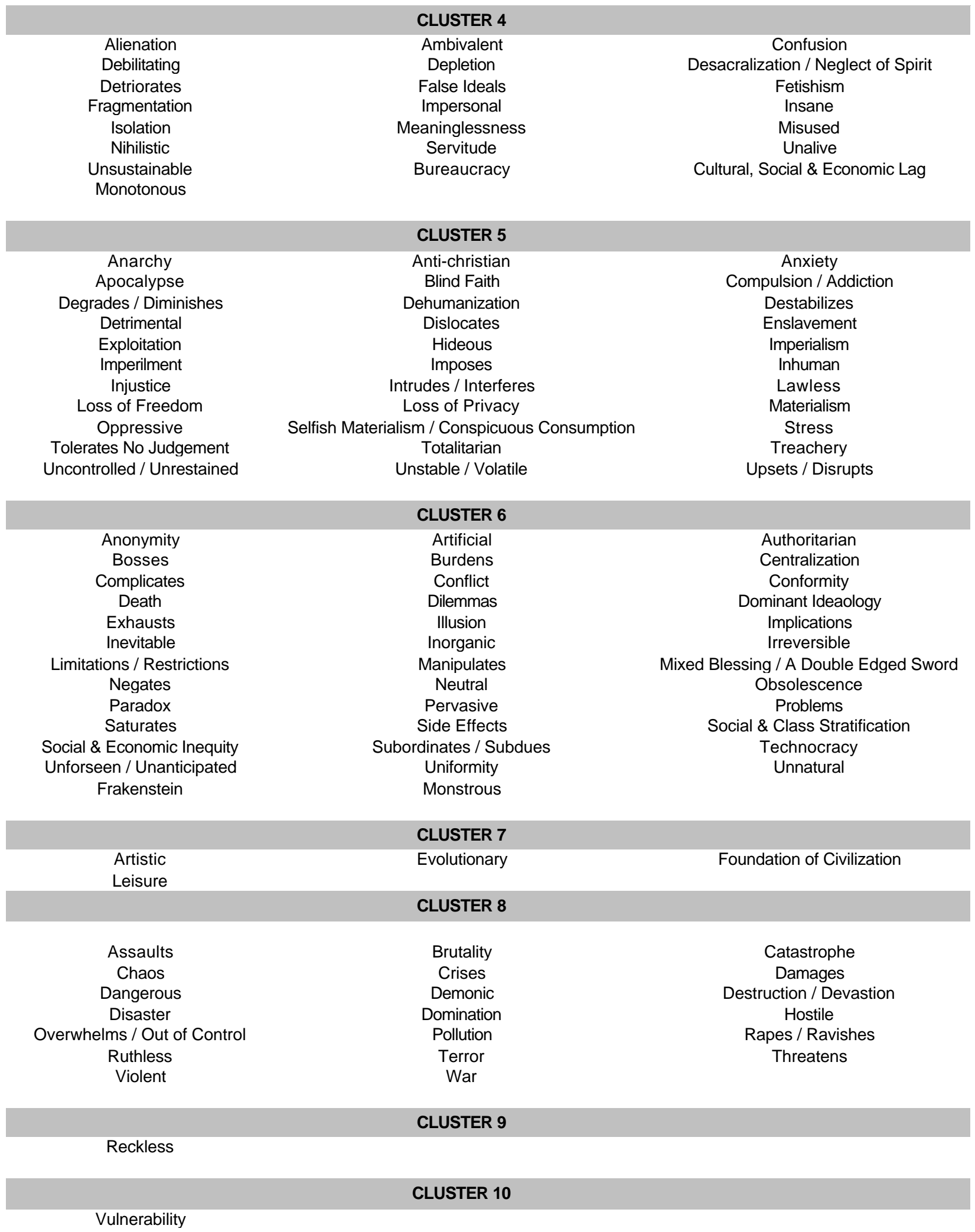




\section{APPENDIX I}

\section{APPENDIX I}

Discipline P-values by Semantic Factor 


\section{APPENDIX I}

Discipline P-Values by Semantic Factors

\section{Evaluative P-Values Discipline by Discipline}

\begin{tabular}{|c|c|c|c|c|c|c|c|c|c|c|c|c|c|c|c|c|}
\hline & 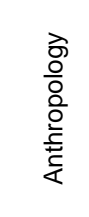 & 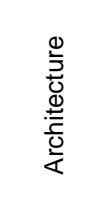 & 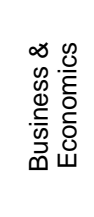 & 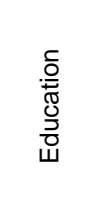 & 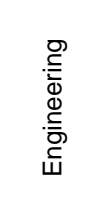 & 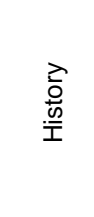 & 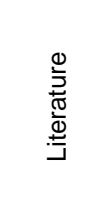 & 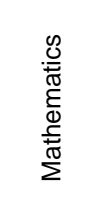 & 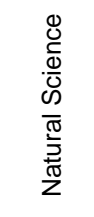 & 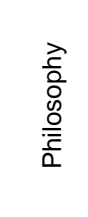 & 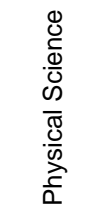 & 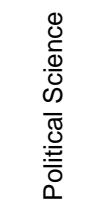 & 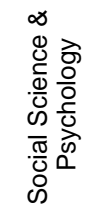 & 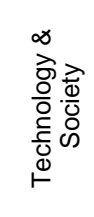 & $\begin{array}{l}\text { वे } \\
\text { 응 } \\
\stackrel{\Phi}{E} \\
\stackrel{F}{*}\end{array}$ & $\stackrel{\frac{1}{ \pm}}{\frac{ \pm}{3}}$ \\
\hline Anthropology & & 0.128 & 0.375 & 0.697 & 0.280 & 0.224 & 0.015 & 0.148 & 0.002 & 0.018 & 0.610 & 0.006 & 0.166 & 0.081 & 0.091 & 0.018 \\
\hline Architecture & 0.128 & & 0.408 & 0.106 & 0.423 & 0.405 & 0.623 & 0.628 & 0.239 & 0.890 & 0.066 & 0.707 & 0.575 & 0.774 & 0.912 & 0.987 \\
\hline Business \& Economics & 0.375 & 0.408 & & 0.282 & 0.841 & 0.826 & 0.115 & 0.554 & 0.013 & 0.099 & 0.125 & 0.038 & 0.646 & 0.405 & 0.278 & 0.141 \\
\hline Education & 0.697 & 0.106 & 0.282 & & 0.202 & 0.160 & 0.008 & 0.126 & 0.001 & 0.016 & 0.853 & 0.005 & 0.129 & 0.068 & 0.055 & 0.016 \\
\hline Engineering & 0.280 & 0.423 & 0.841 & 0.202 & & 0.984 & 0.147 & 0.631 & 0.014 & 0.128 & 0.065 & 0.051 & 0.781 & 0.470 & 0.323 & 0.167 \\
\hline History & 0.224 & 0.405 & 0.826 & 0.160 & 0.984 & & 0.102 & 0.617 & 0.006 & 0.077 & 0.035 & 0.028 & 0.744 & 0.455 & 0.278 & 0.116 \\
\hline Literature & 0.015 & 0.623 & 0.115 & 0.008 & 0.147 & 0.102 & & 0.374 & 0.318 & 0.849 & 0.002 & 0.807 & 0.245 & 0.420 & 0.930 & 0.809 \\
\hline Mathematics & 0.148 & 0.628 & 0.554 & 0.126 & 0.631 & 0.617 & 0.374 & & 0.600 & 0.417 & 0.043 & 0.228 & 0.809 & 0.867 & 0.565 & 0.489 \\
\hline Natural Science & 0.002 & 0.239 & 0.013 & 0.001 & 0.014 & 0.006 & 0.318 & 0.600 & & 0.179 & 0.000 & 0.347 & 0.021 & 0.094 & 0.350 & 0.150 \\
\hline Philosophy & 0.018 & 0.890 & 0.099 & 0.016 & 0.128 & 0.077 & 0.849 & 0.417 & 0.179 & & 0.001 & 0.603 & 0.201 & 0.540 & 0.923 & 0.921 \\
\hline Physical Science & 0.610 & 0.066 & 0.125 & 0.853 & 0.065 & 0.035 & 0.002 & 0.043 & 0.000 & 0.001 & & 0.000 & 0.027 & 0.023 & 0.027 & 0.001 \\
\hline Political Science & 0.006 & 0.707 & 0.038 & 0.005 & 0.051 & 0.028 & 0.807 & 0.228 & 0.347 & 0.603 & 0.000 & & 0.089 & 0.282 & 0.823 & 0.570 \\
\hline Social Science \& Psychology & 0.166 & 0.575 & 0.646 & 0.129 & 0.781 & 0.744 & 0.245 & 0.809 & 0.021 & 0.201 & 0.027 & 0.089 & & 0.723 & 0.368 & 0.264 \\
\hline Technology \& Society & 0.081 & 0.774 & 0.405 & 0.068 & 0.470 & 0.455 & 0.420 & 0.867 & 0.094 & 0.540 & 0.023 & 0.282 & 0.723 & & 0.580 & 0.570 \\
\hline Theology & 0.091 & 0.912 & 0.278 & 0.055 & 0.323 & 0.278 & 0.930 & 0.565 & 0.350 & 0.923 & 0.027 & 0.823 & 0.368 & 0.580 & & 0.899 \\
\hline Writer & 0.018 & 0.987 & 0.141 & 0.016 & 0.167 & 0.116 & 0.809 & 0.489 & 0.150 & 0.921 & 0.001 & 0.570 & 0.264 & 0.570 & 0.899 & \\
\hline
\end{tabular}




\section{APPENDIX I (continued)}

\section{Activity P-Values Discipline by Discipline}

\begin{tabular}{|c|c|c|c|c|c|c|c|c|c|c|c|c|c|c|c|c|}
\hline & 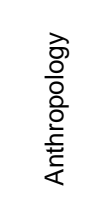 & 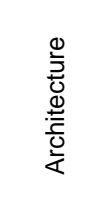 & 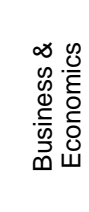 & 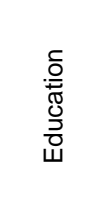 & 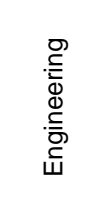 & 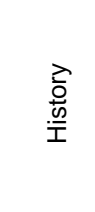 & 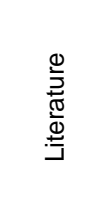 & 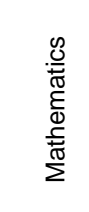 & 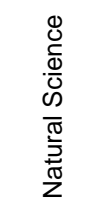 & 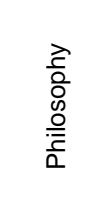 & 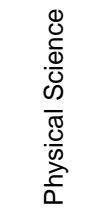 & 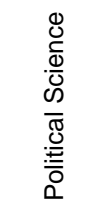 & 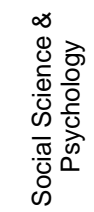 & 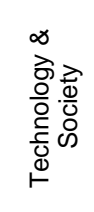 & 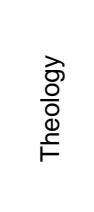 & $\stackrel{\stackrel{\Phi}{*}}{\stackrel{ \pm}{*}}$ \\
\hline Anthropology & & 0.155 & 0.437 & 0.855 & 0.223 & 0.190 & 0.732 & 0.070 & 0.387 & 0.116 & 0.098 & 0.079 & 0.796 & 0.190 & 0.870 & 0.424 \\
\hline Architecture & 0.155 & & 0.345 & 0.220 & 0.414 & 0.493 & 0.326 & 0.801 & 0.499 & 0.595 & 0.637 & 0.734 & 0.206 & 0.606 & 0.162 & 0.442 \\
\hline Business \& Economics & 0.437 & 0.345 & & 0.662 & 0.639 & 0.535 & 0.859 & 0.219 & 0.778 & 0.342 & 0.342 & 0.292 & 0.598 & 0.515 & 0.518 & 0.902 \\
\hline Education & 0.855 & 0.220 & 0.662 & & 0.403 & 0.380 & 0.865 & 0.143 & 0.531 & 0.243 & 0.224 & 0.176 & 0.961 & 0.368 & 0.773 & 0.673 \\
\hline Engineering & 0.223 & 0.414 & 0.639 & 0.403 & & 0.950 & 0.589 & 0.390 & 0.903 & 0.646 & 0.608 & 0.504 & 0.300 & 0.810 & 0.261 & 0.774 \\
\hline History & 0.190 & 0.493 & 0.535 & 0.380 & 0.950 & & 0.549 & 0.416 & 0.895 & 0.672 & 0.595 & 0.519 & 0.227 & 0.791 & 0.238 & 0.668 \\
\hline Literature & 0.732 & 0.326 & 0.859 & 0.865 & 0.589 & 0.549 & & 0.236 & 0.621 & 0.371 & 0.312 & 0.273 & 0.823 & 0.401 & 0.668 & 0.874 \\
\hline Mathematics & 0.070 & 0.801 & 0.219 & 0.143 & 0.390 & 0.416 & 0.236 & & 0.403 & 0.639 & 0.717 & 0.802 & 0.093 & 0.634 & 0.090 & 0.334 \\
\hline Natural Science & 0.387 & 0.499 & 0.778 & 0.531 & 0.903 & 0.895 & 0.621 & 0.403 & & 0.664 & 0.531 & 0.477 & 0.428 & 0.697 & 0.315 & 0.812 \\
\hline Philosophy & 0.116 & 0.595 & 0.342 & 0.243 & 0.646 & 0.672 & 0.371 & 0.639 & 0.664 & & 0.879 & 0.759 & 0.128 & 0.954 & 0.134 & 0.451 \\
\hline Physical Science & 0.098 & 0.637 & 0.342 & 0.224 & 0.608 & 0.595 & 0.312 & 0.717 & 0.531 & 0.879 & & 0.891 & 0.125 & 0.807 & 0.104 & 0.465 \\
\hline Political Science & 0.079 & 0.734 & 0.292 & 0.176 & 0.504 & 0.519 & 0.273 & 0.802 & 0.477 & 0.759 & 0.891 & & 0.117 & 0.727 & 0.096 & 0.379 \\
\hline Social Science \& Psychology & 0.796 & 0.206 & 0.598 & 0.961 & 0.300 & 0.227 & 0.823 & 0.093 & 0.428 & 0.128 & 0.125 & 0.117 & & 0.227 & 0.844 & 0.562 \\
\hline Technology \& Society & 0.190 & 0.606 & 0.515 & 0.368 & 0.810 & 0.791 & 0.401 & 0.634 & 0.697 & 0.954 & 0.807 & 0.727 & 0.227 & & 0.199 & 0.597 \\
\hline Theology & 0.870 & 0.162 & 0.518 & 0.773 & 0.261 & 0.238 & 0.668 & 0.090 & 0.315 & 0.134 & 0.104 & 0.096 & 0.844 & 0.199 & & 0.507 \\
\hline Writer & 0.424 & 0.442 & 0.902 & 0.673 & 0.774 & 0.668 & 0.874 & 0.334 & 0.812 & 0.451 & 0.465 & 0.379 & 0.562 & 0.597 & 0.507 & \\
\hline
\end{tabular}


APPENDIX I (continued)

Potency P-Values Discipline by Discipline

\begin{tabular}{|c|c|c|c|c|c|c|c|c|c|c|c|c|c|c|c|c|}
\hline & 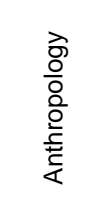 & 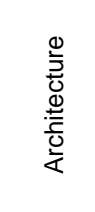 & 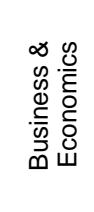 & 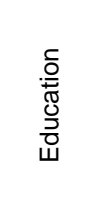 & 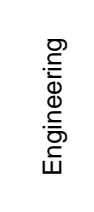 & $\frac{7}{\frac{7}{0}}$ & 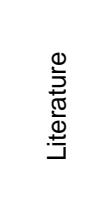 & 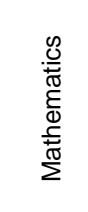 & 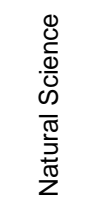 & 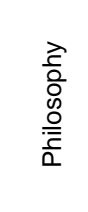 & 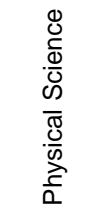 & 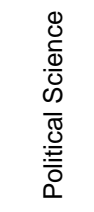 & 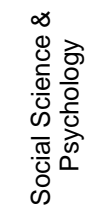 & 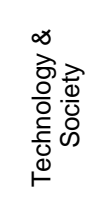 & $\begin{array}{l}\text { ठे } \\
\text { 응 } \\
\Phi \\
\stackrel{\Phi}{F}\end{array}$ & $\frac{\frac{\bar{\phi}}{*}}{3}$ \\
\hline Anthropology & & 0.227 & 0.476 & 0.470 & 0.269 & 0.356 & 0.014 & 0.412 & 0.040 & 0.089 & 0.333 & 0.083 & 0.398 & 0.569 & 0.260 & 0.240 \\
\hline Architecture & 0.227 & & 0.326 & 0.451 & 0.470 & 0.363 & 0.767 & 0.391 & 0.838 & 0.658 & 0.042 & 0.728 & 0.401 & 0.358 & 0.623 & 0.560 \\
\hline Business \& Economics & 0.476 & 0.326 & & 0.902 & 0.692 & 0.867 & 0.120 & 0.969 & 0.130 & 0.338 & 0.062 & 0.282 & 0.857 & 0.899 & 0.477 & 0.608 \\
\hline Education & 0.470 & 0.451 & 0.902 & & 0.773 & 0.921 & 0.090 & 0.872 & 0.197 & 0.412 & 0.126 & 0.331 & 0.862 & 0.934 & 0.428 & 0.744 \\
\hline Engineering & 0.269 & 0.470 & 0.692 & 0.773 & & 0.744 & 0.176 & 0.743 & 0.248 & 0.557 & 0.022 & 0.495 & 0.786 & 0.649 & 0.613 & 0.949 \\
\hline History & 0.356 & 0.363 & 0.867 & 0.921 & 0.744 & & 0.107 & 0.879 & 0.137 & 0.327 & 0.026 & 0.296 & 0.988 & 0.827 & 0.527 & 0.690 \\
\hline Literature & 0.014 & 0.767 & 0.120 & 0.090 & 0.176 & 0.107 & & 0.139 & 0.983 & 0.373 & 0.001 & 0.552 & 0.161 & 0.085 & 0.883 & 0.226 \\
\hline Mathematics & 0.412 & 0.391 & 0.969 & 0.872 & 0.743 & 0.879 & 0.139 & & 0.403 & 0.639 & 0.717 & 0.301 & 0.876 & 0.924 & 0.442 & 0.641 \\
\hline Natural Science & 0.040 & 0.838 & 0.130 & 0.197 & 0.248 & 0.137 & 0.983 & 0.403 & & 0.419 & 0.003 & 0.535 & 0.177 & 0.146 & 0.714 & 0.275 \\
\hline Philosophy & 0.089 & 0.658 & 0.338 & 0.412 & 0.557 & 0.327 & 0.373 & 0.639 & 0.419 & & 0.003 & 0.830 & 0.436 & 0.357 & 0.833 & 0.668 \\
\hline Physical Science & 0.333 & 0.042 & 0.062 & 0.126 & 0.022 & 0.026 & 0.001 & 0.717 & 0.003 & 0.003 & & 0.005 & 0.050 & 0.118 & 0.060 & 0.022 \\
\hline Political Science & 0.083 & 0.728 & 0.282 & 0.331 & 0.495 & 0.296 & 0.552 & 0.301 & 0.535 & 0.830 & 0.005 & & 0.375 & 0.292 & 0.946 & 0.574 \\
\hline Social Science \& Psychology & 0.398 & 0.401 & 0.857 & 0.862 & 0.786 & 0.988 & 0.161 & 0.876 & 0.177 & 0.436 & 0.050 & 0.375 & & 0.829 & 0.568 & 0.736 \\
\hline Technology \& Society & 0.569 & 0.358 & 0.899 & 0.934 & 0.649 & 0.827 & 0.085 & 0.924 & 0.146 & 0.357 & 0.118 & 0.292 & 0.829 & & 0.428 & 0.599 \\
\hline Theology & 0.260 & 0.623 & 0.477 & 0.428 & 0.613 & 0.527 & 0.883 & 0.442 & 0.714 & 0.833 & 0.060 & 0.946 & 0.568 & 0.428 & & 0.744 \\
\hline Writer & 0.240 & 0.560 & 0.608 & 0.744 & 0.949 & 0.690 & 0.226 & 0.641 & 0.275 & 0.668 & 0.022 & 0.574 & 0.736 & 0.599 & 0.744 & \\
\hline
\end{tabular}




\section{APPENDIX $J$}

\section{APPENDIX J}

Discipline to Discipline Comparisons of Significant Difference 


\section{APPENDIX J}

\section{Discipline to Discipline Comparisons of Significant Difference}

Anthropology v. Literature

\begin{tabular}{|ll|r|r|r|}
\hline & GROUP & $\mathrm{N}$ & Mean Rank & $\begin{array}{c}\text { Sum of } \\
\text { Ranks }\end{array}$ \\
\hline Evaluative & Anthropology & 47 & 47.04 & 2211.00 \\
& Literature & 35 & 34.06 & 1192.00 \\
& Total & 82 & & \\
\hline Activity & Anthropology & 47 & 40.72 & 1914.00 \\
& Literature & 35 & 42.54 & 1489.00 \\
& Total & 82 & & \\
\hline Potency & Anthropology & 47 & 47.07 & 2212.50 \\
& Literature & 35 & 34.01 & 1190.50 \\
& Total & 82 & & \\
\hline
\end{tabular}

Test Statistics

\begin{tabular}{|l|r|r|r|}
\hline & Evaluative & \multicolumn{1}{c|}{ Activity } & \multicolumn{1}{c|}{ Potency } \\
\hline Mann-Whitney U & 562.000 & 786.000 & 560.500 \\
Z & -2.443 & -.342 & -2.458 \\
P-Value & .015 & .732 & .014 \\
\hline
\end{tabular}

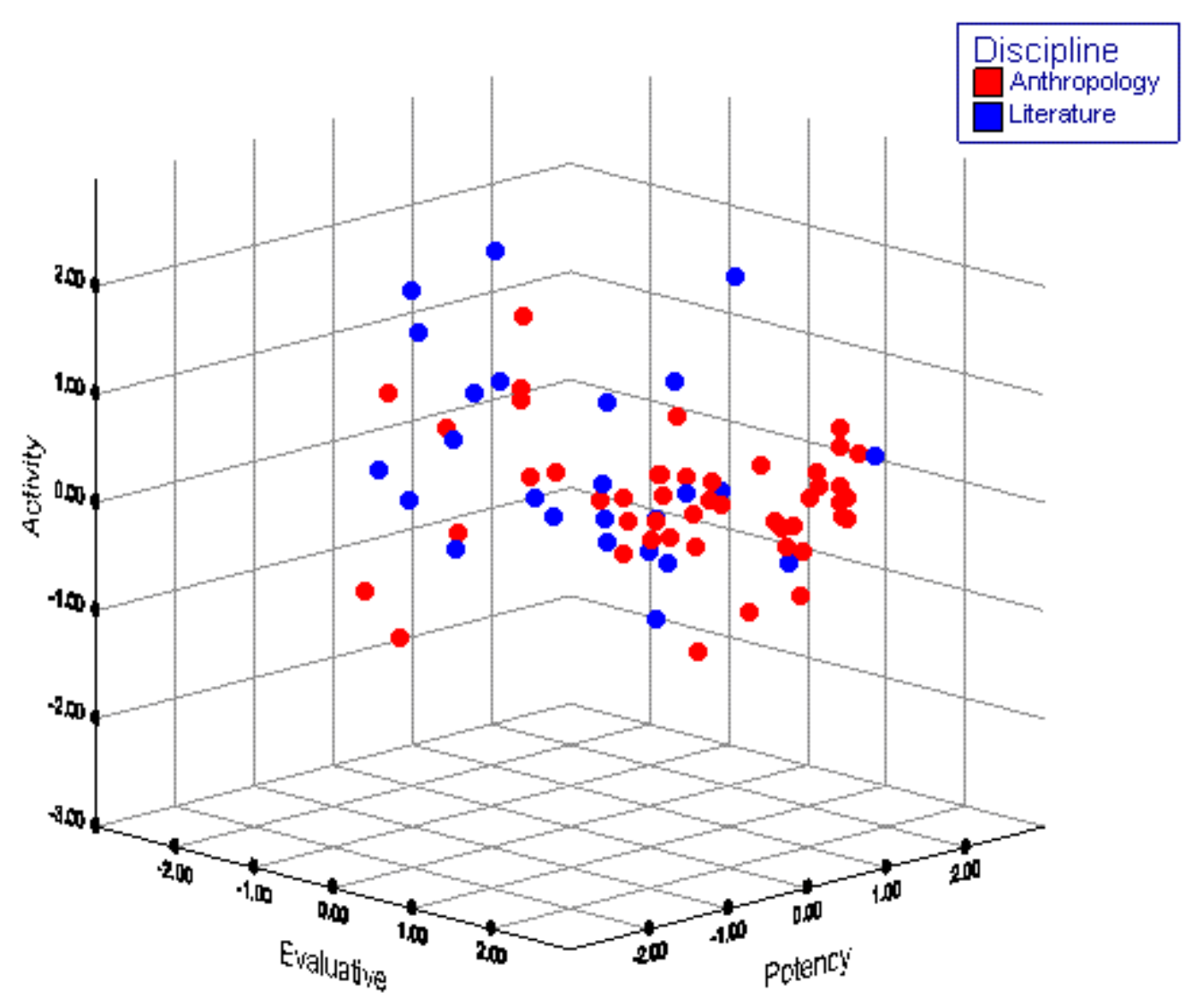


APPENDIX J (continued)

Anthropology v. Natural Science

\begin{tabular}{|ll|r|r|c|}
\hline & GROUP & $\mathrm{N}$ & Mean Rank & $\begin{array}{c}\text { Sum of } \\
\text { Ranks }\end{array}$ \\
\hline Evaluative & Anthropology & 47 & 51.85 & 2437.00 \\
& Natural Science & 40 & 34.78 & 1391.00 \\
& Total & 87 & & \\
\hline Activity & Anthropology & 47 & 41.84 & 1966.50 \\
& Natural Science & 40 & 46.54 & 1861.50 \\
& Total & 87 & & \\
\hline Potency & Anthropology & 47 & 49.12 & 2308.50 \\
& Natural Science & 40 & 37.99 & 1519.50 \\
& Total & 87 & & \\
\hline
\end{tabular}

Test Statistics

\begin{tabular}{|l|r|r|r|}
\hline & Evaluative & \multicolumn{1}{|c|}{ Activity } & \multicolumn{1}{|c|}{ Potency } \\
\hline Mann-Whitney U & 571.000 & 838.500 & 699.500 \\
Z & -3.144 & -.866 & -2.049 \\
P-Value & .002 & .387 & .040 \\
\hline
\end{tabular}

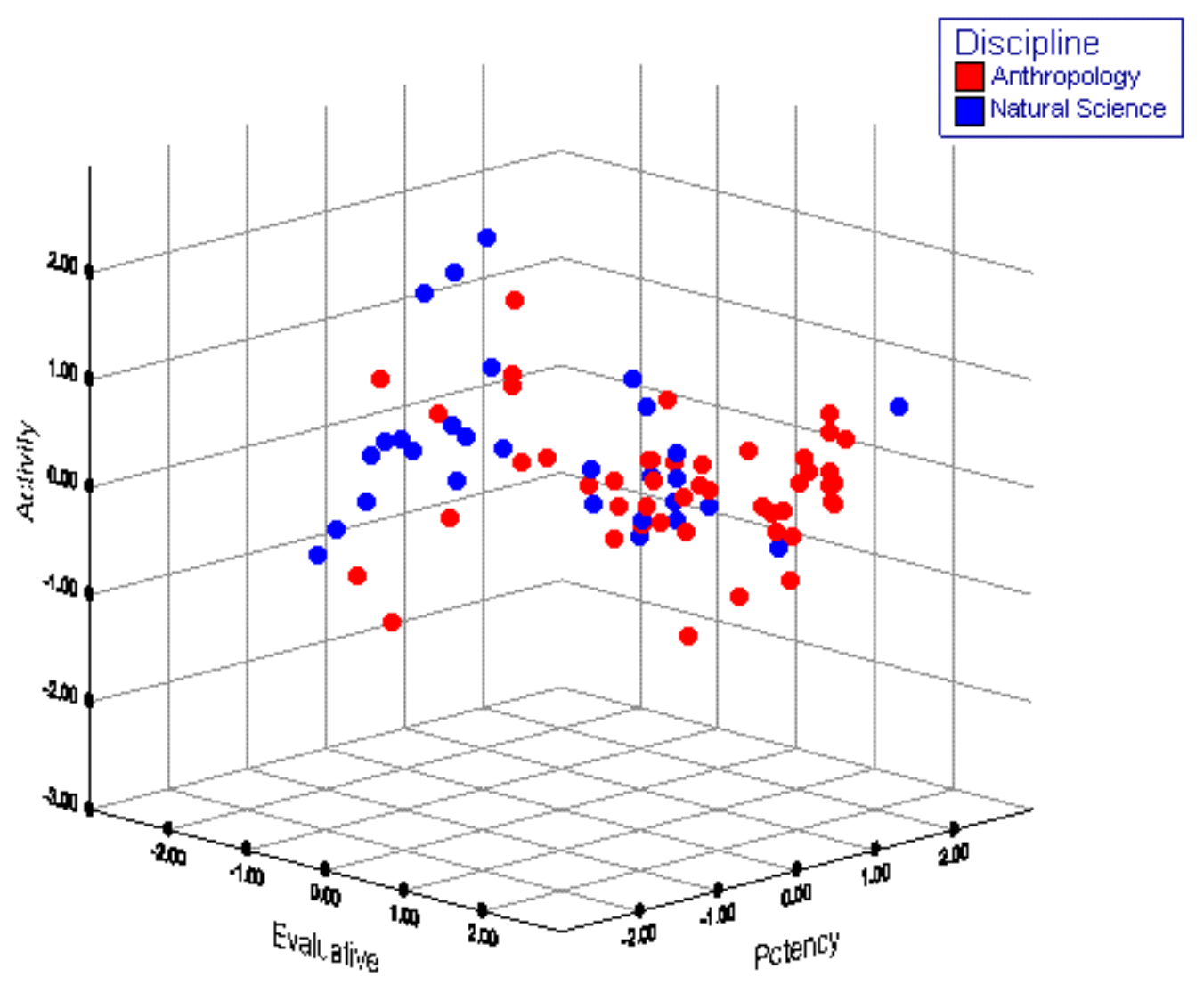


APPENDIX J (continued)

Anthropology v. Philosophy

\begin{tabular}{|ll|r|r|r|}
\hline & GROUP & $\mathrm{N}$ & Mean Rank & \multicolumn{1}{c|}{$\begin{array}{c}\text { Sum of } \\
\text { Ranks }\end{array}$} \\
\hline Evaluative & Anthropology & 47 & 101.74 & 4782.00 \\
& Philosophy & 126 & 81.50 & 10269.00 \\
& Total & 173 & & \\
\hline Activity & Anthropology & 47 & 77.20 & 3628.50 \\
& Philosophy & 126 & 90.65 & 11422.50 \\
& Total & 173 & & \\
\hline Potency & Anthropology & 47 & 97.61 & 4587.50 \\
& Philosophy & 126 & 83.04 & 10463.50 \\
& Total & 173 & & \\
\hline
\end{tabular}

Test Statistics

\begin{tabular}{|l|r|r|r|}
\hline & Evaluative & \multicolumn{1}{|c|}{ Activity } & \multicolumn{1}{c|}{ Potency } \\
\hline Mann-Whitney U & 2268.000 & 2500.500 & 2462.500 \\
Z & -2.365 & -1.572 & -1.702 \\
P-Value & .018 & .116 & .089 \\
\hline
\end{tabular}

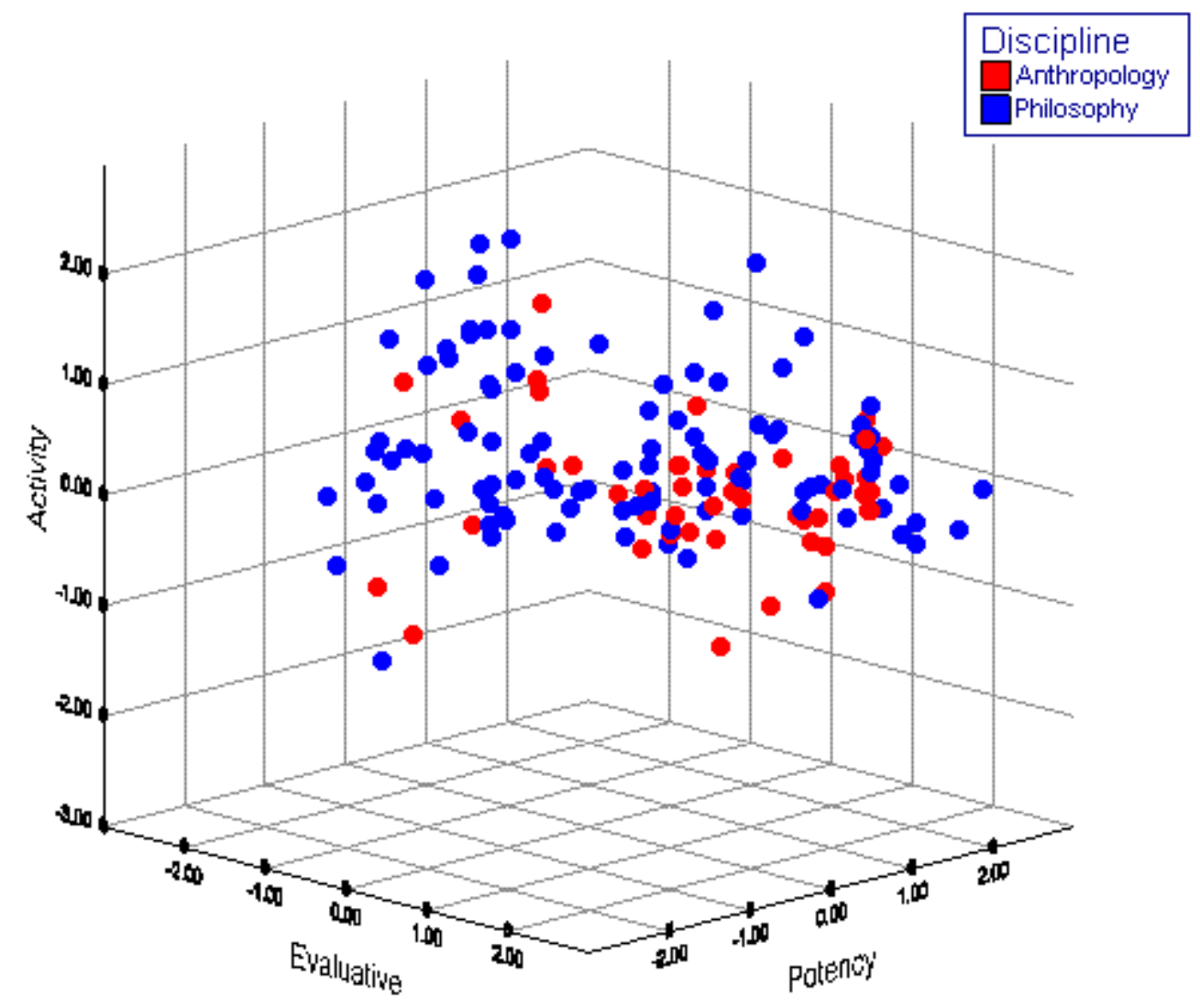


APPENDIX J (continued)

Anthropology v. Political Science

\begin{tabular}{|ll|r|r|c|}
\hline & GROUP & $\mathrm{N}$ & Mean Rank & \multicolumn{1}{c|}{$\begin{array}{c}\text { Sum of } \\
\text { Ranks }\end{array}$} \\
\hline Evaluative & Anthropology & 47 & 77.68 & 3651.00 \\
& Political Science & 83 & 58.60 & 4864.00 \\
& Total & 130 & & \\
\hline Activity & Anthropology & 47 & 57.79 & 2716.00 \\
& Political Science & 83 & 69.87 & 5799.00 \\
& Total & 130 & & \\
\hline Potency & Anthropology & 47 & 73.11 & 3436.00 \\
& Political Science & 83 & 61.19 & 5079.00 \\
& Total & 130 & & \\
\hline
\end{tabular}

Test Statistics

\begin{tabular}{|l|r|r|r|}
\hline & Evaluative & \multicolumn{1}{|c|}{ Activity } & \multicolumn{1}{c|}{ Potency } \\
\hline Mann-Whitney U & 1378.000 & 1588.000 & 1593.000 \\
Z & -2.775 & -1.758 & -1.733 \\
P-Value & .006 & .079 & .083 \\
\hline
\end{tabular}

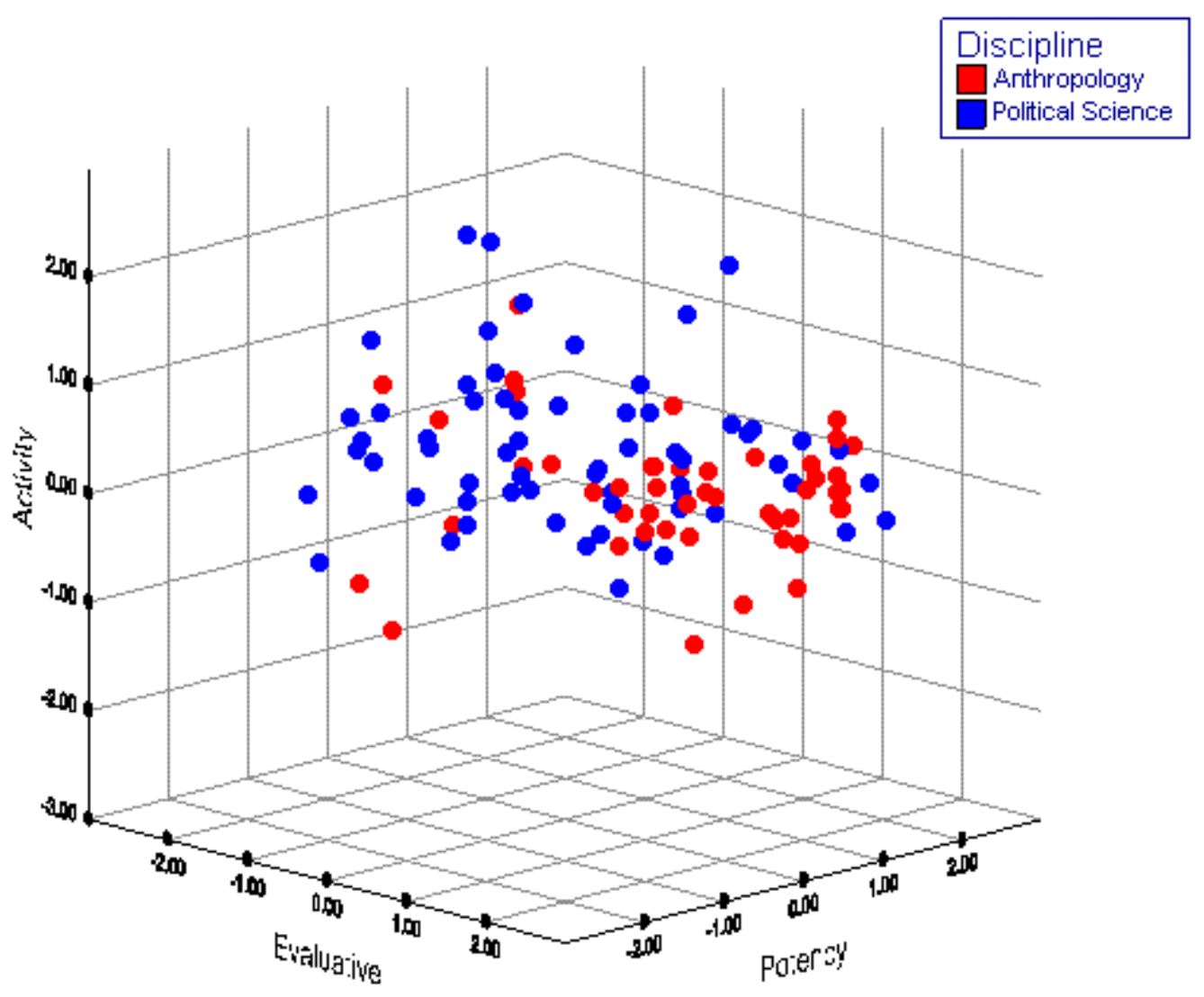


APPENDIX J (continued)

Anthropology v. Writer

\begin{tabular}{|ll|r|r|r|}
\hline & GRouP & $\mathrm{N}$ & Mean Rank & $\begin{array}{c}\text { Sum of } \\
\text { Ranks }\end{array}$ \\
\hline Evaluative & Anthropology & 47 & 75.86 & 3565.50 \\
& Writer & 83 & 59.63 & 4949.50 \\
& Total & 130 & & \\
\hline Activity & Anthropology & 47 & 61.99 & 2913.50 \\
& Writer & 83 & 67.49 & 5601.50 \\
& Total & 130 & & \\
\hline Potency & Anthropology & 47 & 70.66 & 3321.00 \\
& Writer & 83 & 62.58 & 5194.00 \\
& Total & 130 & & \\
\hline
\end{tabular}

\section{Test Statistics}

\begin{tabular}{|l|r|r|r|}
\hline & Evaluative & \multicolumn{1}{|c|}{ Activity } & \multicolumn{1}{c|}{ Potency } \\
\hline Mann-Whitney U & 1463.500 & 1785.500 & 1708.000 \\
Z & -2.360 & -.800 & -1.175 \\
P-Value & .018 & .424 & .240 \\
\hline
\end{tabular}

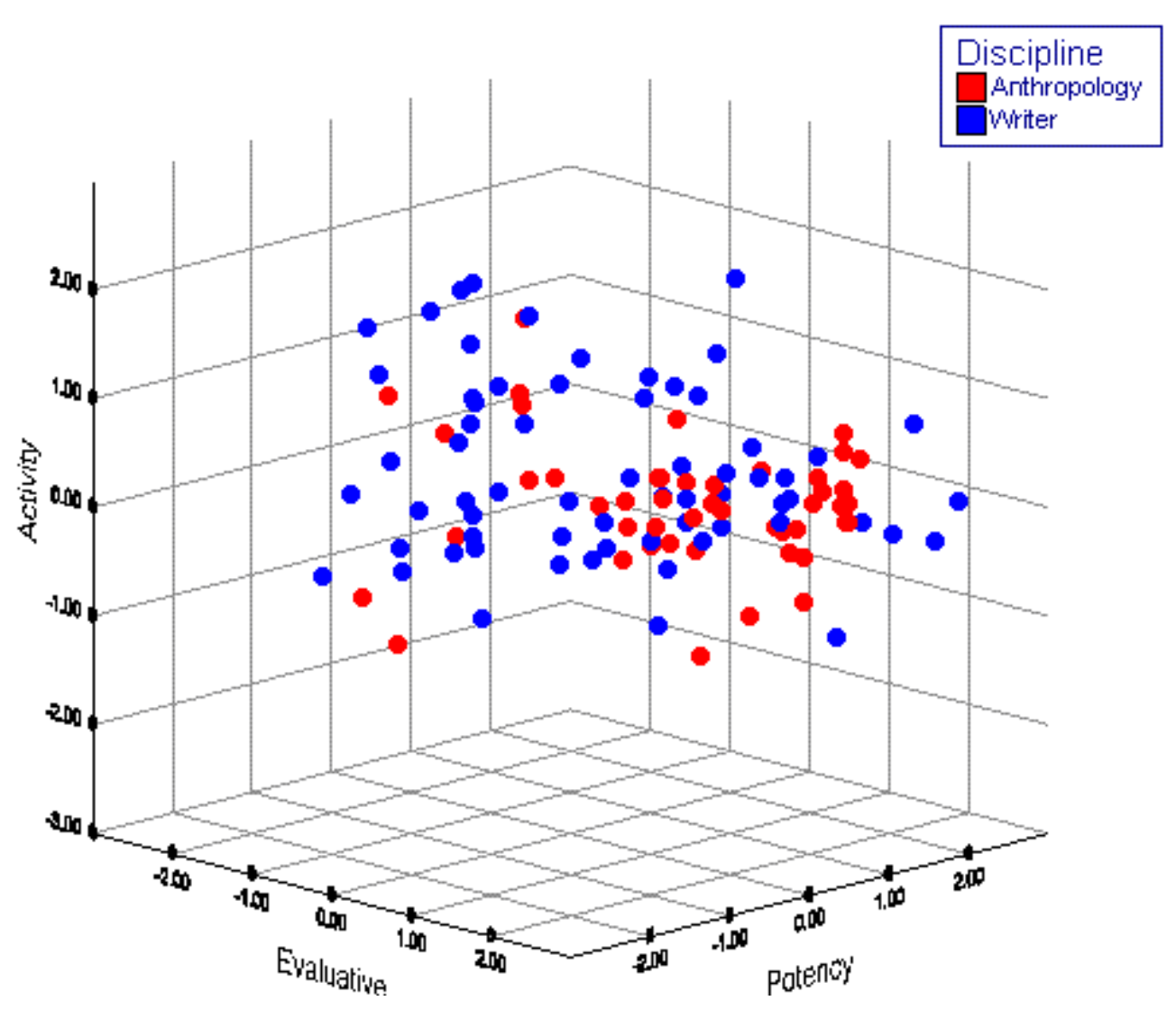


APPENDIX J (continued)

Business \& Economics v. Natural Science

\begin{tabular}{|ll|r|r|c|}
\hline & GROUP & $\mathrm{N}$ & Mean Rank & $\begin{array}{c}\text { Sum of } \\
\text { Ranks }\end{array}$ \\
\hline Evaluative & Business \& Economics & 102 & 76.84 & 7838.00 \\
& Natural Science & 40 & 57.88 & 2315.00 \\
& Total & 142 & & \\
\hline Activity & Business \& Economics & 102 & 70.89 & 7231.00 \\
& Natural Science & 40 & 73.05 & 2922.00 \\
& Total & 142 & & \\
\hline Potency & Business \& Economics & 102 & 74.77 & 7626.50 \\
& Natural Science & 40 & 63.16 & 2526.50 \\
& Total & 142 & & \\
\hline
\end{tabular}

Test Statistics

\begin{tabular}{|l|r|r|r|}
\hline & Evaluative & \multicolumn{1}{c|}{ Activity } & \multicolumn{1}{c|}{ Potency } \\
\hline Mann-Whitney U & 1495.000 & 1978.000 & 1706.500 \\
Z & -2.472 & -.281 & -1.513 \\
P-Value & .013 & .778 & .130 \\
\hline
\end{tabular}

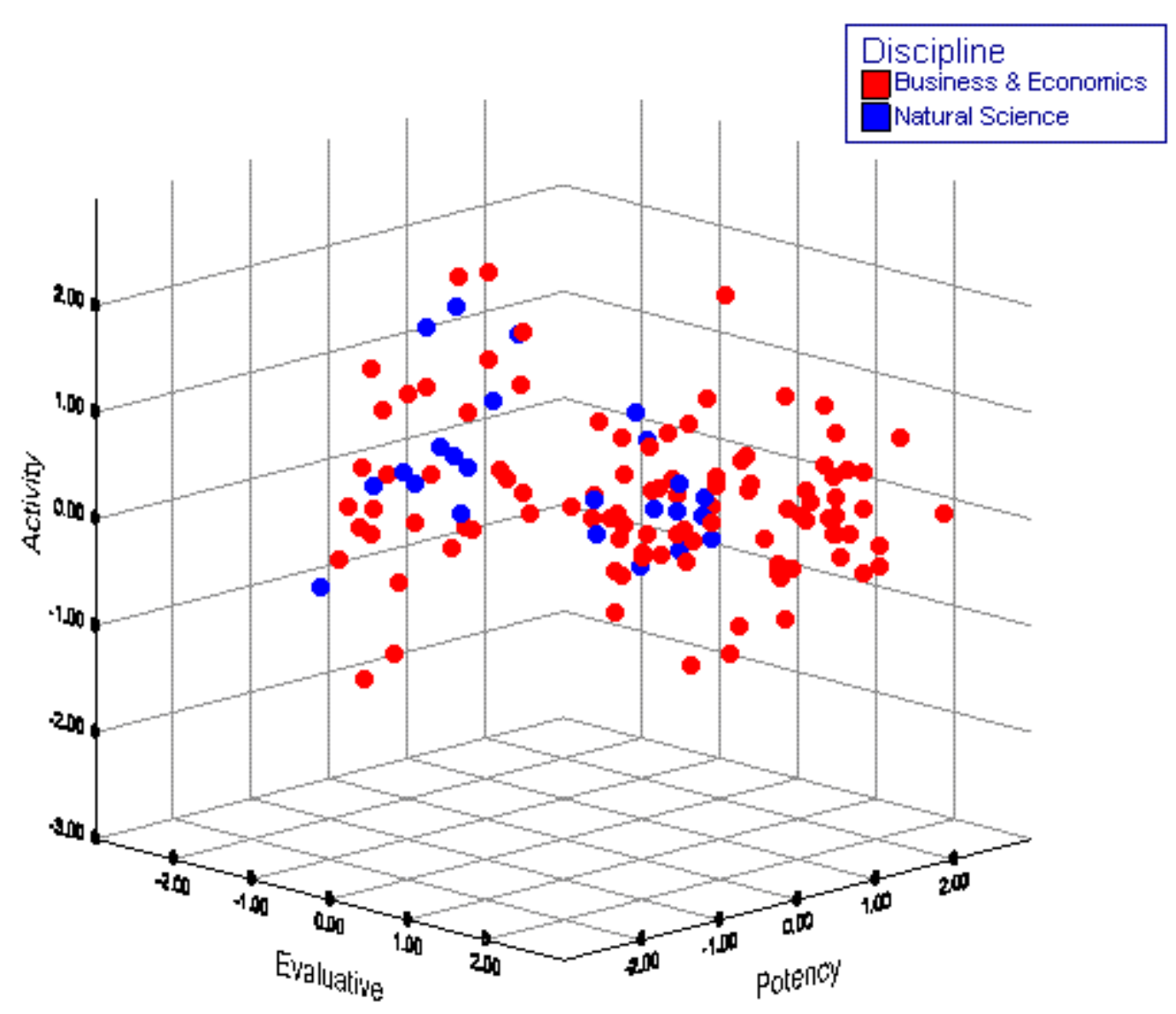


Business \& Economics v. Political Science

\begin{tabular}{|ll|r|r|r|}
\hline & GROUP & $\mathrm{N}$ & Mean Rank & \multicolumn{1}{c|}{$\begin{array}{c}\text { Sum of } \\
\text { Ranks }\end{array}$} \\
\hline Evaluative & Business \& Economics & 102 & 100.38 & 10239.00 \\
& Political Science & 83 & 83.93 & 6966.00 \\
& Total & 185 & & \\
\hline Activity & Business \& Economics & 102 & 89.26 & 9104.50 \\
& Political Science & 83 & 97.60 & 8100.50 \\
& Total & 185 & & \\
\hline Potency & Business \& Economics & 102 & 96.82 & 9876.00 \\
& Political Science & 83 & 88.30 & 7329.00 \\
& Total & 185 & & \\
\hline
\end{tabular}

Test Statistics

\begin{tabular}{|l|r|r|r|}
\hline & Evaluative & \multicolumn{1}{|c|}{ Activity } & \multicolumn{1}{c|}{ Potency } \\
\hline Mann-Whitney U & 3480.000 & 3851.500 & 3843.000 \\
Z & -2.079 & -1.054 & -1.077 \\
P-Value & .038 & .292 & .282 \\
\hline
\end{tabular}

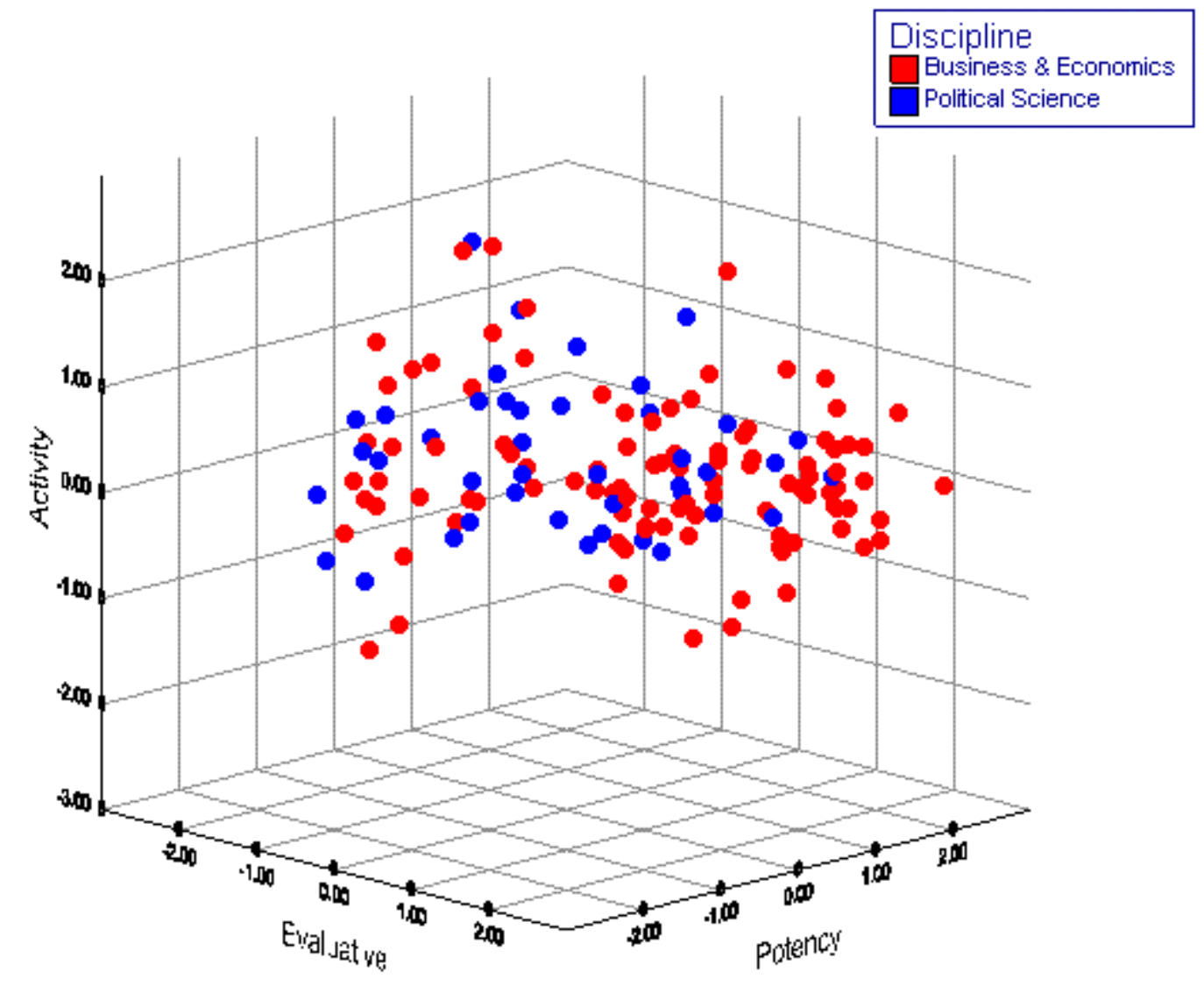


APPENDIX J (continued)

Education v. Literature

\begin{tabular}{|ll|r|r|c|}
\hline & GRouP & $\mathrm{N}$ & Mean Rank & $\begin{array}{l}\text { Sum of } \\
\text { Ranks }\end{array}$ \\
\hline Evaluative & Education & 35 & 41.90 & 1466.50 \\
& Literature & 35 & 29.10 & 1018.50 \\
& Total & 70 & & \\
\hline Activity & Education & 35 & 35.09 & 1228.00 \\
& Literature & 35 & 35.91 & 1257.00 \\
& Total & 70 & & \\
\hline Potency & Education & 35 & 39.63 & 1387.00 \\
& Literature & 35 & 31.37 & 1098.00 \\
& Total & 70 & & \\
\hline
\end{tabular}

Test Statistics

\begin{tabular}{|l|r|r|r|}
\hline & Evaluative & \multicolumn{1}{|c|}{ Activity } & \multicolumn{1}{|c|}{ Potency } \\
\hline Mann-Whitney U & 388.500 & 598.000 & 468.000 \\
Z & -2.632 & -.170 & -1.698 \\
P-Value & .008 & .865 & .090 \\
\hline
\end{tabular}

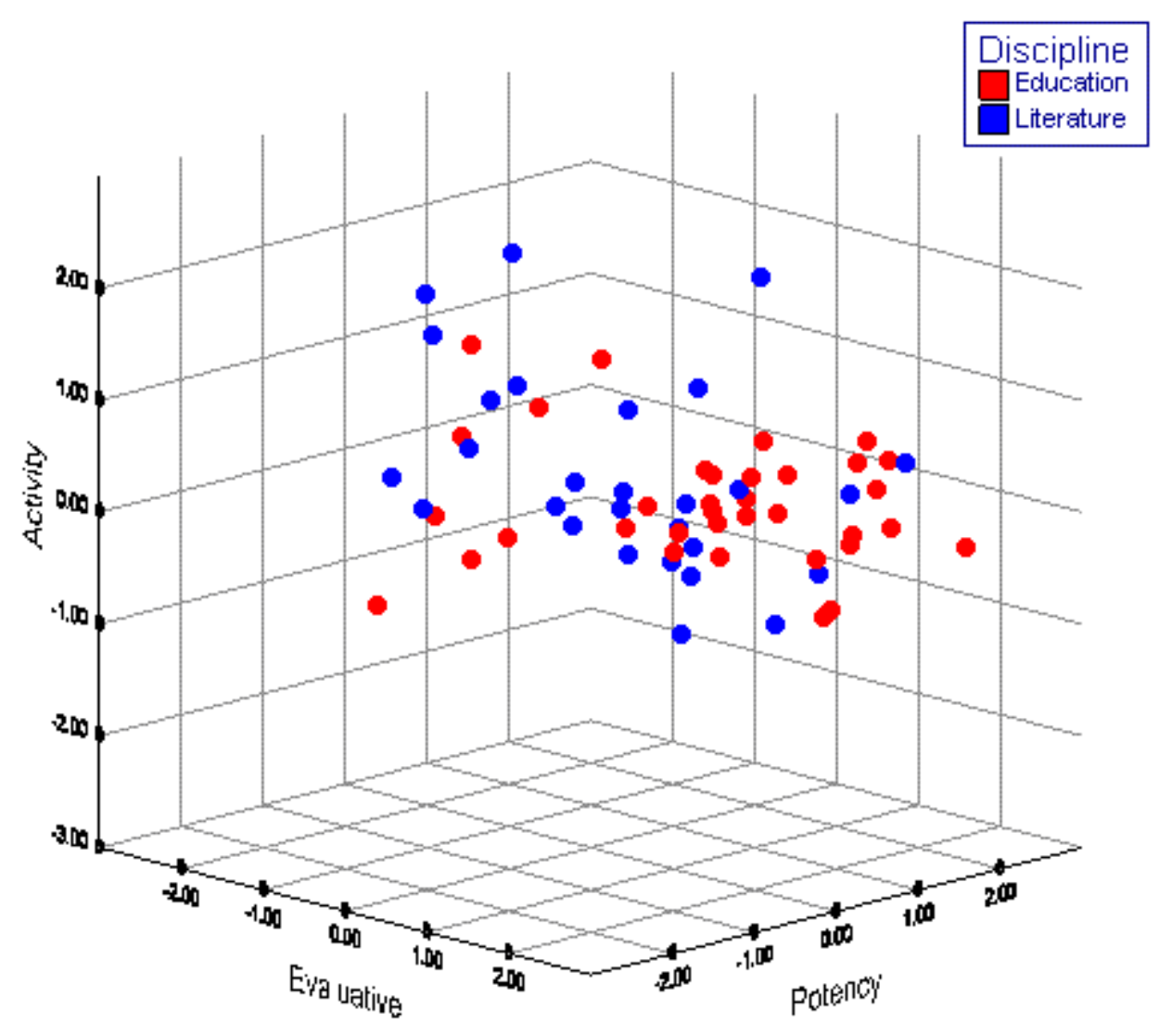


APPENDIX J (continued)

Education v. Natural Science

\begin{tabular}{|ll|r|r|r|}
\hline & GROUP & $\mathrm{N}$ & Mean Rank & $\begin{array}{c}\text { Sum of } \\
\text { Ranks }\end{array}$ \\
\hline Evaluative & Education & 35 & 46.83 & 1639.00 \\
& Natural Science & 40 & 30.27 & 1211.00 \\
& Total & 75 & & \\
\hline Activity & Education & 35 & 36.31 & 1271.00 \\
& Natural Science & 40 & 39.47 & 1579.00 \\
& Total & 75 & & \\
\hline Potency & Education & 35 & 41.47 & 1451.50 \\
& Natural Science & 40 & 34.96 & 1398.50 \\
& Total & 75 & & \\
\hline
\end{tabular}

\section{Test Statistics}

\begin{tabular}{|l|r|r|r|}
\hline & Evaluative & \multicolumn{1}{|c|}{ Activity } & \multicolumn{1}{|c|}{ Potency } \\
\hline Mann-Whitney U & 391.000 & 641.000 & 578.500 \\
Z & -3.282 & -.627 & -1.291 \\
P-Value & .001 & .531 & .197 \\
\hline
\end{tabular}

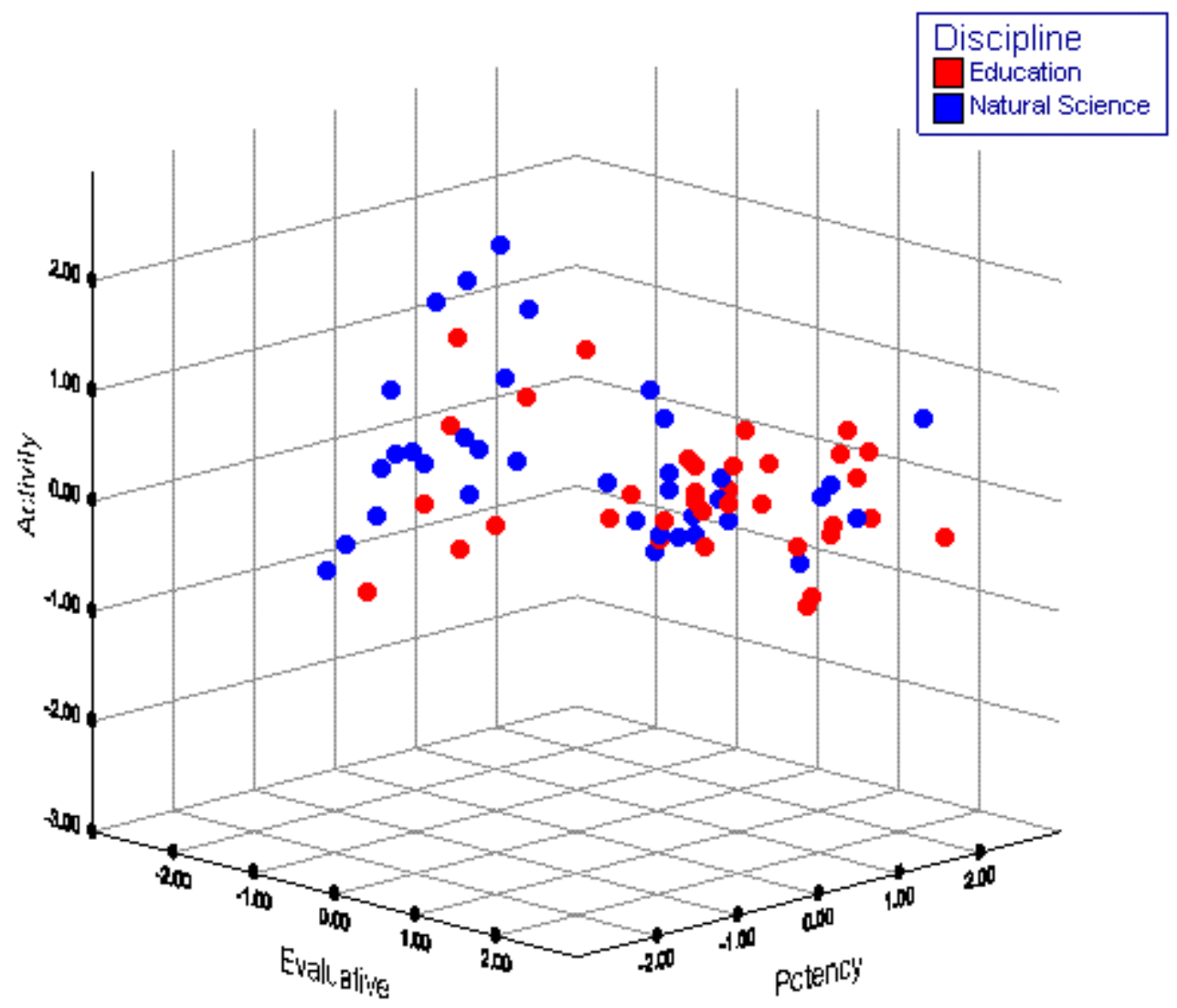


APPENDIX J (continued)

Education v. Philosophy

\begin{tabular}{|ll|r|r|r|}
\hline & GROUP & $\mathrm{N}$ & \multicolumn{1}{c|}{$\begin{array}{c}\text { Sum of } \\
\text { Ranks }\end{array}$} \\
\hline Evaluative & Education & 35 & 97.79 & 3422.50 \\
& Philosophy & 126 & 76.34 & 9618.50 \\
& Total & 161 & & \\
\hline Activity & Education & 35 & 72.87 & 2550.50 \\
& Philosophy & 126 & 83.26 & 10490.50 \\
& Total & 161 & & \\
\hline Potency & Education & 35 & 86.71 & 3035.00 \\
& Philosophy & 126 & 79.41 & 10006.00 \\
& Total & 161 & & \\
\hline
\end{tabular}

Test Statistics

\begin{tabular}{|l|r|r|r|}
\hline & Evaluative & \multicolumn{1}{|c|}{ Activity } & \multicolumn{1}{c|}{ Potency } \\
\hline Mann-Whitney U & 1617.500 & 1920.500 & 2005.000 \\
Z & -2.408 & -1.167 & -.820 \\
P-Value & .016 & .243 & .412 \\
\hline
\end{tabular}

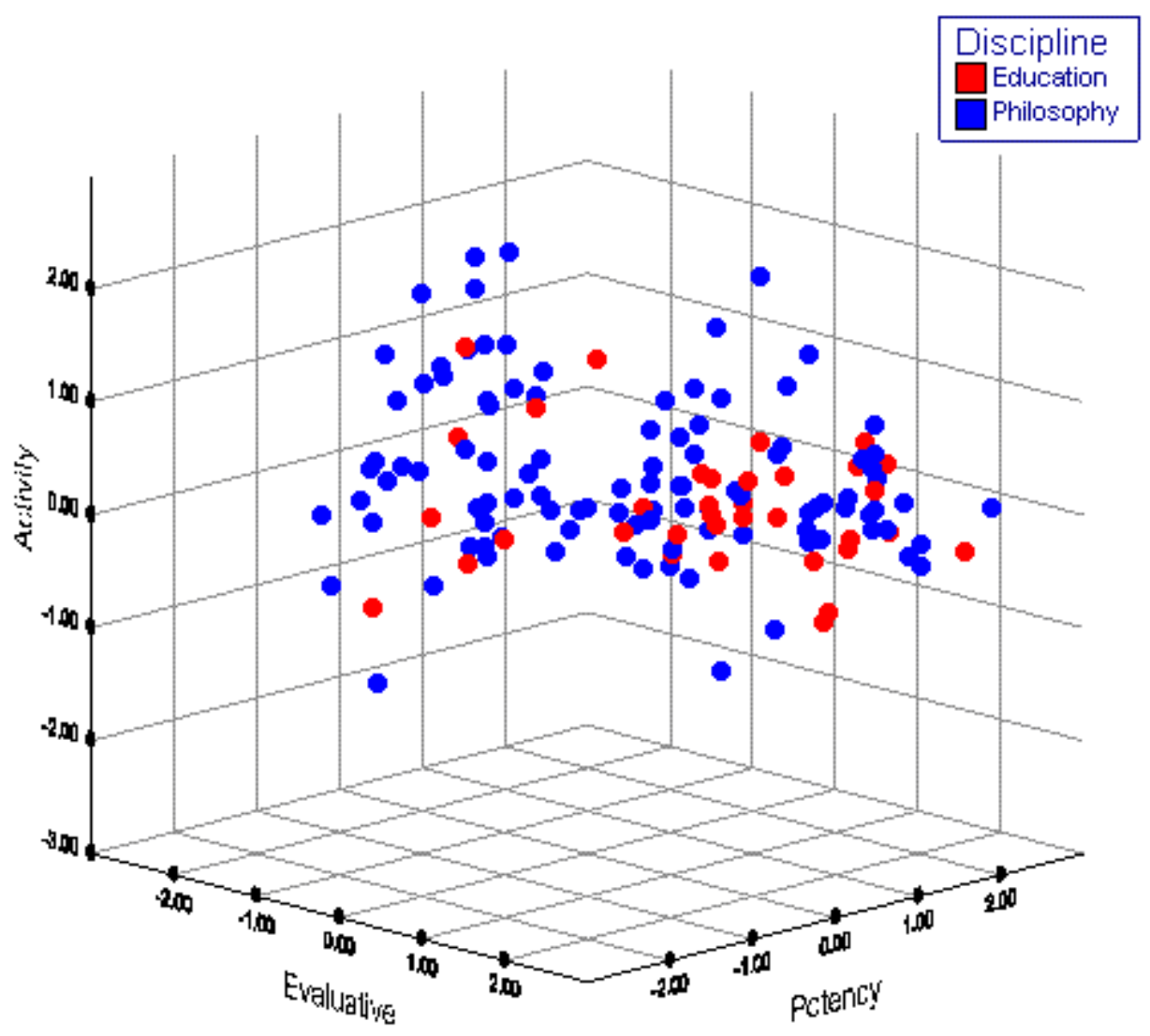


APPENDIX J (continued)

Education v. Political Science

\begin{tabular}{|ll|r|r|r|}
\hline & GRouP & $\mathrm{N}$ & Mean Rank & $\begin{array}{c}\text { Sum of } \\
\text { Ranks }\end{array}$ \\
\hline Evaluative & Education & 35 & 73.14 & 2560.00 \\
& Political Science & 83 & 53.75 & 4461.00 \\
& Total & 118 & & \\
\hline Activity & Education & 35 & 52.94 & 1853.00 \\
& Political Science & 83 & 62.27 & 5168.00 \\
& Total & 118 & & \\
\hline Potency & Education & 35 & 64.21 & 2247.50 \\
& Political Science & 83 & 57.51 & 4773.50 \\
& Total & 118 & & \\
\hline
\end{tabular}

\section{Test Statistics}

\begin{tabular}{|l|r|r|r|}
\hline & Evaluative & \multicolumn{1}{|c|}{ Activity } & \multicolumn{1}{c|}{ Potency } \\
\hline Mann-Whitney U & 975.000 & 1223.000 & 1287.500 \\
Z & -2.814 & -1.353 & -.972 \\
P-Value & .005 & .176 & .331 \\
\hline
\end{tabular}

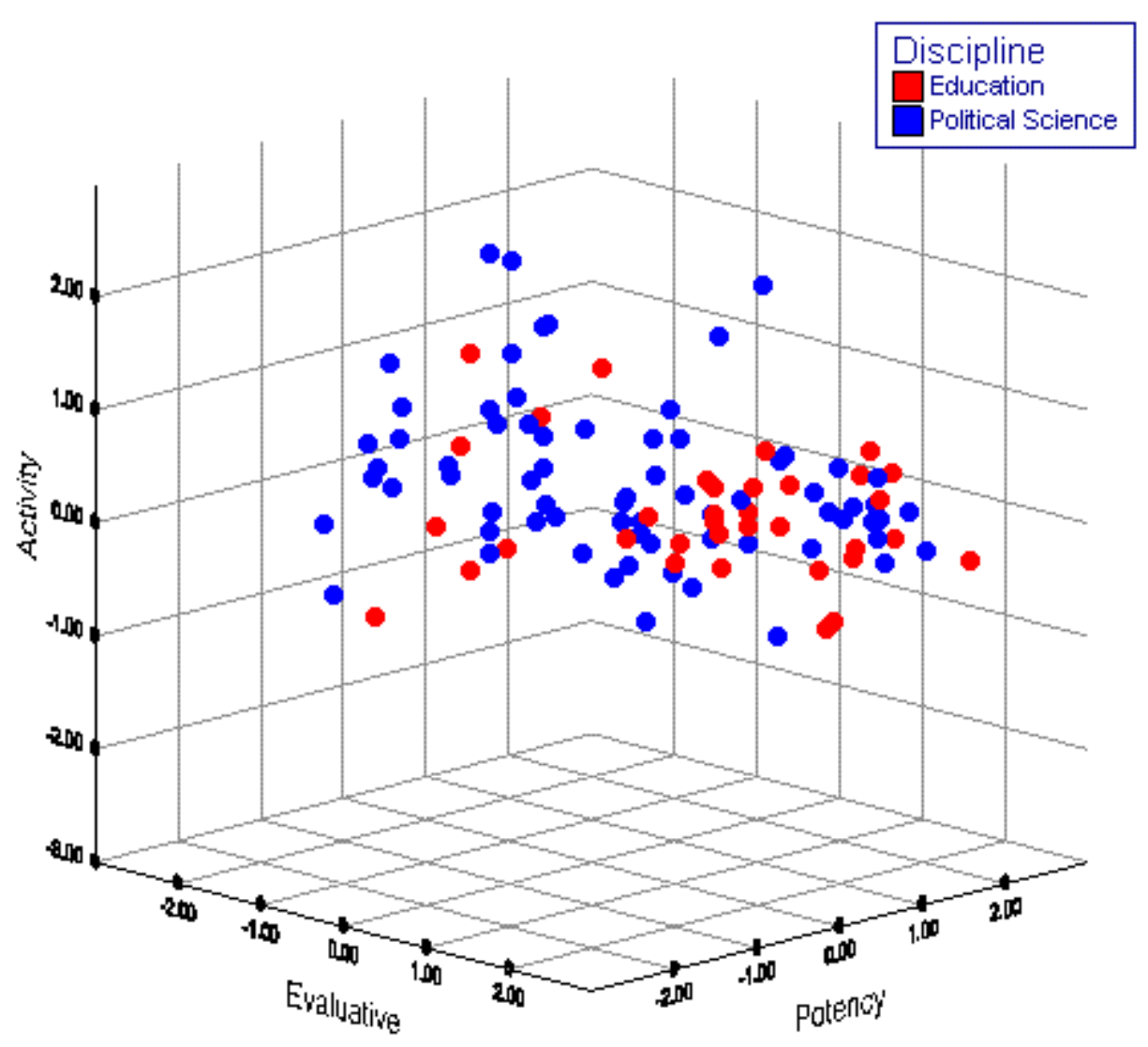


APPENDIX J (continued)

Education v. Writer

\begin{tabular}{|ll|r|r|r|}
\hline & GROUP & $\mathrm{N}$ & Mean Rank & $\begin{array}{c}\text { Sum of } \\
\text { Ranks }\end{array}$ \\
\hline Evaluative & Education & 35 & 71.23 & 2493.00 \\
& Writer & 83 & 54.55 & 4528.00 \\
& Total & 118 & & \\
\hline Activity & Education & 35 & 57.46 & 2011.00 \\
& Writer & 83 & 60.36 & 5010.00 \\
& Total & 118 & & \\
\hline Potency & Education & 35 & 61.09 & 2138.00 \\
& Writer & 83 & 58.83 & 4883.00 \\
& Total & 118 & & \\
\hline
\end{tabular}

Test Statistics

\begin{tabular}{|l|r|r|r|}
\hline & Evaluative & \multicolumn{1}{|c|}{ Activity } & \multicolumn{1}{c|}{ Potency } \\
\hline Mann-Whitney U & 1042.000 & 1381.000 & 1397.000 \\
Z & -2.419 & -.421 & -.327 \\
P-Value & .016 & .673 & .744 \\
\hline
\end{tabular}

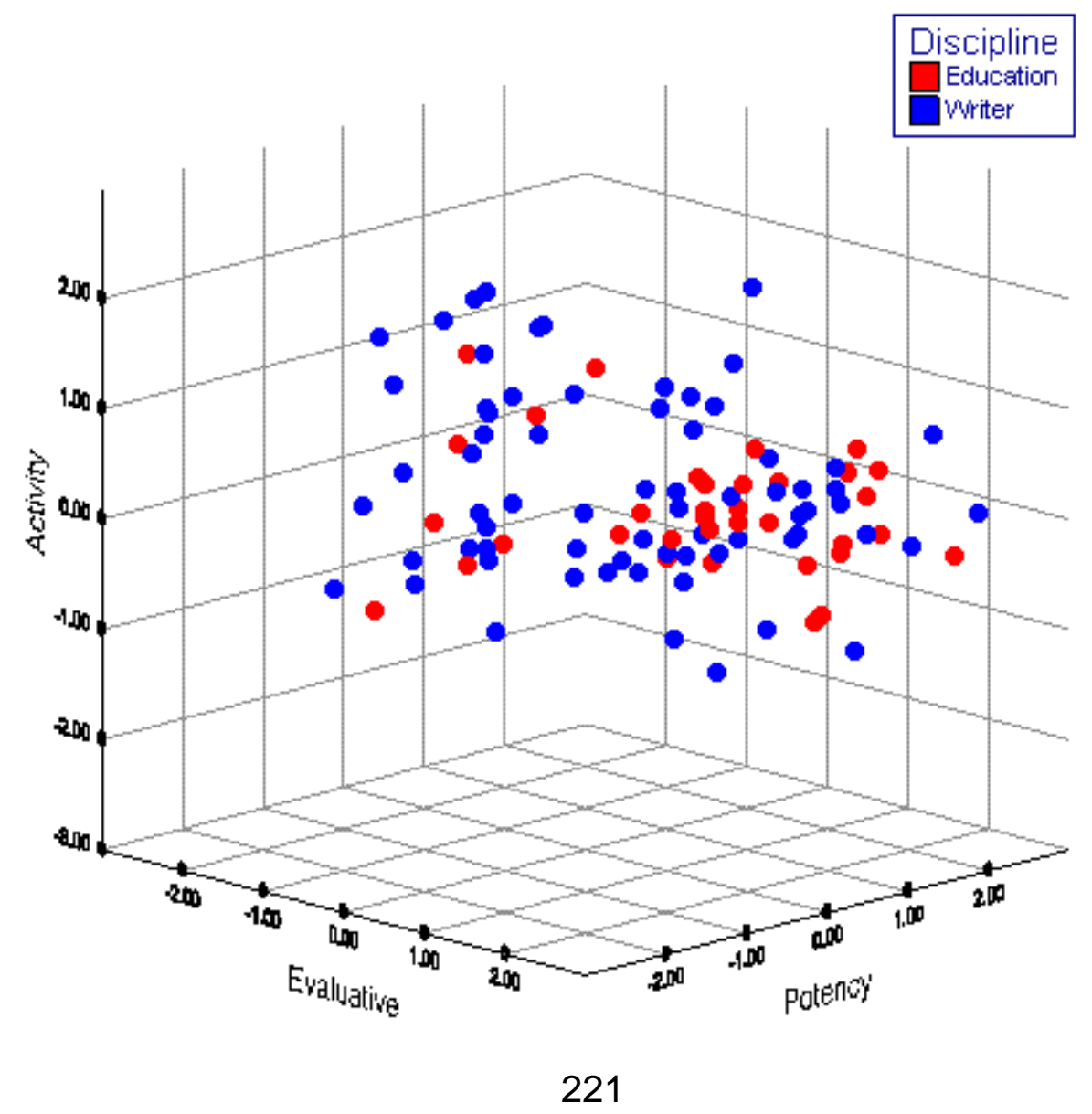




\section{APPENDIX J (continued)}

\section{Engineering v. Natural Science}

\begin{tabular}{|ll|r|r|c|}
\hline & GROUP & $\mathrm{N}$ & Mean Rank & $\begin{array}{c}\text { Sum of } \\
\text { Ranks }\end{array}$ \\
\hline Evaluative & Engineering & 101 & 76.33 & 7709.50 \\
& Natural Science & 40 & 57.54 & 2301.50 \\
& Total & 141 & & \\
\hline Activity & Engineering & 101 & 71.26 & 7197.50 \\
& Natural Science & 40 & 70.34 & 2813.50 \\
& Total & 141 & & \\
\hline Potency & Engineering & 101 & 73.50 & 7423.50 \\
& Natural Science & 40 & 64.69 & 2587.50 \\
& Total & 141 & & \\
\hline
\end{tabular}

Test Statistics

\begin{tabular}{|l|r|r|r|}
\hline & Evaluative & \multicolumn{1}{c|}{ Activity } & \multicolumn{1}{c|}{ Potency } \\
\hline Mann-Whitney U & 1481.500 & 1993.500 & 1767.500 \\
Z & -2.463 & -.121 & -1.155 \\
P-Value & .014 & .903 & .248 \\
\hline
\end{tabular}

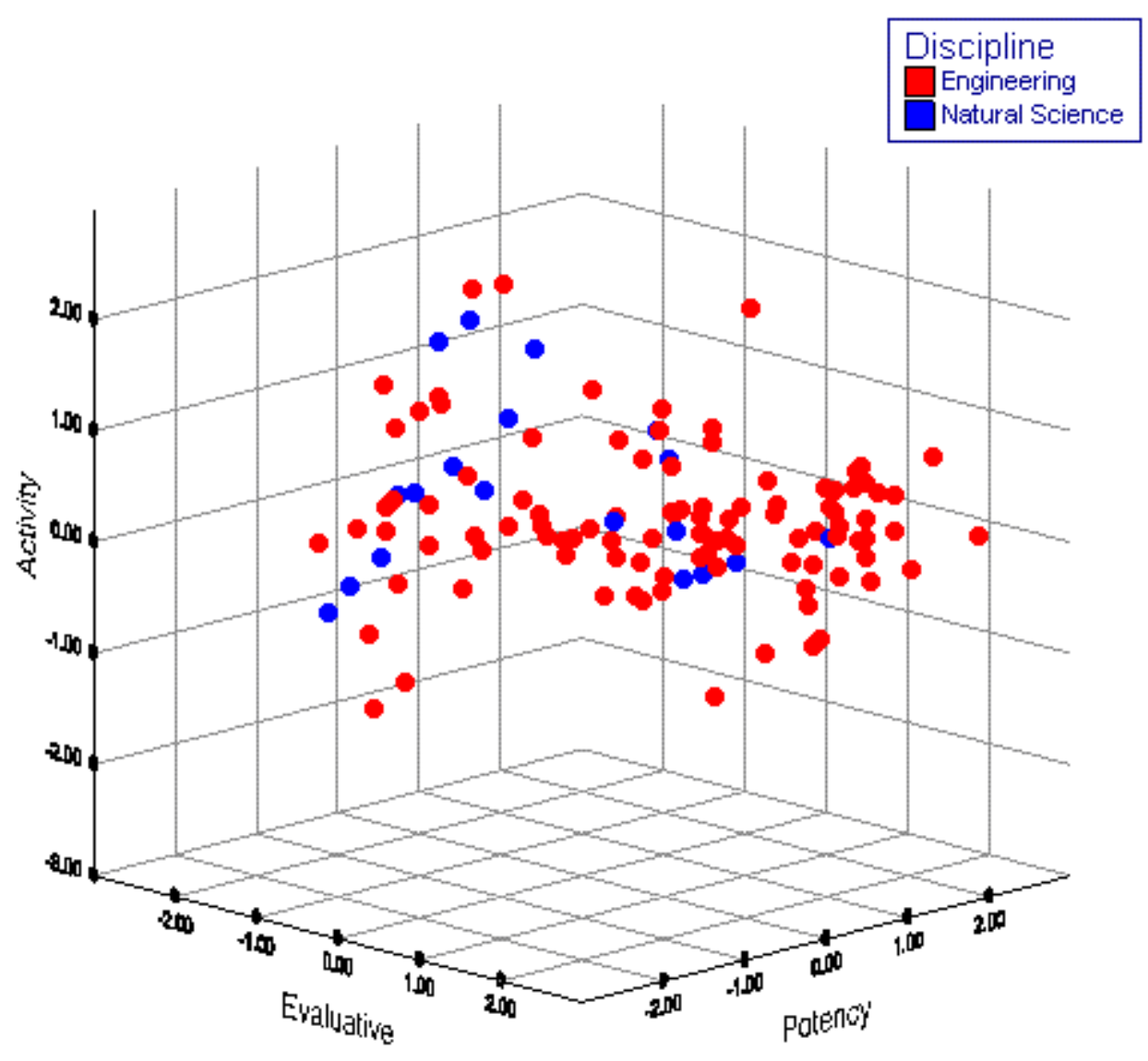


APPENDIX J (continued)

History v. Natural Science

\begin{tabular}{|ll|r|r|r|}
\hline & GRouP & $\mathrm{N}$ & Mean Rank & \multicolumn{1}{c|}{$\begin{array}{c}\text { Sum of } \\
\text { Ranks }\end{array}$} \\
\hline Evaluative & History & 166 & 109.09 & 18109.00 \\
& Natural Science & 40 & 80.30 & 3212.00 \\
& Total & 206 & & \\
\hline Activity & History & 166 & 103.77 & 17225.50 \\
& Natural Science & 40 & 102.39 & 4095.50 \\
& Total & 206 & & \\
\hline Potency & History & 166 & 106.53 & 17684.50 \\
& Natural Science & 40 & 90.91 & 3636.50 \\
& Total & 206 & & \\
\hline
\end{tabular}

Test Statistics

\begin{tabular}{|l|r|r|r|}
\hline & Evaluative & \multicolumn{1}{|c|}{ Activity } & \multicolumn{1}{c|}{ Potency } \\
\hline Mann-Whitney U & 2392.000 & 3275.500 & 2816.500 \\
Z & -2.742 & -.132 & -1.488 \\
P-Value & .006 & .895 & .137 \\
\hline
\end{tabular}

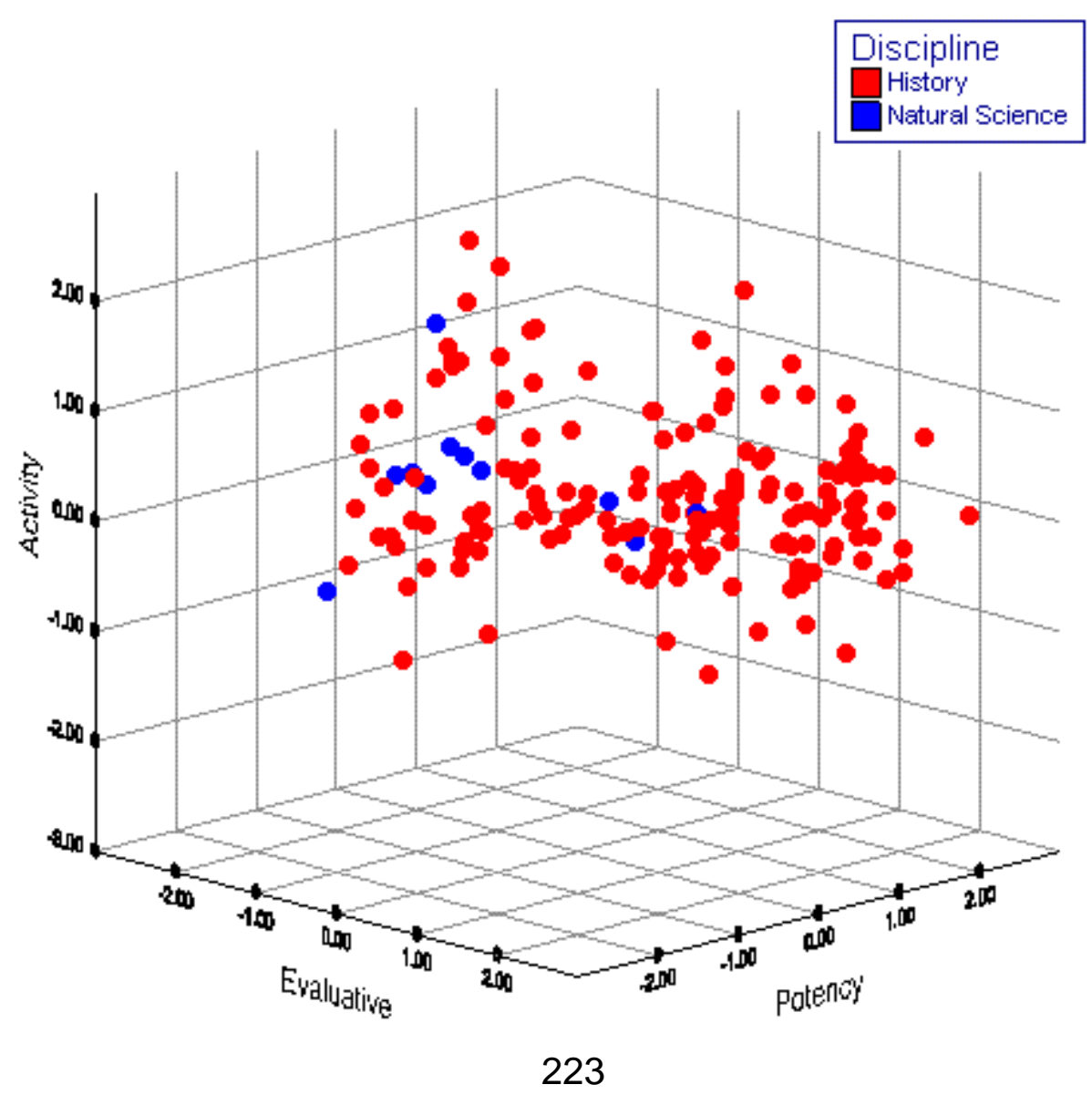


APPENDIX J (continued)

History v. Physical Science

\begin{tabular}{|ll|r|r|r|}
\hline & GROUP & $\mathrm{N}$ & Mean Rank & \multicolumn{1}{c|}{$\begin{array}{c}\text { Sum of } \\
\text { Ranks }\end{array}$} \\
\hline Evaluative & History & 166 & 115.53 & 19178.50 \\
& Physical Science & 77 & 135.94 & 10467.50 \\
& Total & 243 & & \\
\hline Activity & History & 166 & 120.37 & 19981.50 \\
& Physical Science & 77 & 125.51 & 9664.50 \\
& Total & 243 & & \\
\hline Potency & History & 166 & 115.14 & 19114.00 \\
& Physical Science & 77 & 136.78 & 10532.00 \\
& Total & 243 & & \\
\hline
\end{tabular}

Test Statistics

\begin{tabular}{|l|r|r|r|}
\hline & Evaluative & \multicolumn{1}{c|}{ Activity } & \multicolumn{1}{c|}{ Potency } \\
\hline Mann-Whitney U & 5317.500 & 6120.500 & 5253.000 \\
Z & -2.106 & -.531 & -2.233 \\
P-Value & .035 & .595 & .026 \\
\hline
\end{tabular}

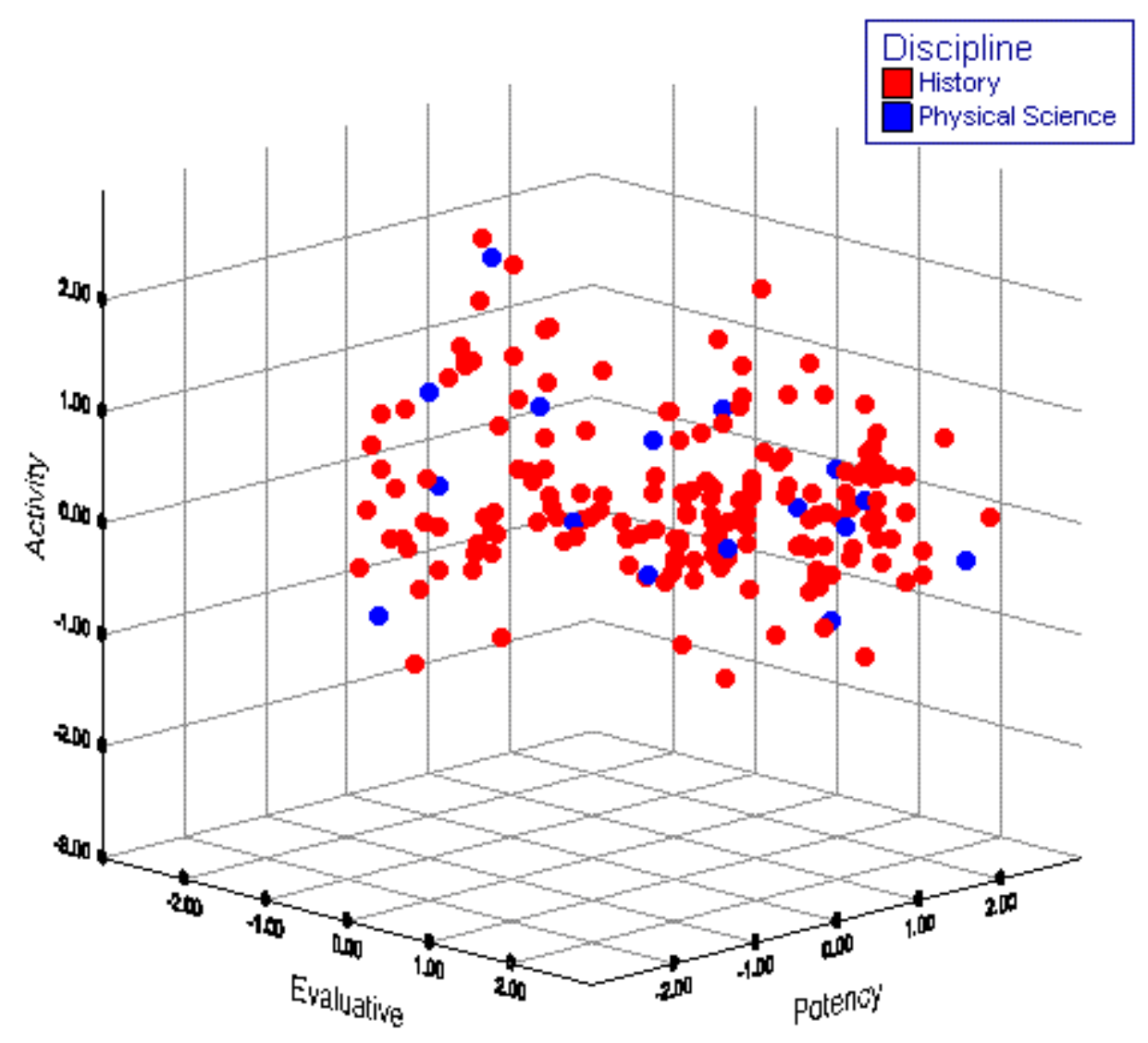


APPENDIX J (continued)

History v. Political Science

\begin{tabular}{|ll|r|r|r|}
\hline & GRouP & $\mathrm{N}$ & Mean Rank & \multicolumn{1}{c|}{$\begin{array}{c}\text { Sum of } \\
\text { Ranks }\end{array}$} \\
\hline Evaluative & History & 166 & 132.08 & 21926.00 \\
& Political Science & 83 & 110.83 & 9199.00 \\
& Total & 249 & & \\
\hline Activity & History & 166 & 122.92 & 20405.00 \\
& Political Science & 83 & 129.16 & 10720.00 \\
& Total & 249 & & \\
\hline Potency & History & 166 & 128.37 & 21309.50 \\
& Political Science & 83 & 118.26 & 9815.50 \\
& Total & 249 & & \\
\hline
\end{tabular}

Test Statistics

\begin{tabular}{|l|r|r|r|}
\hline & Evaluative & \multicolumn{1}{|c|}{ Activity } & \multicolumn{1}{c|}{ Potency } \\
\hline Mann-Whitney U & 5713.000 & 6544.000 & 6329.500 \\
Z & -2.195 & -.644 & -1.044 \\
P-Value & .028 & .519 & .296 \\
\hline
\end{tabular}

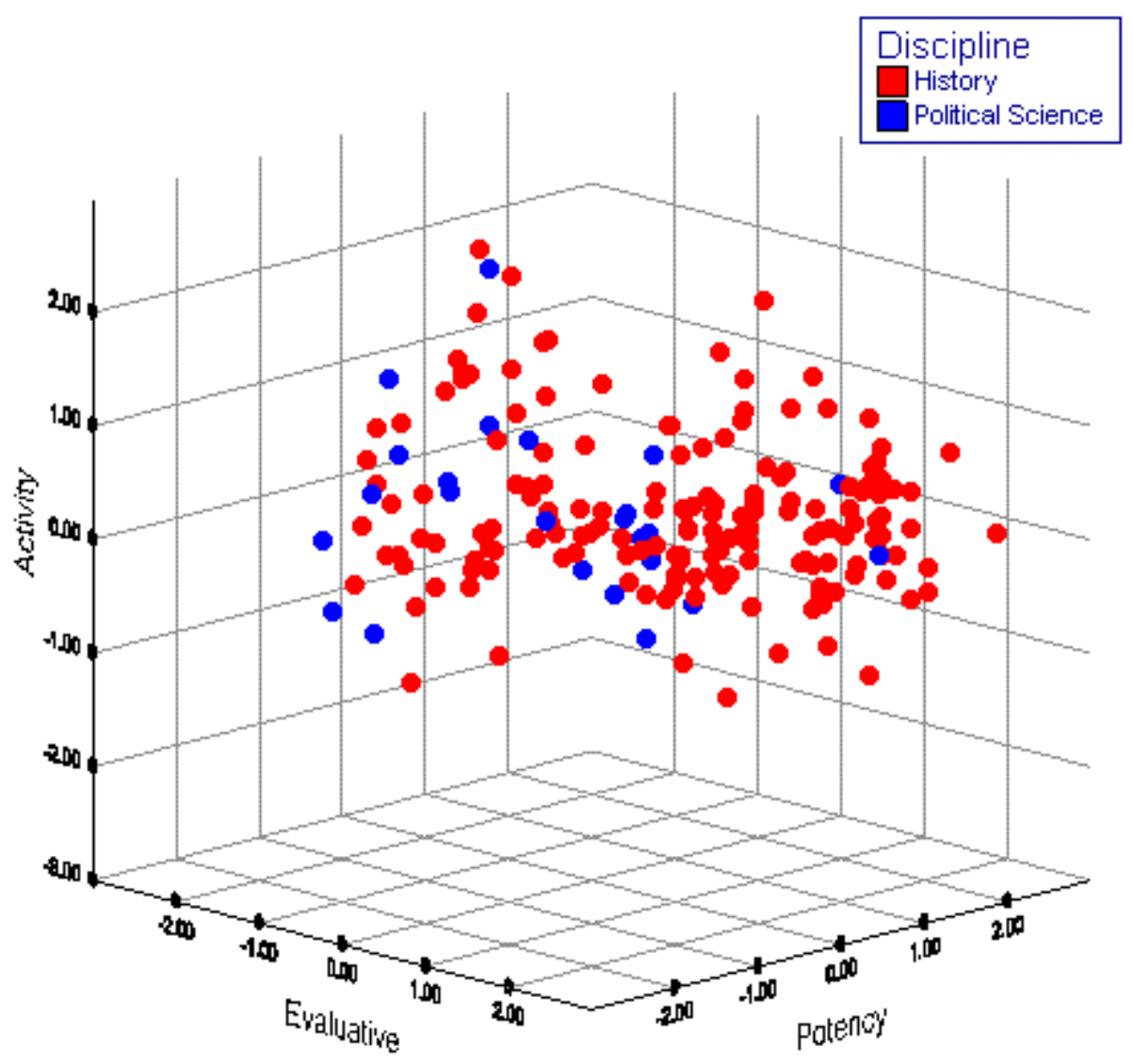


APPENDIX J (continued)

Literature v. Physical Science

\begin{tabular}{|ll|r|r|r|}
\hline & GRouP & $\mathrm{N}$ & Mean Rank & $\begin{array}{c}\text { Sum of } \\
\text { Ranks }\end{array}$ \\
\hline Evaluative & Literature & 35 & 42.34 & 1482.00 \\
& Physical Science & 77 & 62.94 & 4846.00 \\
& Total & 112 & & \\
\hline Activity & Literature & 35 & 51.90 & 1816.50 \\
& Physical Science & 77 & 58.59 & 4511.50 \\
& Total & 112 & & \\
\hline Potency & Literature & 35 & 41.69 & 1459.00 \\
& Physical Science & 77 & 63.23 & 4869.00 \\
& Total & 112 & & \\
\hline
\end{tabular}

Test Statistics

\begin{tabular}{|l|r|r|r|}
\hline & Evaluative & \multicolumn{1}{|c|}{ Activity } & \multicolumn{1}{c|}{ Potency } \\
\hline Mann-Whitney U & 852.000 & 1186.500 & 829.000 \\
Z & -3.111 & -1.011 & -3.256 \\
P-Value & .002 & .312 & .001 \\
\hline
\end{tabular}

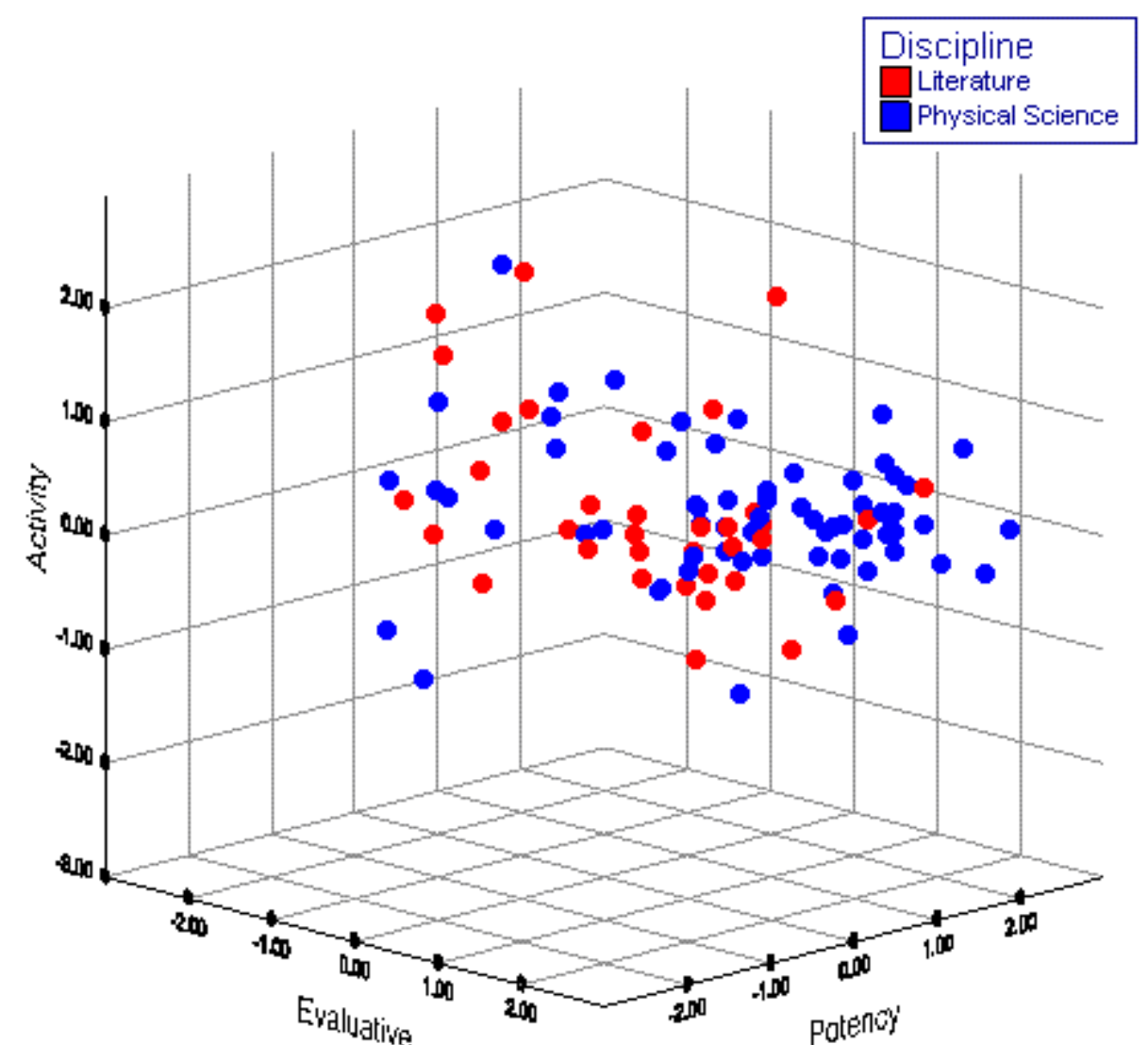


APPENDIX J (continued)

Mathematics v. Physical Science

\begin{tabular}{|ll|r|r|r|}
\hline & GROUP & $\mathrm{N}$ & Mean Rank & $\begin{array}{c}\text { Sum of } \\
\text { Ranks }\end{array}$ \\
\hline Evaluative & Mathematics & 50 & 55.79 & 2789.50 \\
& Physical Science & 77 & 69.33 & 5338.50 \\
& Total & 127 & & \\
\hline Activity & Mathematics & 50 & 65.47 & 3273.50 \\
& Physical Science & 77 & 63.05 & 4854.50 \\
& Total & 127 & & \\
\hline Potency & Mathematics & 50 & 57.23 & 2861.50 \\
& Physical Science & 77 & 68.40 & 5266.50 \\
& Total & 127 & & \\
\hline
\end{tabular}

Test Statistics

\begin{tabular}{|l|r|r|r|}
\hline & Evaluative & \multicolumn{1}{|c|}{ Activity } & \multicolumn{1}{c|}{ Potency } \\
\hline Mann-Whitney U & 1514.500 & 1851.500 & 1586.500 \\
Z & -2.026 & -.363 & -1.671 \\
P-Value & .043 & .717 & .095 \\
\hline
\end{tabular}

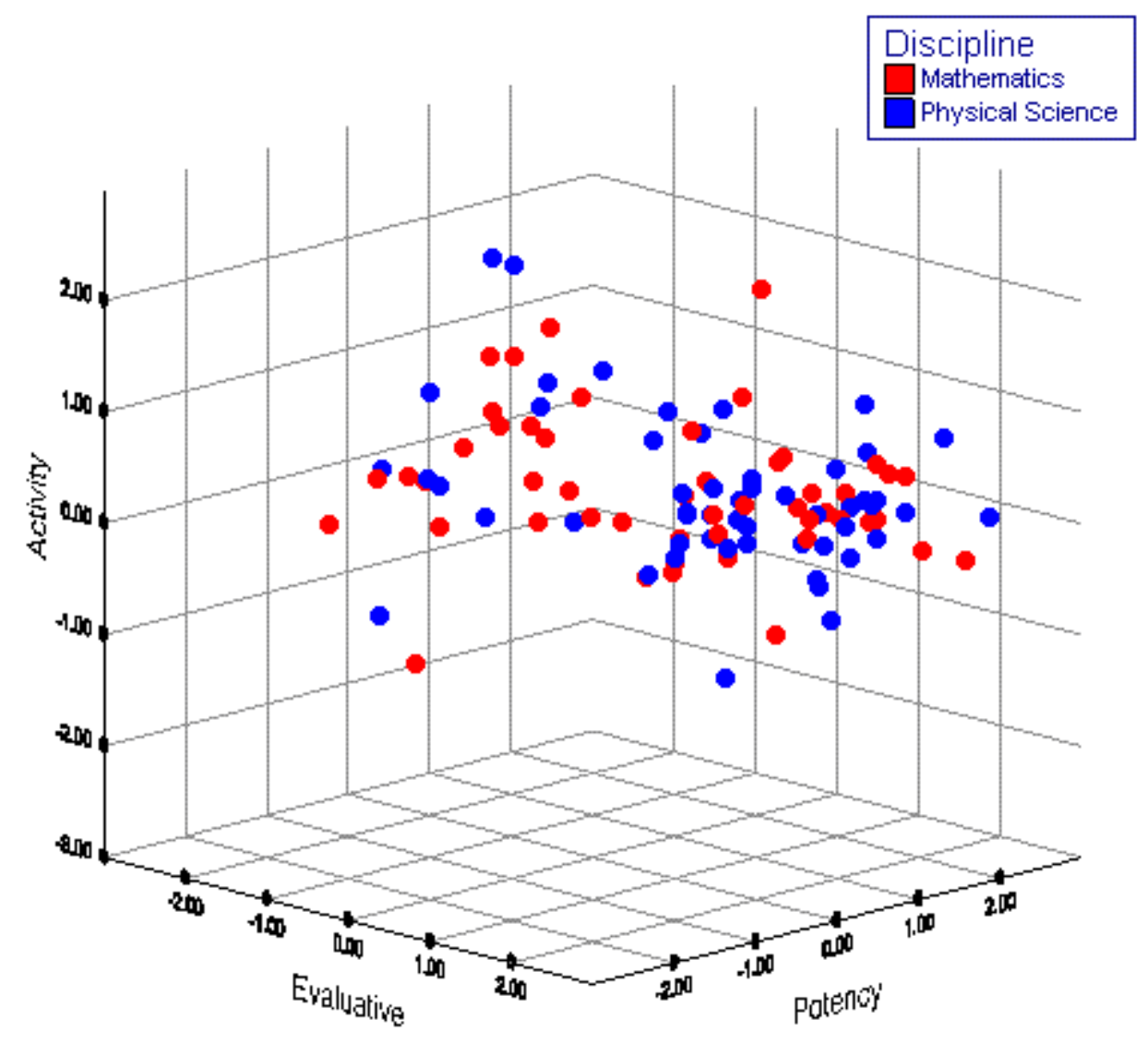


APPENDIX J (continued)

Natural Science v. Physical Science

\begin{tabular}{|ll|r|r|r}
\hline & GROUP & $\mathrm{N}$ & Mean Rank & $\begin{array}{c}\text { Sum of } \\
\text { Ranks }\end{array}$ \\
\hline Evaluative & Natural Science & 40 & 42.54 & 1701.50 \\
& Physical Science & 77 & 67.55 & 5201.50 \\
& Total & 117 & & \\
\hline Activity & Natural Science & 40 & 56.28 & 2251.00 \\
& Physical Science & 77 & 60.42 & 4652.00 \\
& Total & 117 & & \\
\hline Potency & Natural Science & 40 & 46.28 & 1851.00 \\
& Physical Science & 77 & 65.61 & 5052.00 \\
& Total & 117 & & \\
\hline
\end{tabular}

Test Statistics

\begin{tabular}{|l|r|r|r|}
\hline & Evaluative & \multicolumn{1}{|c|}{ Activity } & \multicolumn{1}{c|}{ Potency } \\
\hline Mann-Whitney U & 881.500 & 1431.000 & 1031.000 \\
Z & -3.784 & -.627 & -2.926 \\
P-Value & .000 & .531 & .003 \\
\hline
\end{tabular}

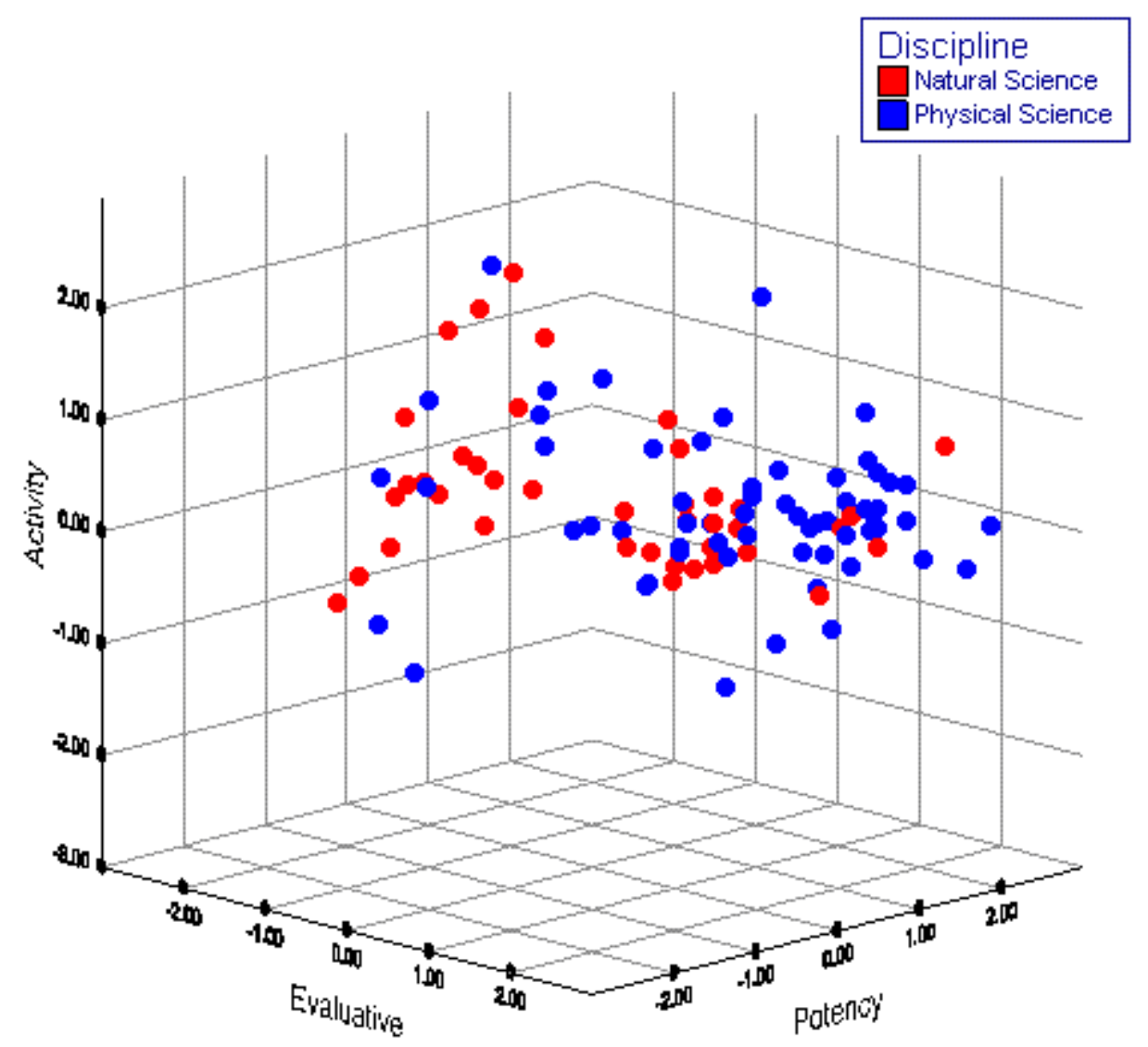


Natural Science v. Social Science \& Psychology

\begin{tabular}{|ll|r|r|r|}
\hline & & & & \multicolumn{1}{c|}{$\begin{array}{c}\text { Sum of } \\
\text { Ranks }\end{array}$} \\
\hline Evaluative & Natural Science & N & Mean Rank & 2100.00 \\
& Social Science \& Psychology & 86 & 52.50 & 5901.00 \\
& Total & 126 & & \\
\hline Activity & Natural Science & 40 & 67.28 & 2691.00 \\
& Social Science \& Psychology & 86 & 61.74 & 5310.00 \\
& Total & 126 & & \\
\hline Potency & Natural Science & 40 & 57.06 & 2282.50 \\
& Social Science \& Psychology & 86 & 66.49 & 5718.50 \\
& Total & 126 & & \\
\hline
\end{tabular}

Test Statistics

\begin{tabular}{|l|r|r|r|}
\hline & Evaluative & \multicolumn{1}{|c|}{ Activity } & \multicolumn{1}{c|}{ Potency } \\
\hline Mann-Whitney U & 1280.000 & 1569.000 & 1462.500 \\
Z & -2.306 & -.792 & -1.350 \\
P-Value & .021 & .428 & .177 \\
\hline
\end{tabular}

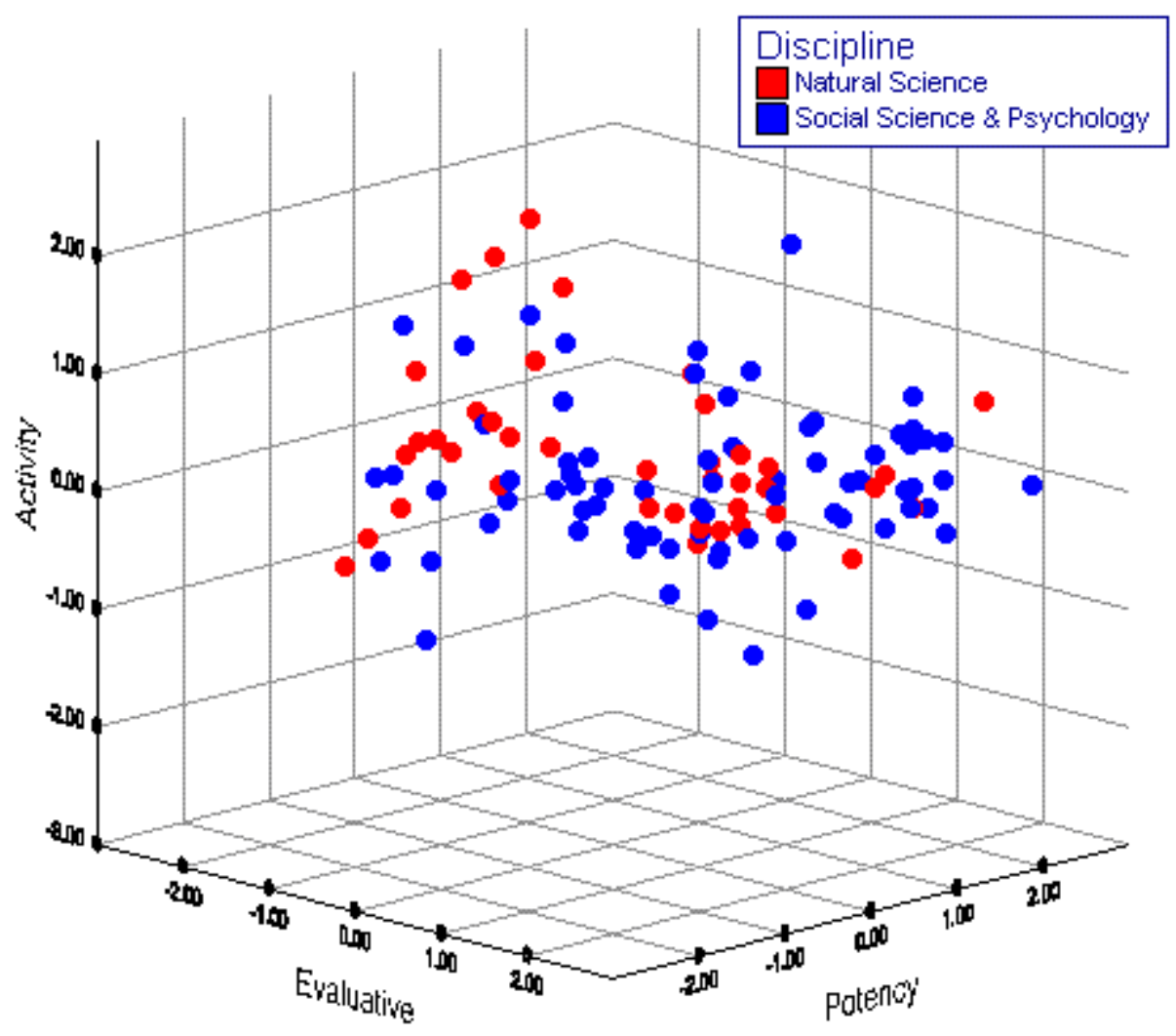


APPENDIX J (continued)

Philosophy v. Physical Science

\begin{tabular}{|ll|r|r|r|}
\hline & GROUP & $\mathrm{N}$ & Mean Rank & \multicolumn{1}{c|}{$\begin{array}{c}\text { Sum of } \\
\text { Ranks }\end{array}$} \\
\hline Evaluative & Philosophy & 126 & 91.37 & 11512.50 \\
& Physical Science & 77 & 119.40 & 9193.50 \\
& Total & 203 & & \\
\hline Activity & Philosophy & 126 & 101.51 & 12790.00 \\
& Physical Science & 77 & 102.81 & 7916.00 \\
& Total & 203 & & \\
\hline Potency & Philosophy & 126 & 92.37 & 11638.50 \\
& Physical Science & 77 & 117.76 & 9067.50 \\
& Total & 203 & & \\
\hline
\end{tabular}

Test Statistics

\begin{tabular}{|l|r|r|r|}
\hline & Evaluative & \multicolumn{1}{|c|}{ Activity } & \multicolumn{1}{|c|}{ Potency } \\
\hline Mann-Whitney U & 3511.500 & 4789.000 & 3637.500 \\
Z & -3.299 & -.153 & -2.989 \\
P-Value & .001 & .879 & .003 \\
\hline
\end{tabular}

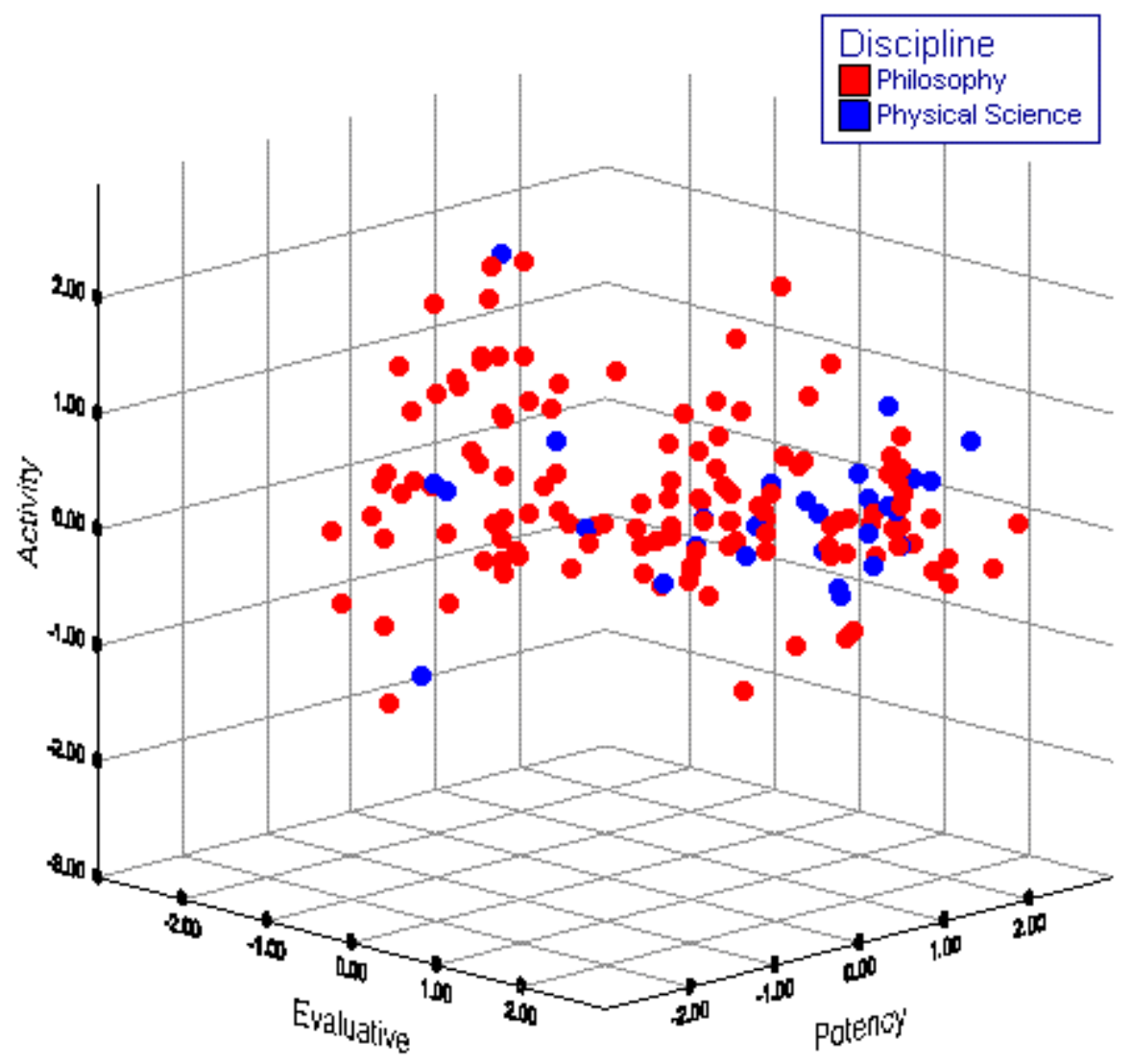


Physical Science v. Political Science

\begin{tabular}{|ll|r|r|c|}
\hline & GRouP & $\mathrm{N}$ & Mean Rank & $\begin{array}{c}\text { Sum of } \\
\text { Ranks }\end{array}$ \\
\hline Evaluative & Physical Science & 77 & 94.55 & 7280.50 \\
& Political Science & 83 & 67.46 & 5599.50 \\
& Total & 160 & & \\
\hline Activity & Physical Science & 77 & 79.98 & 6158.50 \\
& Political Science & 83 & 80.98 & 6721.50 \\
& Total & 160 & & \\
\hline Potency & Physical Science & 77 & 91.29 & 7029.00 \\
& Political Science & 83 & 70.49 & 5851.00 \\
& Total & 160 & & \\
\hline
\end{tabular}

Test Statistics

\begin{tabular}{|l|r|r|r|}
\hline & Evaluative & \multicolumn{1}{|c|}{ Activity } & \multicolumn{1}{c|}{ Potency } \\
\hline Mann-Whitney U & 2113.500 & 3155.500 & 2365.000 \\
Z & -3.695 & -.137 & -2.837 \\
P-Value & .000 & .891 & .005 \\
\hline
\end{tabular}

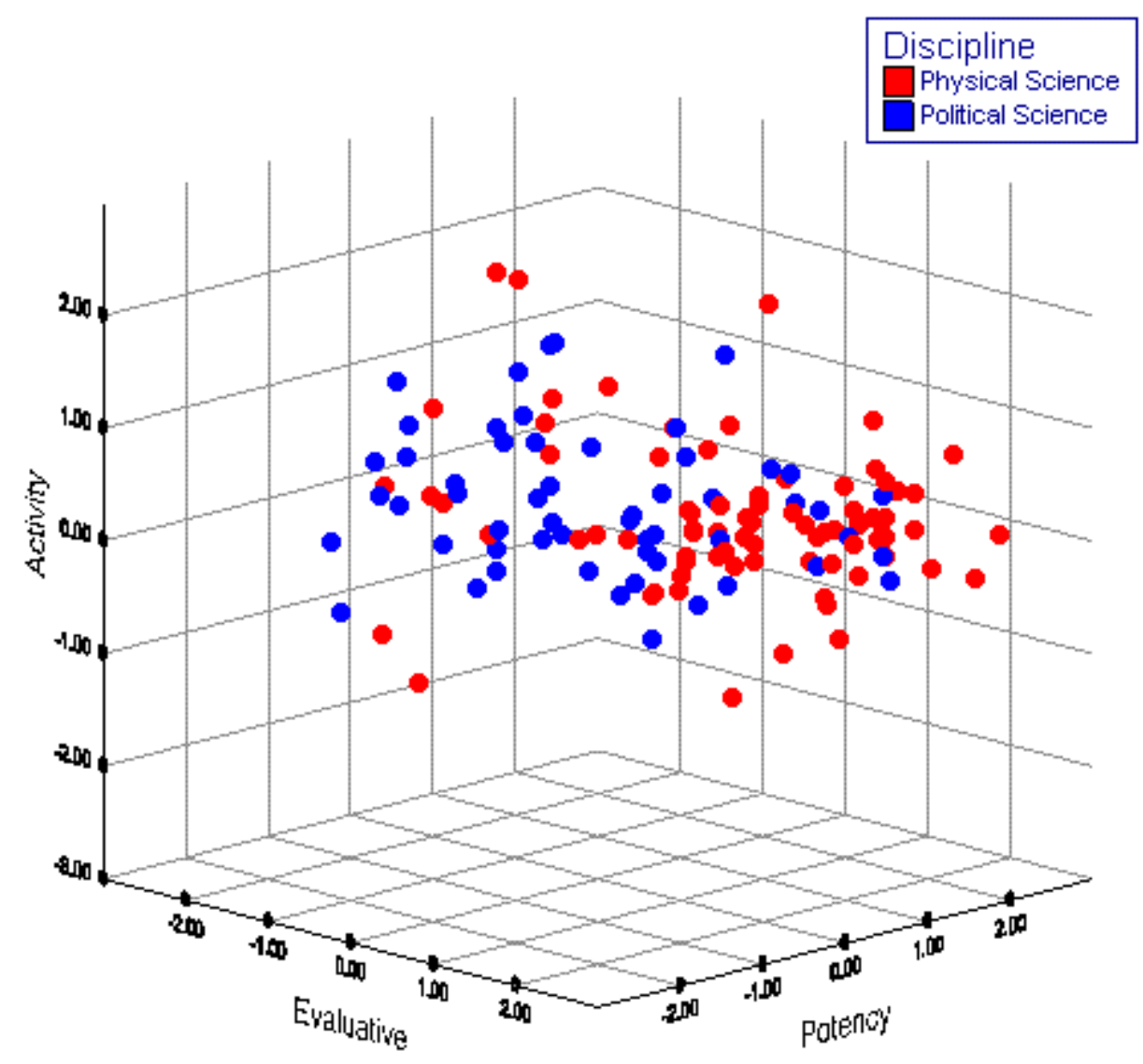


Physical Science v. Social Science \& Psychology

\begin{tabular}{|ll|r|r|r|}
\hline & GROUP & $\mathrm{N}$ & Mean Rank & \multicolumn{1}{c|}{$\begin{array}{c}\text { Ranks of } \\
\text { Evaluative }\end{array}$} \\
& Physical Science & 77 & 90.64 & 6979.50 \\
& Social Science \& Psychology & 86 & 74.26 & 6386.50 \\
& Total & 163 & & \\
\hline Activity & Physical Science & 77 & 87.99 & 6775.50 \\
& Social Science \& Psychology & 86 & 76.63 & 6590.50 \\
& Total & 163 & & \\
\hline Potency & Physical Science & 77 & 89.65 & 6903.00 \\
& Social Science \& Psychology & 86 & 75.15 & 6463.00 \\
& Total & 163 & & \\
\hline
\end{tabular}

Test Statistics

\begin{tabular}{|l|r|r|r|}
\hline & Evaluative & \multicolumn{1}{|c|}{ Activity } & \multicolumn{1}{c|}{ Potency } \\
\hline Mann-Whitney U & 2645.500 & 2849.500 & 2722.000 \\
Z & -2.212 & -1.535 & -1.958 \\
P-Value & .027 & .125 & .050 \\
\hline
\end{tabular}

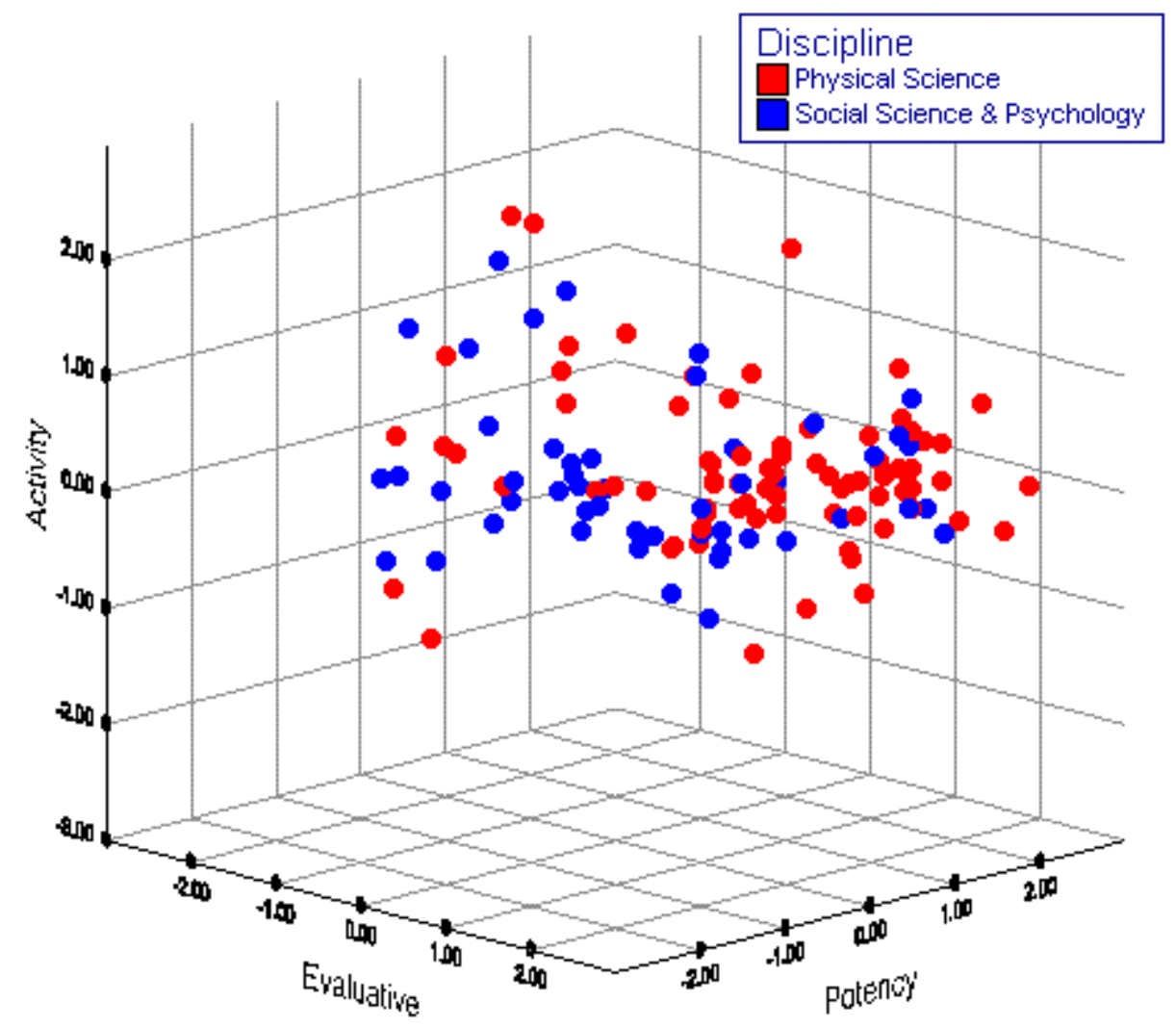


Physical Science v. Technology \& Society

\begin{tabular}{|ll|r|r|c|}
\hline & GROUP & $\mathrm{N}$ & Mean Rank & $\begin{array}{c}\text { Sum of } \\
\text { Ranks }\end{array}$ \\
\hline Evaluative & Physical Science & 77 & 68.81 & 5298.50 \\
& Technology \& Society & 48 & 53.68 & 2576.50 \\
& Total & 125 & & \\
\hline Activity & Physical Science & 77 & 63.62 & 4899.00 \\
& Technology \& Society & 48 & 62.00 & 2976.00 \\
& Total & 125 & & \\
\hline Potency & Physical Science & 77 & 67.00 & 5159.00 \\
& Technology \& Society & 48 & 56.58 & 2716.00 \\
& Total & 125 & & \\
\hline
\end{tabular}

Test Statistics

\begin{tabular}{|l|r|r|r|}
\hline & Evaluative & \multicolumn{1}{c|}{ Activity } & \multicolumn{1}{c|}{ Potency } \\
\hline Mann-Whitney U & 1400.500 & 1800.000 & 1540.000 \\
Z & -2.272 & -.244 & -1.564 \\
P-Value & .023 & .807 & .118 \\
\hline
\end{tabular}

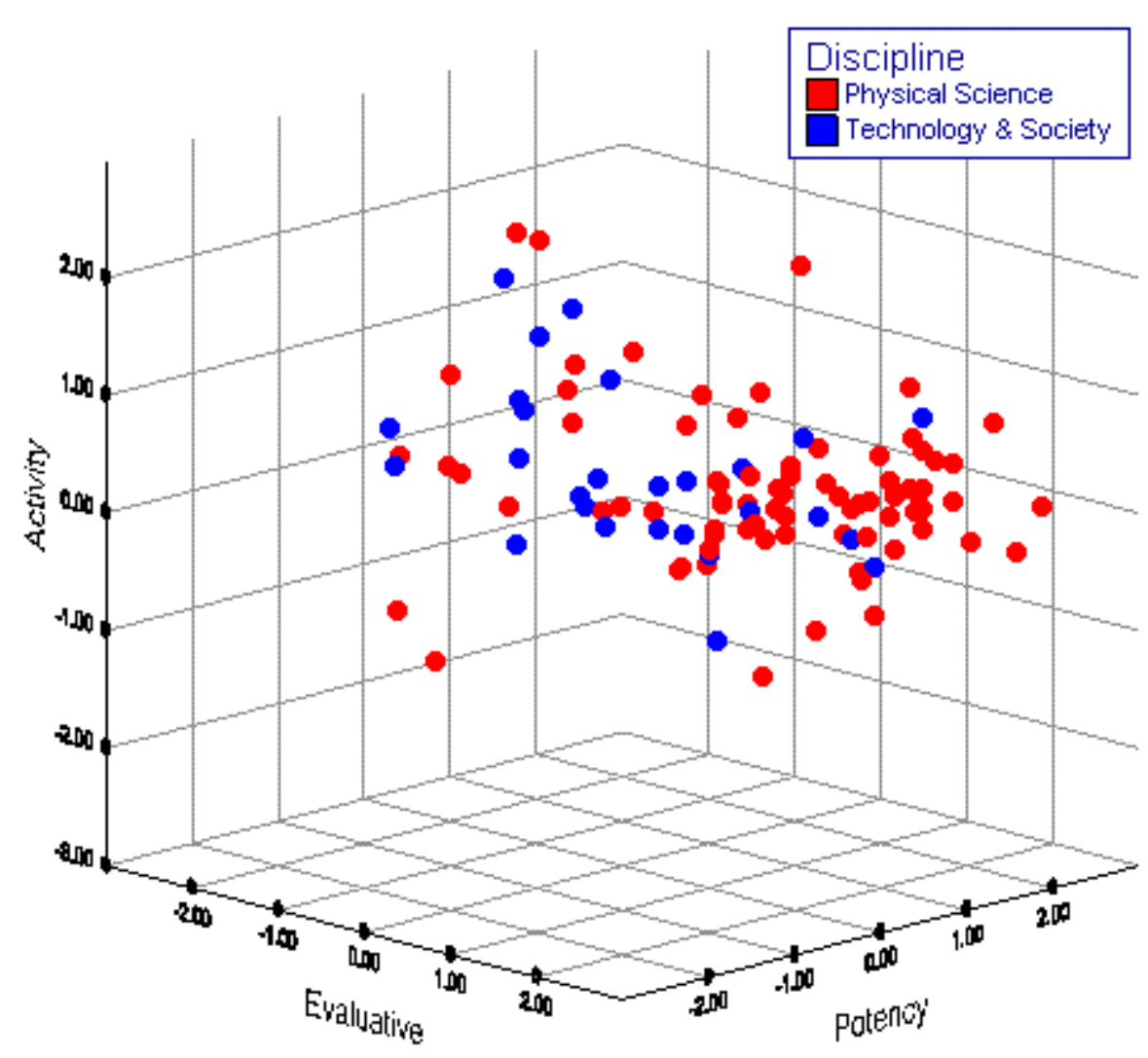


APPENDIX J (continued)

Physical Science v. Theology

\begin{tabular}{|ll|r|r|c|}
\hline & GROUP & $\mathrm{N}$ & Mean Rank & $\begin{array}{c}\text { Sum of } \\
\text { Ranks }\end{array}$ \\
\hline Evaluative & Physical Science & 77 & 61.06 & 4702.00 \\
& Theology & 35 & 46.46 & 1626.00 \\
& Total & 112 & & \\
\hline Activity & Physical Science & 77 & 59.86 & 4609.50 \\
& Theology & 35 & 49.10 & 1718.50 \\
& Total & 112 & & \\
\hline Potency & Physical Science & 77 & 60.38 & 4649.50 \\
& Theology & 35 & 47.96 & 1678.50 \\
& Total & 112 & & \\
\hline
\end{tabular}

Test Statistics

\begin{tabular}{|l|r|r|r|}
\hline & Evaluative & \multicolumn{1}{|c|}{ Activity } & \multicolumn{1}{c|}{ Potency } \\
\hline Mann-Whitney U & 996.000 & 1088.500 & 1048.500 \\
Z & -2.207 & -1.627 & -1.877 \\
P-Value & .027 & .104 & .060 \\
\hline
\end{tabular}

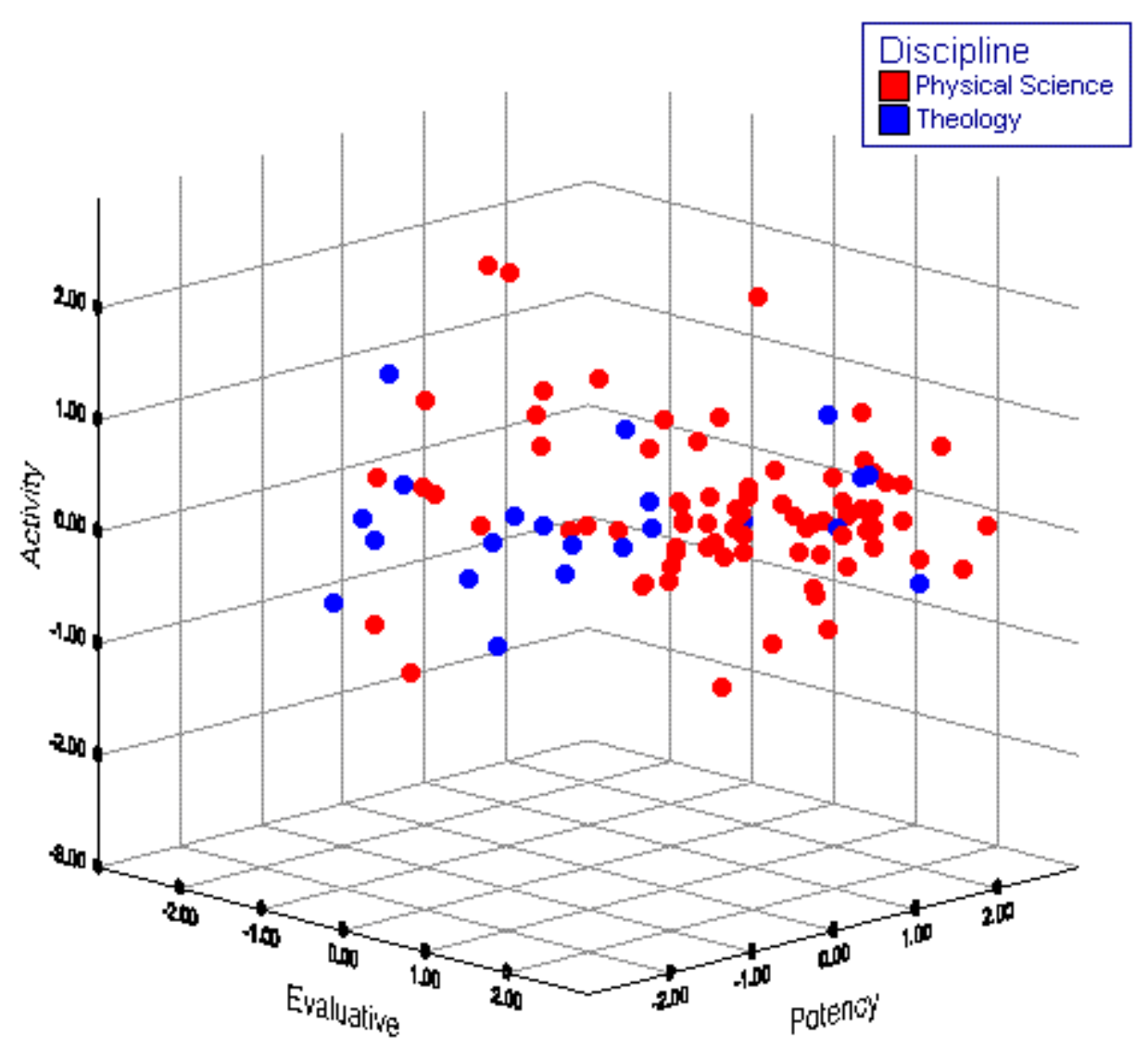


APPENDIX J (continued)

Physical Science v. Writer

\begin{tabular}{|ll|r|r|c|}
\hline & GROUP & $\mathrm{N}$ & Mean Rank & $\begin{array}{c}\text { Sum of } \\
\text { Ranks }\end{array}$ \\
\hline Evaluative & Physical Science & 77 & 92.58 & 7128.50 \\
& Writer & 83 & 69.30 & 5751.50 \\
& Total & 160 & & \\
\hline Activity & Physical Science & 77 & 83.28 & 6412.50 \\
& Writer & 83 & 77.92 & 6467.50 \\
& Total & 160 & & \\
\hline Potency & Physical Science & 77 & 89.23 & 6870.50 \\
& Writer & 83 & 72.40 & 6009.50 \\
& Total & 160 & & \\
\hline
\end{tabular}

Test Statistics

\begin{tabular}{|l|r|r|r|}
\hline & Evaluative & \multicolumn{1}{|c|}{ Activity } & \multicolumn{1}{c|}{ Potency } \\
\hline Mann-Whitney U & 2265.500 & 2981.500 & 2523.500 \\
Z & -3.176 & -.731 & -2.296 \\
P-Value & .001 & .465 & .022 \\
\hline
\end{tabular}

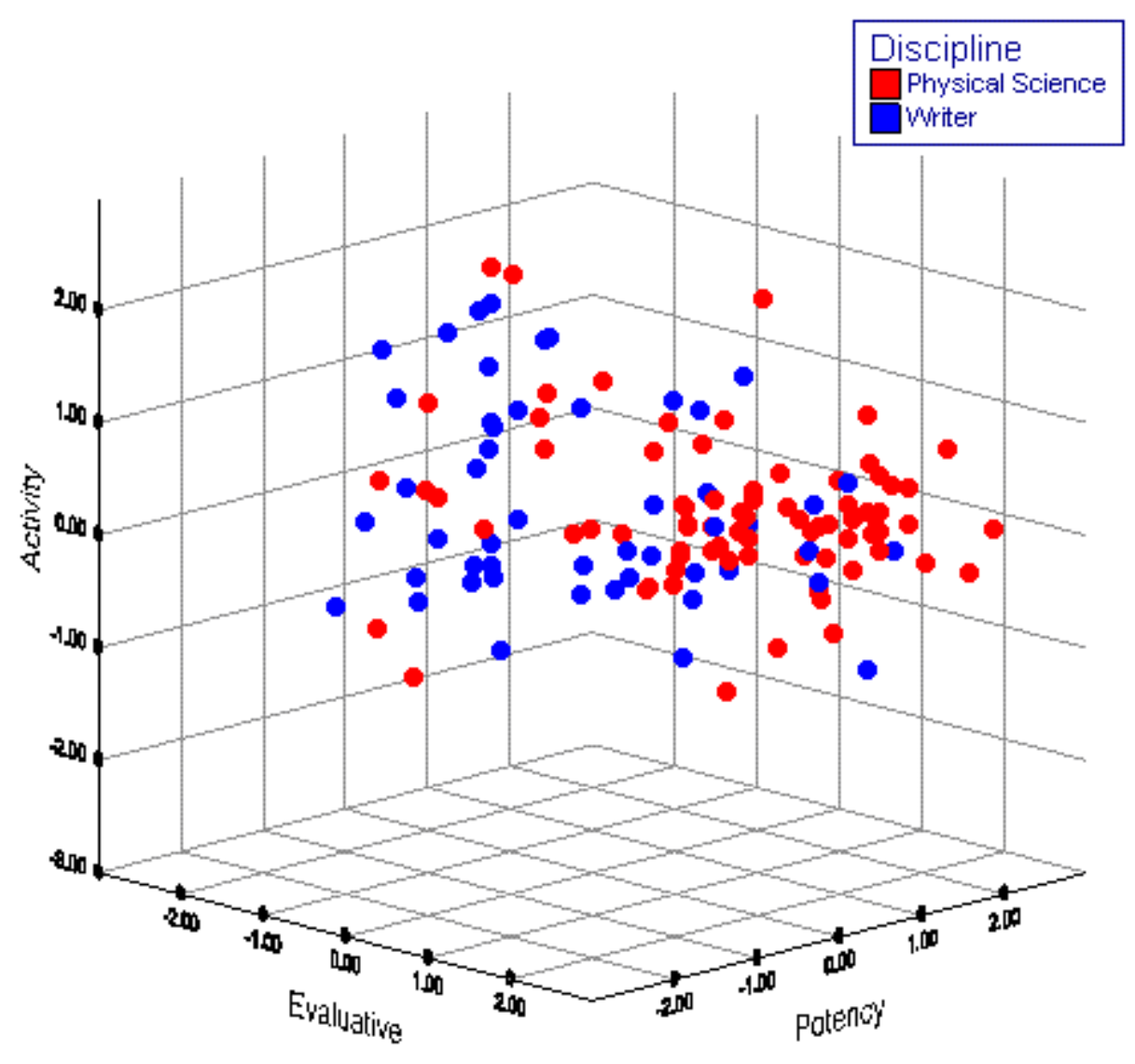


APPENDIX J (continued)

Engineering v. Physical Science

\begin{tabular}{|ll|r|r|r|}
\hline & GROUP & $\mathrm{N}$ & Mean Rank & $\begin{array}{c}\text { Sum of } \\
\text { Ranks }\end{array}$ \\
\hline Evaluative & Engineering & 101 & 83.28 & 8411.50 \\
& Physical Science & 77 & 97.66 & 7519.50 \\
& Total & 178 & & \\
\hline Activity & Engineering & 101 & 87.77 & 8865.00 \\
& Physical Science & 77 & 91.77 & 7066.00 \\
& Total & 178 & & \\
\hline Potency & Engineering & 101 & 81.76 & 8257.50 \\
& Physical Science & 77 & 99.66 & 7673.50 \\
& Total & 178 & & \\
\hline
\end{tabular}

Test Statistics

\begin{tabular}{|l|r|r|r|}
\hline & Evaluative & \multicolumn{1}{|c|}{ Activity } & \multicolumn{1}{|c|}{ Potency } \\
\hline Mann-Whitney U & 3260.500 & 3714.000 & 3106.500 \\
Z & -1.844 & -.513 & -2.296 \\
P-Value & .065 & .608 & .022 \\
\hline
\end{tabular}

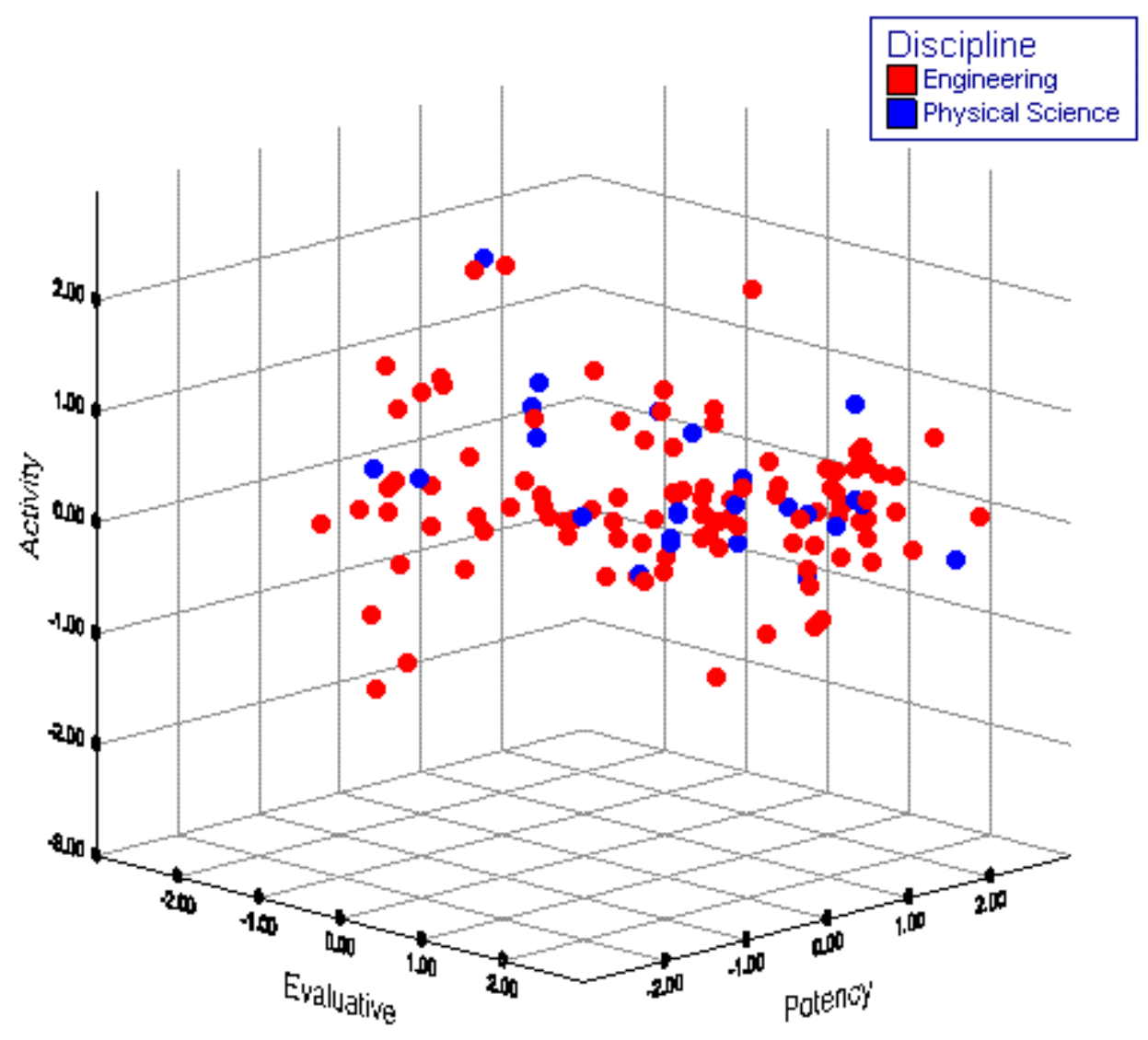


APPENDIX J (continued)

Architecture v. Physical Science

\begin{tabular}{|ll|r|r|r|}
\hline & GRouP & $\mathrm{N}$ & Mean Rank & \multicolumn{1}{c|}{$\begin{array}{c}\text { Sum of } \\
\text { Ranks }\end{array}$} \\
\hline Evaluative & Architecture & 21 & 39.40 & 827.50 \\
& Physical Science & 77 & 52.25 & 4023.50 \\
& Total & 98 & & \\
\hline Activity & Architecture & 21 & 52.10 & 1094.00 \\
& Physical Science & 77 & 48.79 & 3757.00 \\
& Total & 98 & & \\
\hline Potency & Architecture & 21 & 38.33 & 805.00 \\
& Physical Science & 77 & 52.55 & 4046.00 \\
& Total & 98 & & \\
\hline
\end{tabular}

Test Statistics

\begin{tabular}{|l|r|r|r|}
\hline & Evaluative & \multicolumn{1}{|c|}{ Activity } & \multicolumn{1}{|c|}{ Potency } \\
\hline Mann-Whitney U & 596.500 & 754.000 & 574.000 \\
Z & -1.836 & -.472 & -2.031 \\
P-Value & .066 & .637 & .042 \\
\hline
\end{tabular}

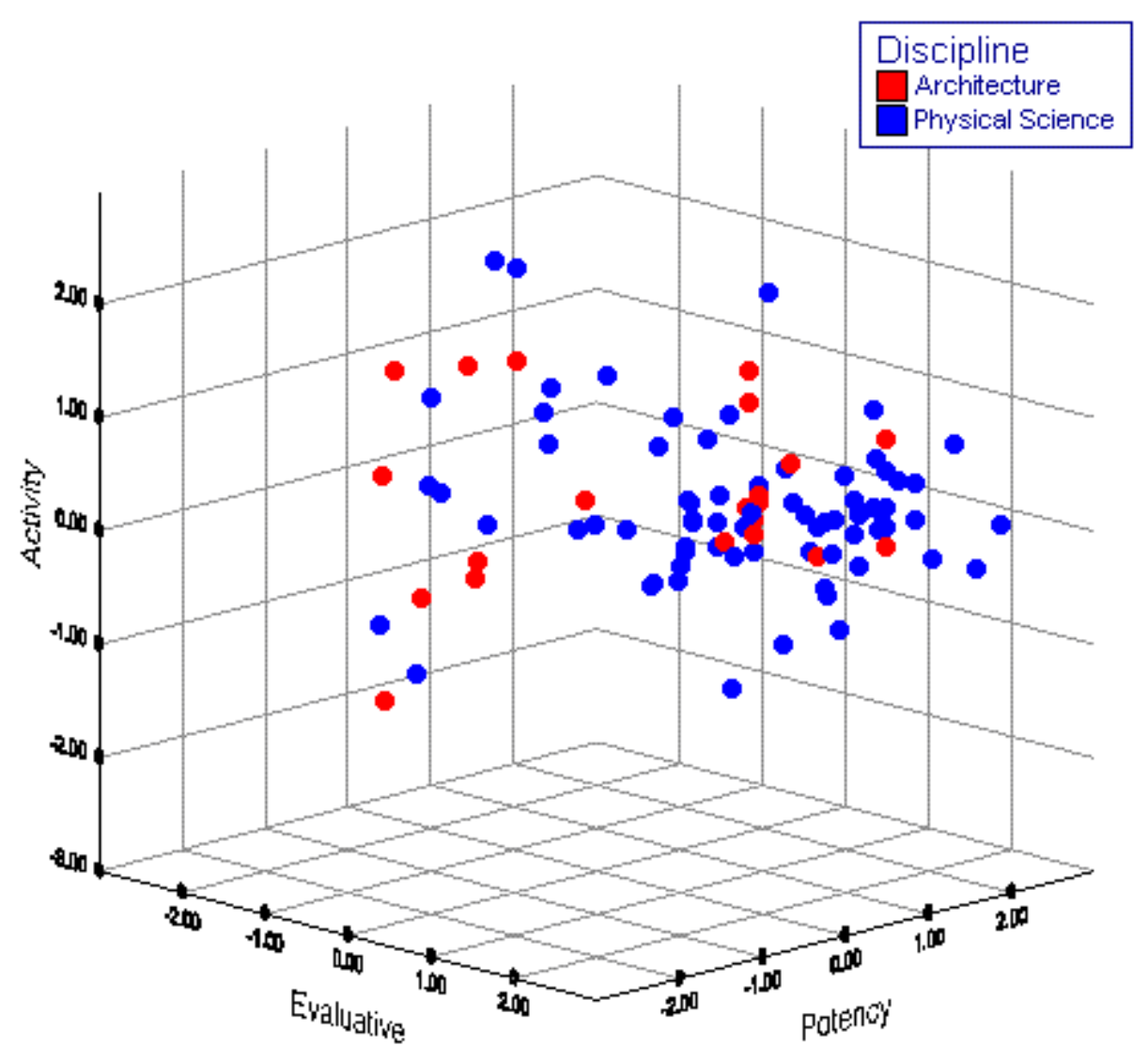


APPENDIX K

\section{APPENDIX K}

Discipline Statistics by Factor 
APPENDIX K

\begin{tabular}{|c|c|c|c|c|}
\hline Discipline & Statistic & Evaluative & Activity & Potency \\
\hline \multirow[t]{4}{*}{ Anthropology } & $\mathrm{N}$ & 47 & 47 & 47 \\
\hline & Mean & 0.56 & -0.03 & 0.9 \\
\hline & Median & 0.82 & 0.03 & 0.94 \\
\hline & Std. Deviation & 1.34 & 0.52 & 0.52 \\
\hline \multirow[t]{4}{*}{ Architecture } & $\mathrm{N}$ & 21 & 21 & 21 \\
\hline & Mean & -0.07 & 0.2 & 0.63 \\
\hline & Median & 0.56 & 0.18 & 0.76 \\
\hline & Std. Deviation & 1.59 & 0.71 & 0.68 \\
\hline \multirow[t]{4}{*}{ Business \& Economics } & $\mathrm{N}$ & 102 & 102 & 102 \\
\hline & Mean & 0.28 & 0.09 & 0.8 \\
\hline & Median & 0.61 & 0.05 & 0.84 \\
\hline & Std. Deviation & 1.6 & 0.61 & 0.67 \\
\hline \multirow[t]{4}{*}{ Education } & $\mathrm{N}$ & 35 & 35 & 35 \\
\hline & Mean & 0.62 & 0.04 & 0.85 \\
\hline & Median & 0.85 & 0 & 0.76 \\
\hline & Std. Deviation & 1.36 & 0.49 & 0.58 \\
\hline \multirow[t]{4}{*}{ Engineering } & $\mathrm{N}$ & 101 & 101 & 101 \\
\hline & Mean & 0.25 & 0.11 & 0.77 \\
\hline & Median & 0.59 & 0.06 & 0.8 \\
\hline & Std. Deviation & 1.52 & 0.59 & 0.66 \\
\hline \multirow[t]{4}{*}{ History } & $\mathrm{N}$ & 166 & 166 & 166 \\
\hline & Mean & 0.25 & 0.15 & 0.79 \\
\hline & Median & 0.62 & 0.06 & 0.85 \\
\hline & Std. Deviation & 1.47 & 0.59 & 0.63 \\
\hline \multirow[t]{4}{*}{ Literature } & $\mathrm{N}$ & 35 & 35 & 35 \\
\hline & Mean & -0.1 & 0.12 & 0.66 \\
\hline & Median & 0.26 & -0.03 & 0.59 \\
\hline & Std. Deviation & 1.31 & 0.66 & 0.53 \\
\hline \multirow[t]{4}{*}{ Mathematics } & $\mathrm{N}$ & 50 & 50 & 50 \\
\hline & Mean & 0.15 & 0.2 & 0.8 \\
\hline & Median & 0.41 & 0.17 & 0.75 \\
\hline & Std. Deviation & 1.48 & 0.56 & 0.68 \\
\hline \multirow[t]{4}{*}{ Natural Science } & $\mathrm{N}$ & 40 & 40 & 40 \\
\hline & Mean & -0.46 & 0.15 & 0.63 \\
\hline & Median & -0.16 & 0.03 & 0.73 \\
\hline & Std. Deviation & 1.53 & 0.53 & 0.68 \\
\hline
\end{tabular}


APPENDIXK (continued)

\begin{tabular}{|c|c|c|c|c|}
\hline Philosophy & $\mathrm{N}$ & 126 & 126 & 126 \\
\hline & Mean & -0.06 & 0.17 & 0.72 \\
\hline & Median & 0.21 & 0.08 & 0.75 \\
\hline & Std. Deviation & 1.58 & 0.6 & 0.66 \\
\hline \multirow[t]{4}{*}{ Physical Science } & $\mathrm{N}$ & 77 & 77 & 77 \\
\hline & Mean & 0.68 & 0.15 & 1 \\
\hline & Median & 0.88 & 0.18 & 1.06 \\
\hline & Std. Deviation & 1.39 & 0.57 & 0.58 \\
\hline \multirow[t]{4}{*}{ Political Science } & $\mathrm{N}$ & 83 & 83 & 83 \\
\hline & Mean & -0.17 & 0.19 & 0.69 \\
\hline & Median & -0.06 & 0.12 & 0.76 \\
\hline & Std. Deviation & 1.47 & 0.57 & 0.67 \\
\hline \multirow[t]{4}{*}{ Social Science \& Psychology } & $\mathrm{N}$ & 86 & 86 & 86 \\
\hline & Mean & 0.22 & 0.06 & 0.78 \\
\hline & Median & 0.47 & 0 & 0.85 \\
\hline & Std. Deviation & 1.41 & 0.6 & 0.67 \\
\hline \multirow[t]{4}{*}{ Technology \& Society } & $\mathrm{N}$ & 48 & 48 & 48 \\
\hline & Mean & 0.11 & 0.16 & 0.83 \\
\hline & Median & 0.44 & 0.15 & 0.81 \\
\hline & Std. Deviation & 1.49 & 0.6 & 0.6 \\
\hline \multirow[t]{4}{*}{ Theology } & $\mathrm{N}$ & 35 & 35 & 35 \\
\hline & Mean & -0.06 & 0.02 & 0.71 \\
\hline & Median & 0 & -0.03 & 0.65 \\
\hline & Std. Deviation & 1.66 & 0.58 & 0.76 \\
\hline \multirow[t]{4}{*}{ Writer } & $\mathrm{N}$ & 83 & 83 & 83 \\
\hline & Mean & -0.02 & 0.12 & 0.77 \\
\hline & Median & 0.12 & 0.03 & 0.8 \\
\hline & Std. Deviation & 1.46 & 0.68 & 0.66 \\
\hline \multirow[t]{4}{*}{ Total } & $\mathrm{N}$ & 1,135 & 1,135 & 1,135 \\
\hline & Mean & 0.16 & 0.13 & 0.78 \\
\hline & Median & 0.47 & 0.06 & 0.8 \\
\hline & Std. Deviation & 1.5 & 0.59 & 0.64 \\
\hline
\end{tabular}




\section{APPENDIX L}

\section{APPENDIX L}

Graphical Presentation of Discipline Means on Factors 


\section{APPENDIX L}

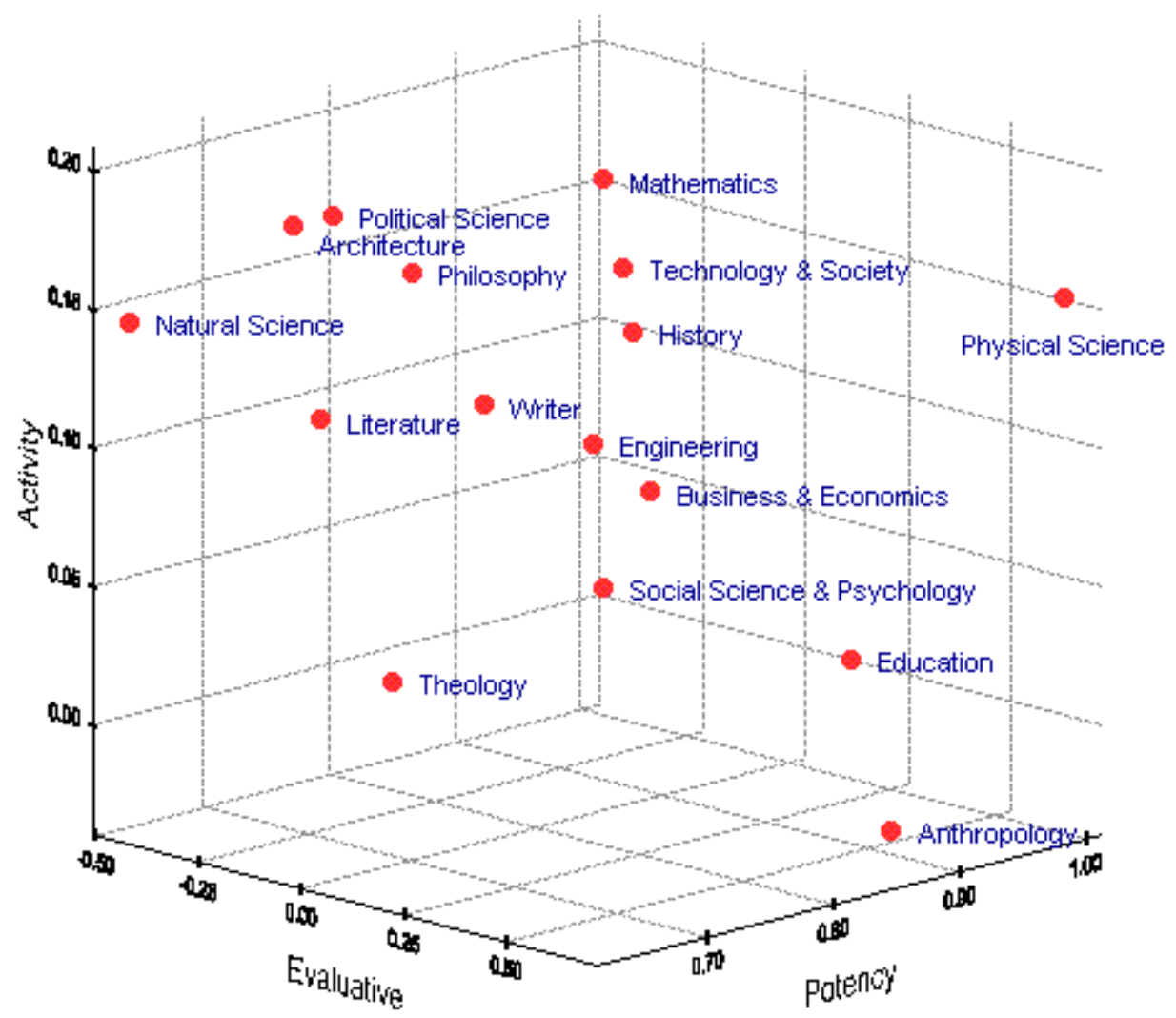

Discipline Mean Scores on The Three Semantic Factors

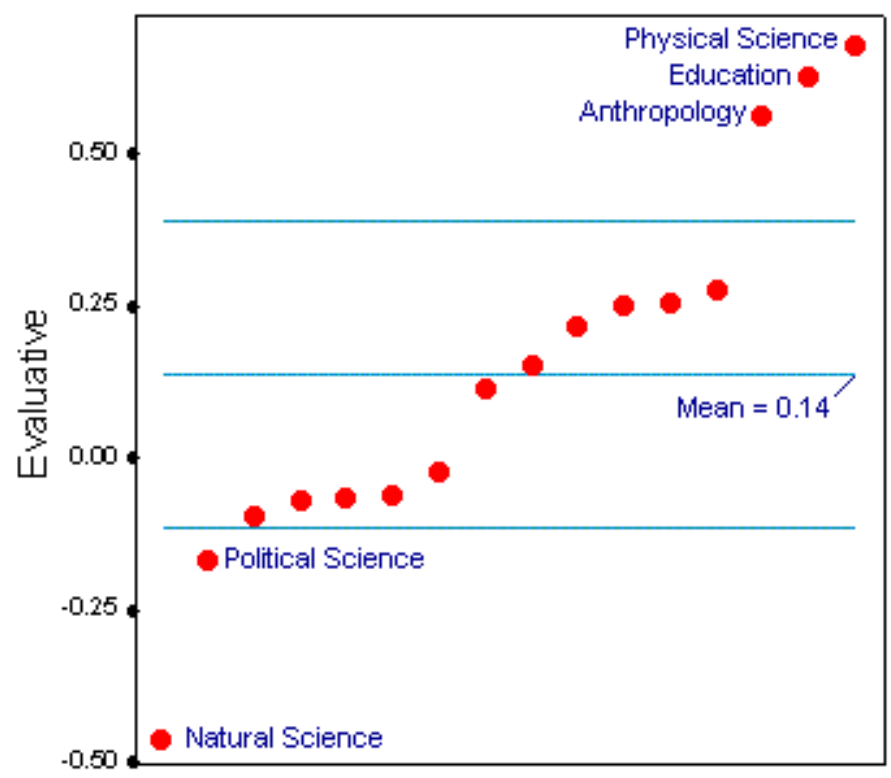

Discipline Mean Scores on the Evaluative Factor: Mean interval line at $99.5 \%$ confidence level 
APPENDIX L (continued)

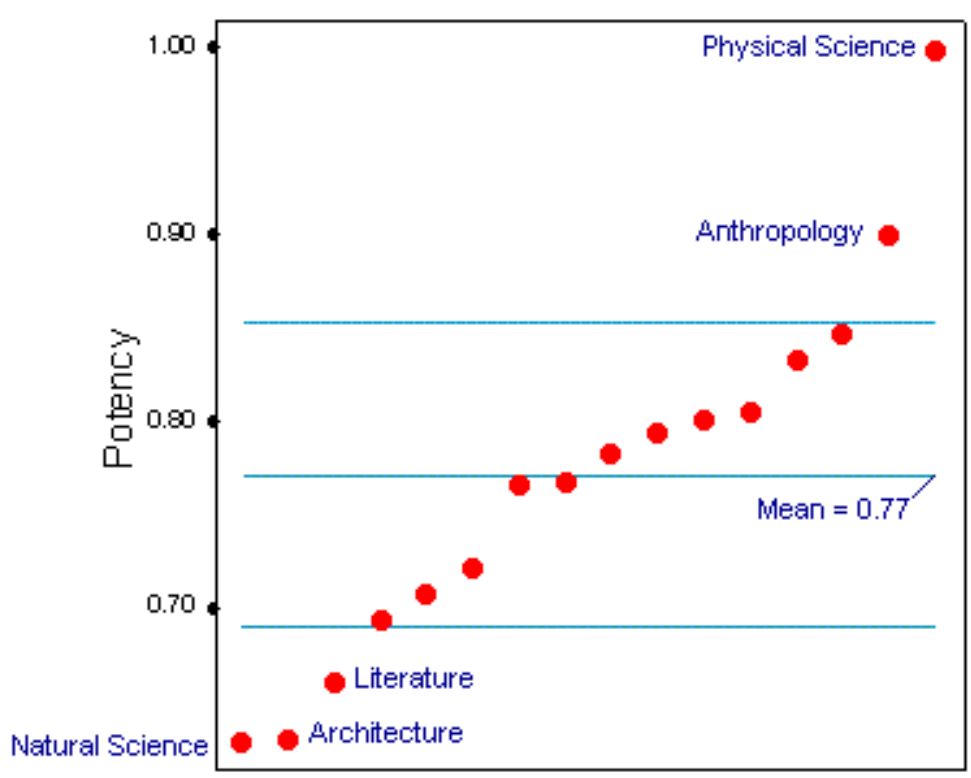

Discipline Mean Scores on the Potency Factor: Mean interval line at 99.5\% confidence level

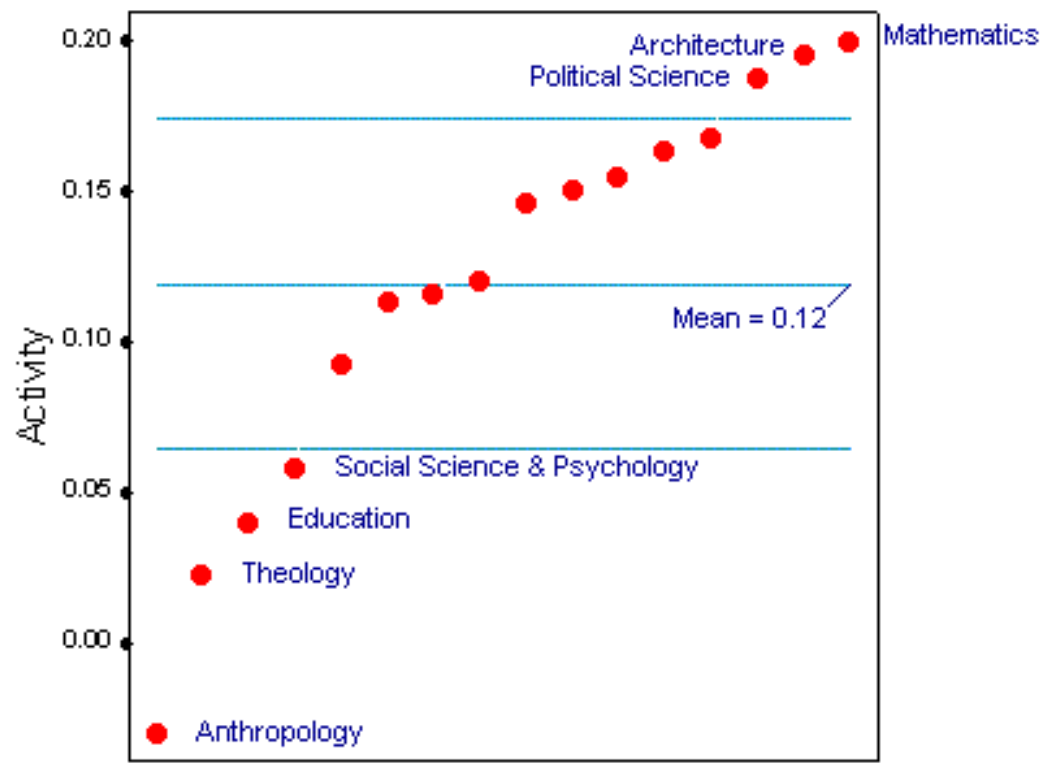

Discipline Mean Scores on the Activity Factor: Mean interval line at 99.5\% confidence level 


\title{
DETERMINING PERSPECTIVES OF SELECTED DISCIPLINES CONCERNING THE NATURE OF TECHNOLOGY WITHIN CLASSIC LITERATURE
}

By

Bryan Calvin Maser

\author{
A DISSERTATION \\ Submitted to the \\ College of Human Resources and Education \\ at \\ West Virginia University \\ in partial fulfillment of requirements for \\ the degree of \\ Doctor of Education \\ Technology Education \\ Department of Advanced Educational Studies \\ APPROVAL OF EXAMINING COMMITTEE
}

Randyl D. Elkin, Ph.D.

Richard T. Walls, Ph.D.

John G. Wells, Ph.D.

Gary Winn, Ph.D.

Edward C. Pytlik, Ph.D. (Chair)

$\underline{11-16-98}$

Date 